\title{
Structurally Integrated Coatings for Wear and Corrosion
}

\author{
DE-FC36-04GO14037 \\ Final Technical Report
}

Report No. DOE/GO14037

November 18, 2008

Period of Performance: January 2004 - September 2008

\author{
M. Brad Beardsley \\ Beardsley_M_Brad@cat.com \\ ph. 309-578-8514 \\ Jason L. Sebright \\ Sebright_Jason_L@cat.com \\ ph. 309-578-0185 \\ Caterpillar Inc. \\ Peoria, IL 61656-1875 \\ Project Team \\ Oak Ridge National Laboratory \\ Iowa State University \\ QuesTek Innovations, LLC \\ National Energy Technology Laboratory \\ Missouri University of Science and Technology \\ University of Illinois - Urbana/Champaign
}


Acknowledgment: This report is based upon work supported by the U. S. Department of Energy under Award No. DE-FC36-04GO14037.

Disclaimer: Any findings, opinions, and conclusions or recommendations expressed in this report are those of the author(s) and do not necessarily reflect the views of the Department of Energy.

Proprietary Data Notice: No proprietary data is contained in this report. 


\section{Table of Contents}

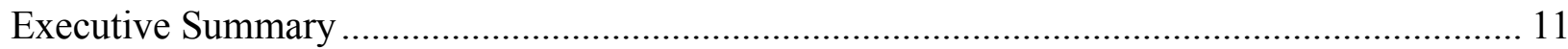

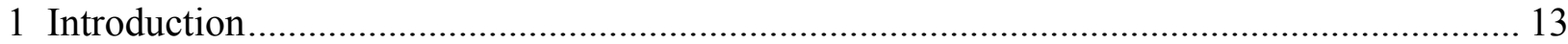

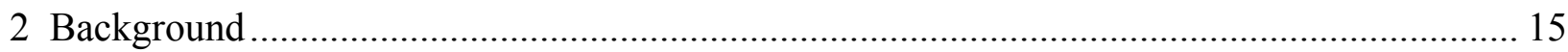

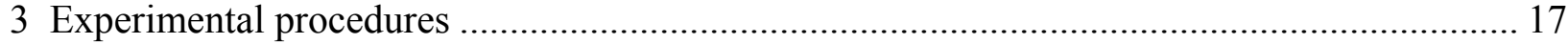

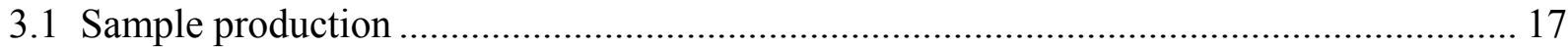

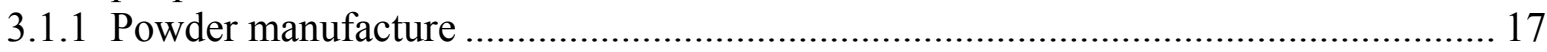

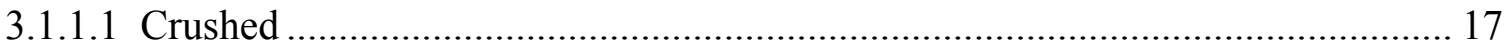

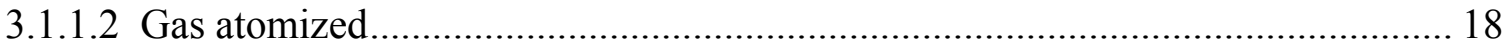

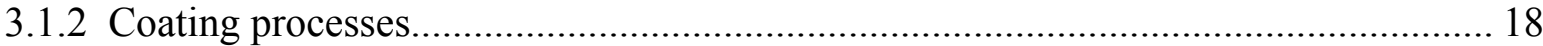

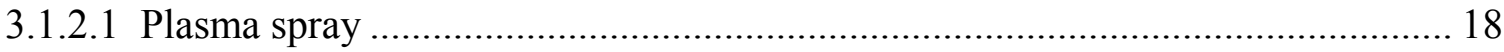

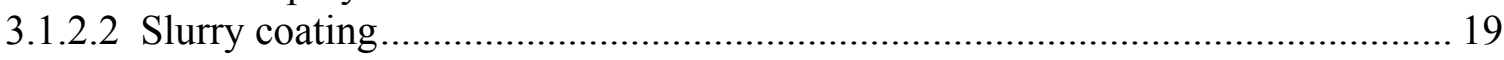

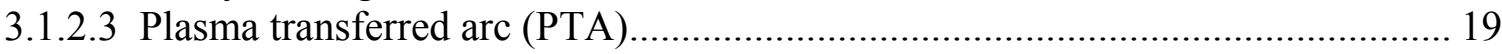

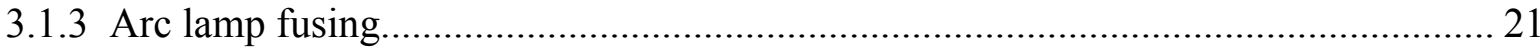

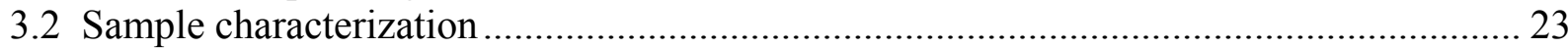

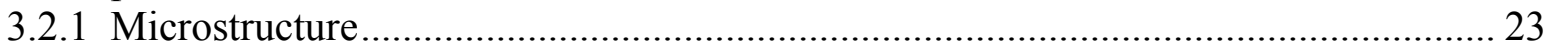

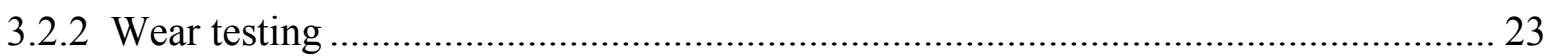

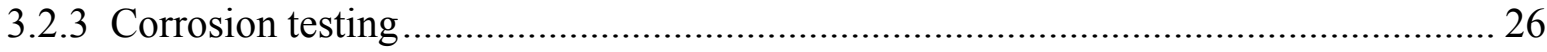

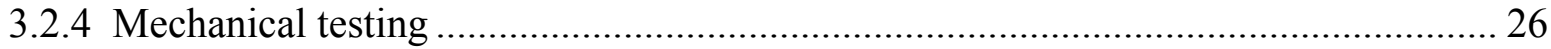

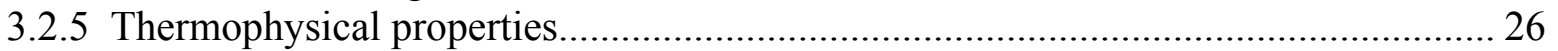

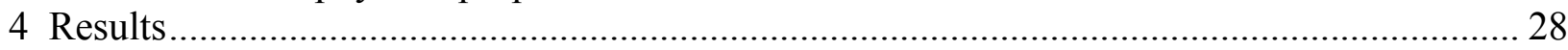

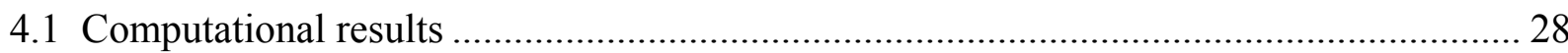

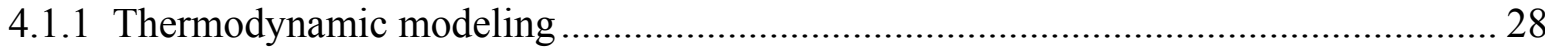

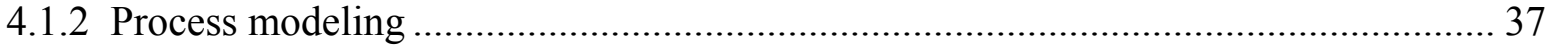

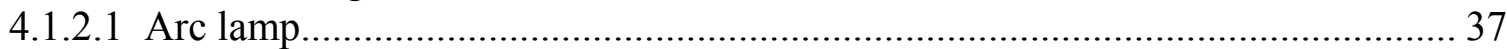

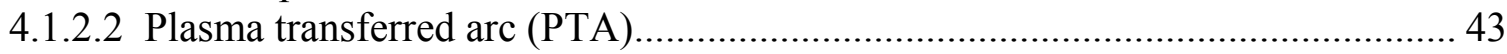

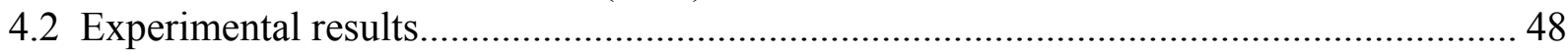

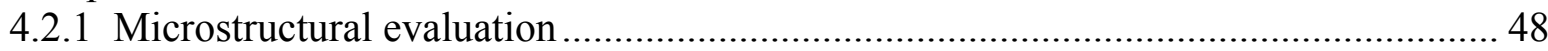

4.2.1.1 Equilibrium microstructures ...................................................................... 48

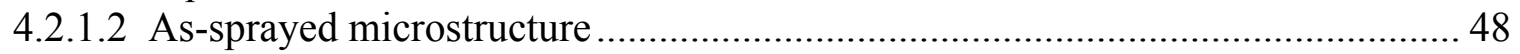

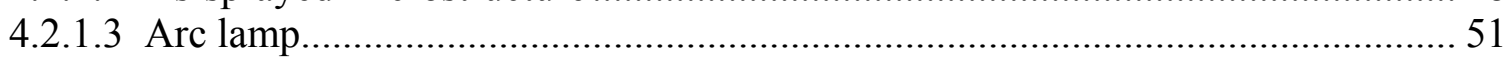

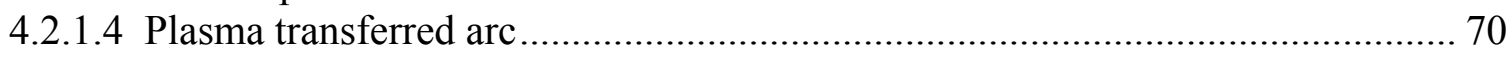

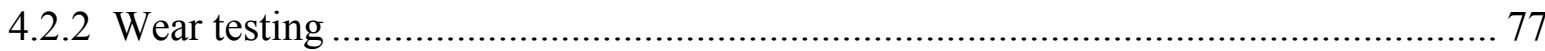

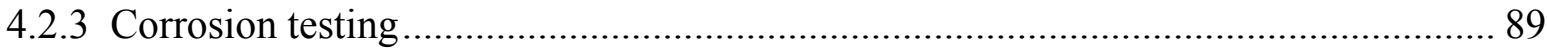

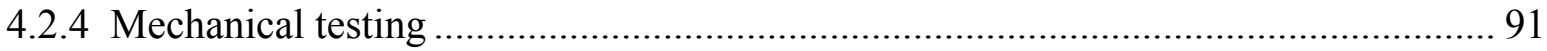

4.2.5 Thermophysical property measurement............................................................... 100

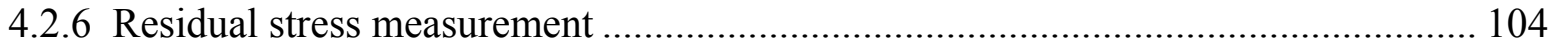

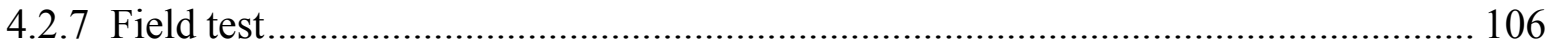

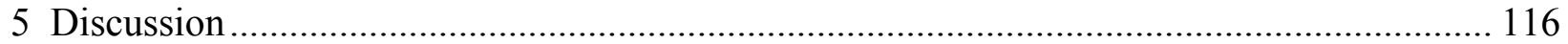

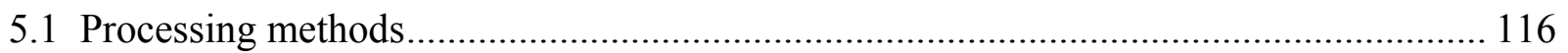

5.2 Coating alloy compositions....................................................................................... 117

5.3 Wear resistance of coated samples .......................................................................... 117

5.4 Corrosion resistance of coated samples ………………................................................. 118 
5.5 Usefulness of computational modeling .................................................................. 119

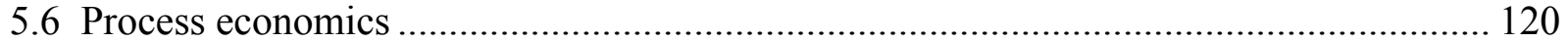

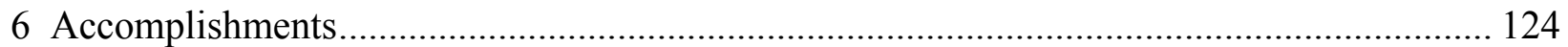

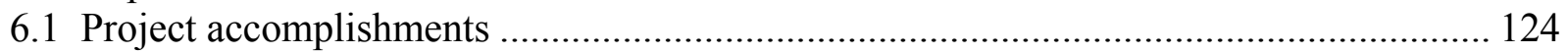

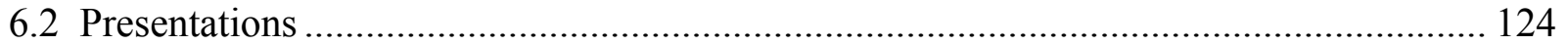

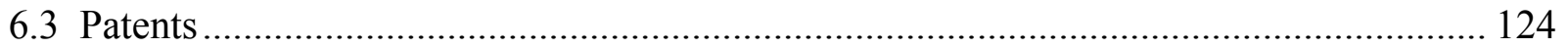

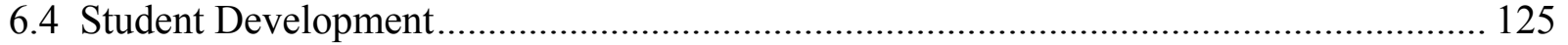

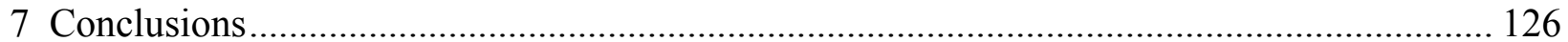

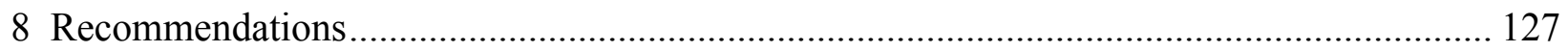

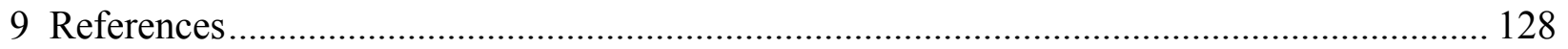




\section{List of Acronyms}

$\begin{array}{ll}\text { CCD } & \text { Charge coupled device } \\ \text { DSRW } & \text { Dry Sand Rubber Wheel } \\ \text { DTA } & \text { Differential Thermal Analysis } \\ \text { EDS } & \text { Energy Dispersive Spectroscopy } \\ \text { EPMA } & \text { Electron Probe Microanalysis } \\ \text { FEA } & \text { Finite Element Analysis } \\ \text { GET } & \text { Ground-Engaging Tool } \\ \text { HDI } & \text { High-density infrared } \\ \text { HRC } & \text { Rockwell C hardness } \\ \text { ISU } & \text { Iowa State University } \\ \text { MS\&T } & \text { Missouri University of Science and Technology } \\ \text { NEMA } & \text { National Electrical Manufacturers Association } \\ \text { NETL } & \text { National Energy Technology Lab - Albany } \\ \text { ORNL } & \text { Oak Ridge National Lab } \\ \text { PAL } & \text { Plasma Arc Lamp } \\ \text { POD } & \text { Pin on Drum } \\ \text { PTA } & \text { Plasma Transferred Arc } \\ \text { SEM } & \text { Scanning Electron Microscope/Microscopy } \\ \text { SICWC } & \text { Structurally Integrated Coatings for Wear and Corrosion } \\ \text { UI } & \text { University of Illinois - Urbana/Champaign } \\ \text { UMR } & \text { University of Missouri - Rolla (now the Missouri University of Science and } \\ \text { Technology) } & \\ \text { XRD } & \text { X-ray Diffraction }\end{array}$




\section{List of Figures}

Figure 1. Schematic diagram of the PTA coating process.................................................... 20

Figure 2. PTA coating process in operation..................................................................... 20

Figure 3. Schematic diagram of arc lamp fusing. .............................................................. 22

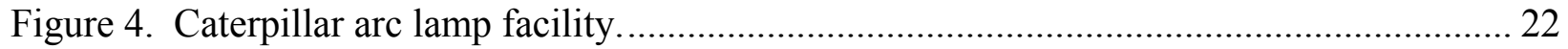

Figure 5. Pin on drum test schematic and apparatus........................................................ 24

Figure 6. Impeller wear test apparatus............................................................................ 24

Figure 7. Typical wear surfaces observed for the wear tests of interest in this project.............. 25

Figure 8. Optical photographs of (a) a test coupon and (b) the bend test fixture for interfacial

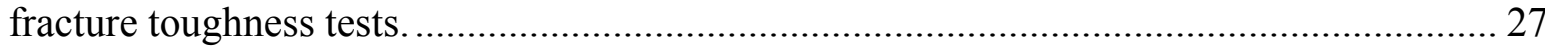

Figure 9. Equilibrium phase diagram of the Fe-Mo-B system at $1000^{\circ} \mathrm{C}$.............................. 30

Figure 10. Equilibrium solidification pathways for SICWC alloys 1-3 ............................... 30

Figure 11. Equilibrium solidification pathways for SICWC alloys 4-6.............................. 31

Figure 12. Equilibrium solidification pathways for SICWC alloys 7-9............................ 32

Figure 13. Equilibrium solidification pathways for QuesTek alloys SAQ1, SAQ4, and SAQ7. 35

Figure 14. Typical PrecipiCalc output.............................................................................. 36

Figure 15. Calculated boride phase radius as a function of cooling rate. ................................ 36

Figure 16. Assumed 2-D spatial heat flux distribution of the arc lamp................................. 39

Figure 17. Substrate temperature as functions of depth below the surface and time for an arc

lamp scan at a traverse speed of $10 \mathrm{~mm} / \mathrm{s}$ and a power level of $500 \mathrm{~kW}$....................... 39

Figure 18. Compositional modeling of a coating-substrate system during arc lamp processing. 39

Figure 19. Heat transfer modeling of arc lamp processing a cylinder................................... 40

Figure 20. Temperature profiles at various radial locations around a cylinder during arc lamp

processing with a constant arc power level.............................................................. 40

Figure 21. Temperature profiles at various radial locations around a cylinder during arc lamp

processing with a variable arc power level. ........................................................... 40

Figure 22. Heat transfer calculations for a cylinder rotated at (a) $60 \mathrm{rpm}$ and (b) $600 \mathrm{rpm}$....... 41

Figure 23. Schematic diagram of empirical heat transfer model........................................ 45

Figure 24. Comparison of model predictions (blue line) with experimental data (green line)... 45

Figure 25. Calculated pulse time at $500 \mathrm{~kW}$ required for the surface of an arc lamp processed

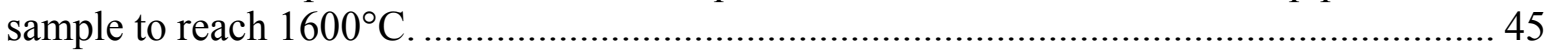

Figure 26. Comparisons of predicted and measured thermal profiles from ORNL................... 46

Figure 27. Calculated temperature field during PTA processing. ........................................... 47

Figure 28. Time-temperature curves for different PTA processing conditions. ....................... 47

Figure 29. Equilibrium microstructure map for the nine initial SICWC alloys........................ 49

Figure 30. Summary of thermodynamic model validation experiments................................ 49

Figure 31. Morphology and microstructure for alloy SA7 powder. .................................... 50

Figure 32. Comparison of as-sprayed and equilibrated microstructure for alloy SA7 .............. 50

Figure 33. Power levels and stability analysis for the arc lamp at various setpoint currents. ..... 53

Figure 34. Temperature of a silicon wafer heated in the arc lamp for short pulses and

equilibrated for 4 minutes. ............................................................................... 53

Figure 35. Microstructures of alloy SA9 in the as-sprayed, equilibrated, and arc lamp processed

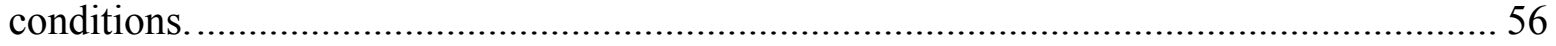

Caterpillar Inc. - DE-FC36-04GO14037 Page 6 of 129 
Figure 36. XRD analysis of alloy SA9 in the as-sprayed, equilibrated, and arc lamp processed

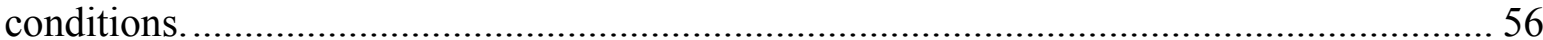

Figure 37. SICWC alloy SA6 processed at various times and power levels in the arc lamp. ..... 57

Figure 38. SICWC alloy SA8 processed at various times and power levels in the arc lamp......58

Figure 39. SICWC alloy SA9 processed at various times and power levels in the arc lamp. ..... 59

Figure 40. Detailed phase analysis of arc lamp processed alloy SA9 .........................................6 60

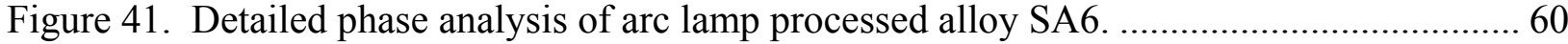

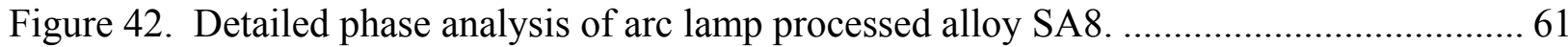

Figure 43. Average hardness values for SICWC alloys SA6, SA8, and SA9. Thermal treatments

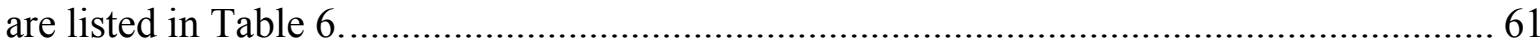

Figure 44. SICWC alloys SA6 (top) and SA9 (bottom) showing dendrites growing from the substrate toward the coating. The substrate in both samples is at the bottom of each micrograph.

Figure 45. SICWC alloys SA1 (top) and SA8 (bottom) showing the effect of embedded alumina grit on the heat transfer from coating to substrate. The substrate in both samples is at the bottom of each micrograph.

Figure 46. Arc lamp modified coating SA6-6 (left) compared to the equilibrium microstructure of SA6 (right).

Figure 47. Optical images of alloy SAQ1 arc lamp processed coating. A $2 \%$ Nital etchant was used to reveal the microstructure.

Figure 48. Optical images of alloy SAQ4 arc lamp processed coatings. A 2\% Nital etchant was used to reveal the microstructure.

Figure 49. SEM images of alloys SAQ1-8 (a and b), SAQ1-9 (c and d), and SAQ4-8 (e and f).67

Figure 50. Thermographic camera image of a typical arc lamp fusing process. 68

Figure 51. Arc lamp processed slurry coated samples of alloy SAQ4. These samples were processed at high power levels.

Figure 52. Arc lamp processed slurry coated samples of alloy SAQ4. These samples were processed at low power levels

Figure 53. Arc lamp processed slurry coated samples of alloy SAQ4 processed in air and nitrogen atmospheres. These samples were processed at appropriate power levels........... 69

Figure 54. Optical micrographs of fused coatings produced in air (left) and nitrogen (right). ... 69 Figure 55. Microstructures of PTA coatings of a commercial wear resistant alloy with air cooling

Figure 56. Microstructures of PTA coatings of a commercial wear resistant alloy with oil cooling

Figure 57. Hardness profiles through the PTA coatings. The drop in hardness shown at approximately $4.4 \mathrm{~mm}$ corresponds to a transition zone between the first and second PTA layers. This zone has a fine equiaxed microstructure.

Figure 58. (a) Backscattered electron image of the Deloro PTA coating showing a dendritic microstructure. (b) Secondary electron image of PTA coating and base metal interface. Heat affected zone next to the PTA coating has a bainitic microstructure.

Figure 59. Microhardness profile of the heat affected zone (HAZ) and Deloro 60 coating material. The PTA coating interface is positioned at zero and the negative direction is into the steel base metal. 
Figure 60. Microstructure of a commercially available wear resistant alloy (Deloro 60) on a top mounted wear plate.

Figure 61. Microstructures of SA7 (top) and SAQ4 (bottom) coatings on top mounted wear

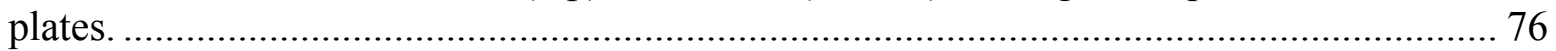

Figure 62. DSRW test results from SICWC and commercially available alloys. ..................... 80

Figure 63. POD test results from SICWC and commercially available alloys........................ 80

Figure 64. Relationship between POD and DSRW wear rates for SICWC and commercially

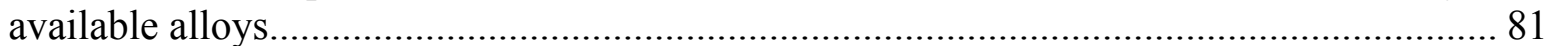

Figure 65. POD wear rate as a function of hardness for selected SICWC alloys..................... 81

Figure 66. Typical wear surface of a SICWC alloy after the DSRW test. .............................. 82

Figure 67. Typical wear surface of a SICWC alloy after the POD test................................ 82

Figure 68. Photograph showing a chipped coating after sample preparation for the impact

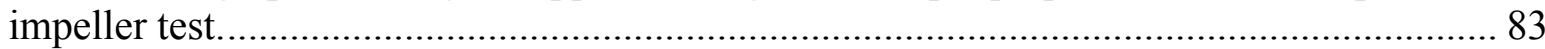

Figure 69. As-sprayed and arc lamp processed SICWC alloy samples after impeller testing.... 83

Figure 70. Wear rate of as-sprayed and arc lamp processed SICWC alloys after impeller impact

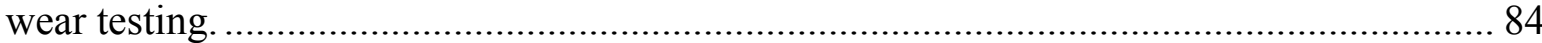

Figure 71. Photographs of the best performing samples from the impact impeller wear test. .... 84 Figure 72. Photograph of coating removal points after impeller wear testing ......................... 85 Figure 73. Correlation between mass loss and coating area remaining after impeller wear testing.

Figure 74. Mass loss for the first and second hours of impeller wear testing. The samples with the lowest wear rate for the as-sprayed (light green) and arc lamp fused (dark green) are

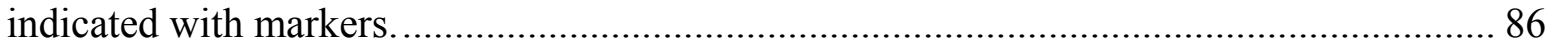

Figure 75. Overview of POD and impeller wear test results. ............................................. 86

Figure 76. Relationship between POD and impeller wear test results.................................. 87

Figure 77. Relationship between POD and impeller wear test results for arc lamp processed

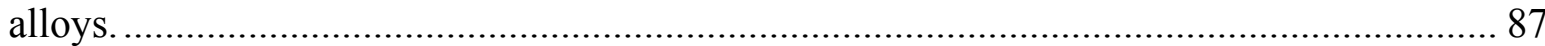

Figure 78. Mass loss in the impeller wear test as function of hardness................................. 88

Figure 79. Photographs of corrosion tested samples of SICWC alloys SA6, SA8, and SA9..... 90

Figure 80. Photographs of (a) the Deloro test coupon and (b) the bend test fixture for PTA

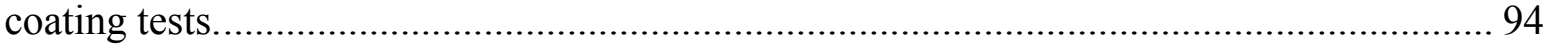

Figure 81. Photograph of dog-bone shaped tensile specimen used to measure monotonic tensile properties of PTA Deloro 60 coating..................................................................... 95

Figure 82. Measured stress and strain response of the Deloro tensile specimen. Strain was measured with an MTS laser extensometer. ................................................................ 95

Figure 83. Finite element model of MS\&T test specimen geometry................................... 96 Figure 84. Calculated stress intensity range for a load of 2,200 N (500 lbf) and a load ratio of

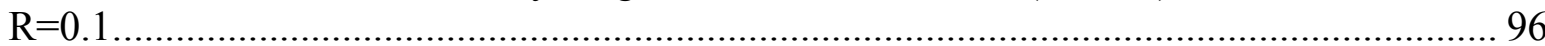

Figure 85. Initial mechanical test samples showing through-coating cracks.......................... 97

Figure 86. Mechanical test sample 1 showing the notch is entirely within the coating. ............ 97 Figure 87. Coating microstructure showing dendrites oriented in the direction of crack

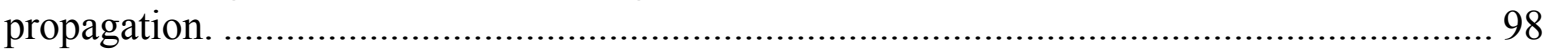

Figure 88 . Stress intensity factor for thin (1.5 mm, top images) and thick (4.5 mm, bottom

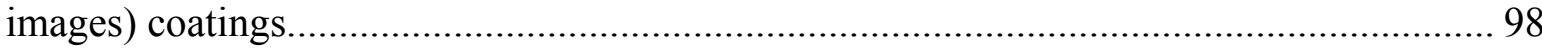


Figure 89. Effect of coating thickness on stress intensity factor along the interface and through the coating.

Figure 90. Thermophysical properties determined for the substrate (labeled "BASE" in this figure), and for the composite coatings as thermally sprayed onto the substrate - a) Specific heat, (b) thermal diffusivity, and c.) thermal conductivity. 102

Figure 91. Example of 3D laser profilometry scan determined for splat samples demonstrating non-uniform thicknesses. 103

Figure 92. Specific Heat data plots determined for comparing stand-alone coating materials for two (2) of the coating compositions of interest. 103

Figure 93. Residual stress profile in the substrate of a commercial material. The arrow indicates the coating location. 105

Figure 94. Residual stress profile in the substrate of a composite material. The arrow indicates the coating location. 105

Figure 95. Top mounted wear plate coated with SICWC and commercial alloys installed on a

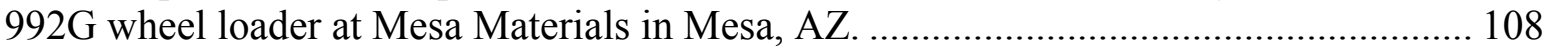

Figure 96. Wear plate from the field test at Gila River. ........................................................... 109

Figure 97. Wear plate from the field test at Mesa Materials. ...................................................... 109

Figure 98. Wear plate from the field test at Vulcan Quarry.................................................. 110

Figure 99. Wear plate from field test at North Vulcan Quarry................................................. 110

Figure 100. Wear plate from the field test at Luck Stone...................................................... 111

Figure 101. Ultrasonic thickness measurements of a wear plate before field test..................... 112

Figure 102. Ultrasonic thickness measurements of a wear plate after field test........................ 112 Figure 103. Wear rates of PTA coatings on top mounted wear plates from field test in Gila River Sand and Gravel.

Figure 104. PTA coating process for a 24M motor grader blade wear strip (top) and the wear strip on the blade after installation (bottom).

Figure 105. Track shoe bolts with arc lamp fused SICWC alloy coatings. 115 


\section{List of Tables}

Table 1. Key personnel at each organization participating in the SICWC project.................... 16

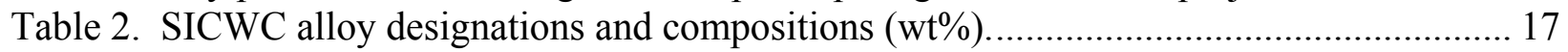

Table 3. Plasma spray parameters used for the SICWC alloys............................................ 18

Table 4. Parameters used in PrecipiCalc microstructural modeling ........................................ 33

Table 5. Boride size and volume fraction for QuesTek alloys. ............................................ 34

Table 6. Thermal treatment numbers for arc lamp processing. .............................................. 54

Table 7. Commercial alloys used as baselines for wear testing ......................................... 77

Table 8. Arc lamp processing parameters for various processing designations. ...................... 89

Table 9. Monotonic properties of PTA Deloro 60 coating ............................................... 92

Table 10. Elastic properties used in finite element model ...................................................... 92

Table 11. Samples used for thermophysical property determination. ................................. 100

Table 12. Top mounted wear plate field test sites. ............................................................ 106

Table 13. SICWC alloy feedstock costs. ......................................................................... 120

Table 14. Comparison of estimated electricity usage of the three coating processing methods.

Table 15. Comparison of estimated material costs of the three coating processing methods. .. 121

Table 16. Comparison of estimated labor costs of the three coating processing methods. ....... 122

Table 17. Comparison of estimated capital costs of the three coating processing methods...... 122

Table 18. Economic analysis summary. ............................................................................ 123 


\section{Executive Summary}

Wear and corrosion of structures cuts across industries and continues to challenge materials scientists and engineers to develop cost effective solutions. Industries typically seek mature technologies that can be implemented for production with rapid or minimal development and have little appetite for the longer-term materials research and development required to solve complex problems.

The collaborative work performed in this project addressed the complexity of this problem in a multi-year program that industries would be reluctant to undertake without government partnership. This effort built upon the prior development of Advanced Abrasion Resistant Materials conduct by Caterpillar Inc. under DOE Cooperative Agreement No. DE-FC2601NT41054. In this referenced work, coatings were developed that exhibited significant wear life improvements over standard carburized heat treated steel in abrasive wear applications. The technology used in this referenced work, arc lamp fusing of thermal spray coatings, was one of the primary technical paths in this work effort. In addition to extending the capability of the coating technology to address corrosion issues, additional competitive coating technologies were evaluated to insure that the best technology was developed to meet the goals of the program. From this, plasma transferred arc (PTA) welding was selected as the second primary technology that was investigated.

Specifically, this project developed improved, cost effective surfacing materials and processes for wear and corrosion resistance in both sliding and abrasive wear applications. Materials with wear and corrosion performance improvements that are 4 to 5 times greater than heat treated steels were developed. The materials developed were based on low cost material systems utilizing ferrous substrates and stainless steel type matrix with hard particulates formed from borides and carbides. Affordability was assessed against other competing hard surfacing or coating techniques, balanced with overall materials performance. State-of-the-art design and simulation capabilities were used to guide materials and process refinement.

Caterpillar was the lead of the multi-partner collaborative project. Specific tasks were performed by the partners base on their unique capabilities. The project team was selected to include leaders in the field of material development, processing, modeling, and material characterization. Specifically, industrial members include the suppliers Deloro Stellite and Powder Alloy Corporation., who provided the experimental alloys and who aided in the development of the costs for the alloys, the Missouri University of Science and Technology and Iowa State University, who provided help in the alloy development and material characterization, QuesTek Innovations, a small company specializing the microstructural modeling of materials, and the DOE laboratories, Oak Ridge National Laboratory and National Energy Technology Laboratory (Albany), who provided unique coating process capability and wear characterization testing.

The technologies developed in this program are expected to yield energy savings of about $50 \%$ over existing technologies, or 110 trillion BTUs per year by 2020 when fully implemented. Primary applications by Caterpillar are to replace the surface of machine components which are 
currently carburized and heat treated with new cladding materials with double the wear life. The new cladding technologies will consume less energy than carburizing. Thus, nearly 50\% energy savings can be expected as a result from elimination of the heat treat process and the reduce wear of the materials.

Additionally, when technologies from this project are applied on titanium or other non-ferrous substrates to make lighter weight, more wear resistant, and more efficient structures, significant fuel savings can be realized. With the anticipated drastic reduction in cost for refining titaniumcontaining ores, the usage of titanium alloys in earthmoving and related machinery is expected to increase multiple folds in the next decade. A major technical hurdle associated with the implementation of titanium alloys for heavy machinery is that of overcoming poor wear resistance.

Proof of concept of the technologies developed in this project has been demonstrated by both laboratory testing of coupons and field testing of selected components. Further development will be required in order to have fully validated materials and process for production introduction and several technical hurdles remain to be addressed particular for use of the arc lamp fusing technology. The current project has reduced the risk of failure and provided sufficient data to encourage further investment by industry. 


\section{Introduction}

The objective of this project was the development of cost effective surfacing materials and processes for wear and corrosion resistance in both sliding and abrasive wear applications. A material with increased wear resistance would require less wear material to be present on a given part. This lighter weight part requires less fuel to move resulting in a net energy savings. The target performance improvement was 4 to 8 times greater than heat-treated steels. Progress toward this objective was achieved through experimental and computational studies that related alloy microstructure and physical properties to wear and corrosion behavior both in the lab and in the field. Computational modeling was used to accelerate alloy composition refinement and the development of novel processing conditions. In addition to lab and field test performance, raw material and processing costs were evaluated and compared with commercially available materials.

The proposed work effort is expected to yield energy savings of about $50 \%$ over existing technologies, or 110 trillion BTUs per year by 2020 as discussed below. The plan is to replace targeted machine components that are currently carburized and heat treated by one-half (double the wear life) with technologies that consume less energy than carburizing. Thus, nearly 50\% energy savings can be expected as a result. Additionally, when technologies from this project are applied on titanium or other nonferrous substrates to make lighter weight, more wear resistant, and more efficient structures, significant fuel savings can be realized. With the anticipated drastic reduction in cost for refining titanium-containing ores, the usage of titanium alloys in earthmoving and related machinery is expected to increase multiple folds in the next decade. A major technical hurdle associated with the implementation of titanium alloys for heavy machinery is that of overcoming poor wear resistance. Through the use of lighter weight materials in such machinery significant fuel savings can be realized. For example, the annual worldwide sales of excavators in the 22 to 94 ton range is approximately 50,000 units. Assuming these units are in service approximately 12 hours a day, nine months a year, and consume 10 gallons an hour of diesel fuel to operate a $140 \mathrm{~kW}$ engine, these machines alone consume 714 trillion BTUs/yr. Prior experience at Caterpillar puts the estimate of a weight reduction of approximately $25 \%$ in the boom, stick, and bucket system to yield a productivity gain of $15 \%$. This gain will result in an overall energy savings of 110 trillion BTUs/yr or a reduction in diesel fuel consumption of 150 million gallons/yr. The above calculations assumed $0 \%$ yearly growth, to be conservative.

The wear and corrosion resistant alloys developed as part of this project may result in the reduction of the number of carburized parts used on Caterpillar equipment. Carburizing is one of the manufacturing heating processes included in the Roadmap for Process Heating Technologies for active improvement in the reduction of emissions and energy usage. Surveys and detailed calculations of potential CO emissions as conducted by Atmosphere Recovery Inc. of a "typical" heat treatment plant showed the amount to be approximately 80 tons a year. Assuming the Caterpillar Inc. plant producing the bulk of the potential undercarriage component to which the developed technologies would be applied is similar in capacity to the surveyed "typical" plant, 
the avoided $\mathrm{CO}$ emissions per year can be estimated at 40 tons per year when technologies from the proposed R\&D are implemented ${ }^{1}$ 


\section{Background}

This project incorporates several technologies to achieve its objectives, such as wear resistant coating alloys and fusing of coatings. The state of the art for these technologies will be examined individually. In terms of wear resistant coatings, one common design strategy for metallic wear materials is based on the use of hard intermetallic particles such as carbides or borides in a ductile matrix. The Fe-Mo-B alloy system is well established as a wear resistant alloy system both in the academic ${ }^{2}, 4$, and patent ${ }^{5,67}$, literature. The wear resistance of this material results from the $\mathrm{FeB}, \mathrm{Fe}_{2} \mathrm{~B}$, and $\mathrm{FeMo}_{2} \mathrm{~B}_{2}$ phases ${ }^{8},{ }^{9}$. Coatings can be fused to produce microstructural changes to enhance wear or corrosion resistance or to metallurgically bond the coating to the substrate. Fusing of coatings can be performed using a laser ${ }^{10},{ }^{11},{ }^{13}{ }^{14}$ or an electron beam ${ }^{1516}$. The fusing technology used in this project is high density infrared (HDI) processing using a plasma arc lamp ${ }^{17},{ }^{18}, 19$. This HDI technology has also been specifically used to enhance wear resistance ${ }^{20}$.

The objectives of the SICWC project were:

- Develop coatings/claddings that are metallurgically bonded to the substrate with wear and corrosion performance improvements that are 4 to 8 times greater than heat-treated steels.

- Develop two economical processes for deposition of coatings: High Intensity Arc Lamp and Plasma Transferred Arc Welding

- Determine intrinsic and extrinsic properties required for modeling of promising materials systems/coatings and model the microstructural evolution of high performance coatings during processing

- Modify existing and develop new testing methods as needed for quantitatively ranking the toughness of high performance, metallurgically-bonded coatings

An early decision was made not to pursue hybrid laser-arc welding. This process required the use of wire feedstock and the alloys under investigation are not easily made into wire because they are relatively hard and brittle.

This project investigated both novel alloy compositions and novel processing methods. The alloy compositions in this project were chosen with two key criteria in mind. The first criterion was the use of at least one low cost ferrous starting material. The second design criterion was the use of boride or carbide particles for wear resistance. The processing methods are intended to melt (completely or partially) the coating and/or substrate to produce a wear and corrosion resistant coating with a metallurgical bond between the coating and substrate. The processing methods investigated were cladding via high intensity arc lamp fusing and plasma transferred arc welding (PTA).

Caterpillar led the multi-partner collaborative project. The project team included leaders in the field of material development, processing, modeling, and characterization. The University of Illinois, Iowa State University, and the University of Missouri - Rolla provided material 
characterization (UI, ISU, UMR) and alloy development (ISU). QuesTek Innovations LLC, provided microstructure design capability. The DOE laboratories, Oak Ridge National Laboratory and National Energy Technology Laboratory, provided unique coating process capability (ORNL), x-ray residual stress measurements (ORNL), and wear characterization testing (NETL). A key part of this project was flow of material and information from initial sample processing (performed by Caterpillar) to characterization (performed by ISU, UI, UMR, ORNL, NETL) to computational model calculations (QuesTek, ORNL, Caterpillar). A list of key personnel with each organization is listed Table 1 below.

Table 1. Key personnel at each organization participating in the SICWC project.

\begin{tabular}{|l|l|}
\hline Person & Organization \\
\hline M. Brad Beardsley & Caterpillar Inc. \\
\hline D. Trent Weaver & Caterpillar Inc. \\
\hline Zhishang Zhang & Caterpillar Inc. \\
\hline Jason Sebright & Caterpillar Inc. \\
\hline Herng-Jeng Jou & QuesTek Innovations LLC \\
\hline Weiming Huang & QuesTek Innovations LLC \\
\hline Brian Gleeson & Iowa State University \\
\hline Bingtao Li & Iowa State University \\
\hline Rebecca Ahrens & Iowa State University \\
\hline David Van Aken & University of Missouri - Rolla \\
\hline Ravi Mokirala & University of Missouri - Rolla \\
\hline Darrell Socie & University of Illinois - Urbana/Champaign \\
\hline Jeffrey Hawk & National Energy Technology Lab - Albany \\
\hline Joseph Tylczak & National Energy Technology Lab - Albany \\
\hline Craig Blue & Oak Ridge National Lab \\
\hline Gail Ludtka & Oak Ridge National Lab \\
\hline Camden Hubbard & Oak Ridge National Lab \\
\hline Thomas Watkins & Oak Ridge National Lab \\
\hline
\end{tabular}




\section{Experimental procedures}

This chapter will describe the lab procedures used to produce the coatings, fuse the coatings, and characterize the fused coatings.

\subsection{Sample production}

The base alloy system examined was the Fe-Mo-B system. From a base alloy (alloy SA1) a matrix of nine alloys was chosen to examine the effect of increasing molybdenum/boron ratio, the effect of increasing overall molybdenum content, the effect of chromium additions, and the effect of chromium and nickel additions. The effects of the alloying additions were evaluated in terms of equilibrium phase composition and phase fraction. The alloy names and compositions are shown in Table 2.

Table 2. SICWC alloy designations and compositions (wt \%).

\begin{tabular}{|c|c|c|c|c|c|c|c|c|c|c|c|c|}
\hline SICWC group naming scheme & $1-1$ & $1-2$ & $1-3$ & $2-1$ & $2-2$ & $2-3$ & $3-1$ & $3-2$ & $3-3$ & & & \\
\hline SICWC alloy & SA1 & SA2 & SA3 & SA4 & SA5 & SA6 & SA7 & SA8 & SA9 & SAQ1 & SAQ4 & SAQ7 \\
\hline target \%Fe & 62.3 & 69.4 & 46.7 & 49.8 & 55.5 & 37.4 & 49.8 & 55.5 & 37.4 & 37.0 & 39.8 & 29.9 \\
\hline target \%Mo & 28.2 & 18.0 & 46.1 & 22.6 & 14.4 & 36.9 & 22.6 & 14.4 & 36.9 & 56.6 & 43.0 & 42.7 \\
\hline target \%B & 9.5 & 12.6 & 7.2 & 7.6 & 10.1 & 5.7 & 7.6 & 10.1 & 5.7 & 6.4 & 6.9 & 6.9 \\
\hline target $\% \mathrm{Cr}$ & 0.0 & 0.0 & 0.0 & 20.0 & 20.0 & 20.0 & 10.0 & 10.0 & 10.0 & 0.0 & 10.3 & 10.2 \\
\hline target \%Ni & 0.0 & 0.0 & 0.0 & 0.0 & 0.0 & 0.0 & 10.0 & 10.0 & 10.0 & 0.0 & 0.0 & 10.3 \\
\hline
\end{tabular}

\subsubsection{Powder manufacture}

One key to all of the processes under evaluation was the use of powder as a feedstock material for the coating process. This is a choice dictated by the properties of the feedstock material, as many wear resistant alloys do not have enough ductility to be formed into wire. The alloy powders in this project were produced using two different methods: crushing and gas atomization.

\subsubsection{Crushed}

Alloys SA1 through SA9 were produced at Caterpillar by sintering and crushing. About 1-3 kg of the required amounts of ferromolybdenum, ferroboron, chrome, nickel, and molybdenum were mixed in a ball mill for 2 hours. The mixed powders were then sintered in a vacuum furnace for 2 hours at a vacuum of $\sim 30$ millitorr and a temperature of 900-1000 $\mathrm{C}$ (the temperature depended on the alloy and was determined by experimentation). After sintering, the alloys were broken apart with a hammer and crushed in a laboratory-scale jaw crusher (made by Sepor Inc.) to a size of $-5 \mathrm{~mm}$. The jaw crushed material was then sent through a laboratory-scale pulverizer (made by Holmes Inc.) that produced powder sizes smaller than 45 microns. The pulverized powder was then sieved into 3 size ranges: $+106,-106+45$, and -45 microns. Each pulverized batch of material was sieved for 6 minutes. The +106 micron powder was recycled through the pulverizer to maximize yield. Only powders in the $-106+45$ micron size range were used for plasma spraying. The typical yield of $-106+45$ powder from the $1-3 \mathrm{~kg}$ of starting material after $5-10$ 
rounds of pulverizing and sieving was 20-30\%. The rest of the powder was disposed of according to Caterpillar hazardous material guidelines.

\subsubsection{Gas atomized}

Alloys SA7, SAQ1, and SAQ4 were produced by gas atomization at two outside suppliers, Powder Alloy Corporation and Stellite, Inc. The details of the supplier processes are not known. A general description of gas atomization is available in the ASM Handbook volume 7. Production of the third alloy calculated by QuesTek (designated Q7) was attempted using gas atomization but was especially difficult. The melting process began using a maximum amount of small ferroalloy lumps ( $<1$ inch) whose lower melting point and small size would facilitate melting and mixing. The furnace was powered with the designated charge and brought to maximum operating temperature (3200-3300 F, 1760-1815 C). However, local liquid and solid zones formed within the furnace that remained after 30 minutes (a typical melting time period). An additional 30 minutes of melting was authorized while keeping watch on temperature and safety devices. Unfortunately, Mo and CrB2 did not appear to be melting over time but rather solidified into larger masses within the furnace. These results are consistent with the liquidus temperature calculated by QuesTek of 1809 C. From these results it appears unlikely that alloy Q7 could be manufactured using any liquid-phase processing techniques. Due to the difficulty in manufacturing this alloy and the high price of the charge materials (the material cost alone of about $\$ 40 / 1 b$ ) it was not investigated further as part of the project.

\subsubsection{Coating processes}

Substrates for the coating trials were made of 1045 steel. The samples were quenched and tempered to $55 \mathrm{HRC}$. The most common substrate geometries were 1 " $\mathrm{x} 1$ " $\mathrm{x} 0.5$ " blocks for slurry coating and 1" x 1" x 10" square rods for plasma spray coating. The plasma sprayed rods were then cut into 2" sections for arc lamp fusing experiments. The substrates were grit blasted with aluminum oxide grit prior to coating application. The effects of this surface preparation method will be discussed in later sections.

\subsubsection{Plasma spray}

Plasma spraying was performed at Caterpillar and at an outside supplier, St. Louis Metallizing. The parameters used for the plasma spray process at Caterpillar are shown in Table 3.

Table 3. Plasma spray parameters used for the SICWC alloys.

\begin{tabular}{|l|l|}
\hline Torch & Sulzer Metco 9MB \\
\hline Anode & GE \\
\hline Voltage & 62 \\
\hline Amperage & 525 \\
\hline Powder port & $\# 2$, perpendicular to the plume from below \\
\hline Plasma gas & $\mathrm{Ar}-49.6 \mathrm{SLPM}$ @ 70 psi \\
\hline Auxiliary gas & $\mathrm{H}_{2}-100$ psi, flow controlled to regulate voltage \\
\hline Standoff & $110 \mathrm{~mm}$ \\
\hline
\end{tabular}




\begin{tabular}{|l|l|}
\hline Traverse speed & $19 \mathrm{~mm} / \mathrm{s}$ \\
\hline Powder feeder & Sulzer Metco 9 MP-CL \\
\hline Powder feed rate & $10 \mathrm{lb} / \mathrm{hr}$ \\
\hline Carrier gas & Nitrogen \\
\hline Carrier gas flow & $10 \mathrm{SLPM}$ \\
\hline Vibrator pressure & $15 \mathrm{psi}$ \\
\hline Hopper pressure & $2.9 \mathrm{psi}$ \\
\hline
\end{tabular}

During the spray process, eight of the 1" $\mathrm{x} 1$ " $\mathrm{x} 10$ " bars were held onto the outside of a cylindrical mounting fixture with band clamps. The fixture was rotated at $227 \mathrm{rpm}$ to achieve a surface speed of $100 \mathrm{~m} / \mathrm{min}$.

\subsubsection{Slurry coating}

Slurry coating was examined as an alternative coating method to plasma spraying. The slurry is a mixture of alloy powder and Lisi $100 \mathrm{i} 9$ binder. Lisi $100 \mathrm{i} 9$ is a proprietary mixture from Warren Paint and Color. The binder is water based and includes a silica-based binder, suspension agent, and corrosion inhibitor. Lisi was recommended by Oak Ridge National Lab for its good green strength and suspension properties. Powders of alloys SAQ1 and SAQ4 were mixed to an 8:1 powder:Lisi ratio by weight. The size of these powders was $-150+105 \mathrm{~mm}$. Other alloy powders and size distributions can be used although the powder:Lisi ratio must be adjusted to achieve a paste-like consistency.

Aluminum molds were fabricated to ensure uniformity of the slurry coating. The mold was designed such that the top surface of the sample to be coated was a specified distance (typically $0.5 \mathrm{~mm}$ ) below the top of the mold. The slurry could then be poured on top of the sample until level with the top of the mold. The slurry-coated samples were allowed to dry in air for at least two hours prior to arc lamp processing. The samples were then carefully removed from the mold.

\subsubsection{Plasma transferred arc (PTA)}

The plasma transferred arc (PTA) coating process is similar to MIG welding. A schematic diagram of the PTA coating process is shown in Figure 1. A photograph of the PTA coating process in operation is shown in Figure 2. In this coating process, an arc is struck between the torch and the substrate. For the SICWC alloys the arc parameters were about 200 amps at 30 volts. The arc melts both the surface of the substrate and the coating powder that is fed into the arc. Due to the fact that both the substrate and coating materials are fully molten, a metallurgical bond was produced between the coating and substrate. Care must be taken to prevent significant mixing of the coating and substrate materials. The wear or corrosion resistance of the coating may be reduced if the composition of the coating is changed by elements from the substrate. 


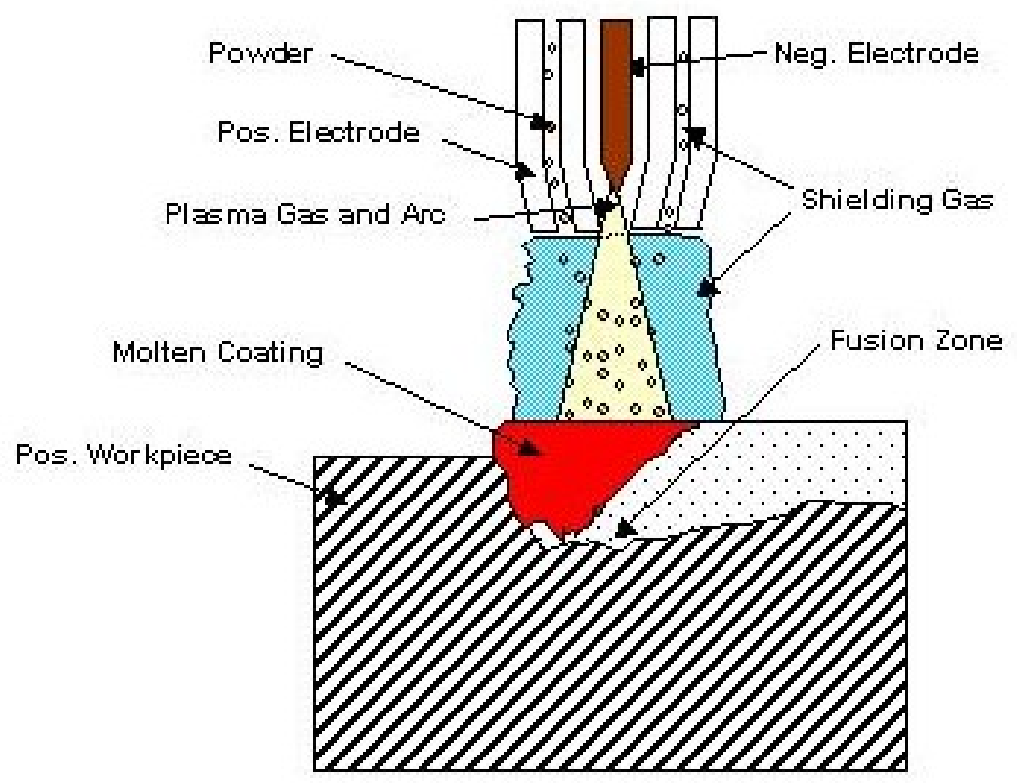

Figure 1. Schematic diagram of the PTA coating process

Figure 2. PTA coating process in operation.

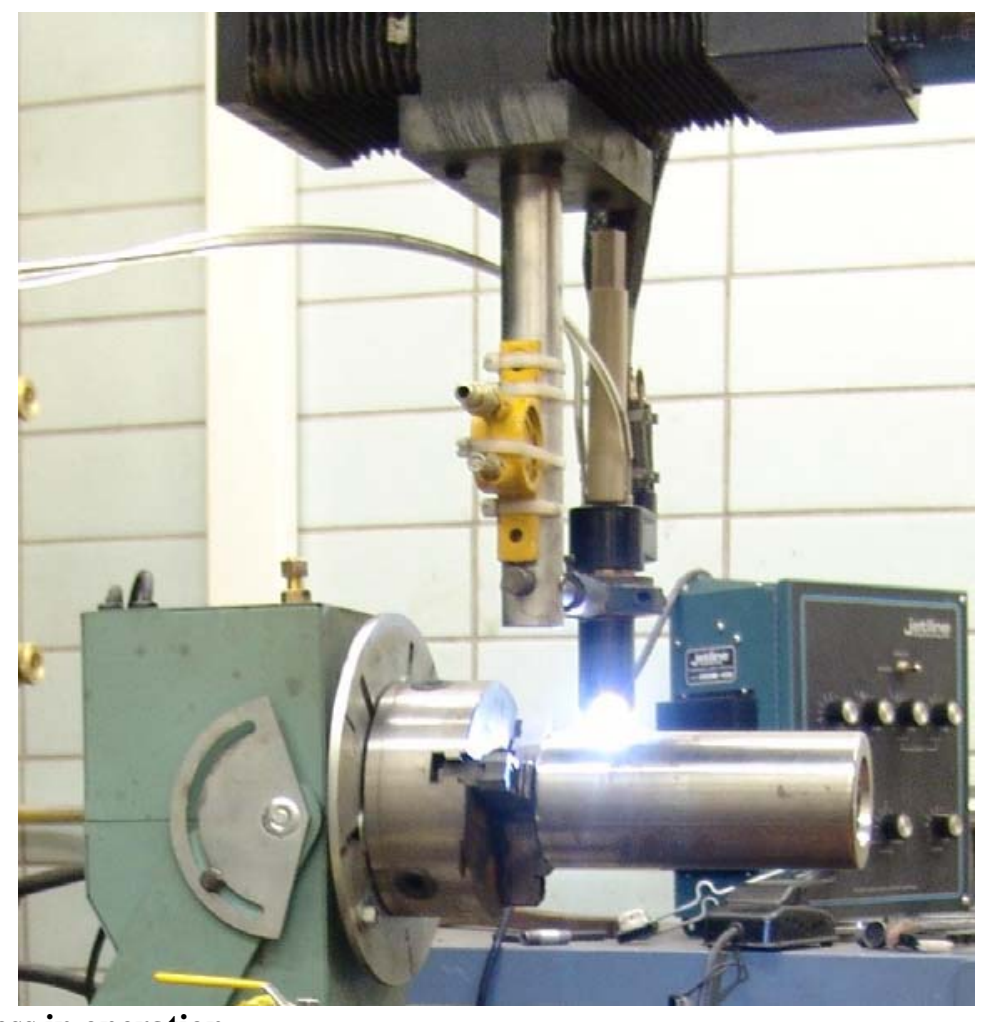




\subsubsection{Arc lamp fusing}

A relatively new technique for producing a metallurgical bond between a coating and substrate is plasma arc lamp fusing. The plasma arc lamp is commercially available from Mattson Technology Inc. A schematic of this process is shown in Figure 3 and the actual arc lamp installation at Caterpillar is shown in Figure 4. Heat is generated by an arc struck between two electrodes that are $200 \mathrm{~mm}$ apart. In Figure 3 the electrodes and the arc are out of the plane of the page. The maximum power of the system is approximately $500 \mathrm{~kW}(420$ volts at 1200 amps). The electrodes and the arc are surrounded by a quartz tube. Deionized water mixed with argon gas enters at the cathode side of the quartz tube through high velocity jets impinging at a

given angle. Due to the high velocity and pressure, the deionized water is impelled to the wall of the quartz tube and spirals down the length of the tube in a uniform film that is 2 to $3 \mathrm{~mm}$ thick. This water film serves multiple purposes: to stabilize the arc, to cool the quartz tube, and to remove any tungsten particulate that may have been expelled from the electrodes. The electromagnetic energy emitted by the arc is focused by a parabolic mirror (called the reflector) surrounding the quartz tube. The focal plane is about $25 \mathrm{~mm}$ below the bottom edge of the reflector. The radiant energy is focused onto an area approximately $200 \mathrm{~mm} \times 25 \mathrm{~mm}$. Assuming no losses, the maximum power density that could be achieved by the lamp is 10 $\mathrm{kW} / \mathrm{cm}^{2}$. In practice losses due to the water, quartz tube, and reflector limit the peak powder density to about $2 \mathrm{~kW} / \mathrm{cm}^{2}$. For comparison a typical $4 \mathrm{~kW}$ laser process has a power density of about $20 \mathrm{~kW} / \mathrm{cm}^{2}$. While the powder density of the arc lamp is much lower than a laser, the area covered by the lamp is much larger making it appealing for fusing large areas of coating.

The intent of the arc lamp is to heat the coating and a thin layer of the substrate to produce a metallurgical bond between the coating and substrate. Rapid heating and cooling is key to this process. The arc lamp can be ramped from idle to maximum power in about 10 milliseconds. Maximum power (1200 amps) can be sustained for about 3 seconds without damaging any lamp components. The reflectors are made from two different materials: copper and aluminum. The main difference is in the temperature tolerance of the reflectors: for a time of 4 hours (this time was specified during the design of the lamp) the copper reflector can be safely operated at 1000 A while the aluminum reflector is limited to $600 \mathrm{~A}$. Both reflectors have rhodium plating on the surface. The rhodium plating is more resistant to scratches or thermal damage than the standard polished aluminum surface.

Samples processed with the arc lamp were held in a custom made chamber built from a NEMA electrical enclosure. A partial vacuum can be pulled inside the chamber $(100 \mathrm{~mm} \mathrm{Hg}$ below atmospheric) to reduce sample oxidation. The chamber can also be filled with nitrogen or argon as a cover gas. A quartz plate separates the samples from the lamp protecting the quartz tube and reflector from any reactions that may occur on the sample surface. 


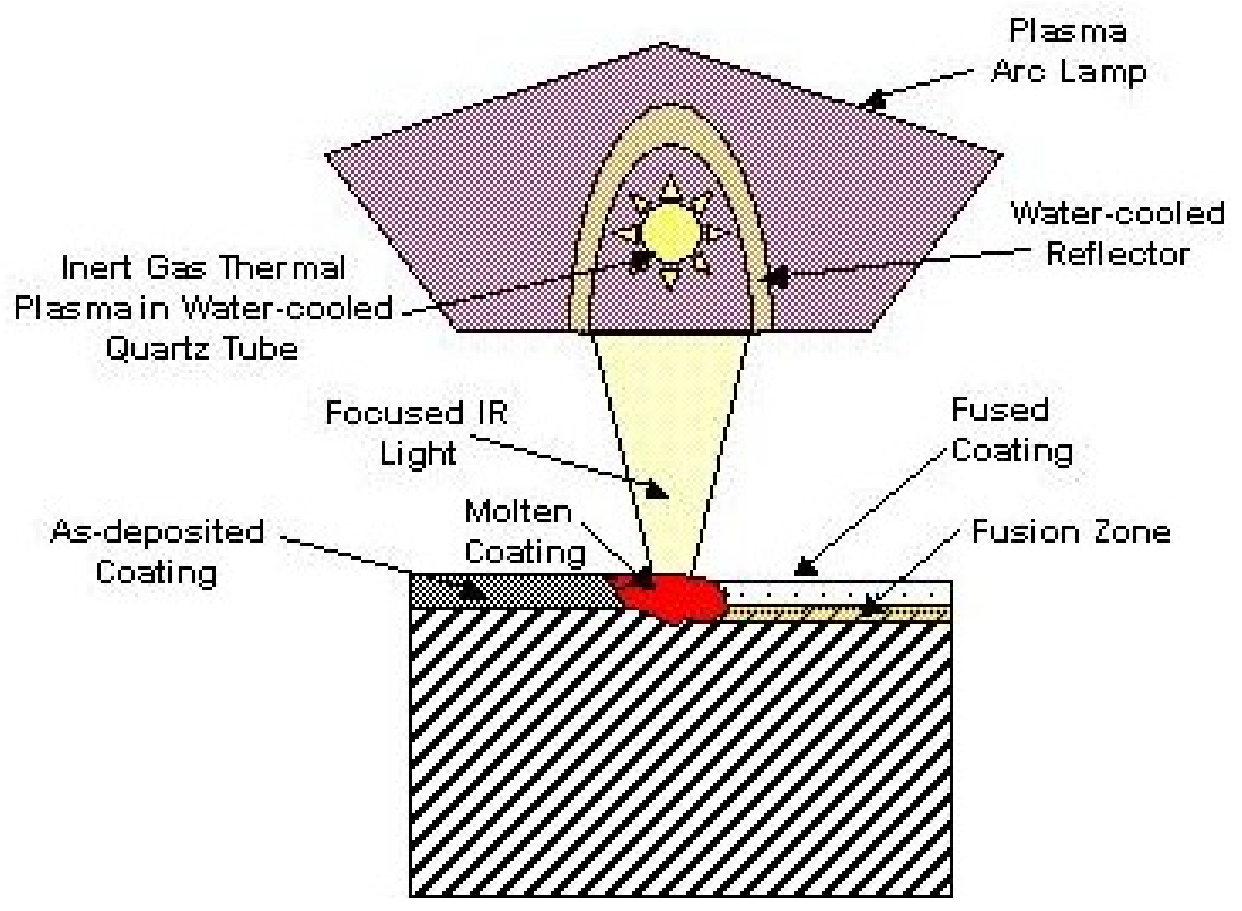

Figure 3. Schematic diagram of arc lamp fusing.

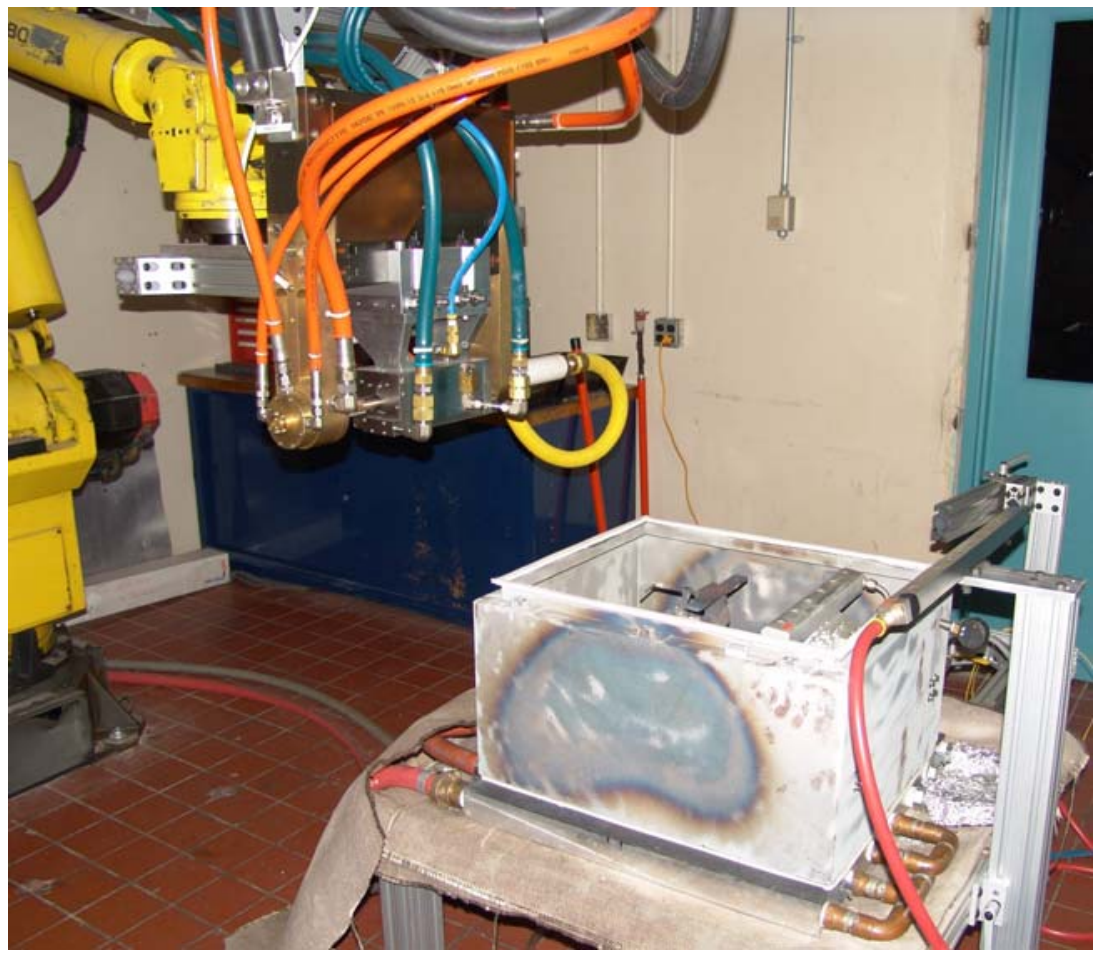

Figure 4. Caterpillar arc lamp facility. 


\subsection{Sample characterization}

This section will detail the characterization techniques used for the samples produced in this project.

\subsubsection{Microstructure}

Microstructural analysis was performed using scanning electron microscopy (SEM), electron probe microanalysis (EPMA), energy dispersive spectroscopy (EDS), and x-ray diffraction (XRD). From these techniques it was possible to examine the number of phases present in a material, the elemental composition of the phases, and the crystal structures of the phases.

\subsubsection{Wear testing}

Wear behavior of the coatings was evaluated using three test methods: dry sand rubber wheel (DSRW), pin on drum (POD), and impeller testing. The DSRW test is described in ASTM G65 and is designed for low load 3-body sliding wear. This test is commonly used and much historical data is available on various alloys; however, it is often difficult to correlate performance in this wear test to wear resistance in the field. In addition, the DSRW test results are difficult to compare quantitatively because the contact area changes as the test progresses. The POD test is not an ASTM standard and is designed for medium load 2-body sliding wear. A schematic diagram and a photograph of the test machine are shown in Figure 5. The material to be tested is machined into a pin. The pin is pressed with a force of $66.7 \mathrm{~N}$ on a drum wrapped in 150 grit $(100 \mu \mathrm{m})$ garnet abrasive paper. The surface speed of the drum is $2.7 \mathrm{~m} / \mathrm{min}$. The test is continued until the sample has been rubbed against the abrasive paper for a distance of 12.8 meters. The impeller test is not an ASTM standard and is designed for high impact 2-body wear. A schematic diagram and a photograph of the test machine are shown in Figure 6. The impeller test consists of two rotating drums. The inner drum holds three samples. The samples are rectangular slabs protruding from the inner drum. The surface speed of the outer edge of the samples is $7 \mathrm{~m} / \mathrm{s}$. The outer drum rotates at about $40 \mathrm{rpm}$ and is lined with a rubber mat that lifts the abrasive media above the samples where it can fall onto the samples. The abrasive media is microcrystalline quartzite rock that is about $2 \mathrm{~cm}$ diameter at the start of the test. 600 grams of media are added at 15 minute intervals over a total test time of one hour. This test is one of the few wear tests that produces very high impact loads (the other notable impact test is the jaw crusher test, which was not used in this study). Unfortunately the variability in this test is large and the results must be interpreted carefully.

Typical wear surfaces for all three tests mentioned in the previous paragraph are shown in Figure 7. All three wear tests directly measure mass loss. For a more physically meaningful comparison of wear rates, the mass loss must be converted to volume loss by dividing by the density. The density of some of the coating materials was measured using helium pycnometry. 

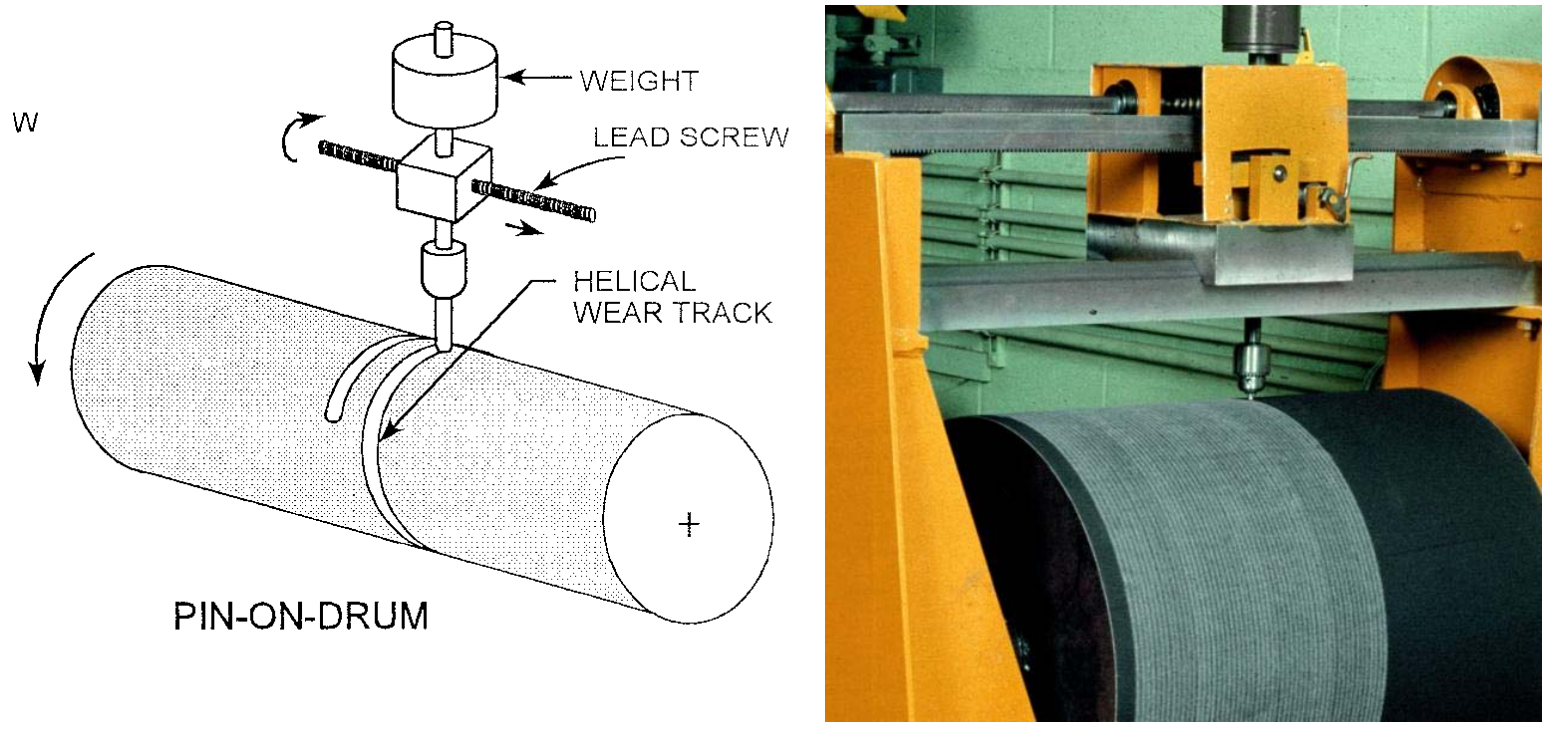

Figure 5. Pin on drum test schematic and apparatus.

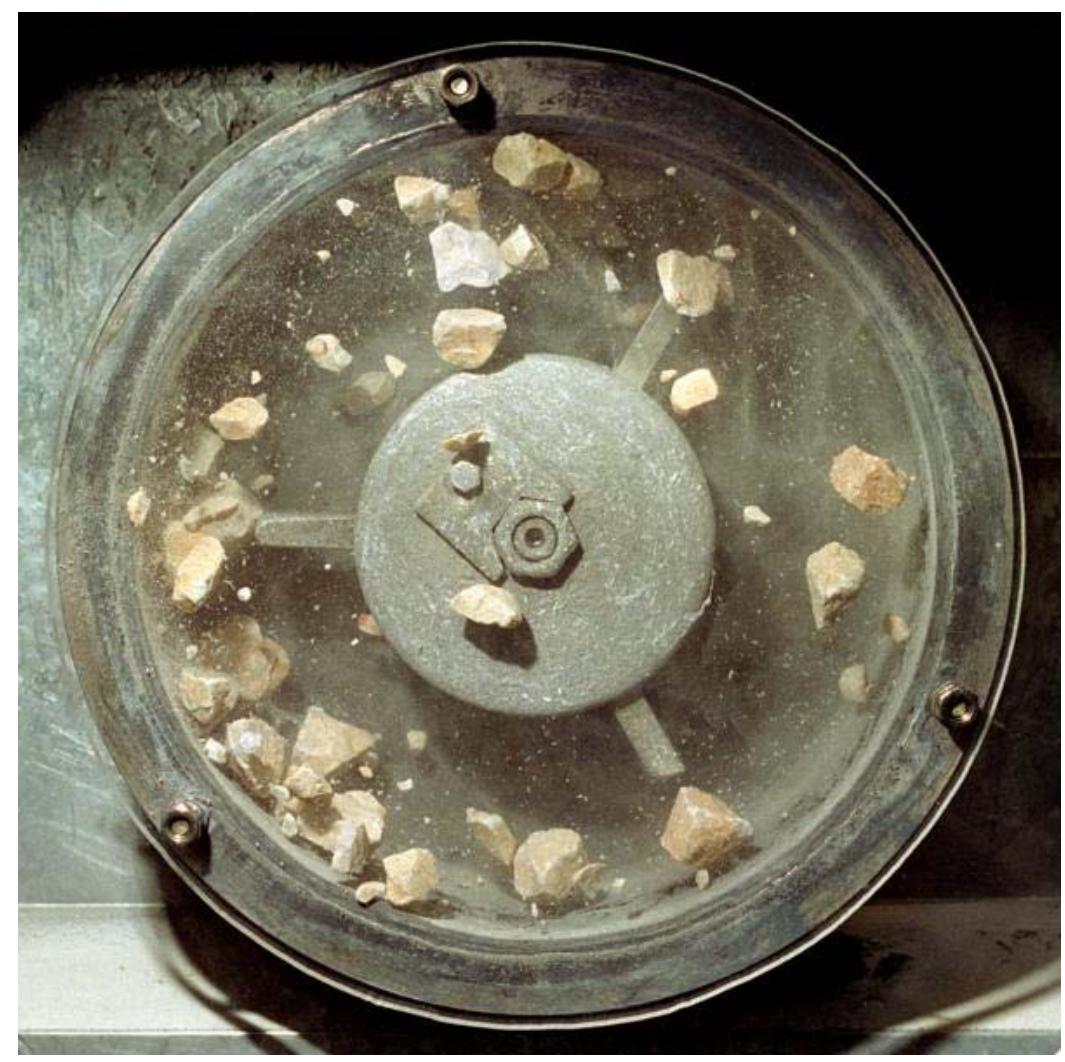

Figure 6. Impeller wear test apparatus. 

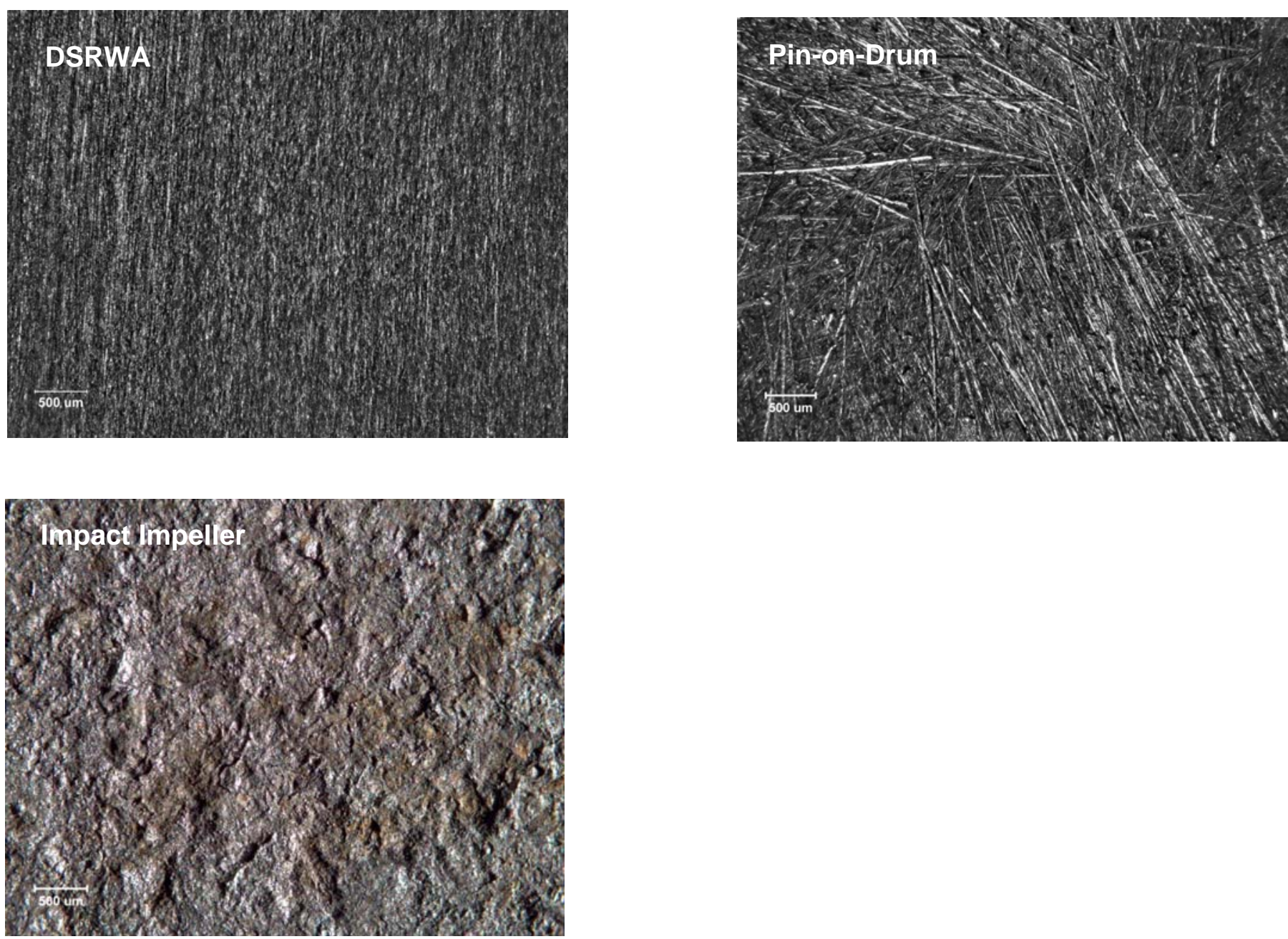

Figure 7. Typical wear surfaces observed for the wear tests of interest in this project. 


\subsubsection{Corrosion testing}

Corrosion testing was performed at Caterpillar according to ASTM B117. This is a salt fog test using a $5 \mathrm{wt} \%$ sodium chloride solution. The test chamber is held at $35^{\circ} \mathrm{C}$.

\subsubsection{Mechanical testing}

UMR designed and built a mini-fatigue apparatus to test coating mechanical properties and measure interfacial fatigue crack propagation. The test specimens for the fatigue apparatus were made using conventional EDM wire cutting. EDM was used to undercut the coating creating a thin cantilever beam of the coating material. A hole was drilled from below the coating to allow an actuator driven rod to push from the underside. The rod was a chisel point rod to produce 3point loading. Coating strength and modulus can be determined using a simple load ramp program to fracture the coating. Fatigue crack propagation behavior at the coating interface can be studied by cycling the push rod to generate and propagate fatigue cracks. Crack propagation was measured optically. Photographs of a test sample and the load frame are in Figure 8.

\subsubsection{Thermophysical properties}

Thermophysical property measurements were performed at Oak Ridge National Lab. Two critical thermophysical properties required for the modeling effort are the thermal diffusivity and specific heat of the coating materials. Thermal diffusivity measurements were obtained using an Anter Flashline 5000 laser flash diffusivity system. At the time of the measurements freestanding coatings were not available. Consequently, it was necessary to measure the thermal diffusivity of the coating-substrate system then use software provided by the manufacturer to calculate the thermal diffusivity of the coating. The thermal diffusivity was measured at temperatures between 200 and $1000^{\circ} \mathrm{C}$. Free-standing coatings were provided for specific heat measurements. 


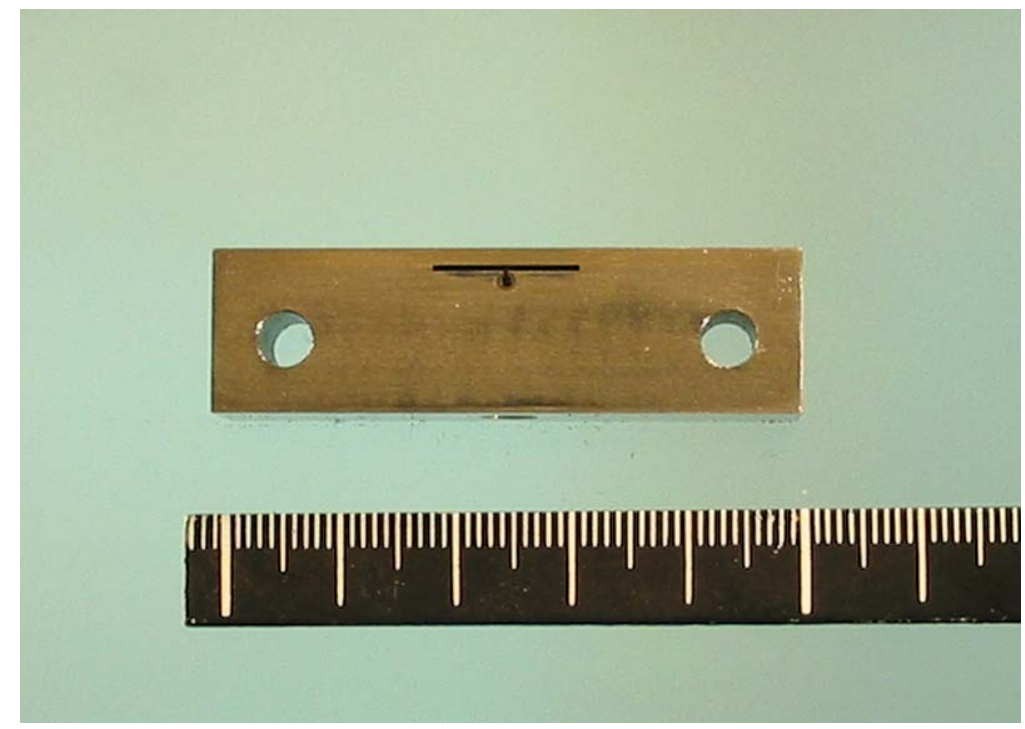

(a)

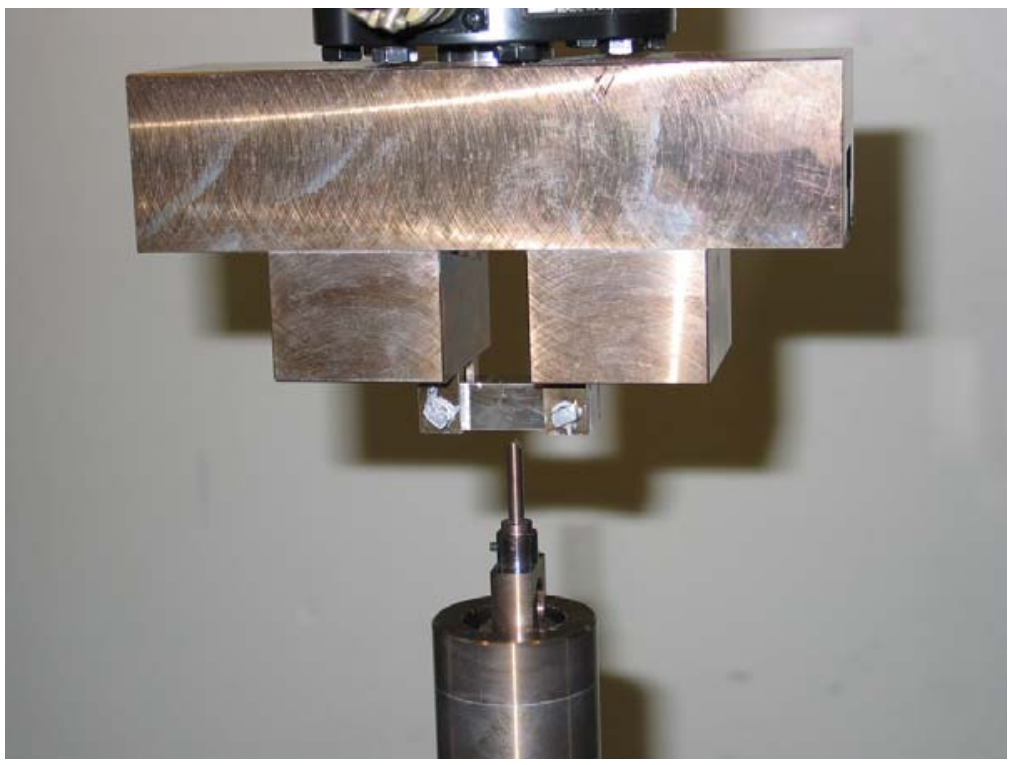

(b)

Figure 8. Optical photographs of (a) a test coupon and (b) the bend test fixture for interfacial fracture toughness tests. 


\section{Results}

This section will describe the results of the experimental procedures in the previous section. Computational results will be discussed first as they provided useful guidance on the subsequent experimental work.

\subsection{Computational results}

This section will detail the computational modeling results from both the thermodynamic models as well as the process models.

\subsubsection{Thermodynamic modeling}

Thermodynamic modeling was performed by QuesTek Innovations LLC. The goal of this modeling effort was to accelerate the development of new alloy compositions with desirable properties. QuesTek had two primary tasks. The first was computational thermodynamic modeling of the alloy system to provide equilibrium phase fractions and phase compositions. The second was computational precipitation modeling to provide guidance on processing parameters to achieve a given size distribution of hard phases during solidification of a given alloy. The program used for the thermodynamic modeling was the commercially available software package ThermoCalc. ThermoCalc is primarily used to calculate phase diagram information such as liquidus projections, phase fractions, and phase compositions. ThermoCalc has several options for modeling different alloy systems and phases. These include the type of model for each phase (describing how alloying or atomic substitution takes place within the phase) and the thermodynamic databases containing interaction parameters for the elements in the alloy. The thermodynamic models used for the various phases included:

- Associate Solution Model—for Liquid

- Substitutional or Interstitial Solution Model - for alloys containing phases with BCC and FCC crystal structures

- Sublattice Model - for borides and intermetallics such as FeMo2B2

The thermodynamic databases used for the various elements include:

- SSOL - SGTE Solution Database

- TC-Fe - TCS Steels/Fe-alloys database

- $\quad$ SSUB - TC substance database

- Fe-SAM-QuesTek Proprietary Database Established for the Design of Fe-based Amorphous Metals

- New thermodynamic property measurements performed under this project

The first step in evaluating the SICWC alloys was calculation of the predicted equilibrium phases and solidification pathways. A $1000^{\circ} \mathrm{C}$ isothermal ternary phase diagram for the Fe-MoB system (i.e., alloys 1-3) is shown in Figure 9. Phase diagrams for the other SICWC alloys are not shown because they are 4 or 5 components and are not easily visualized. Solidification 
pathways for SICWC alloys 1-9 are shown in Figure 10 - Figure 12. In the solidification pathway plots the vertical axis is the fraction of each phase and the horizontal axis is temperature. For each alloy, a high melting point boride phase (typically $\mathrm{FeMo}_{2} \mathrm{~B}_{2}$ or $\mathrm{FeB}$ ) is the first to precipitate from the liquid. As the temperature is lowered additional boride phases may precipitate. The matrix (i.e., the final phase to solidifiy) may be a boride phase or an fcc or bcc phase.

The equilibrium thermodynamic calculations were critical for several reasons. First, they provide predictions that can be verified with experimental data. The comparison of the predicted and experimental data will be discussed in detail in the "4.2.1.1 Equilibrium microstructures" section. After validating the model, the calculations showed that it was possible to obtain a two phase mixture of a hard boride phase within an fcc or bcc matrix. The equilibrium thermodynamic calculations also provide a basis for the precipitation modeling. The calculations also provide information on liquidus temperatures. 


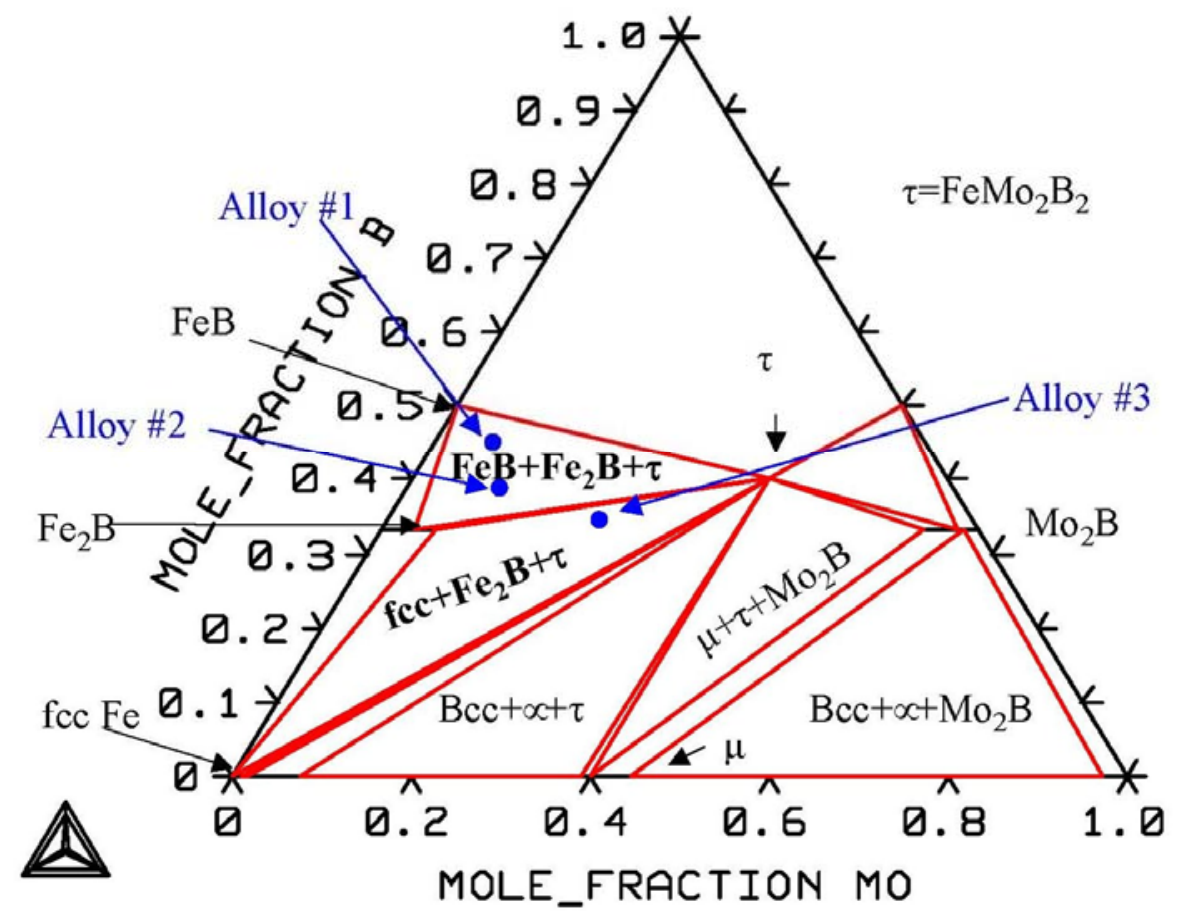

Figure 9. Equilibrium phase diagram of the Fe-Mo-B system at $1000^{\circ} \mathrm{C}$.
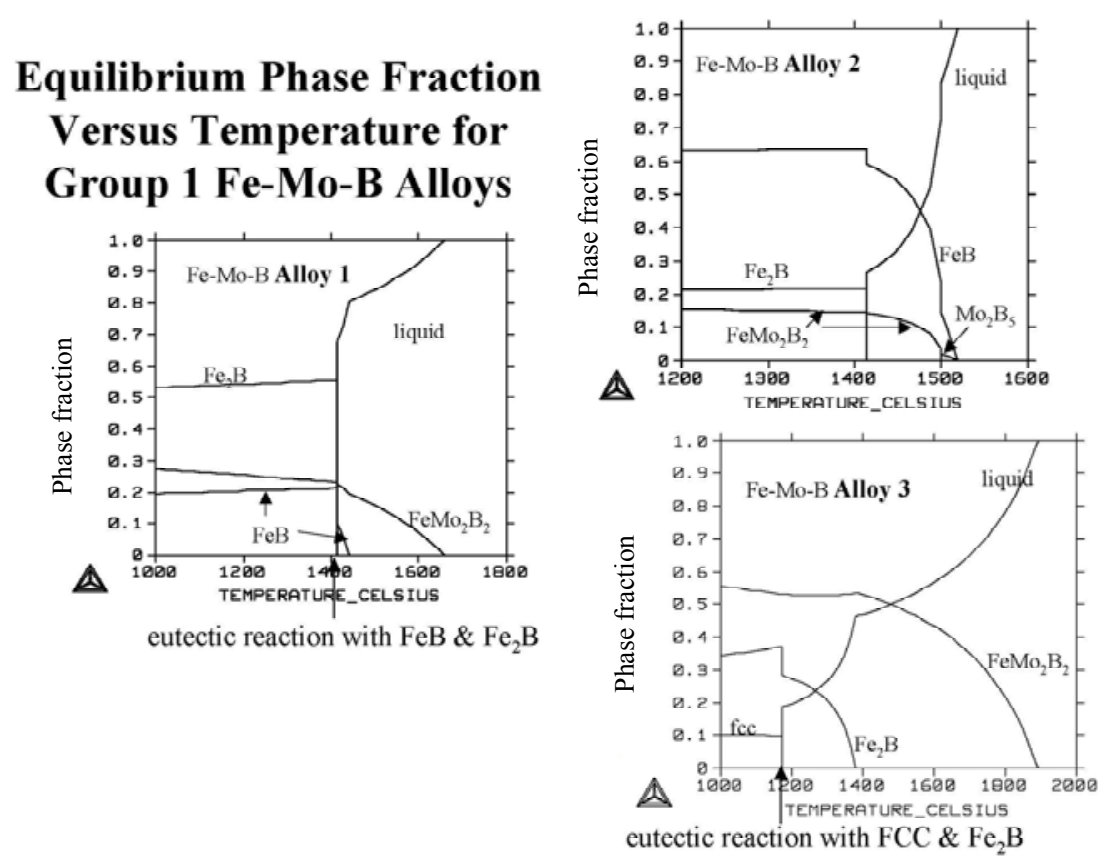

Figure 10. Equilibrium solidification pathways for SICWC alloys 1-3. 


\section{Equilibrium Phase Fraction Versus Temperature for Group 2 Fe-Cr-Mo-B Alloys}
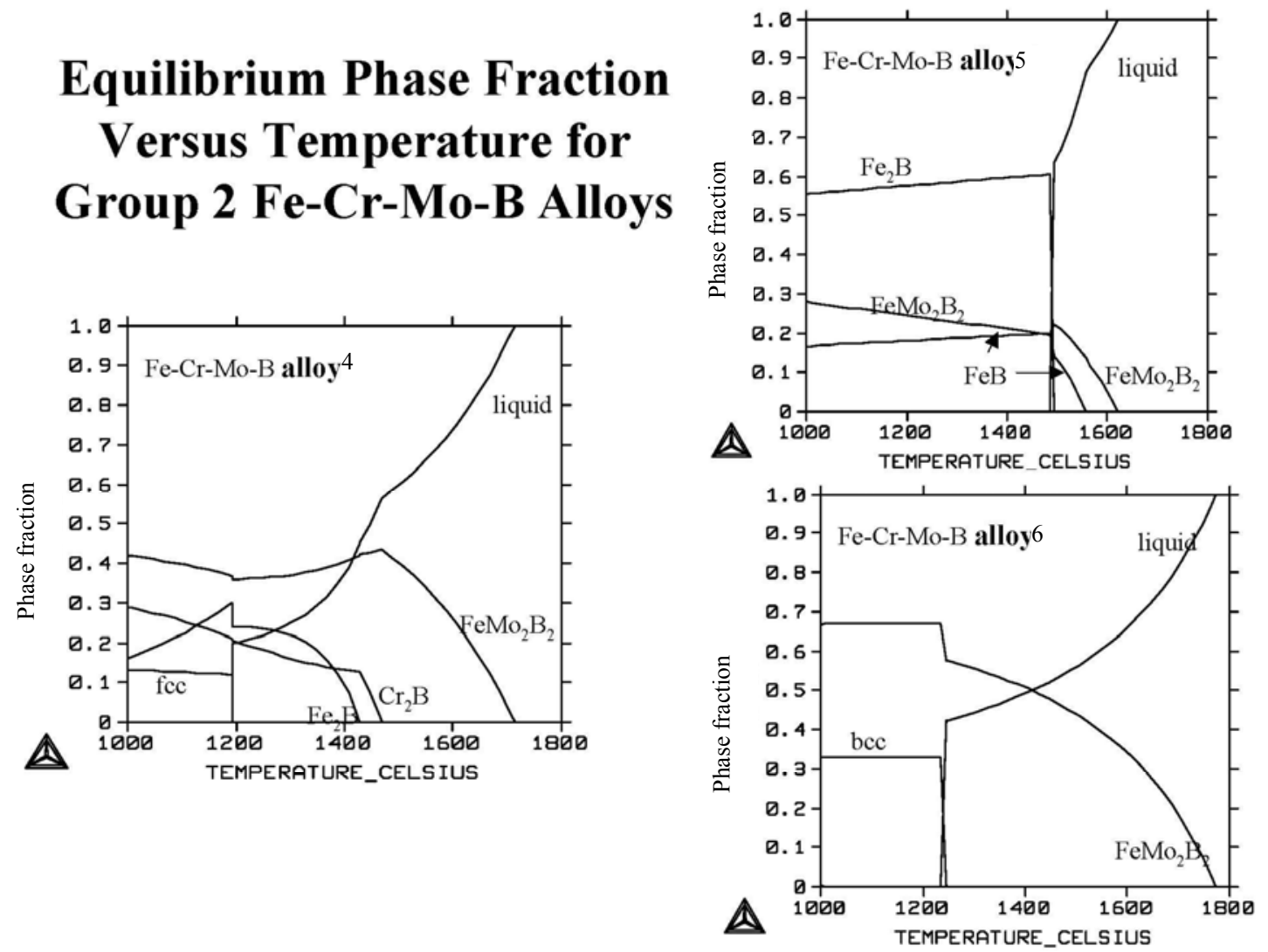

Figure 11. Equilibrium solidification pathways for SICWC alloys 4-6. 


\section{Equilibrium Phase Fraction Versus Temperature for Group 3 Fe-Cr-Mo-Ni-B Alloys}

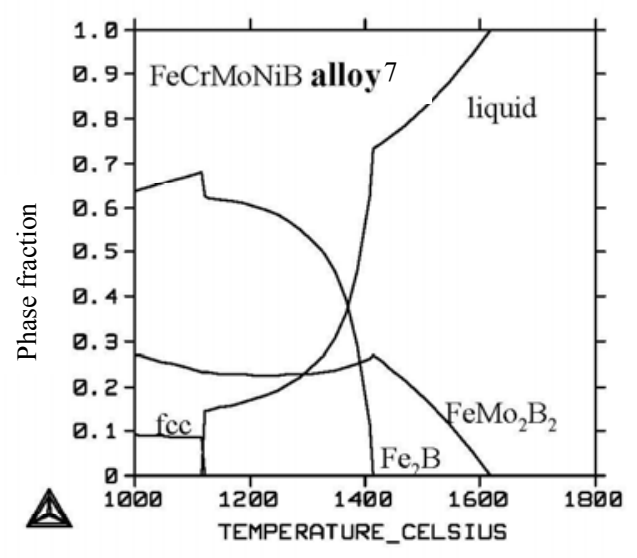

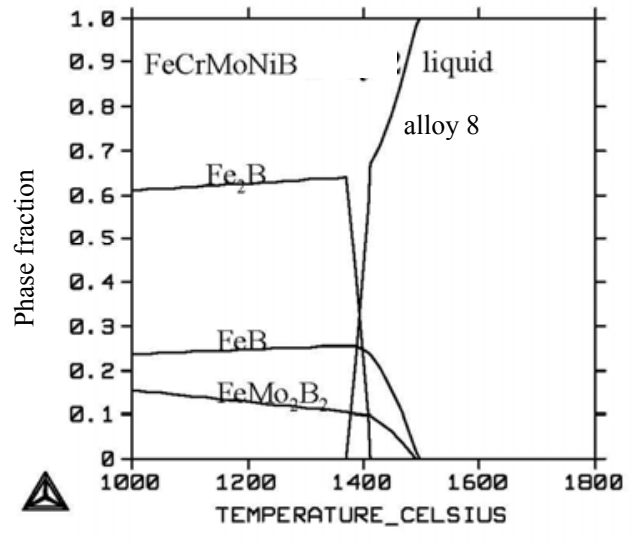

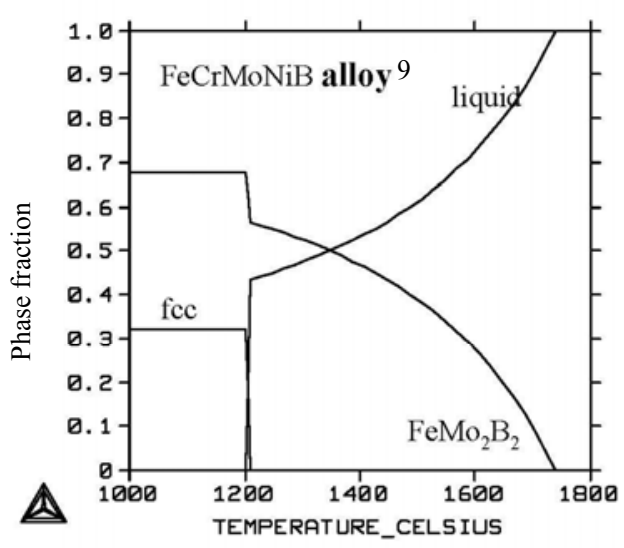

Figure 12. Equilibrium solidification pathways for SICWC alloys 7-9. 
The computational thermodynamic model predicts phase fractions and transformation temperatures during equilibrium cooling from the liquid. This model was validated through differential thermal analysis (DTA) to measure transformation temperatures and metallography, SEM, and EPMA to measure phase fractions. After validation, the model was used to calculate the overall alloy composition that would produce a given mixture of equilibrium phases. A "target microstructure" was specified with a mixture of phases that was likely to result in a tough and wear-resistant coating. This target microstructure was $75 \%$ by volume of discreet boride particles of 5-50 micron diameter. The overall compositions required to produce these microstructures are given in Table 2 for the Fe-Mo-B (i.e., SAQ1), Fe-Mo-B-Cr (i.e., SAQ4), and Fe-Mo-B-Cr-Ni (i.e., SAQ7) alloy systems. Equilibrium solidification pathways for these alloys are shown in Figure 13. While these alloys may have a desirable microstructure, there are two significant issues regarding the use of these alloys. The first is that all three alloys have relatively high liquidus temperatures. The second is that the high molybdenum content increases the cost of these alloys.

One of the goals of the SICWC project was to model the microstructural evolution of high performance coatings during processing. A related goal was to identify intrinsic and extrinsic properties required for modeling of promising materials systems/coatings. A program developed by QuesTek called PrecipiCalc was used to calculate the size distribution of the boride phase under various processing conditions. The inputs required for the PrecipiCalc program and the source or method for estimating the values is shown in Table 4.

Table 4. Parameters used in PrecipiCalc microstructural modeling.

\begin{tabular}{|l|l|}
\hline Quantity & Source/method of estimation \\
\hline Thermodynamic Databases & ThermoCalc \\
\hline Diffusivity in Liquid & Literature values for elements in liquid iron \\
\hline Molar Volumes of Borides & Density data, phase structure, and lattice parameter \\
\hline $\begin{array}{l}\text { Interfacial Energies Between Borides and } \\
\text { Liquid }\end{array}$ & $\begin{array}{l}\text { Typical value for solid/liquid interfacial energy } \\
\left(0.25 \mathrm{~J} / \mathrm{m}^{2}\right) \text { due to unreasonable results from } \\
\text { Spaepen model }\end{array}$ \\
\hline Thermal history & Process modeling \\
\hline
\end{tabular}

Typical output plots from PrecipiCalc are shown in Figure 14. Some of the key calculated quantities are the particle radius, the particle number density, and particle volume fraction. All of these quantities are calculated as functions of time (or temperature because the timetemperature relationship (i.e., thermal history) must be input into the program). PrecipiCalc also predicts a power-law relationship between the boride size and cooling rate as shown in Figure 15. Assuming thermal histories from PTA process modeling, the predicted volume fractions and boride sizes at various distances below the free surface of the coating are shown in Table 5 . 
Table 5. Boride size and volume fraction for QuesTek alloys.

\begin{tabular}{|c|c|c|c|}
\cline { 2 - 4 } \multicolumn{1}{c|}{} & Locations & $\begin{array}{c}\text { Mean Radius } \\
(\mu \mathrm{m})\end{array}$ & VF \\
\hline \multirow{3}{*}{$\#$ 1-Fe-Mo-B } & top & 20.1 & $74 \%$ \\
\cline { 2 - 4 } & $1 \mathrm{~mm}$ & 26.5 & $74 \%$ \\
\cline { 2 - 4 }$\#$ 2-Fe-Mo-B-Cr & $2 \mathrm{~mm}$ & 1.4 & $74 \%$ \\
\cline { 2 - 4 } & top & 18.4 & $72 \%$ \\
\cline { 2 - 4 } & $2 \mathrm{~mm}$ & 21.4 & $72 \%$ \\
\hline \multirow{3}{*}{ \#3-Fe-Mo-B-Cr-Ni } & 33.7 & $72 \%$ \\
\cline { 2 - 4 } & top & 8.6 & $74 \%$ \\
\cline { 2 - 4 } & $2 \mathrm{~mm}$ & 9.6 & $74 \%$ \\
\hline
\end{tabular}



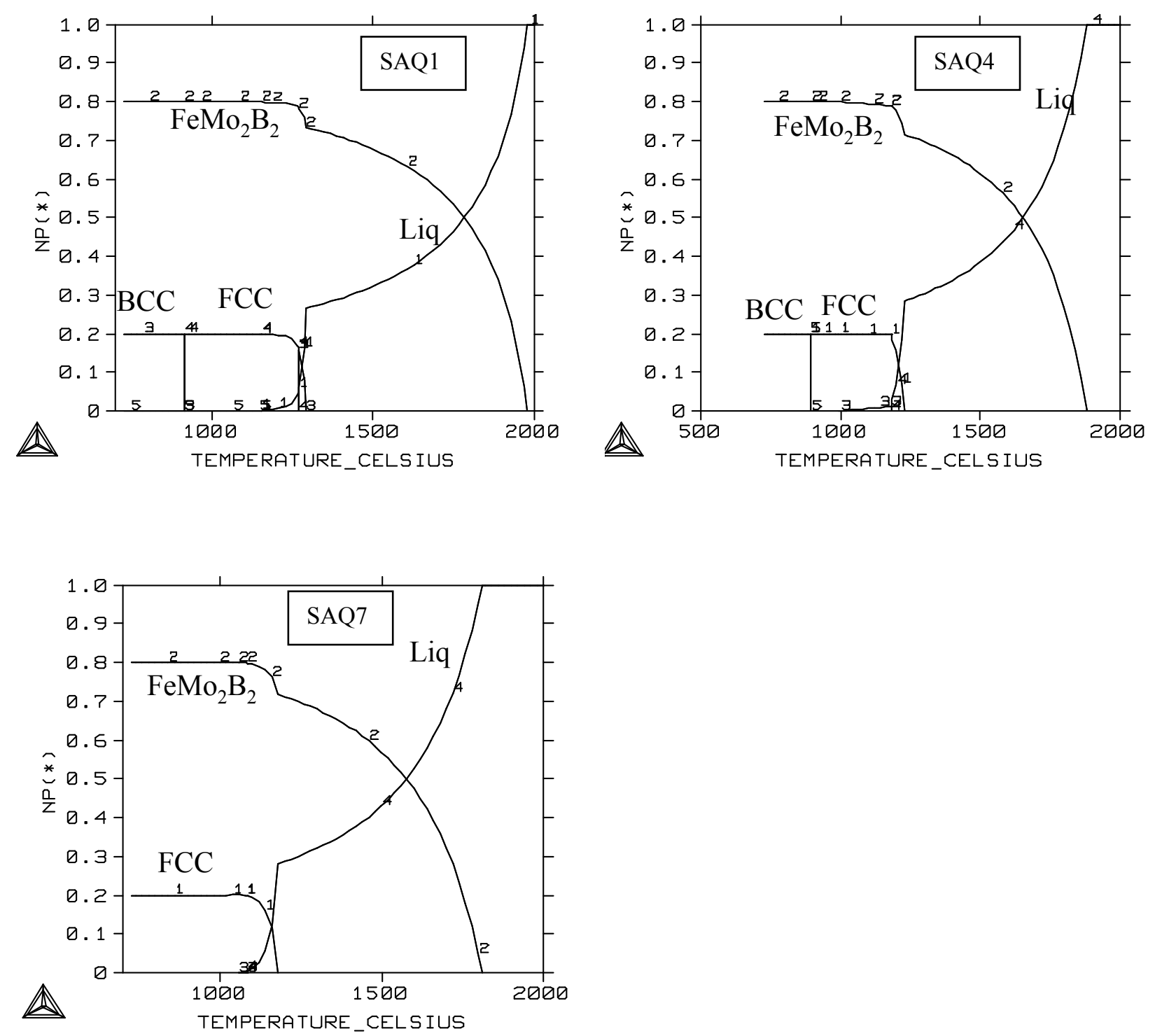

Figure 13. Equilibrium solidification pathways for QuesTek alloys SAQ1, SAQ4, and SAQ7. 

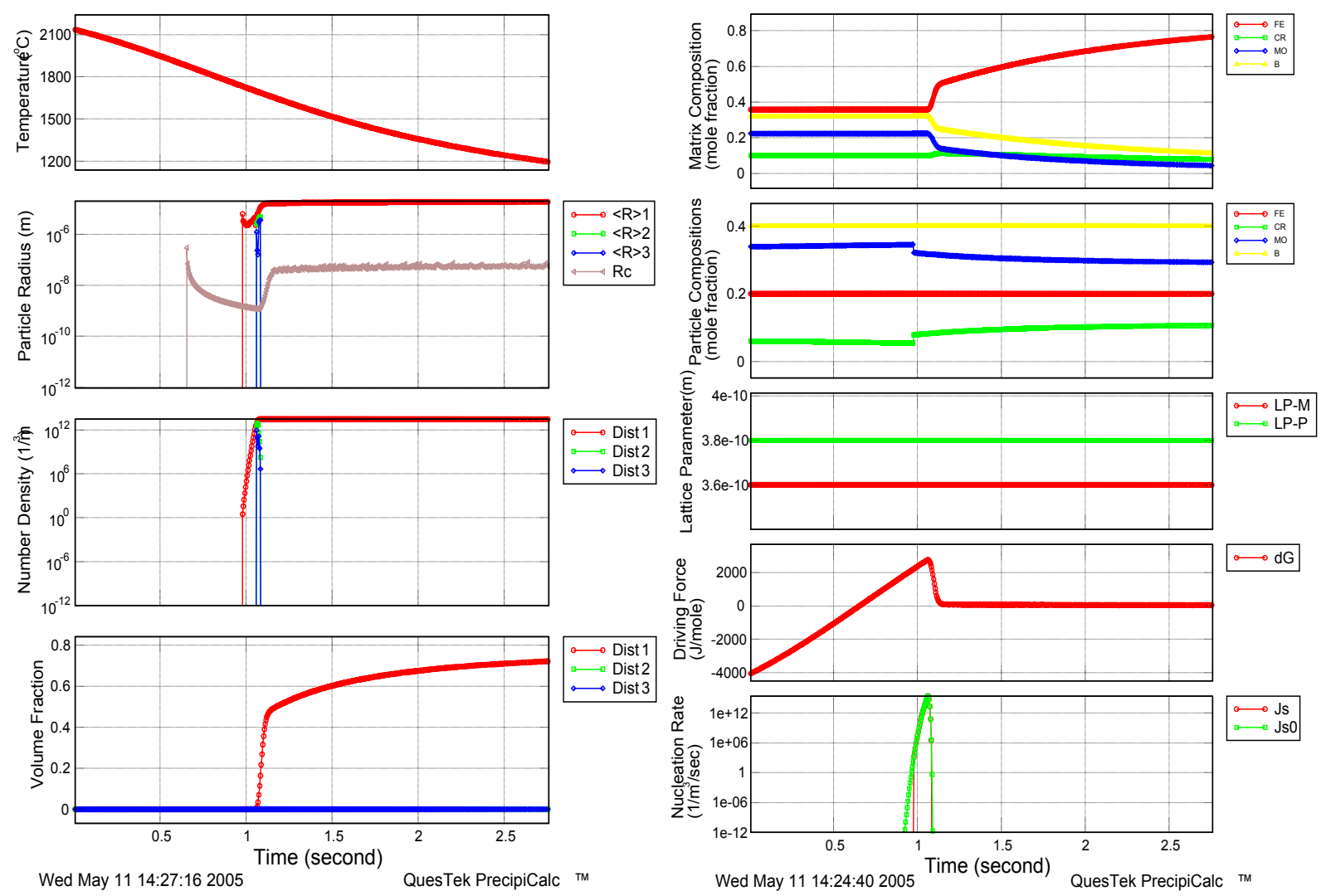

Figure 14. Typical PrecipiCalc output.

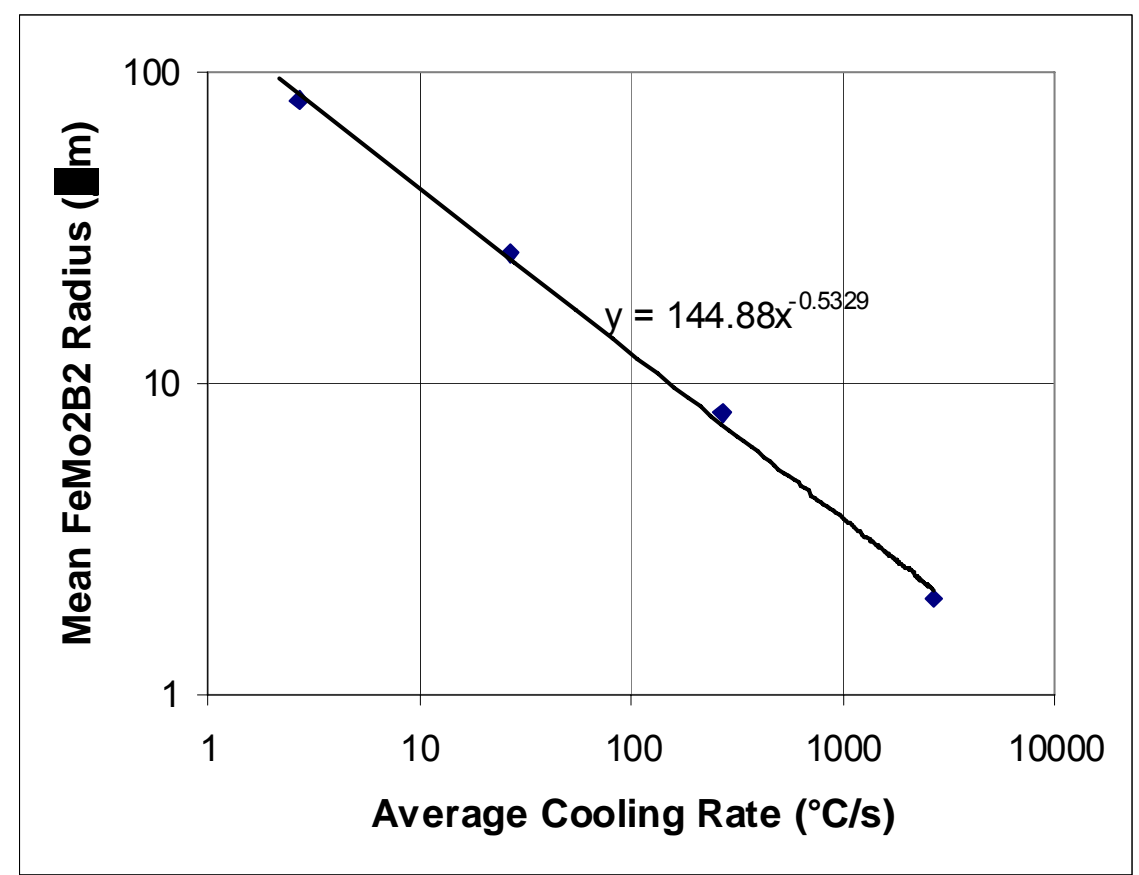

Figure 15. Calculated boride phase radius as a function of cooling rate. 


\subsubsection{Process modeling}

The process modeling performed at Caterpillar is based on finite element analysis (FEA). The ultimate goal of the process modeling work was to integrate heat transfer and phase transformation into a single model.

\subsubsection{Arc lamp}

Two arc lamp process models were developed at Caterpillar. The first model was physics based with the goal of relating process parameters with phase transformations in the coating. Modeling these phenomena required many inputs based on the arc lamp, the substrate material, and the interactions between the substrate and its environment. The material property inputs included heat capacity, thermal conductivity, density, latent heat of fusion, solidus temperature, and liquidus temperature. The inputs from the arc lamp included the spatial heat flux distribution (which incorporates the power level and the distance from the sample to the focal plane) and the spectrum of electromagnetic radiation. The interaction parameters included the heat transfer coefficient and the emissivity. All of the input parameters were required to be known as functions of temperature. None of these parameters were directly measured at the time these calculations were performed. Most of the parameters were estimated from data available in handbooks or the open literature. One key input, the heat flux distribution of the arc lamp, is shown in Figure 16.

Before developing a unified heat-transfer phase-transformation model, each component model was examined individually. The results of a typical heat transfer model calculation are shown in Figure 17. The substrate was assumed to be a flat plate of 1042 steel with the lamp at maximum powder $(500 \mathrm{~kW})$ and scanned over the substrate at $10 \mathrm{~mm} / \mathrm{s}$. The calculations indicate the surface temperature may exceed $2500 \mathrm{~K}$ and that at $1.7 \mathrm{~mm}$ below the surface the temperature may exceed $1500 \mathrm{~K}$. The results of the initial trial of a phase transformation model for arc lamp processing a flat plate is shown in Figure 18. This model shows diffusion between the coating material (shown in red) and the substrate (shown in blue) during a scan of the arc lamp across the material. Unfortunately, due to uncertainty in the model inputs and long computational times the phase transformation modeling effort was not pursued.

After the heat transfer model tests on flat plates, the heat transfer in a cylindrical geometry was examined. The initial FEA results are presented in Figure 19. In this calculation the length of the cylinder was equal to the arc length. The cylinder was rotated under the lamp at $2.4 \mathrm{rpm}$. The time-temperature profiles at various locations around the radius of the cylinder are shown in Figure 20. At a constant arc power level the start/stop location (shown as the pale blue line) was about $400^{\circ} \mathrm{C}$ hotter than the steady-state temperature at other areas around the cylinder. This issue is common in many processing techniques such as welding and laser processing. This transient heat increase can be diminished by reducing the arc lamp power as the lamp approaches the starting point on the cylinder. Another option for reducing the transient heat increases is increasing the rotation speed of the cylinder. Figure 22 shows the temperature profiles at a single point on the cylinder surface as functions of time for a cylinder rotating at $60 \mathrm{rpm}$ and 600 
rpm. At the higher rotation speed the temperature is more uniform both at and below the cylinder surface; however, the zone of highest temperature (shown in red) does not extend as deep into the cylinder. 


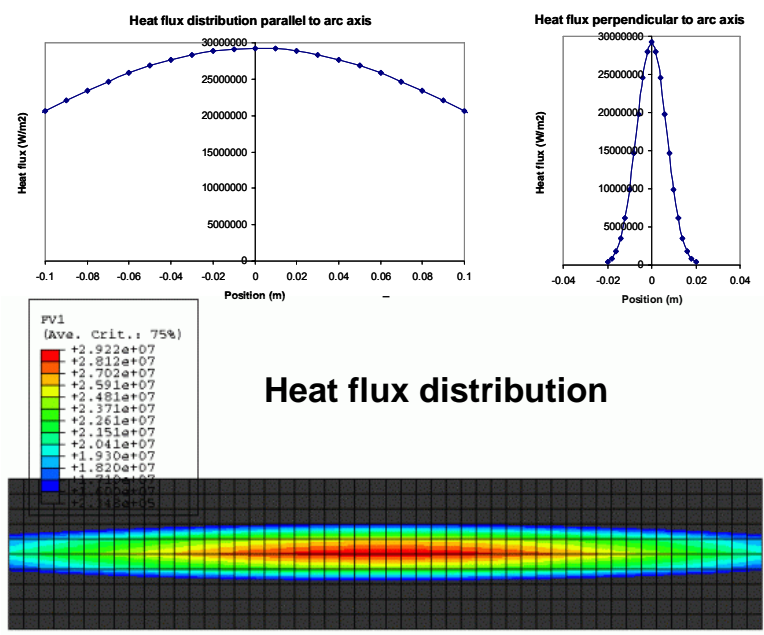

Figure 16. Assumed 2-D spatial heat flux distribution of the arc lamp.

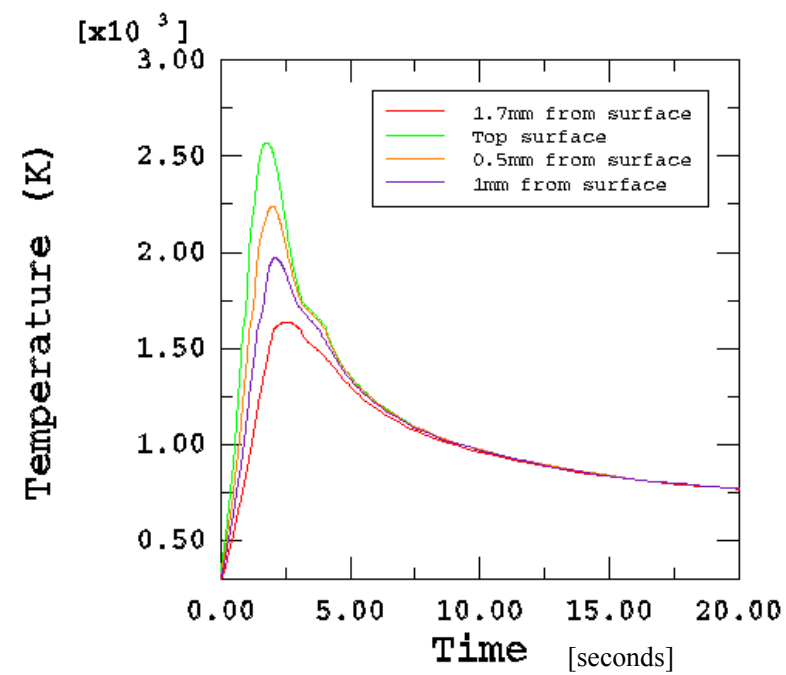

Figure 17. Substrate temperature as functions of depth below the surface and time for an arc lamp scan at a traverse speed of $10 \mathrm{~mm} / \mathrm{s}$ and a power level of $500 \mathrm{~kW}$.

Arc lamp direction of motion

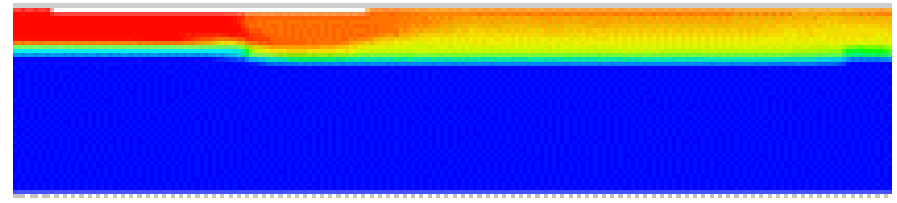

Figure 18. Compositional modeling of a coating-substrate system during arc lamp processing. 

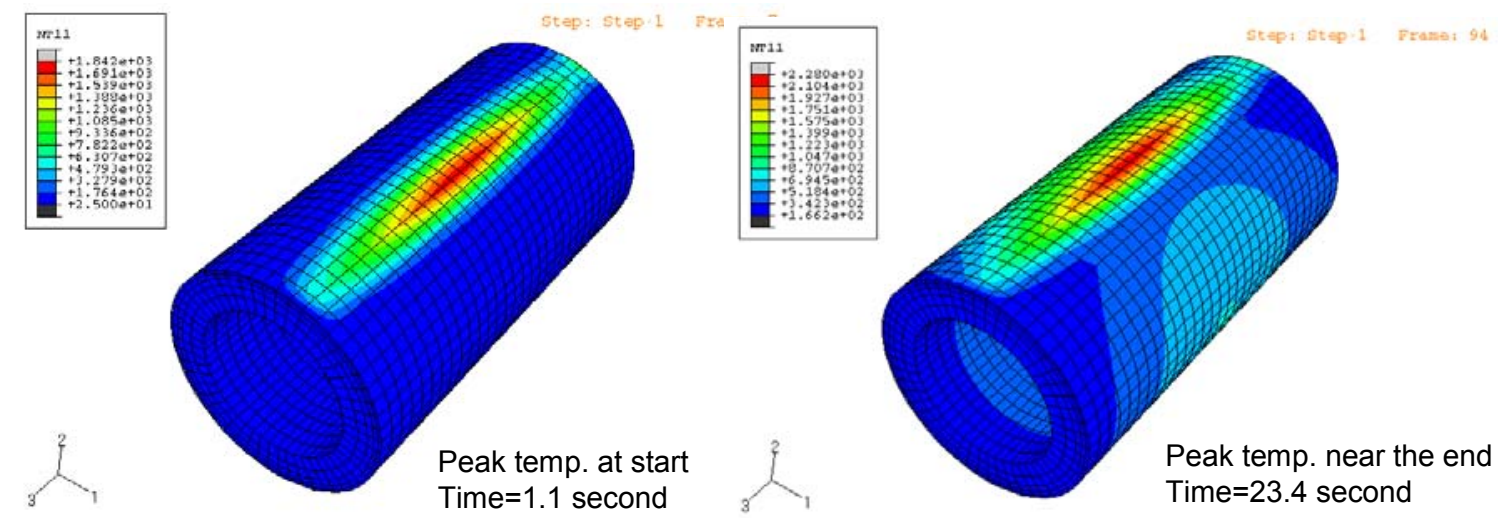

Figure 19. Heat transfer modeling of arc lamp processing a cylinder.

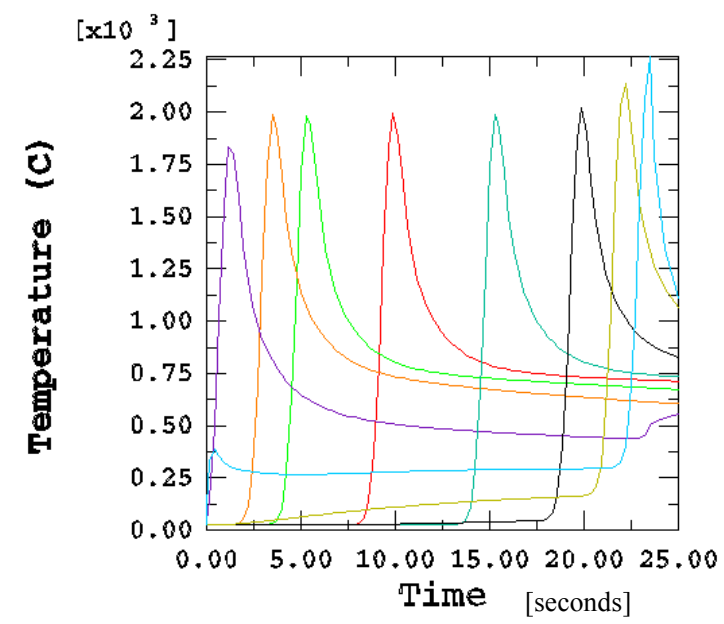

Figure 20. Temperature profiles at various radial locations around a cylinder during arc lamp processing with a constant arc power level.

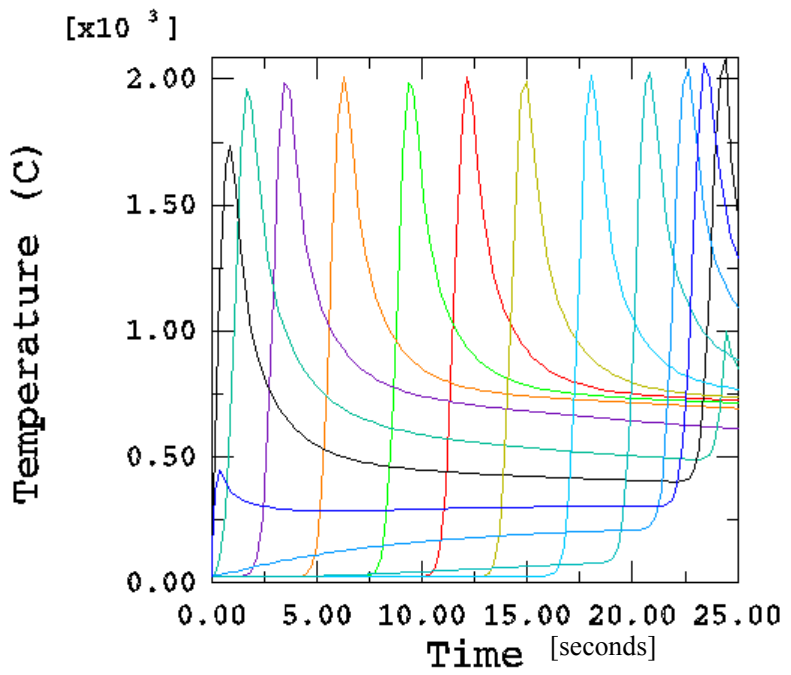

Figure 21. Temperature profiles at various radial locations around a cylinder during arc lamp processing with a variable arc power level. 

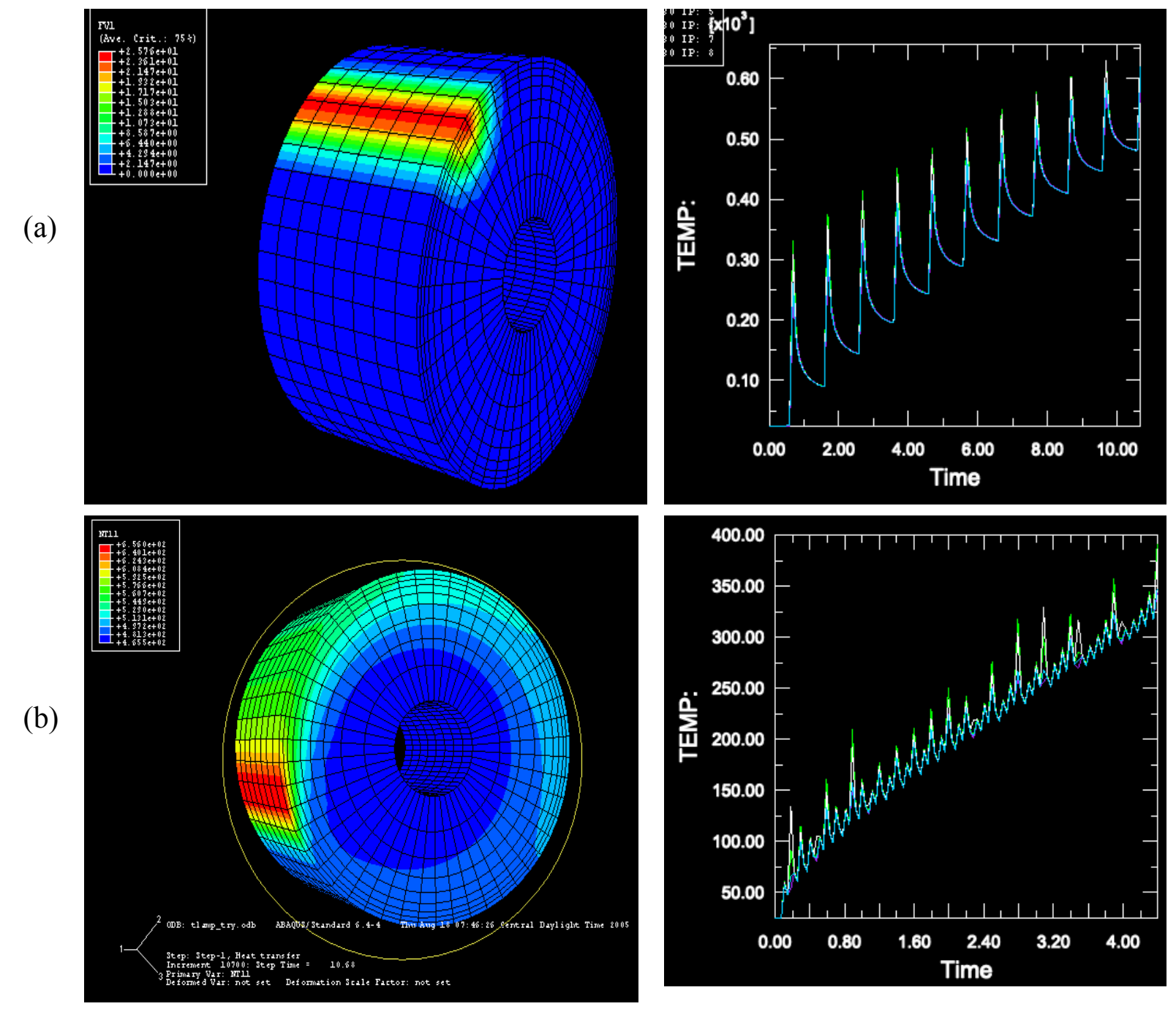

Figure 22. Heat transfer calculations for a cylinder rotated at (a) $60 \mathrm{rpm}$ and (b) $600 \mathrm{rpm}$. 
The first models developed at Caterpillar were physics based, three dimensional, and computationally intensive. The second type of model developed at Caterpillar was an empirical model relating the arc lamp power level to sample temperature. A schematic diagram of the model is shown in Figure 23. Heat flow was assumed to be 2D (i.e., heat flow took place only perpendicular to the arc and the temperature parallel to the arc was uniform) and axisymmetric. The model also assumed convective heat loss to the air surrounding the cube. Material properties such as the thermal conductivity were taken from the ASM Materials Handbook. The model does not take into account directly many of the physical phenomena resulting in heat input to a sample under the arc lamp. The model groups these processes into a calibration determined by curve fitting measured arc lamp power vs. temperature data. The model was calibrated by measuring the temperature of a 1" x 1" x 1" cube of 1045 steel at various arc lamp power levels. The temperature was measured using a type $\mathrm{K}$ thermocouple spot welded to the side of the cube opposite to the lamp. The calibration curves are shown in Figure 24. Based on this calibration, the model was used to predict the length of time a sample would need to be exposed to a $500 \mathrm{~kW}$ arc lamp pulse to reach $1600^{\circ} \mathrm{C}$ at its surface. The results are shown in Figure 25 . Without preheating the sample a 7.6 second pulse would be required. This is outside the safe operating conditions of the lamp. With a pre-heat cycle it is possible to use a 2.2 second pulse, which is within the safe operating capabilities of the lamp. While this model is greatly simplified, it does provide some processing guidance. This model suggests that a pre-heat cycle may be beneficial to achieve higher surface temperatures. The use of pre-heating cycles was explored extensively and will be discussed in the "4.2.1.3 Arc lamp" experimental results section.

Arc lamp modeling was also performed by ORNL to examine the effect of convection during arc lamp processing. The main goal of this effort was two-fold. ORNL first investigated the availability and applicability of various casting computer modeling codes (e.g., Flow3D, and ProCAST) to determine whether these could potentially provide a quick turn-around in evaluating convective mixing. ORNL determined that for FLOW 3D, although it is very accurate, there most likely would be compiler incompatibilities between this code and the convective subroutine needed. For ProCAST, although it would be fast to set-up, melting is not handled well, and the accuracy would most likely not be good enough to predict optimum processing parameters for fusing coatings. The conclusion reached was that these casting codes are not ready at this point for a quick application to model convection during IR processing. An assessment of the new version of the Telluride code revealed that it seems that it can be customized to investigate convective mixing, however, since this new version previously has not been tested at ORNL, it would require an extensive effort to describe the spatial and temporal variation in heat flux on the top surface of the sample during high density infrared processing using the plasma arc lamp. All the modules would:

1.) first, need to be tested to verify that they operate as advertised

2.) the applicability of this code would need to be assessed and validated for its applicability for combined heat transfer/ fluid dynamics/ phase change issues

3.) the user subroutines would need to be implemented for heat flux evolution (spatial and temporal) aspect

4.) an appropriate model would need to be developed to capture the convective mixing 
5.) simulations would need to be run for static positions of the PAL to validate the computer model based on experimental validation (temperature and/or liquid pool depth)

6.) the level of fluid convection and ensuing mixing would need to be verified in the molten region

7.) the experimental program data and computational program would need to be coordinated intimately to assist in an accurate model being developed.

This model would need to be first developed to evaluate convective experiments to evaluate the experiments designed to first control the deposition (spatially) of the composite particles to evaluate the surrogate (the baseline control sample) and then expanded and tested on Caterpillar's actual composite coatings. To accomplish this, user routines would need to be developed to predict the heat flow/flux evolution. These would be incorporated into the parent code. An example of a model that was developed on the baseline Telluride code for a baseline PAL processed test case provides some guidance for a case that was developed without considering the convective aspect during IR processing. Figure 26 depicts these results that were generated to predict optimum processing parameters for fusing alloy based coatings. In particular, this figure demonstrates that for the baseline case (without convection mixing) (a) excellent agreement has been achieved between the experimental and predicted thermal profiles both at the coating-substrate interface and on the back side of the substrate; and (b) that modeling has enabled the thermal flux/temperature to be predicted across a 3 inch wide sample as a function of HDI processing parameters. These latter results demonstrate that sample temperatures can be predicted based on processing parameters - i.e., as a function of HDI lamp speed, enabling HDI processing parameters to be predicted. Further, this effort has demonstrated that we can predict HDI processing parameters (lamp power and scan speed) to obtain UNIFORM thermal flux for a three inch (3") wide sample, eliminating over/under heating. (This provides the flexibility that would facilitate the use of HDI Processing feedback controls). A newly revised version of the Telluride modeling code (Truchas) was briefly evaluated. This latter code was determined to be capable of being used to implement the user subroutines necessary for describing the spatial and temporal variation of heat flux on/in the sample during HDI processing using the plasma arc lamp.

\subsubsection{Plasma transferred arc (PTA)}

FEA heat transfer modeling was also used to model the PTA process. The PTA process parameters were $120 \mathrm{~A}$ at $27 \mathrm{~V}$. The model for the PTA process assumed a line heat source moving at a constant speed of $3 \mathrm{~mm} / \mathrm{s}$. The motion of the arc was assumed to take place in a single direction rather than tracing a $2 \mathrm{D}$ path in the plane of the coating surface. Based on these assumptions, symmetry was assumed around the centerline of the arc and heat transfer for half of the sample was calculated. A typical temperature field is shown in Figure 27. The physical properties of a 1042 steel were assumed for the substrate. For calculation purposes, the physical properties of the coating were assumed to be equal to the 1042 steel (in cases 1 and 2) and equal to an AISI 13Cr-13Ni steel (in cases 3 and 4). In cases 1 and 3 the coating thickness was $2 \mathrm{~mm}$ and in cases 2 and 4 the coating thickness was $3 \mathrm{~mm}$. The results of the calculations for all four cases are shown in Figure 28. For a given set of material properties, the peak temperatures for 
the thinner coating are higher due to the larger power density. For a given thickness, much higher peak temperatures are observed for the material with the lower thermal conductivity (i.e., the AISI 13Cr-13Ni steel in cases 3 and 4). 


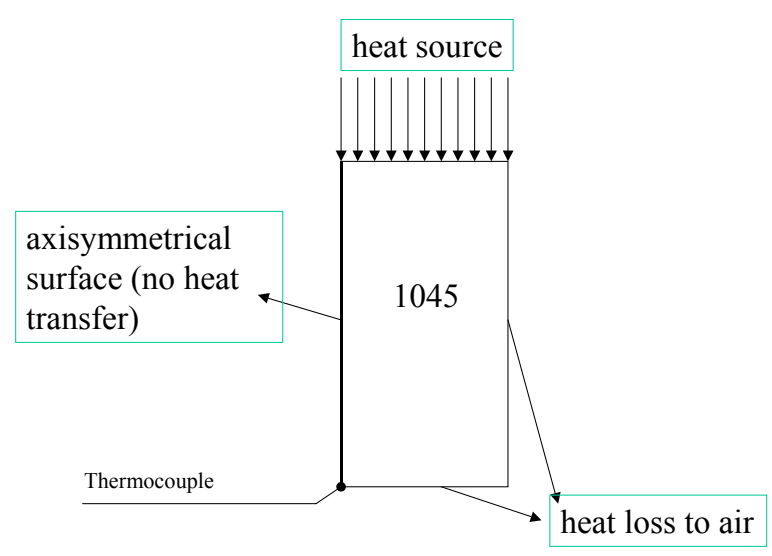

Figure 23. Schematic diagram of empirical heat transfer model.

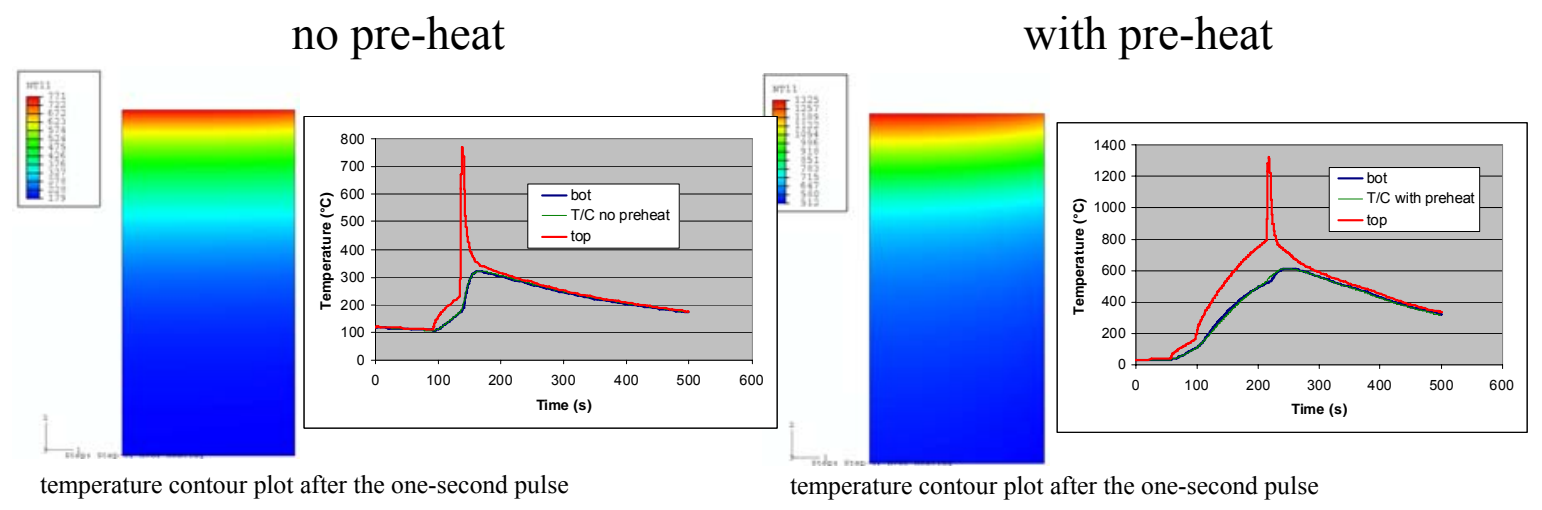

Figure 24. Comparison of model predictions (blue line) with experimental data (green line).

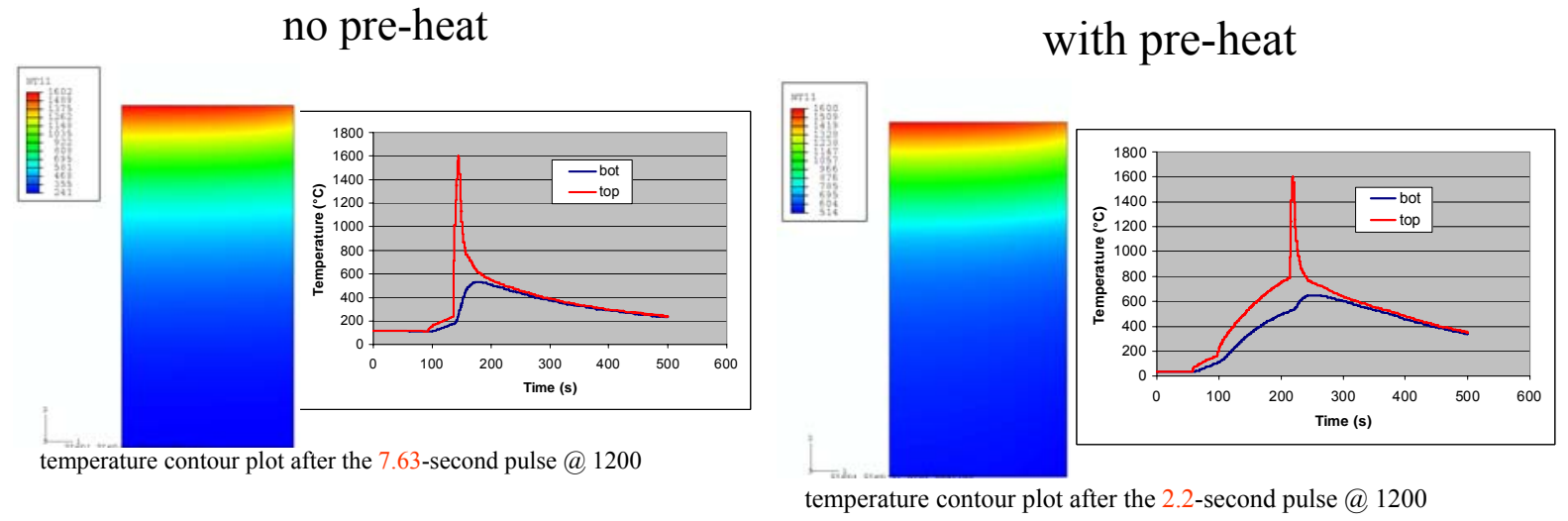

Figure 25. Calculated pulse time at $500 \mathrm{~kW}$ required for the surface of an arc lamp processed sample to reach $1600^{\circ} \mathrm{C}$. 


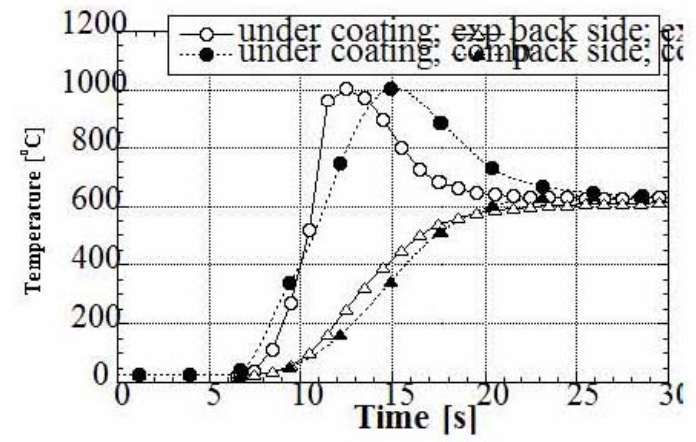

(a)

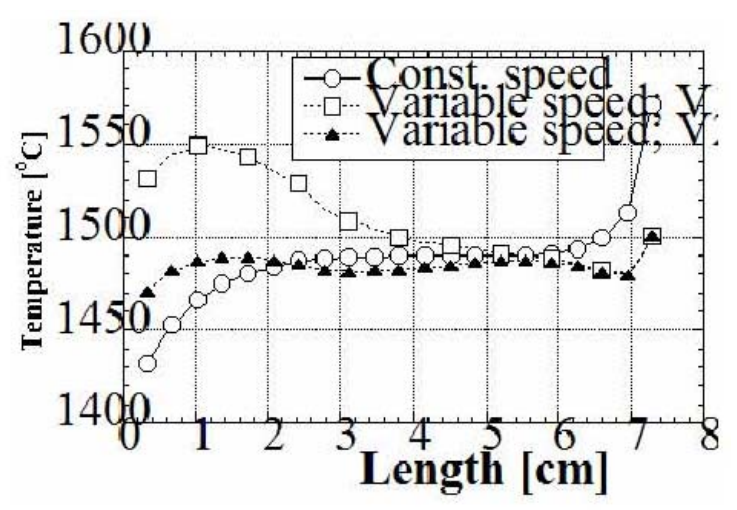

(b)

Figure 26. Comparisons of predicted and measured thermal profiles from ORNL. 


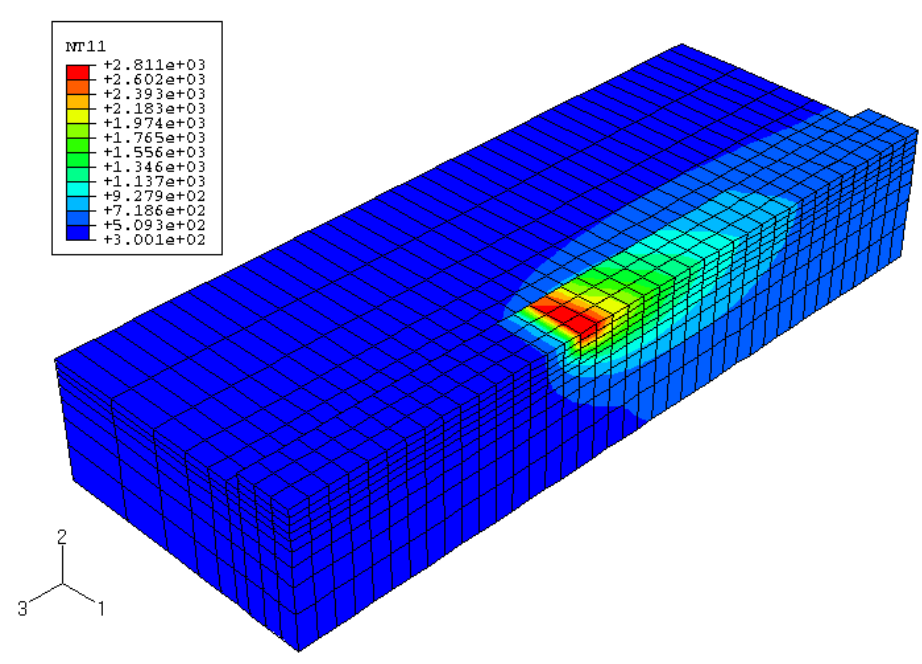

Figure 27. Calculated temperature field during PTA processing.

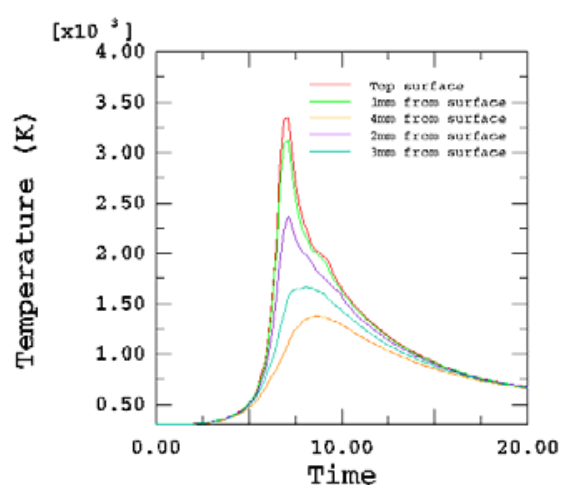

(a) Case 1

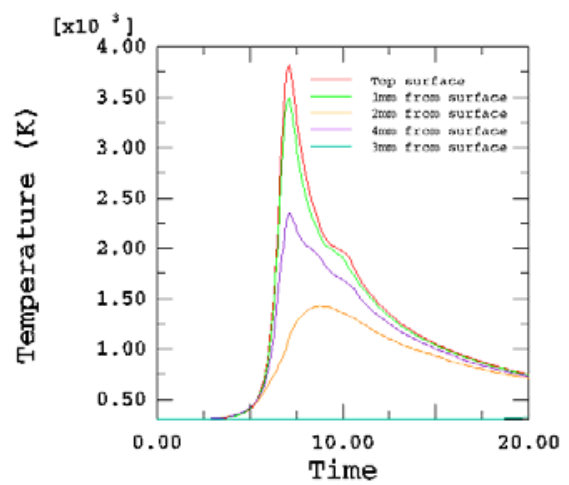

(c) Case 3

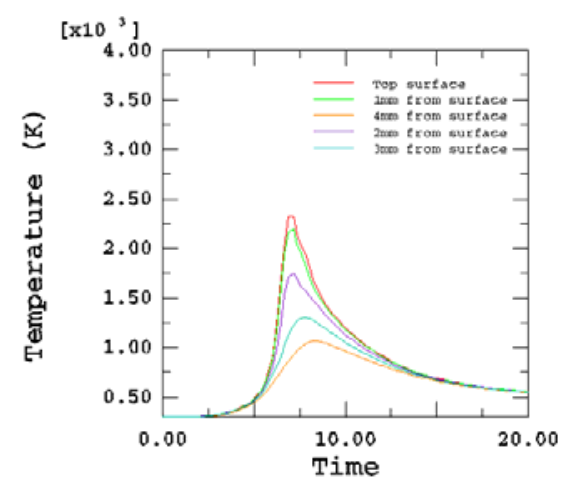

(b) Case 2

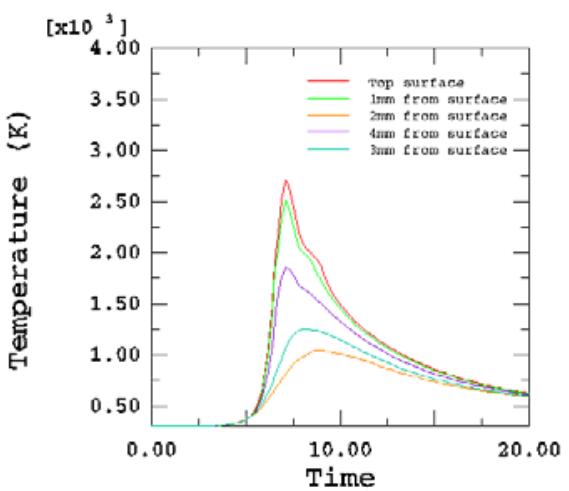

(d) Case 4

Figure 28. Time-temperature curves for different PTA processing conditions. 


\subsection{Experimental results}

This section will detail the experimental results obtained from all of the experimental phases of the project including microstructural evaluations, wear testing, corrosion testing, mechanical testing, thermophysical property measurements, residual stress measurement, and field testing of coated wheel loader bucket components.

\subsubsection{Microstructural evaluation}

This section will show microstructures resulting from equilibrated samples, as-sprayed coatings, arc lamp fused coatings, and plasma transferred arc coatings.

\subsubsection{Equilibrium microstructures}

The first step in validating the thermodynamic models was comparison of the predicted phase fractions and phase compositions with experimental measurements on equilibrated samples. Each of the nine initial alloy compositions was produced by arc melting high purity $(>99.99 \%)$ elemental components under inert gas then annealing at $1000^{\circ} \mathrm{C}$ for 4 weeks. An overview of the equilibrium microstructures of alloys SA1-SA9 is shown in Figure 29. A summary of the comparison of the predicted and measured characteristics is shown in Figure 30. While these results are summarized in a single figure and table, it is important to note that a large amount of experiment and analysis time is supporting this data. Each annealed sample was analyzed using XRD for phase identification, EPMA for phase composition, image analysis for phase fraction, and DTA for transformation temperatures. There was good agreement between the model predictions and the experimental measurements.

\subsubsection{As-sprayed microstructure}

Arc lamp processing requires prior application of the coating material. In order to understand the effect of arc lamp processing it is necessary to understand the prior coating application process and examine the initial microstructure of the coating. The coatings for the arc lamp samples were applied using the plasma spray process. The powders for the initial trials were manufactured at Caterpillar Inc. using the sintering and crushing procedure described earlier. A micrograph showing an example of the morphology of the as-crushed powder is shown in Figure 31. The sintered particles have irregular, angular shapes. In some alloys unsintered constituent particles are visible in cross-section micrographs. Figure 32 shows an example of an as-sprayed coating microstructure in comparison to the equilibrium microstructure. The as-sprayed coatings show highly non-equilibrium microstructures. The coating has a layered structure typical of thermal spray coatings. XRD and EPMA analysis by ISU also indicated the presence of metastable phases in some alloys resulting from the rapid quench rates of the thermal spray process. 

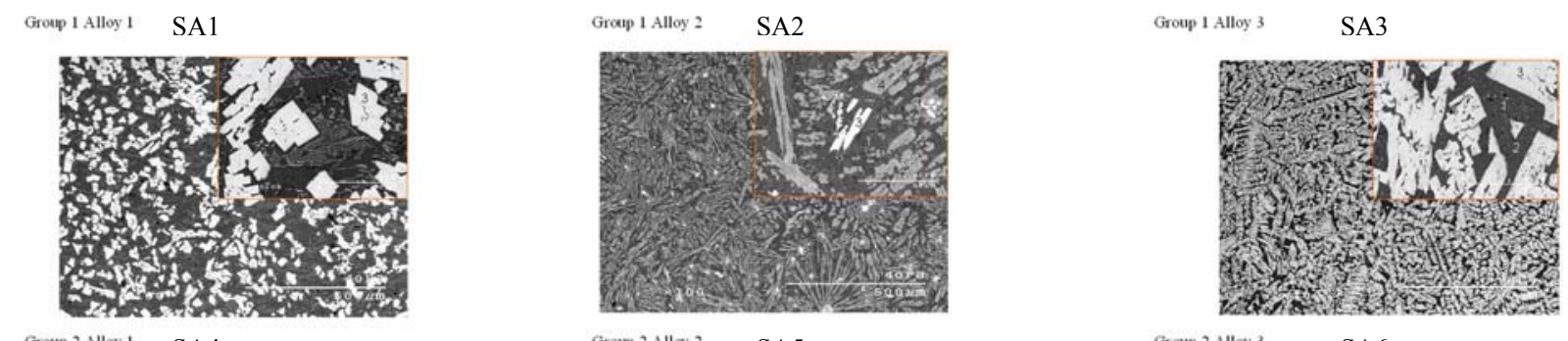

Grotp 2 Alloy $1 \quad \mathrm{SA} 4$
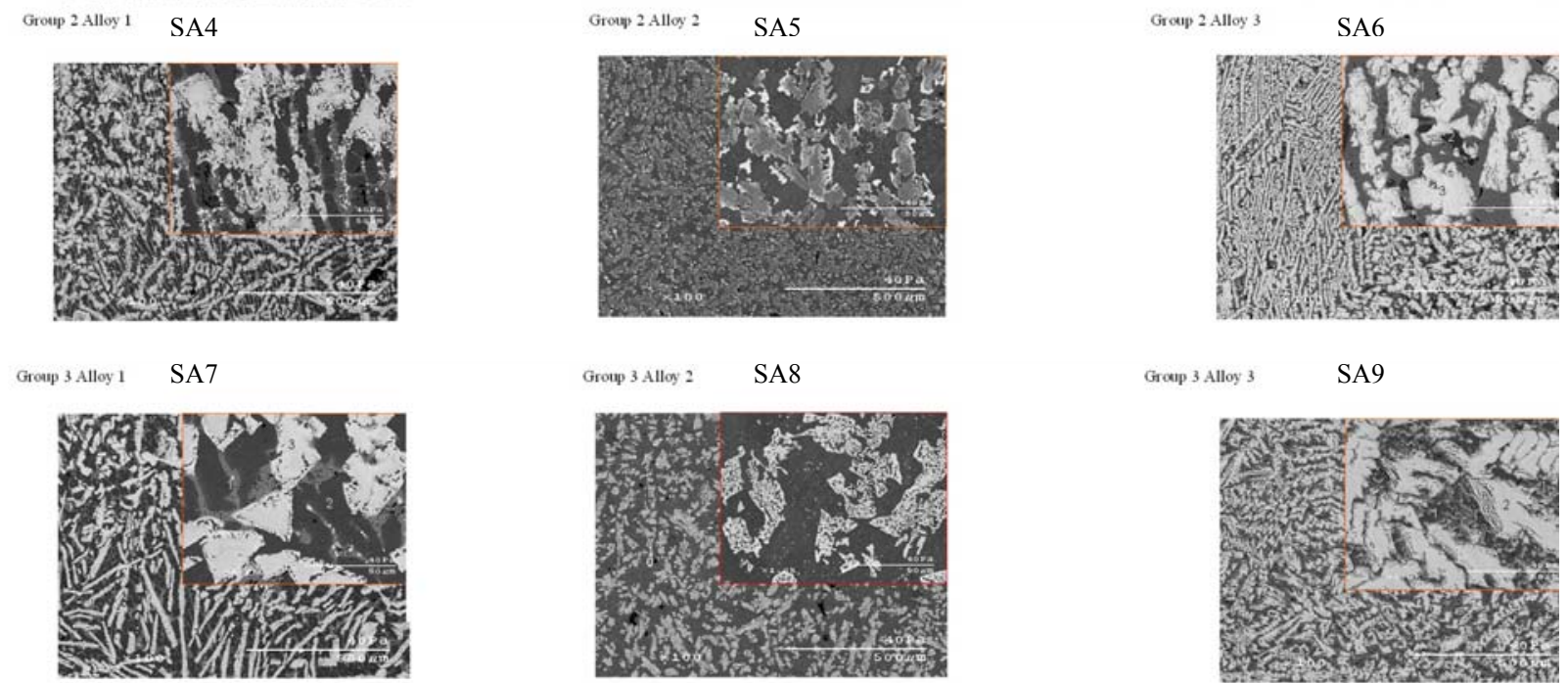

Figure 29. Equilibrium microstructure map for the nine initial SICWC alloys.

$+\quad$ within $\pm 10 \% \quad \times \quad$ within $\pm(10-30) \%$

\begin{tabular}{|c|c|c|c|c|}
\hline \multirow{2}{*}{ Alloys } & \multicolumn{3}{|c|}{ Phases } & $\begin{array}{c}\text { Transformation } \\
\text { Temperatures }\end{array}$ \\
\cline { 2 - 5 } & constituents & compositions & amounts & + \\
\hline SA1 & + & + & + & + \\
\hline SA2 & + & + & + & + \\
\hline SA3 & + & + & + & + \\
\hline SA4 & + & + & + & $\times$ \\
\hline SA5 & + & $\times$ & $\times$ & + \\
\hline SA6 & $\times$ & $\times$ & + & + \\
\hline SA7 & + & + & + & $\times$ \\
\hline SA8 & + & + & $\times$ & $\times$ \\
\hline SA9 & + & + & $\times$ & + \\
\hline
\end{tabular}

Figure 30. Summary of thermodynamic model validation experiments. 
Crushed powder

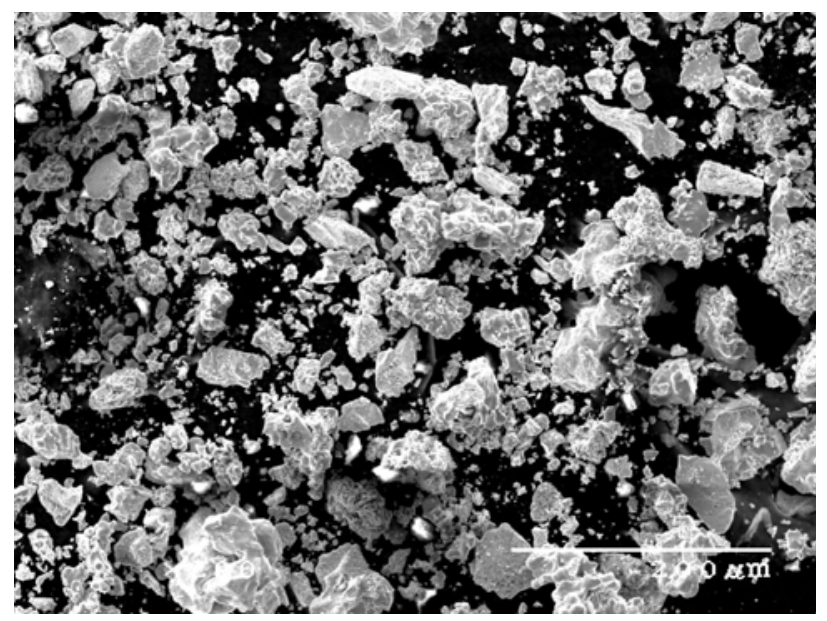

Cross-section

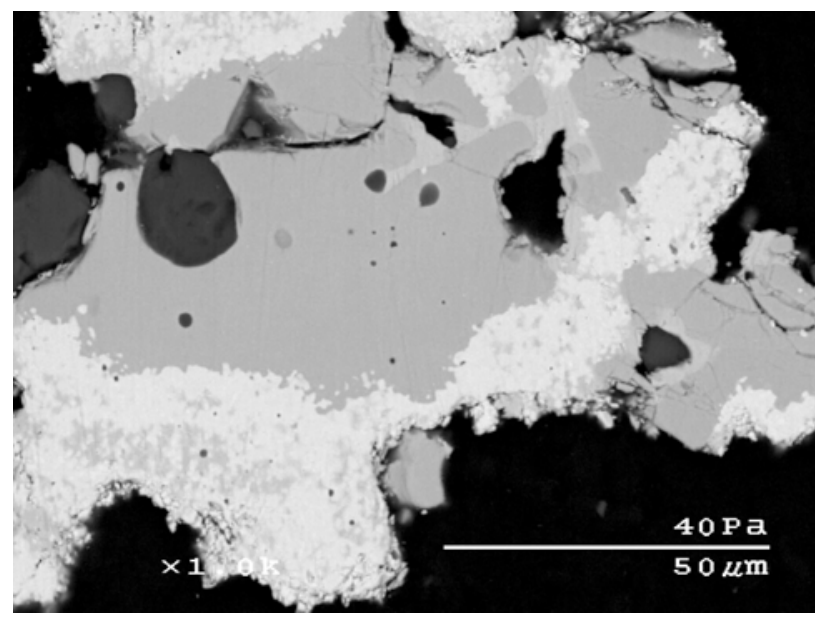

Figure 31. Morphology and microstructure for alloy SA7 powder.

As-sprayed

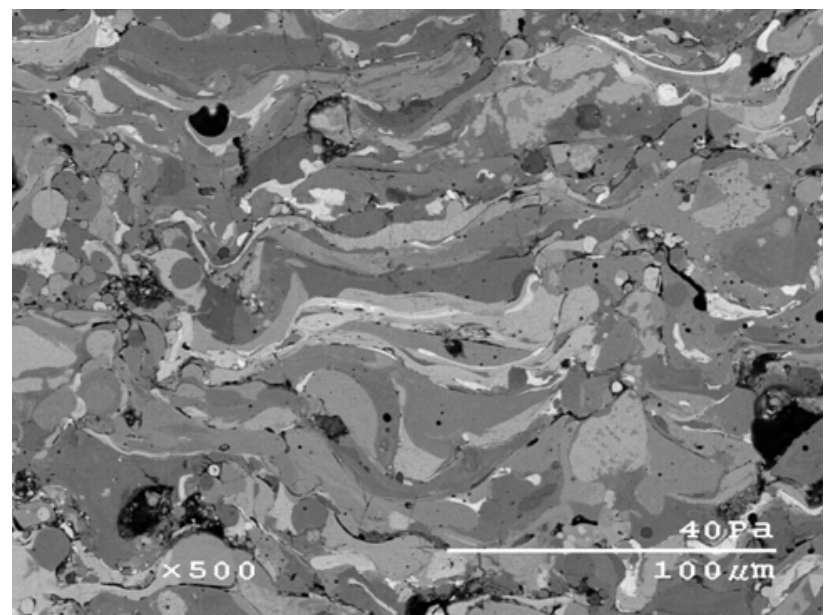

Equilibrium

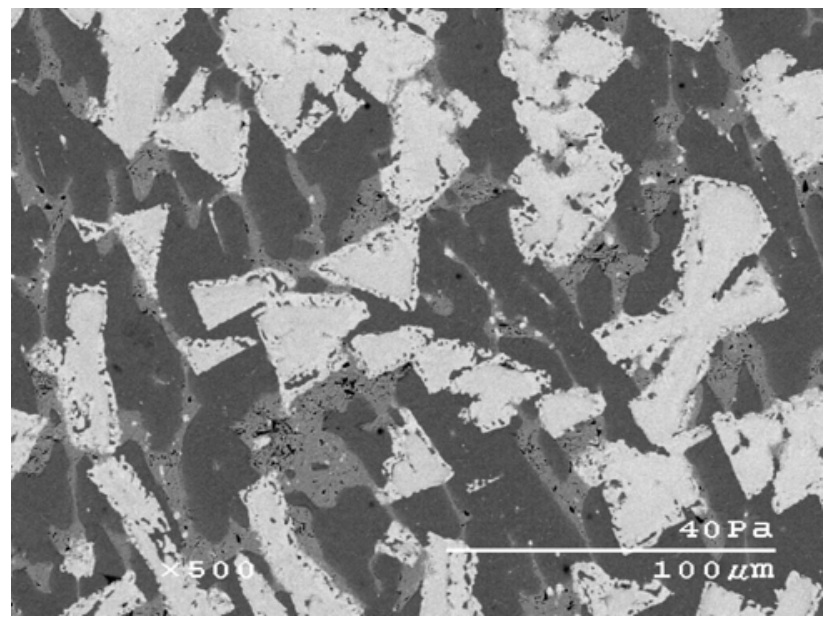

Figure 32. Comparison of as-sprayed and equilibrated microstructure for alloy SA7. 


\subsubsection{Arc lamp}

The first steps in the arc lamp processing studies were some basic characterizations of the lamp itself. The key process parameters in arc lamp processing are the setpoint current, the process time, and the distance of the sample from the focal plane. The current can range from $50 \mathrm{~A}$ to $1200 \mathrm{~A}$. A safe estimate of the process time limit at $1200 \mathrm{~A}$ is approximately 3 seconds. The safe process time increases as the power level decreases up to about 4 hours for $600 \mathrm{~A}$. All of these variables will affect the temperature distribution within the coating and substrate. The arc lamp records can measure processing parameters during processing such as the current and voltage. Using these measurements some basic characteristics of the lamp can be determined. Figure 33 shows the power level (i.e., kilowatts of radiant energy emitted by the arc, voltage multiplied by current) as a function of setpoint current. The power level is a slightly parabolic function of the current and the curve fit shows excellent correlation. Figure 33 also shows the variation in current, voltage, and power level as a function of setpoint current. While the variation in the voltage is relatively constant, the variation in the current increases as the current increases resulting in an increase in the variation of power level as the current increases. At the highest power level one standard deviation is about $4 \mathrm{~kW}$.

The first tests of the Caterpillar arc lamp were performed on a silicon wafer. The silicon wafer was $300 \mu \mathrm{m}$ thick and about $75 \mathrm{~mm}$ in diameter. A thermocouple was held in contact with the backside of the wafer. The wafer was about $65 \mathrm{~mm}$ out of the focal plane of the reflector. The measured maximum temperatures for various setpoint currents and times are shown in Figure 34. There are clear linear trends between time and temperature for both short times (1-12 seconds) and long times (4 minutes). One key lesson learned from these experiments and discussions with ORNL was the importance of the focal distance in arc lamp processing. A distance of $65 \mathrm{~mm}$ from the focal plane is much larger than commonly used. ORNL stressed the importance of having the sample as close to the focal plane as possible. This large distance was chosen because of fixturing issues that limited the positioning of the lamp head and sample. As a result of these experiments and discussions, the fixturing was changed to allow the sample to be closer to the focal plane. In addition to the upgraded fixturing, a CCD camera with an auto iris lens was installed to permit real time monitoring of the process. The CCD camera was interfaced with a computer to record still images and video of the samples during processing. A final improvement to the arc lamp fixturing was performed in 2006 by mounting the sample fixturing in a modified NEMA enclosure. This enclosure could support a low partial vacuum $(\sim 30 \mathrm{~mm}$ $\mathrm{Hg}$ below atmospheric) and permitted the processing of samples either in vacuum or in an inert gas atmosphere (argon or nitrogen).

After the initial experiments on silicon wafers, a series of experiments was performed on samples coated with SICWC alloys. The first material tested was alloy SA1 plasma sprayed on 1045 steel. The coating thicknesses were 500-600 microns. The coating was sprayed on a 1 "x1"x10" square bar that was cut into 2" sections for arc lamp processing. The initial trials were conducted at $65 \mathrm{~mm}$ from the focal plane using relatively long times (up to 90 seconds) and relatively low setpoint currents (up to $600 \mathrm{~A}$ ). During these trials the coating frequently oxidized and emitted black smoke that collected on the quartz plate protecting the lamp. Many of the 
coating samples were unmelted. The samples that were melted tended to form bubbles and draw away from the edges of the substrate. The coatings frequently cracked a few hours after reaching room temperature and in some cases the entire coating delaminated in a single piece. 

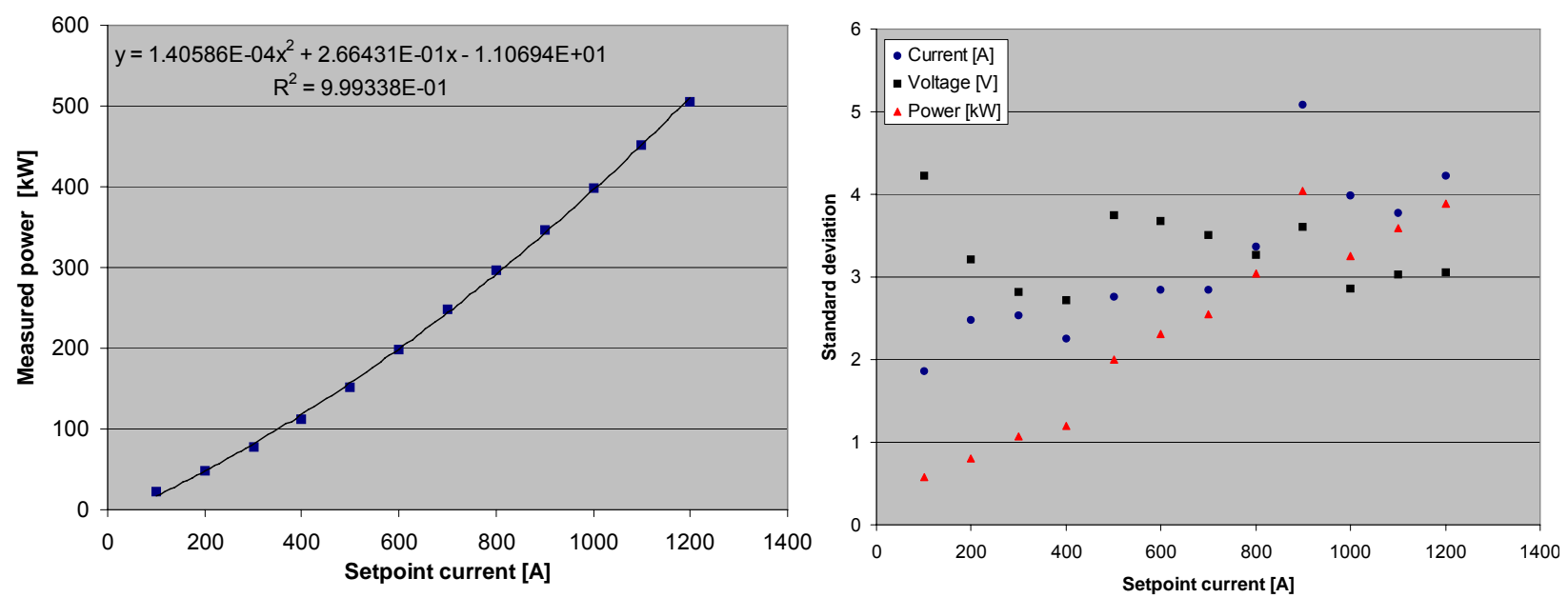

Figure 33. Power levels and stability analysis for the arc lamp at various setpoint currents.

Pulses

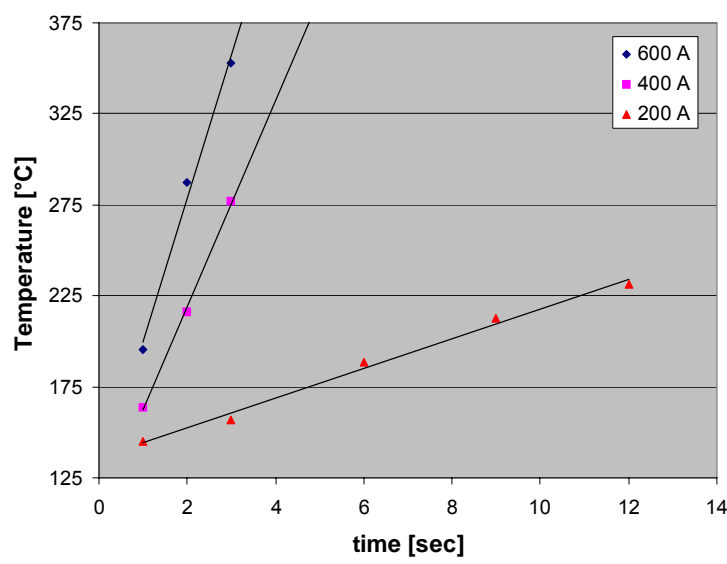

Equilibrium

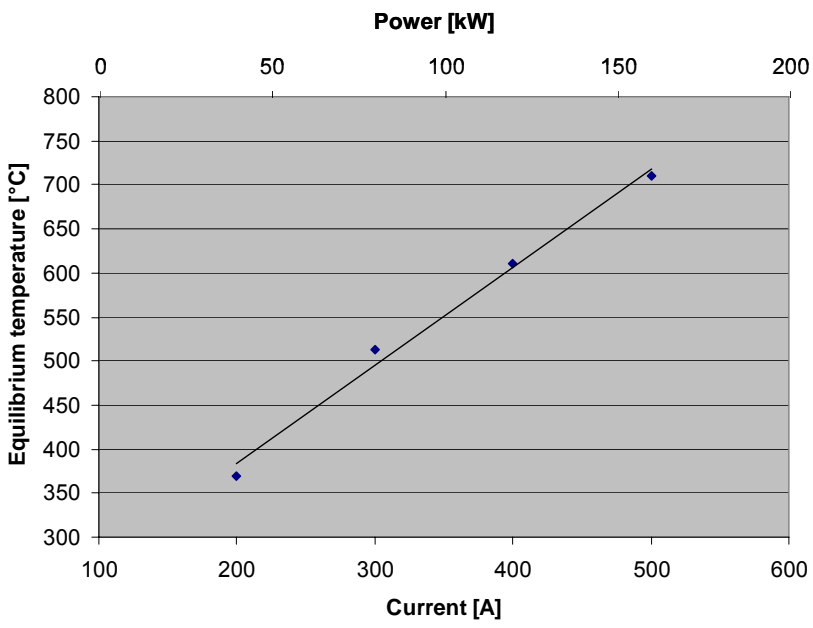

Figure 34. Temperature of a silicon wafer heated in the arc lamp for short pulses and equilibrated for 4 minutes. 
After these initial experiments and discussions with ORNL, several improvements were made to the sample processing. The first improvement in the arc lamp processing of these coatings was the positioning of the sample closer to the focal plane. The new procedure was to place the samples $10 \mathrm{~mm}$ out of the focal plane rather than $65 \mathrm{~mm}$. A second key processing improvement was the introduction of a pre-heating step for 1-2 minutes at 100-200 A followed by a pulse of up to 5 seconds at up to $1000 \mathrm{~A}$. These two processing changes were the keys to producing fused coatings.

Using these process changes, screening tests were performed on all 9 of the initial SICWC alloys to evaluate the quality of the fused coating produced by arc lamp processing. The alloys that produced the best fusion bonds between the coating and substrate were alloys SA6, SA8, and SA9. These alloys were selected from the screening tests for further study. Examples of the differences between the as-sprayed, equilibrium, and arc lamp fused microstructures are shown in Figure 35 and Figure 36. The equilibrium microstructure has large phase regions with no porosity. The as-sprayed microstructure is fine scale with some porosity. The broad XRD peaks indicate a very fine grain size. The arc lamp processed microstructure has spherical porosity and a fine scale microstructure of equilibrium phases.

Experiments and analysis performed by ISU and Caterpillar examined the relationship between arc lamp processing parameters (i.e., time and power level) and microstructure. SICWC alloys SA6, SA8, and SA9 were processed at 600,800 , and 1000A for 1 and 2 seconds after a preheating cycles of 120 seconds at $150 \mathrm{~A}$. Each current/time combination was assigned a thermal treatment number. The thermal treatment numbers are listed in Table 6 .

Table 6. Thermal treatment numbers for arc lamp processing.

\begin{tabular}{|l|c|c|}
\hline & 1 second & 2 seconds \\
\hline $1000 \mathrm{amps}$ & 5 & 6 \\
\hline $800 \mathrm{amps}$ & 3 & 4 \\
\hline $600 \mathrm{amps}$ & 1 & 2 \\
\hline
\end{tabular}

In all three alloys, increasing the power level and time results in agglomerated and more spherical porosity and a larger fusion zone at the interface (see Figure 37 through Figure 42). Hardness values for these alloys at the thermal treatments discussed above are shown in Figure 43. There are also dendrites present in the fusion zone that appear to grow from the substrate toward the coating shown in Figure 44. EPMA and XRD analyses indicate the dendrites are fcc iron.

These experiments showed that a significant fraction of the fusion zone was a result of melting of the substrate. Figure 45 shows two micrographs of alloys with fusion zones. In several locations the interface is curved behind particles of alumina grit that were embedded during the grit blast process. These embedded grit particles are markers of the location of the coating/substrate interface prior to treatment with the arc lamp. The fusion zone surrounds many of the grit particles indicating that the substrate (in addition to the coating matrix) was molten. The 
alumina grit particles have a much lower thermal conductivity than the surrounding metal and act as thermal barriers reducing the heat transfer into the substrate underneath them.

It has been experimentally observed that the embedded alumina grit particles act as a thermal barrier to the formation of the fusion zone between the coating and the substrate. Based on communications with ORNL, these particles also act as a chemical barrier to fusion zone formation due to the poor wetting characteristics of ferrous alloys on alumina. An alternative to alumina for surface preparation is steel shot. Steel shot blasting produces a surface with a lower roughness than oxide grit blasting; however, if there is a metallurgical bond between the coating and substrate after arc lamp processing the surface roughness (needed for a mechanical bond between the coating and substrate) is much less important, or possibly irrelevant, for adhesion.

These experiments also illustrate that for fusion-bonded coatings it is critical to include the substrate properties as well as the coating properties in the design of the coating system. A change in the substrate solidus temperature may change the fusion zone width or fusion bond strength. 


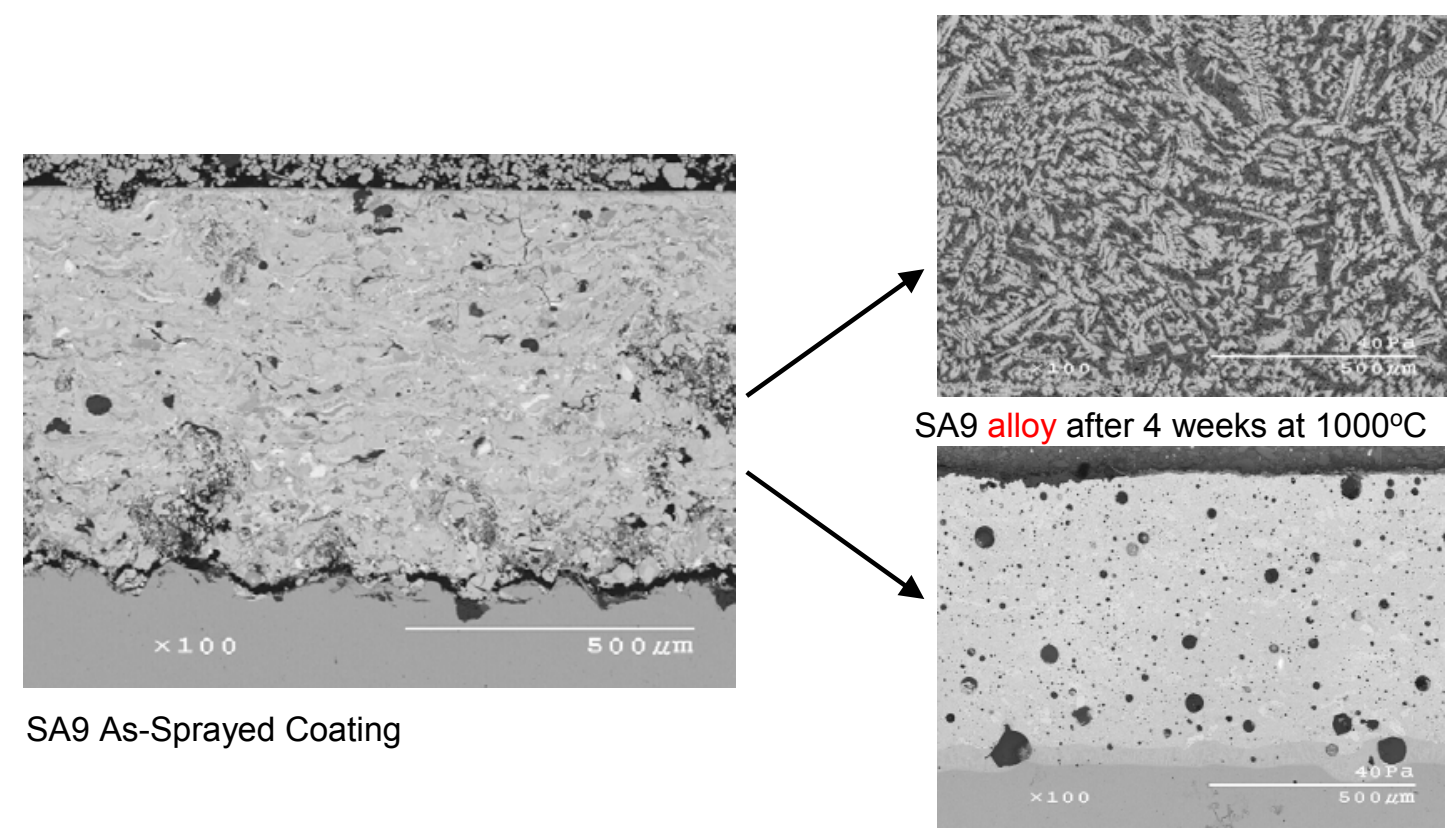

SA9-6 arc-lamp treated 1000A for 2 seconds

Figure 35. Microstructures of alloy SA9 in the as-sprayed, equilibrated, and arc lamp processed conditions.

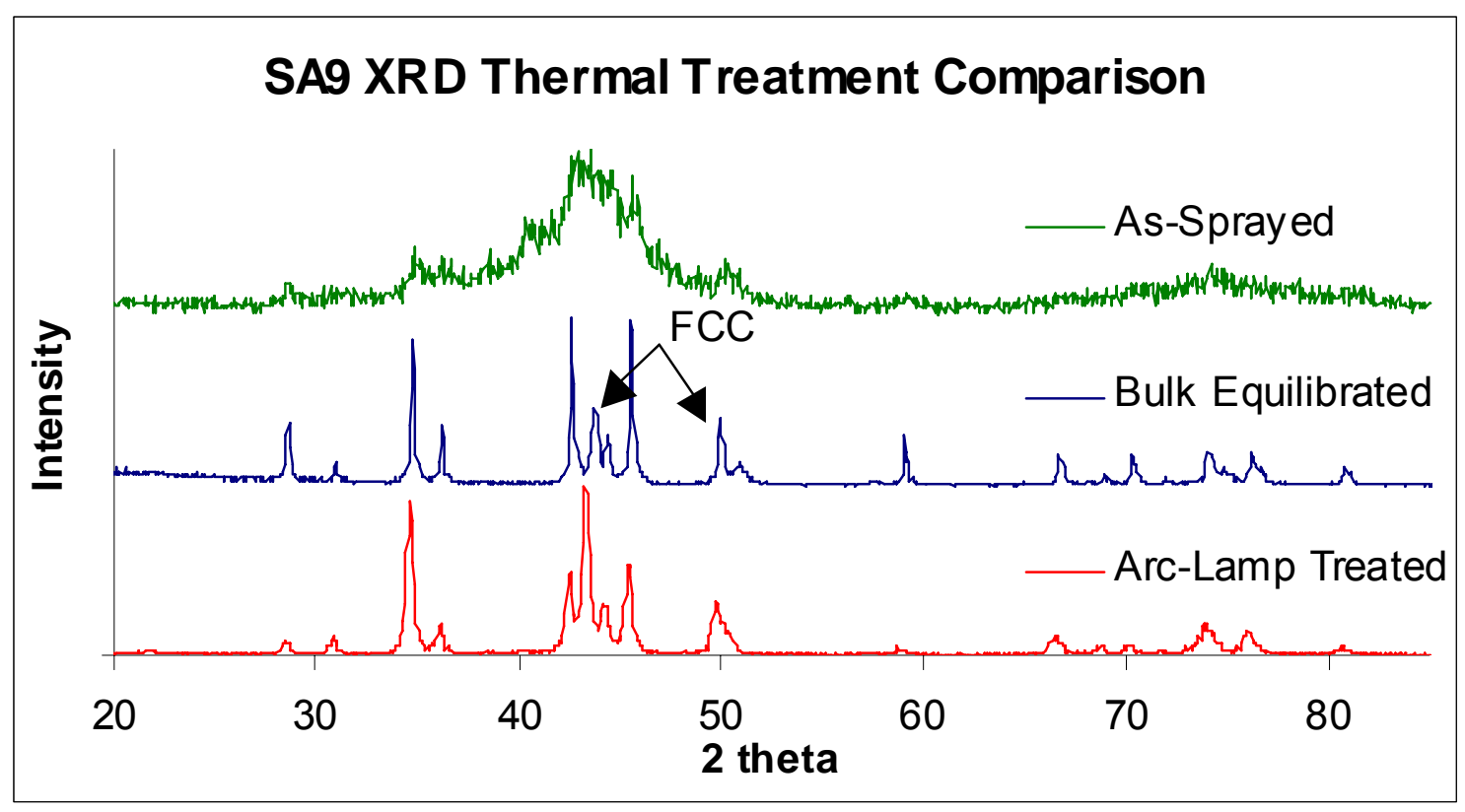

Figure 36. XRD analysis of alloy SA9 in the as-sprayed, equilibrated, and arc lamp processed conditions. 


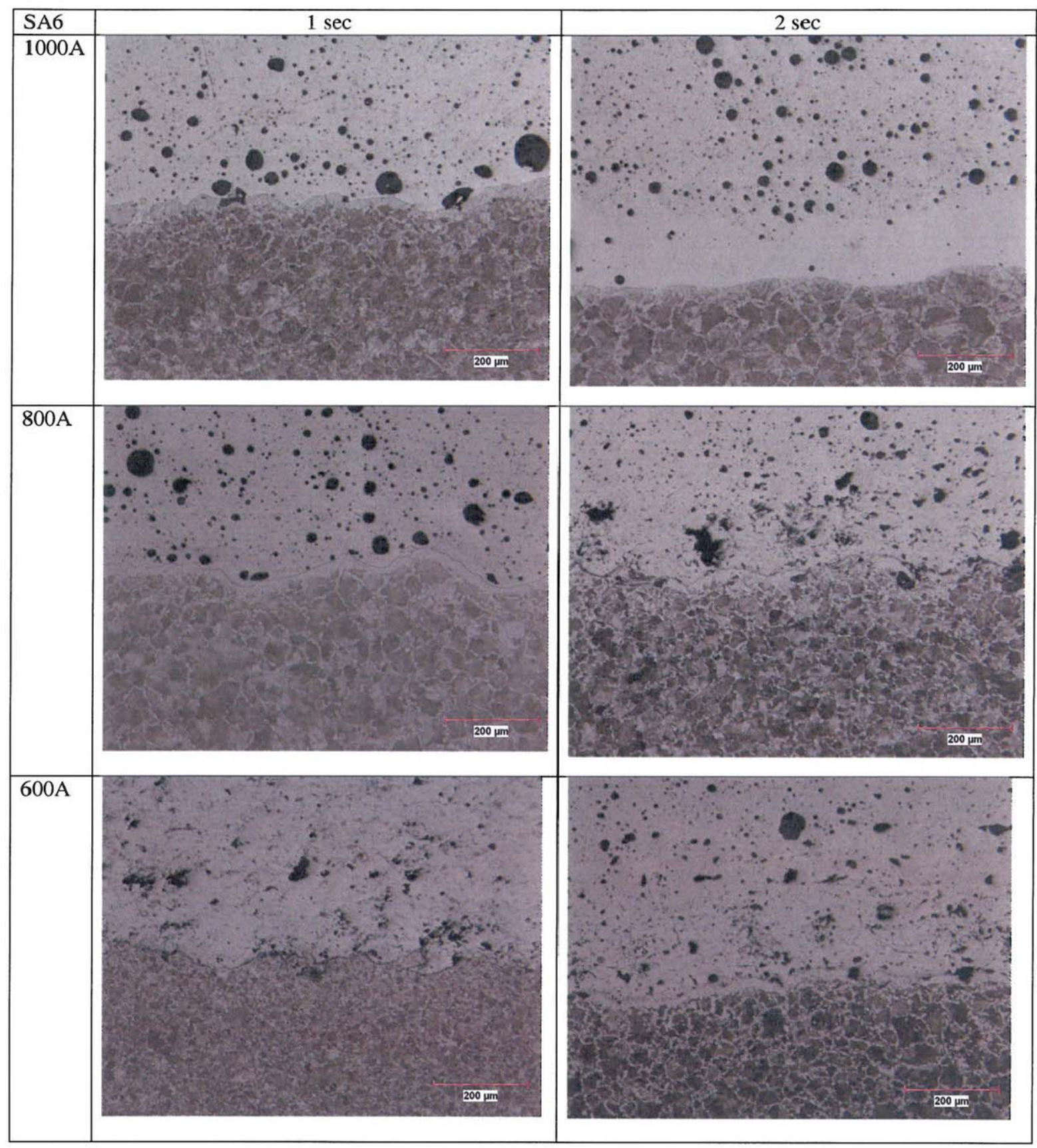

Figure 37. SICWC alloy SA6 processed at various times and power levels in the arc lamp. 


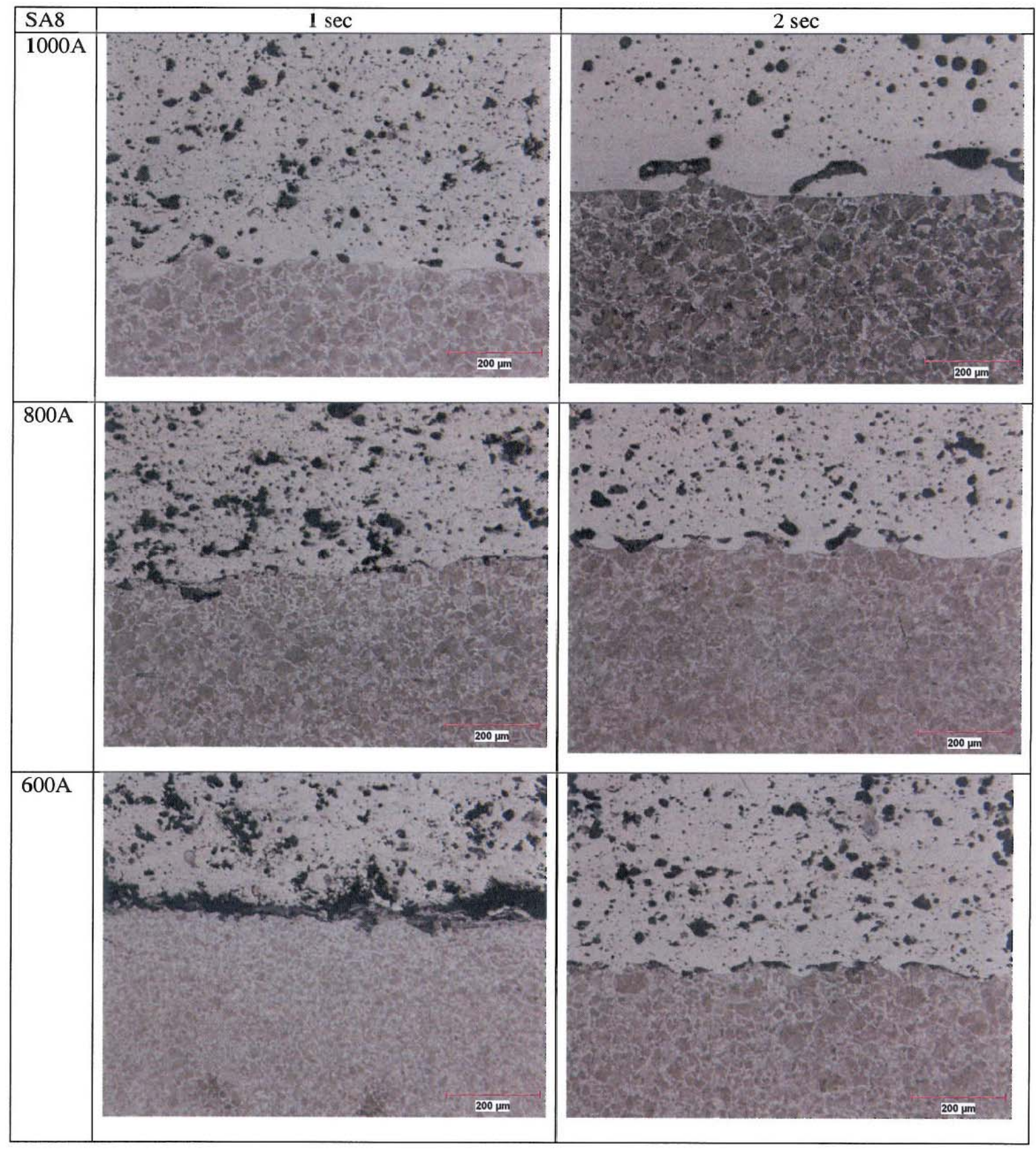

Figure 38. SICWC alloy SA8 processed at various times and power levels in the arc lamp. 


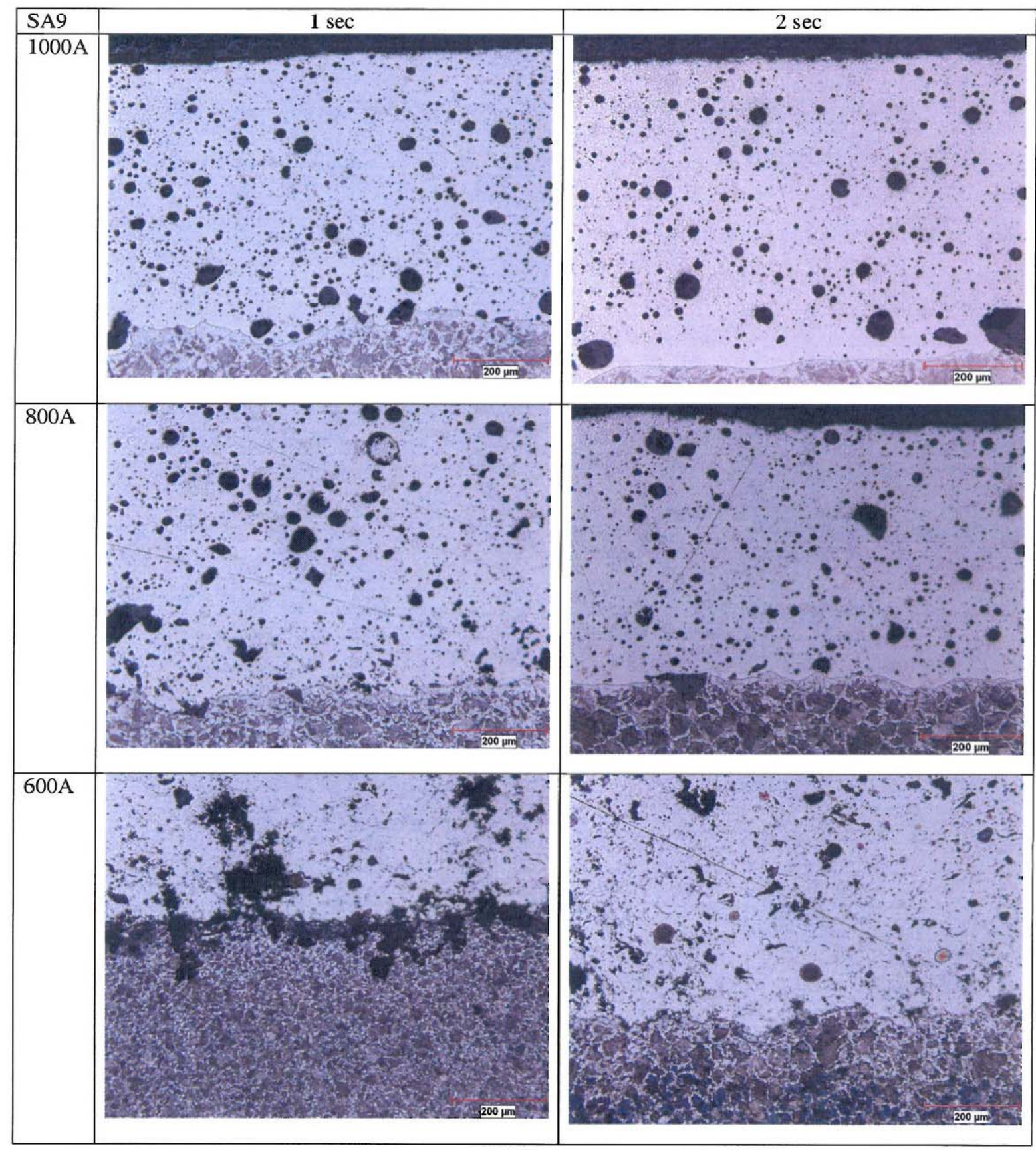

Figure 39. SICWC alloy SA9 processed at various times and power levels in the arc lamp. 

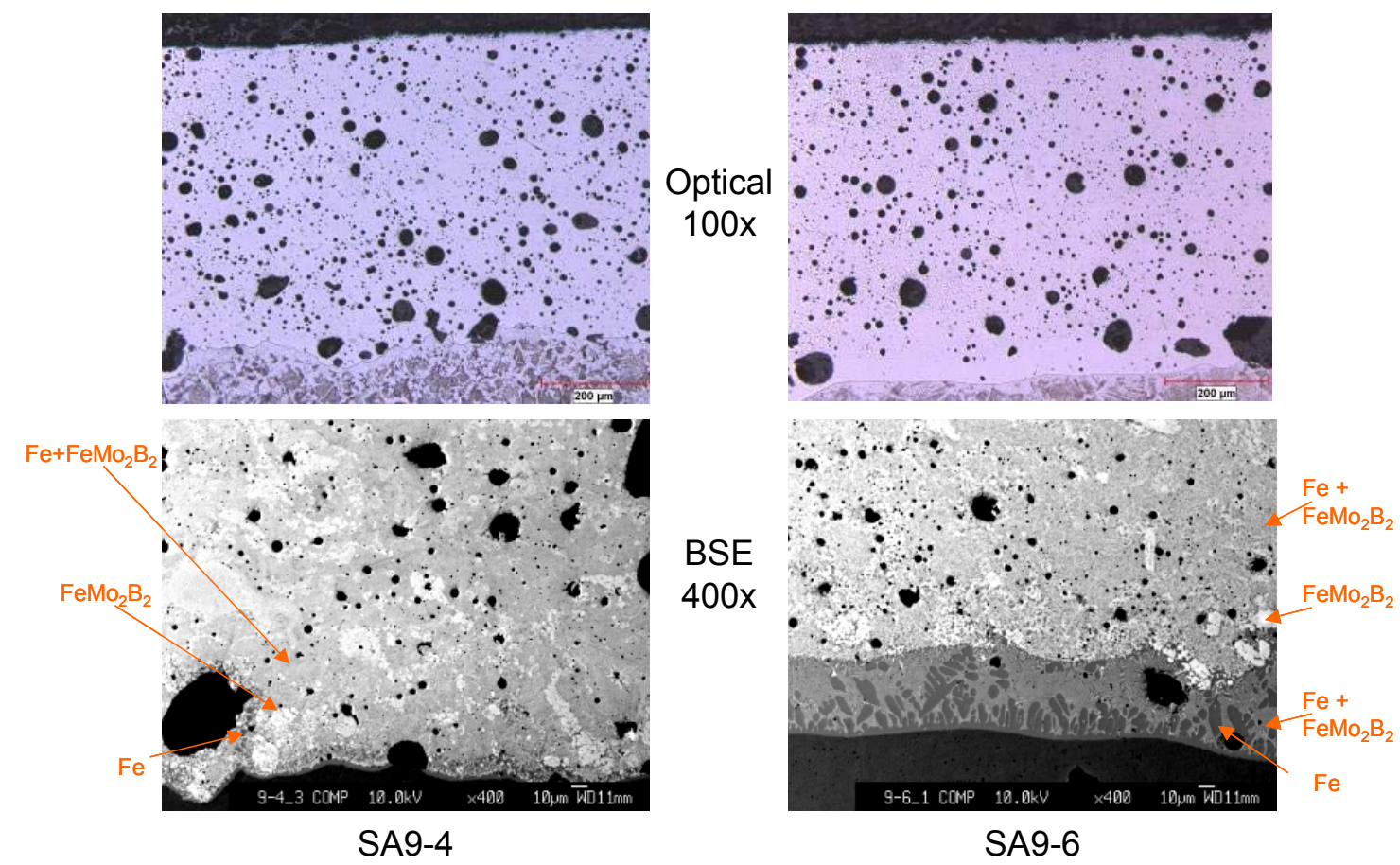

Figure 40. Detailed phase analysis of arc lamp processed alloy SA9.
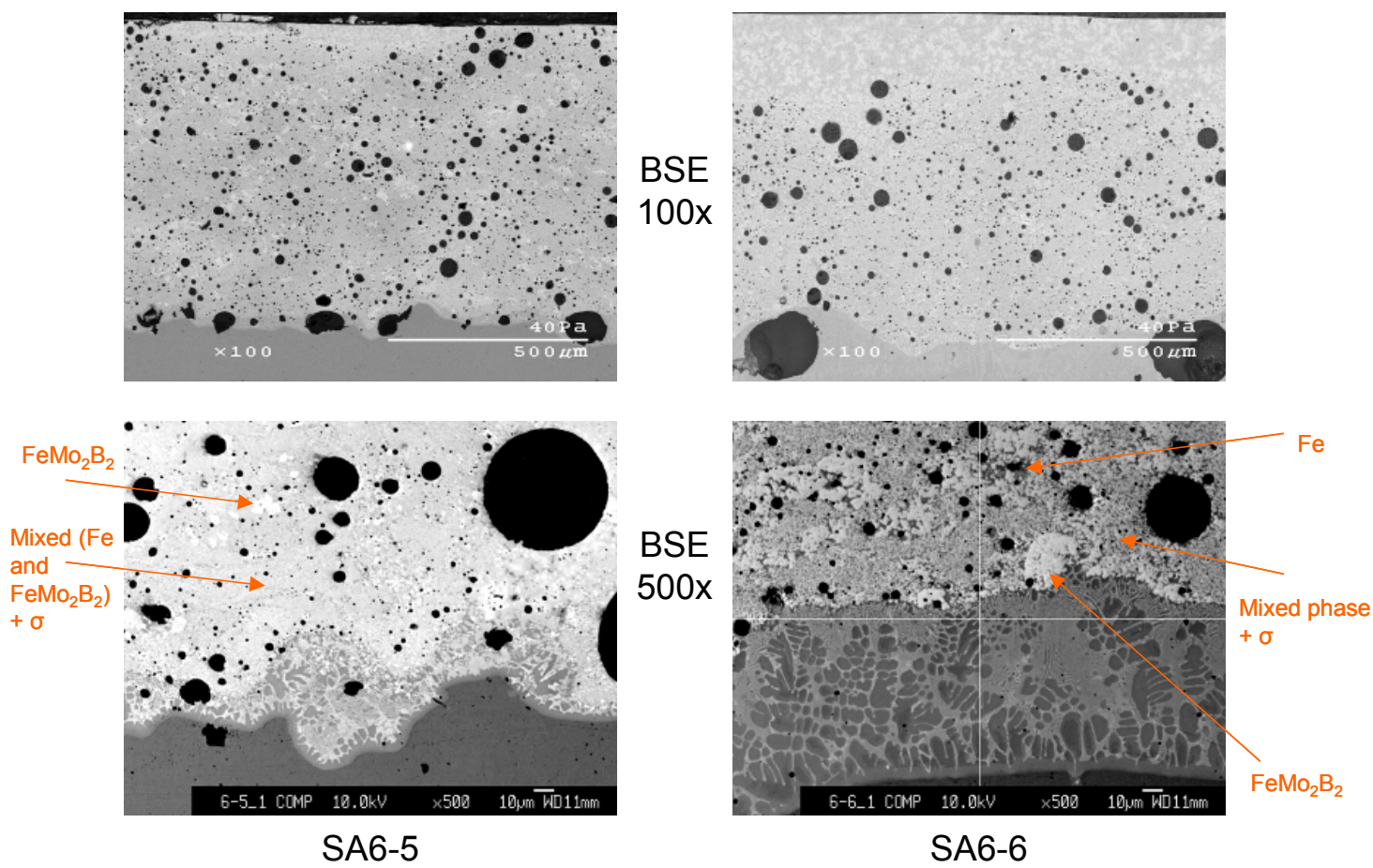

Figure 41. Detailed phase analysis of arc lamp processed alloy SA6. 

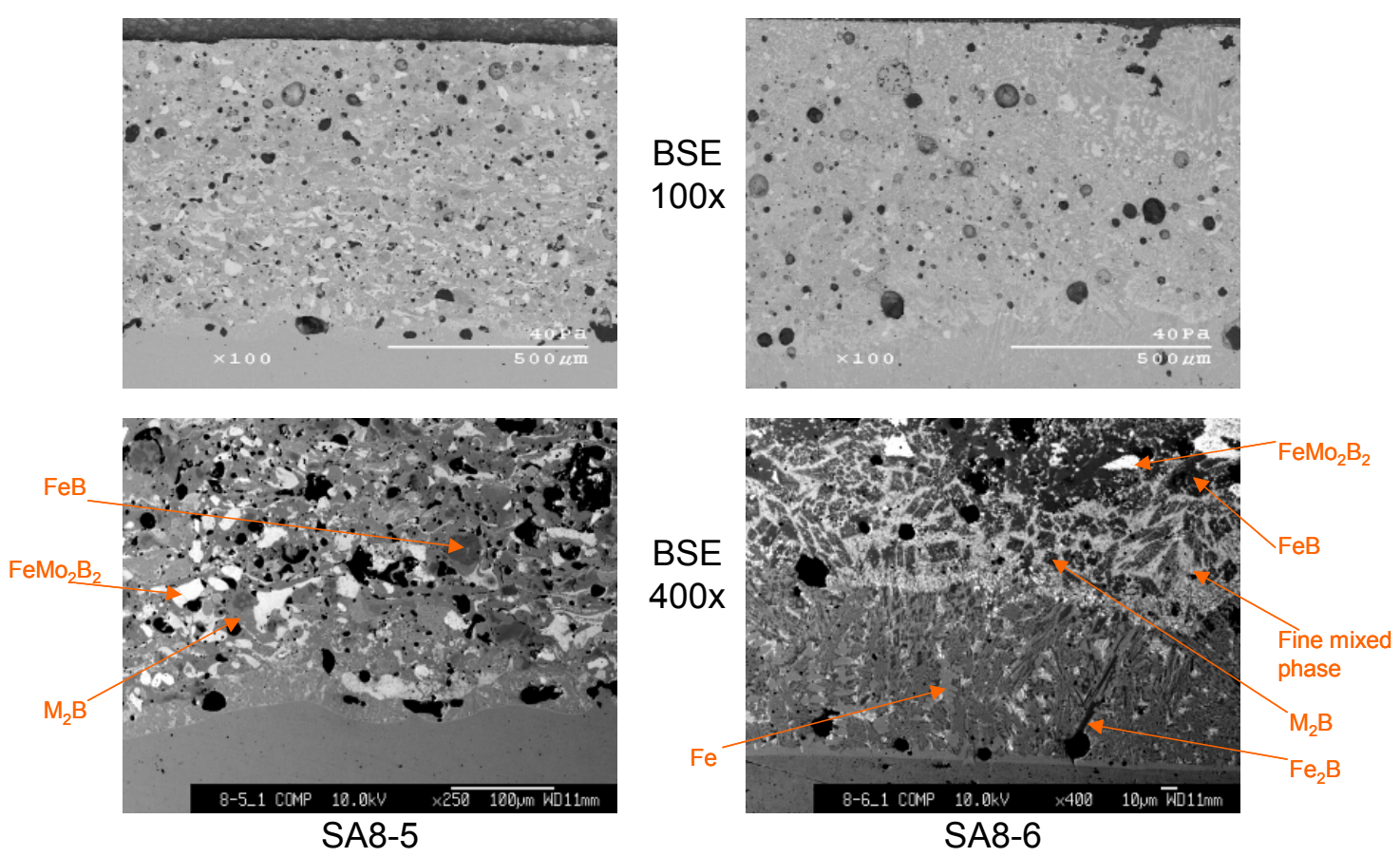

Figure 42. Detailed phase analysis of arc lamp processed alloy SA8.

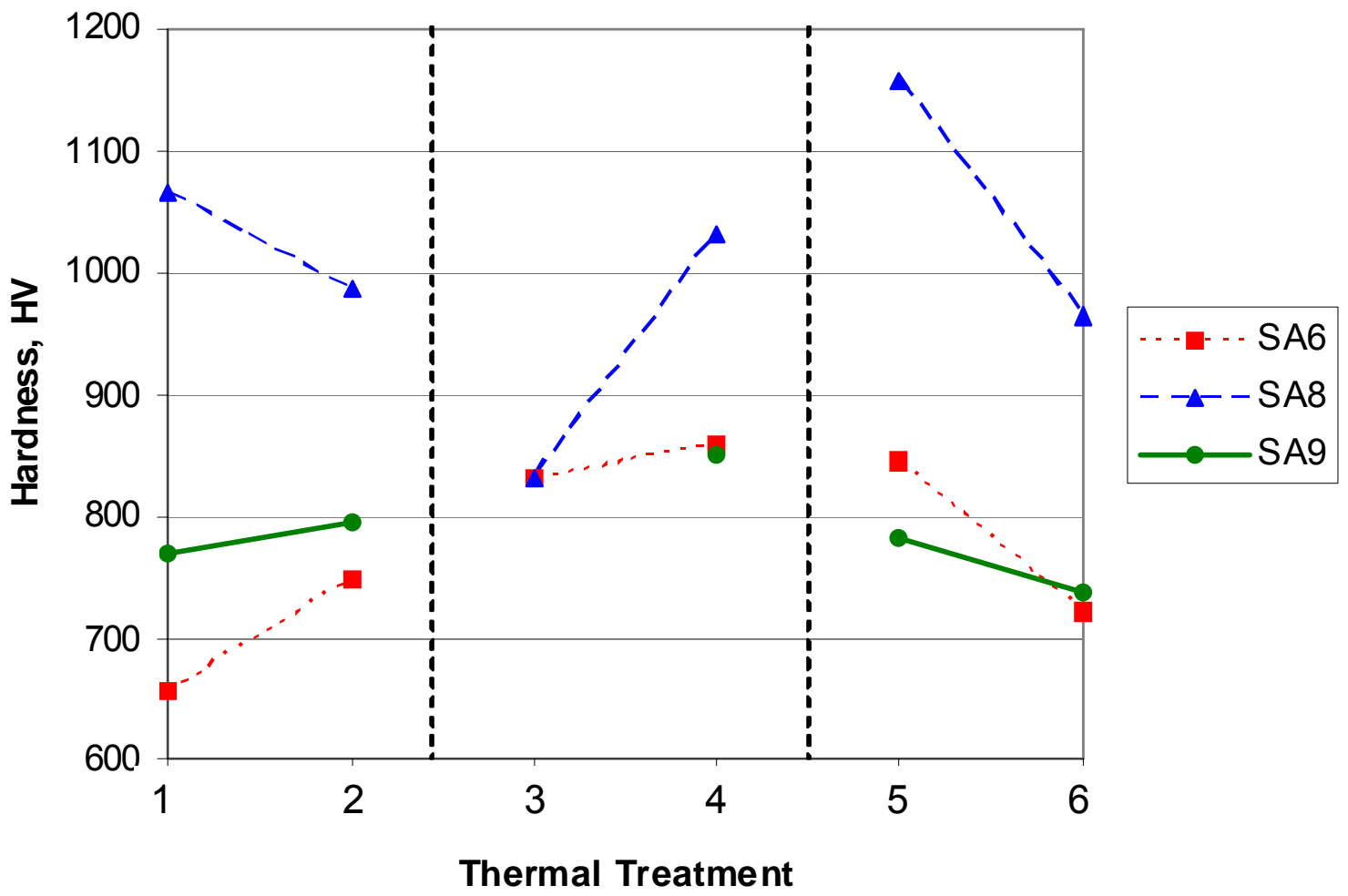

Figure 43. Average hardness values for SICWC alloys SA6, SA8, and SA9. Thermal treatments are listed in Table 6. 

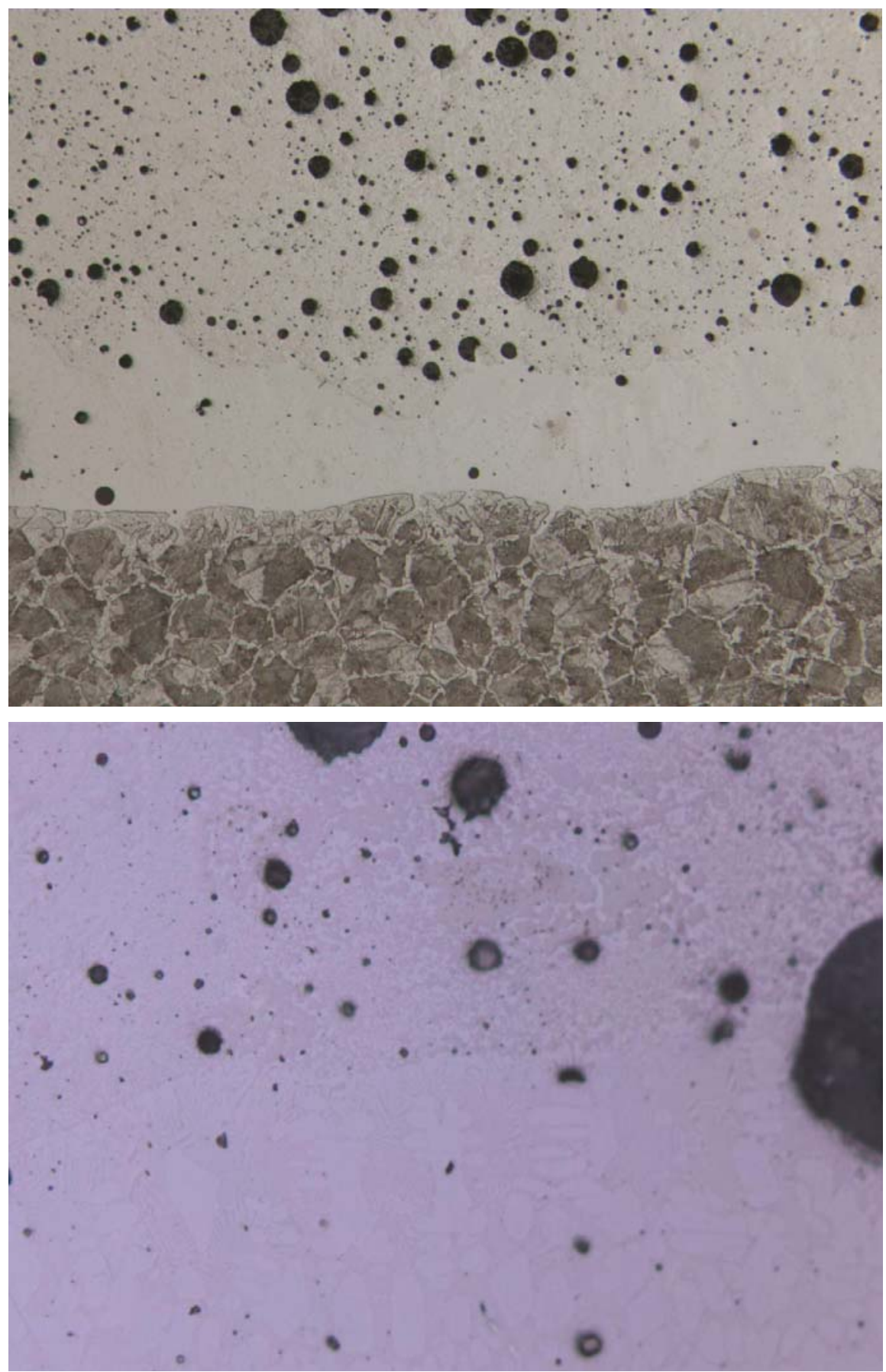

Figure 44. SICWC alloys SA6 (top) and SA9 (bottom) showing dendrites growing from the substrate toward the coating. The substrate in both samples is at the bottom of each micrograph. 

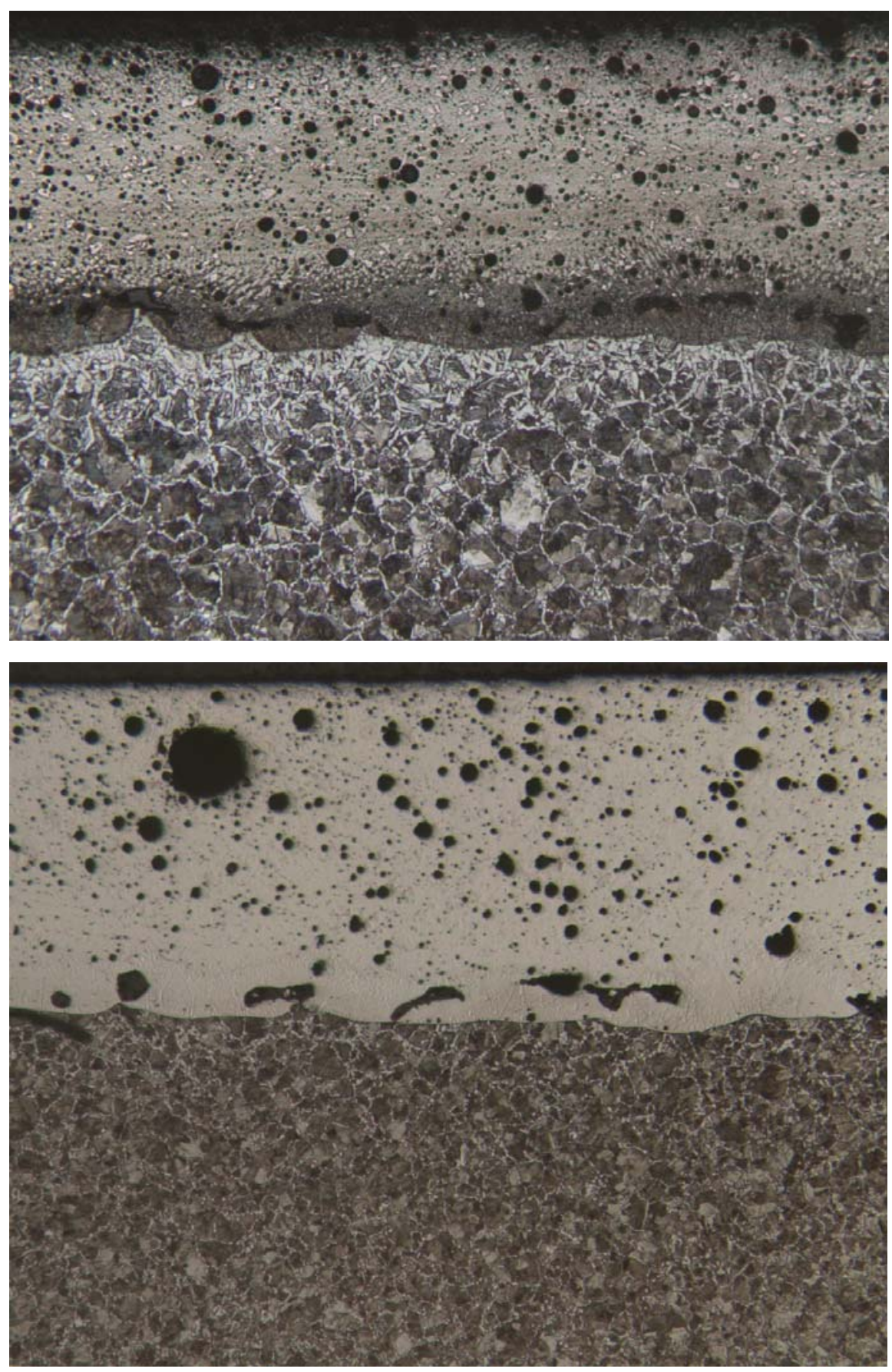

Figure 45. SICWC alloys SA1 (top) and SA8 (bottom) showing the effect of embedded alumina grit on the heat transfer from coating to substrate. The substrate in both samples is at the bottom of each micrograph. 
An example of other microstructural changes in alloy SA6 during arc lamp processing processing is shown below in Figure 46. The free surface of the coating at the top of the micrograph shows a microstructure similar to the equilibrium microstructure. This indicates both the presence of liquid and relatively slow cooling. This micrograph also illustrates that arc lamp processing can produce both equilibrium and non-equilibrium microstructures depending on the heating and cooling rates.

In addition to the 9 initial SICWC alloys, the QuesTek calculated alloy compositions (i.e., the SAQ1 and SAQ4 alloys) were also processed using the arc lamp. The results of the arc lamp processing trials are shown in Figure 47 through Figure 49. It is possible to obtain fused coatings with both of the QuesTek calculated alloy compositions. These alloys also appeared to show less porosity than alloys SA1 through SA9.

Additional experiments were performed on alloy SAQ4 to determine if it is feasible to use a slurry coating technique rather than plasma spraying to apply the coating prior to arc lamp processing. The motivation for this work was to explore the possibility of using a less expensive process for coating application to reduce the overall arc lamp process cost. Arc lamp processing slurry coated samples presents additional challenges that are not present in plasma sprayed coatings. The plasma sprayed coatings have a better bond with the substrate. This promotes heat transfer into the substrate and keeps the coating adhered to the substrate when the coating temperature is above its solidus. The slurry coated samples do not transfer heat into the substrate as well and the coatings tend to ball up when the coating is molten. The lack of heat transfer has been measured using a thermographic camera. Figure 50 shows that when the coating is over $1300{ }^{\circ} \mathrm{C}$ the substrate is less than $600{ }^{\circ} \mathrm{C}$. Figure 51 shows slurry coated samples that were processed with parameters that resulted in overheating of the coating. The coating becomes molten and forms a ball on the substrate. Figure 52 shows slurry coated samples that were processed with parameters that resulted in insufficient heat being transferred into the substrate. The coating absorbed enough radiant energy from the lamp to sinter itself into a sheet; however, the substrate was not hot enough to produce a good fusion bond to the coating (from Figure 44 and Figure 45 it is clear that significant substrate melting and mixing with the coating must take place to form a fusion bond). Consequently, the coating popped off in a single piece after cooling to room temperature. There is a process parameter set that will produce coatings with good fusion bonds (shown in Figure 53). This new procedure requires a modification of the standard procedure used for the plasma sprayed coatings. The standard processing method for plasma sprayed coatings includes a pre-heat cycle of 150 A for 120 seconds. The slurry coated samples require a pre-heat cycle of 100 A for 3-4 minutes. This extended pre-heat cycle results in more heat diffusion into the substrate. The hotter substrate is easier to melt and stays molten long enough to produce a good fusion bond during the high power pulse from the arc lamp. The high power pulse is $800 \mathrm{~A}$ for 2 seconds. There is also a clear different in the surface appearance of samples processed in a nitrogen atmosphere rather than air (Figure 53). While the sample processed in nitrogen clearly has less oxidation, the quality of the coating and the bond are not significantly different (Figure 54).

There is a narrow processing window capable of producing a good fused coating. In the current set of experiments, the pulse must be $800 \mathrm{~A}$ for 2 seconds. A pulse of 1 second is insufficient to 
produce bonding while longer pulses result in overheating. The pre-heat cycle also must be carefully controlled. A pre-heat cycle of 2 minutes does not drive enough heat into the substrate. Both the pre-heat cycle and high power pulse must also be developed in concert to produce a good coating system. A large number of trial and error iterations were required to develop the processing procedure for these samples. Due to the narrow processing window and the uncertainty in the materials properties it is unlikely that process modeling would have been helpful in this case. 

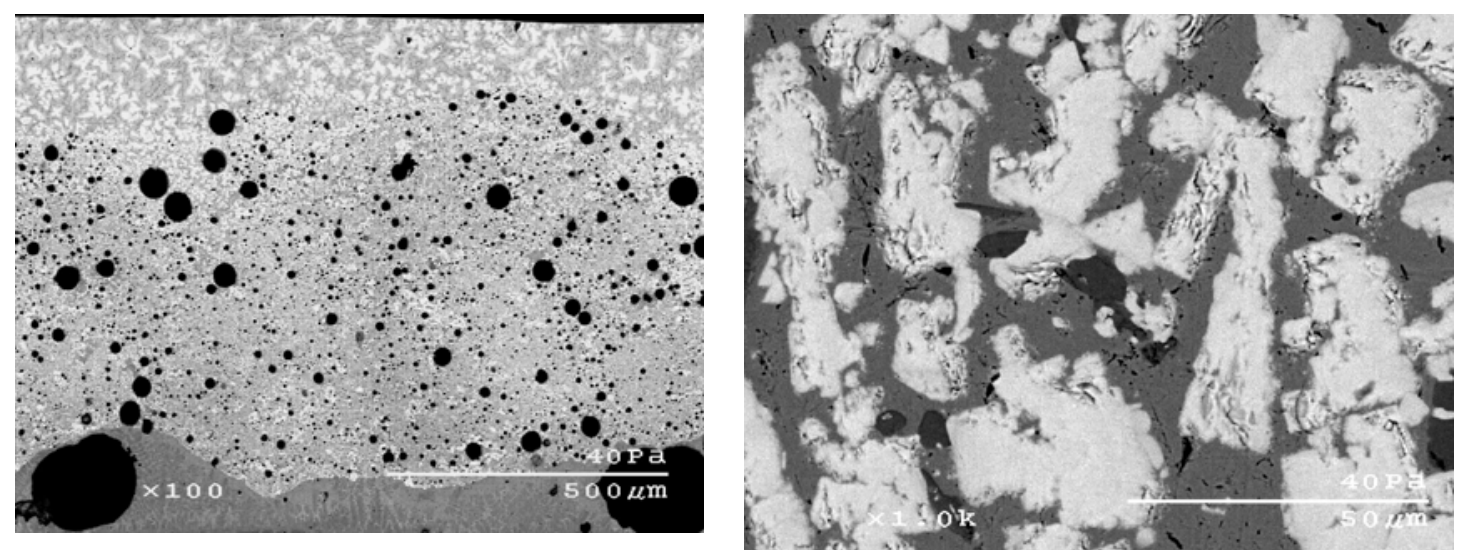

Figure 46. Arc lamp modified coating SA6-6 (left) compared to the equilibrium microstructure of SA6 (right).
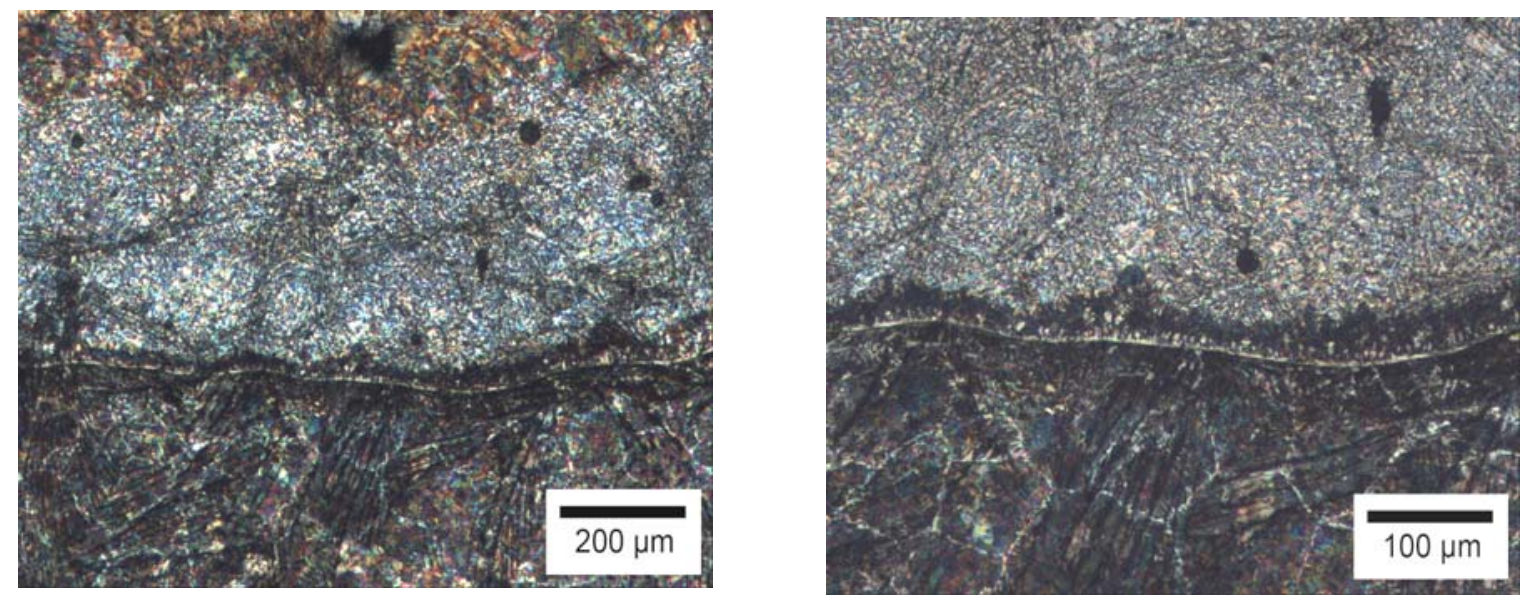

Figure 47. Optical images of alloy SAQ1 arc lamp processed coating. A 2\% Nital etchant was used to reveal the microstructure.
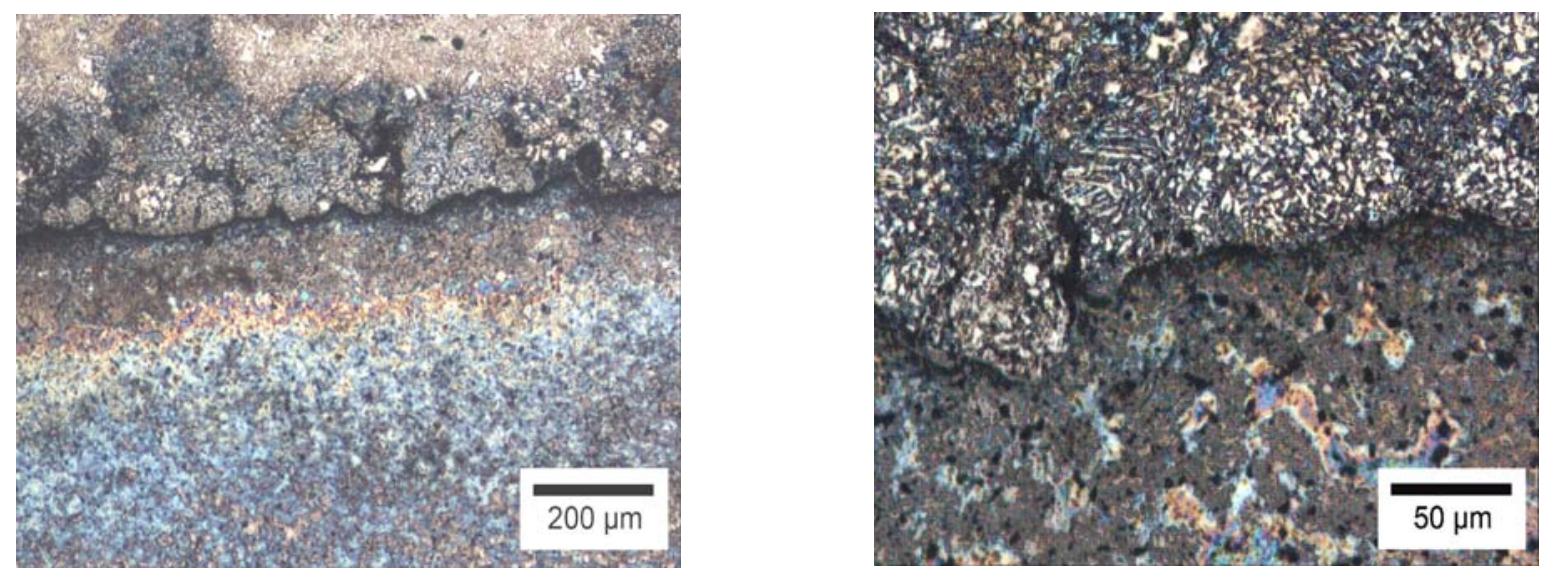

Figure 48. Optical images of alloy SAQ4 arc lamp processed coatings. A $2 \%$ Nital etchant was used to reveal the microstructure. 


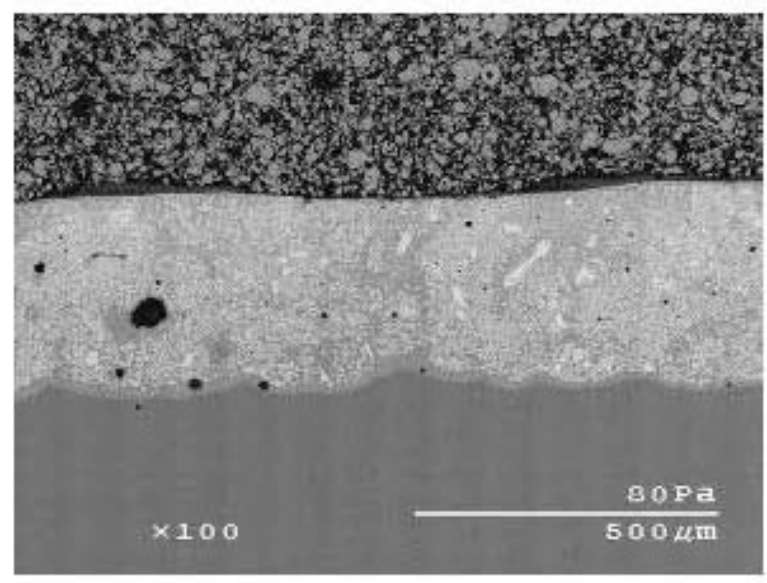

a)

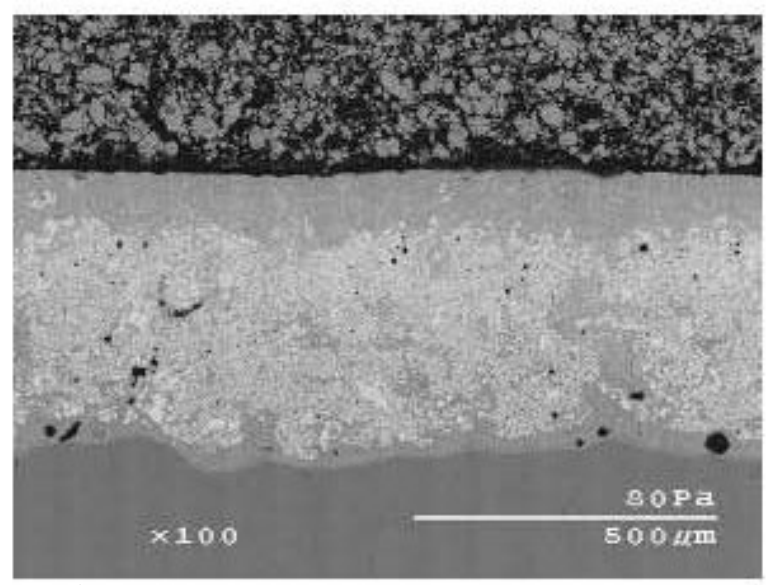

c)

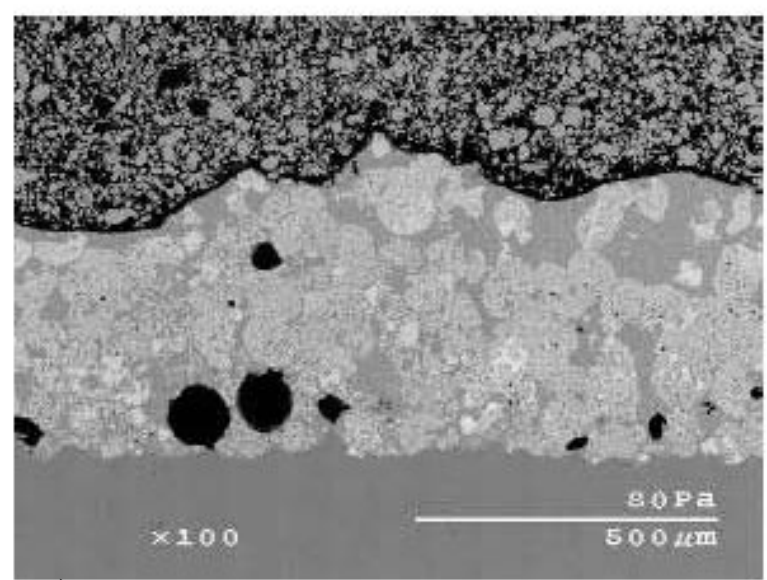

e)

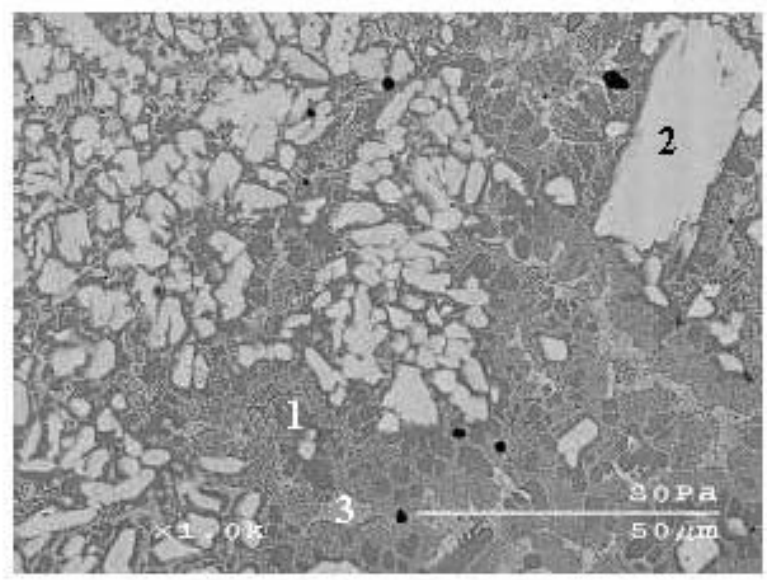

b)

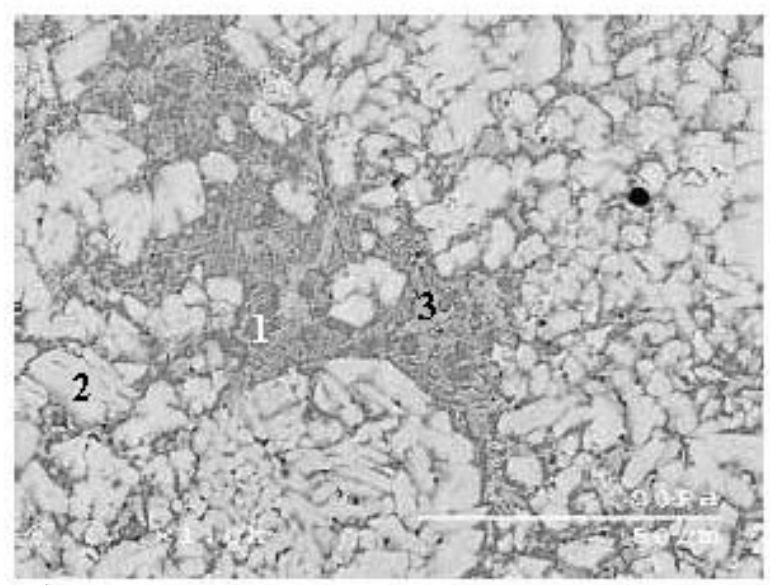

d)

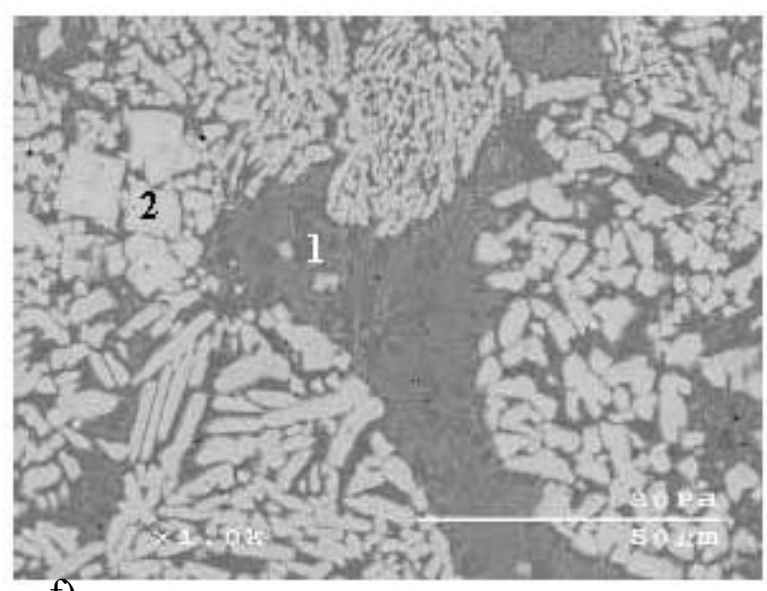

f)

Figure 49. SEM images of alloys SAQ1-8 (a and b), SAQ1-9 (c and d), and SAQ4-8 (e and f). 


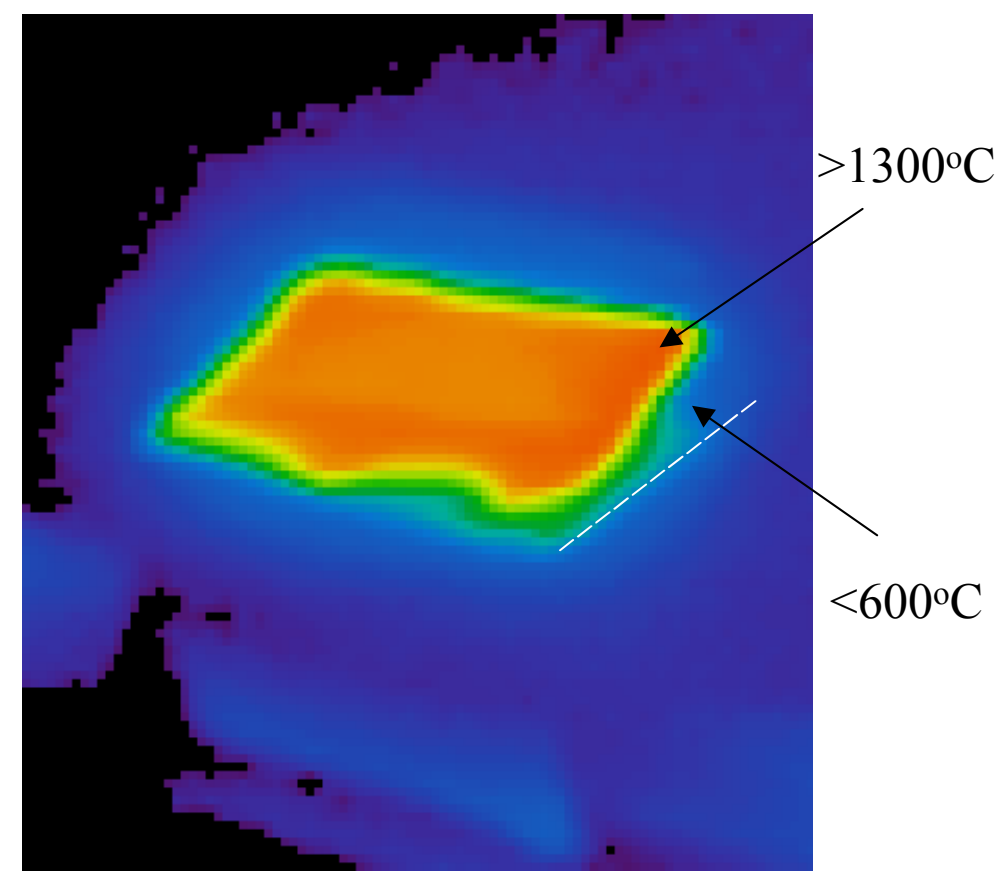

Figure 50. Thermographic camera image of a typical arc lamp fusing process.

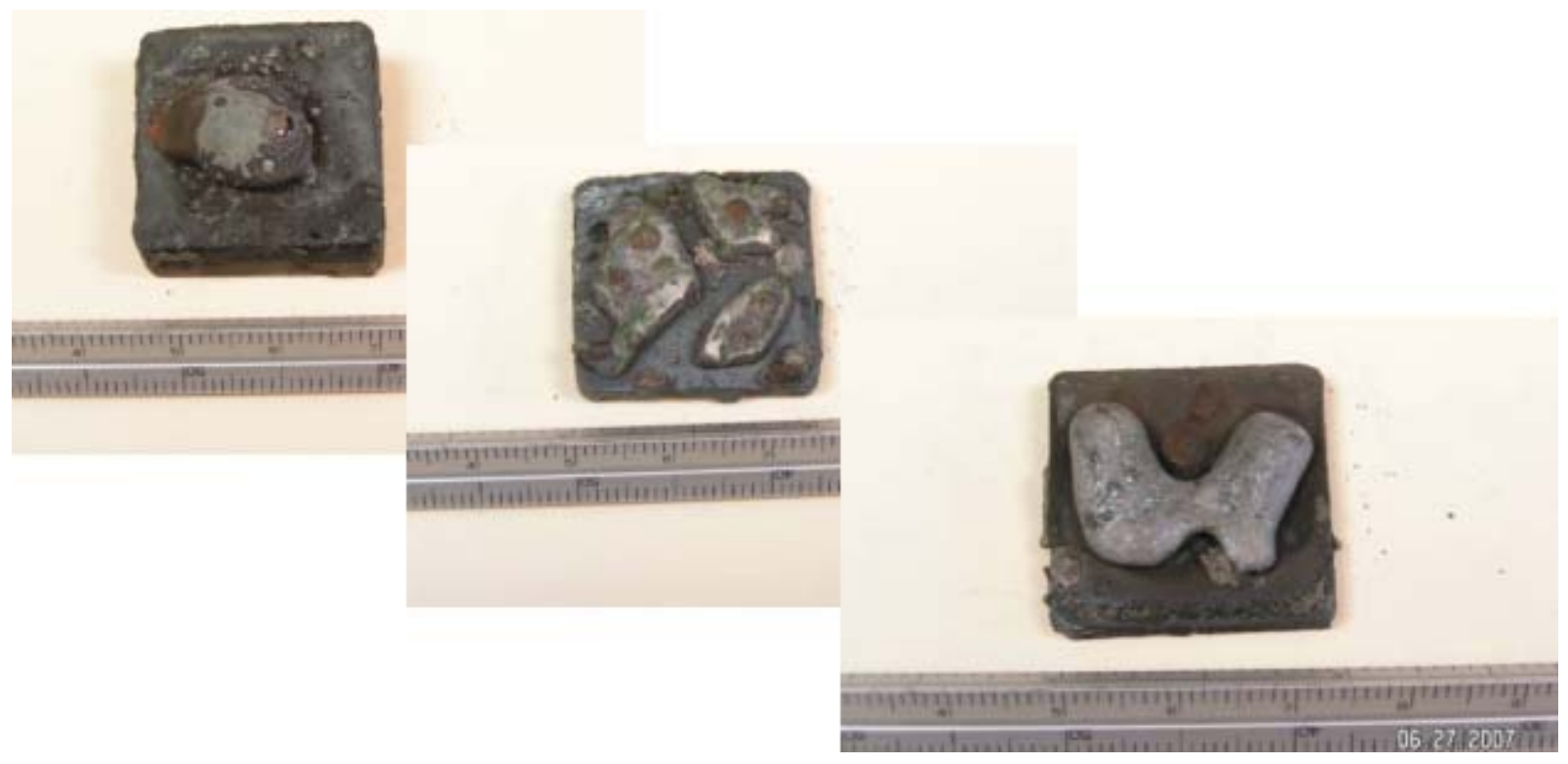

Figure 51. Arc lamp processed slurry coated samples of alloy SAQ4. These samples were processed at high power levels. 

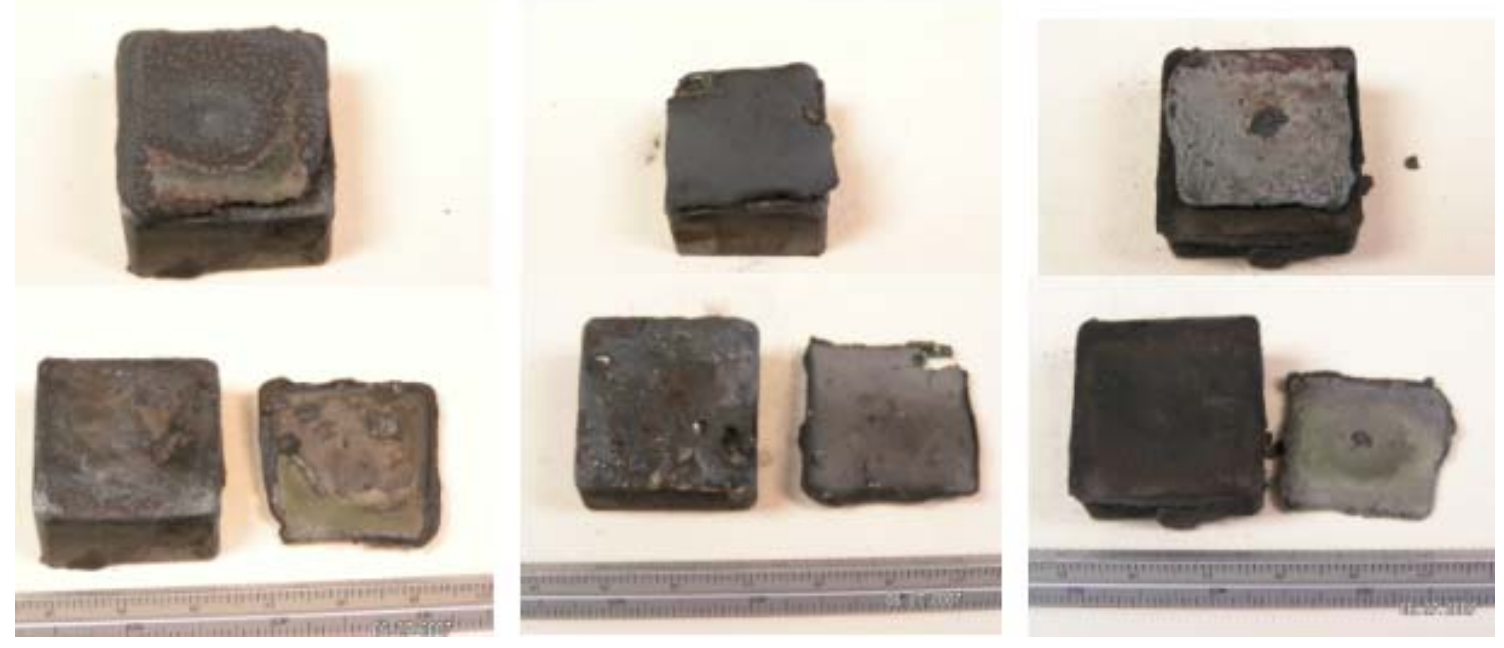

Figure 52. Arc lamp processed slurry coated samples of alloy SAQ4. These samples were processed at low power levels.

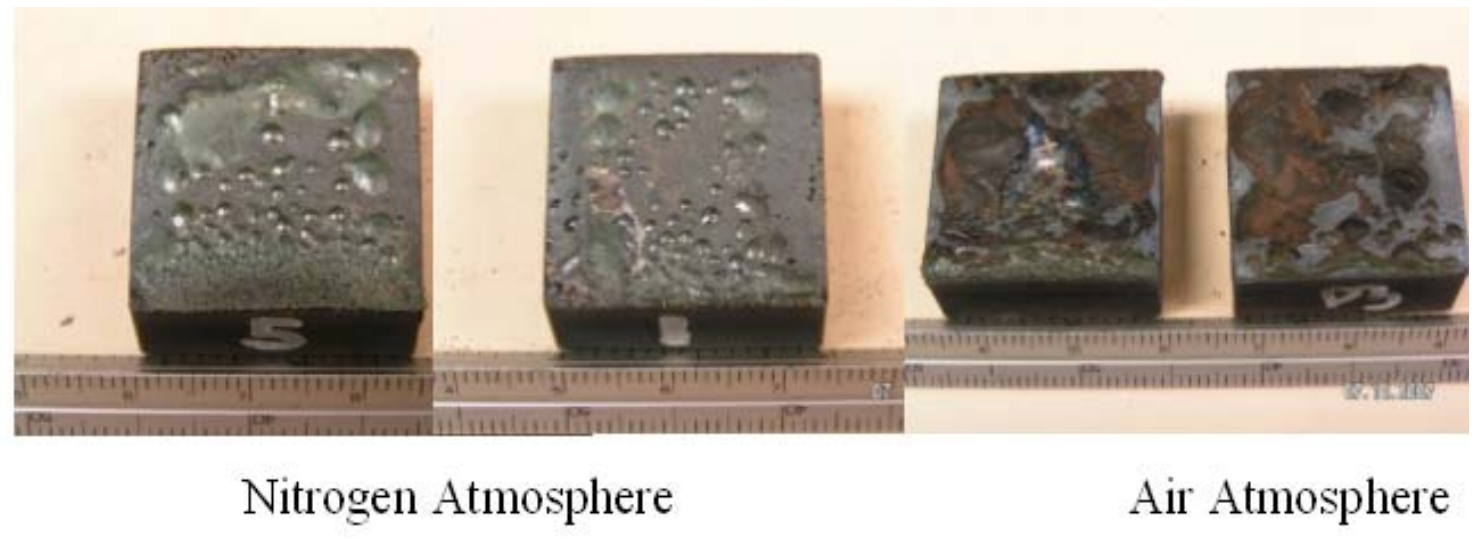

Figure 53. Arc lamp processed slurry coated samples of alloy SAQ4 processed in air and nitrogen atmospheres. These samples were processed at appropriate power levels.
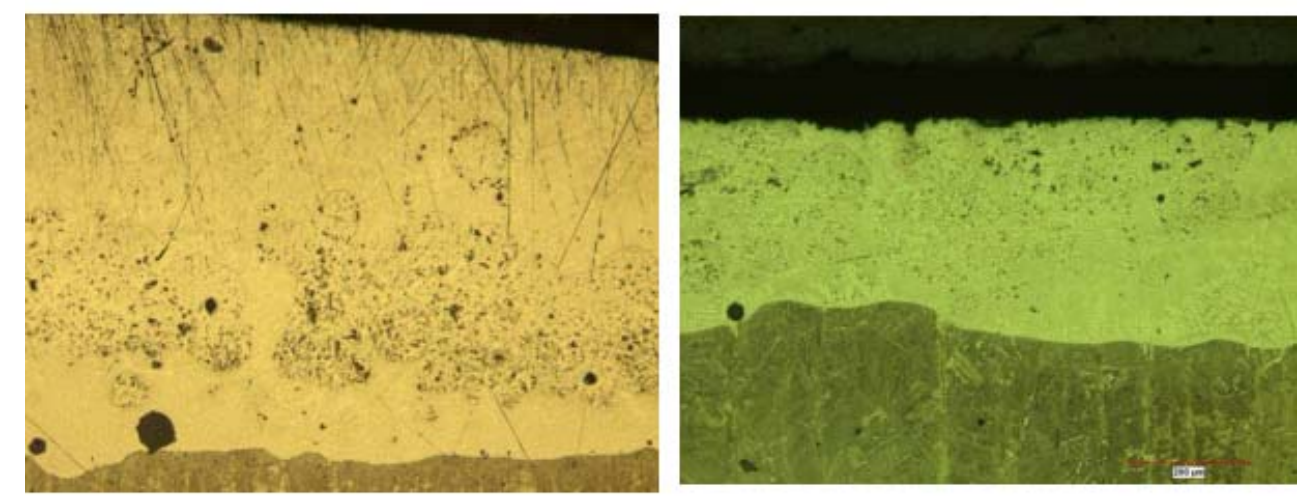

Figure 54. Optical micrographs of fused coatings produced in air (left) and nitrogen (right). 


\subsubsection{Plasma transferred arc}

The plasma transferred arc process is the baseline for comparison to the arc lamp process because it is an established method for the application of wear resistant coatings; however, it must be kept in mind that there are significant differences in the coatings produced with these two methods. As a first step in understanding these differences, UMR performed characterization of PTA coated samples of a commercially available wear resistant alloy WOKA 7439. Samples that were air cooled and oil cooled were processed at Caterpillar and sent to UMR for analysis. Micrographs and hardness profiles of these samples are shown in Figure 55 and Figure 56. Hardness profiles are shown in Figure 57. These coatings were applied in two passes. The micrographs show that the coating microstructure near the coating/substrate interface has a fine equiaxed grain structure and transitions to an acicular microstructure. The acicular plate thickness increases with distance from the substrate and hardness appears to be inversely proportional to acicular plate thickness. The oil cooled specimens exhibit slightly higher hardness and thinner acicular plates. Application of the second pass appears to cause a loss of hardness near the interface between the passes. The second pass also initiates with a fine equiaxed microstructure and transitions to an acicular microstructure with higher hardness. The loss in hardness at the coating surface corresponds to a thicker acicular plate width.

UMR also performed characterization of a PTA coated sample to be used in the crack propagation measurements. This samples was sectioned from a top mounted wear plate that was not used for field testing. The Deloro 60 coating had a dendritic microstructure with minimal porosity and a very sharp microstructural interface between the coating and the substrate (Figure 58). Similar to the WOKA 7439 coatings, the hardness of this coating is reduced near the substrate interface due to microstructural changes in the heat affected zone (Figure 59).

The PTA process was used to coat field test samples for both the top mounted wear plates and the motor grader blade sideshift wear strip. More detail on these components will be given in section "4.2.7 Field test". Microstructures of the top mounted wear plate coating materials are shown in Figure 60 through Figure 61. The commercially available wear resistant material used as a baseline for the top mounted wear plate field test (Deloro 60, Figure 60) has a fine-scale microstructure. SICWC alloys SA7 (Figure 61 top) and SAQ4 (Figure 61 bottom) have a much coarser microstructure. Alloy SAQ4 also has a much higher fraction of hard particles. This is expected because the composition was calculated by QuesTek to have a high volume fraction of the intermetallic phase. 


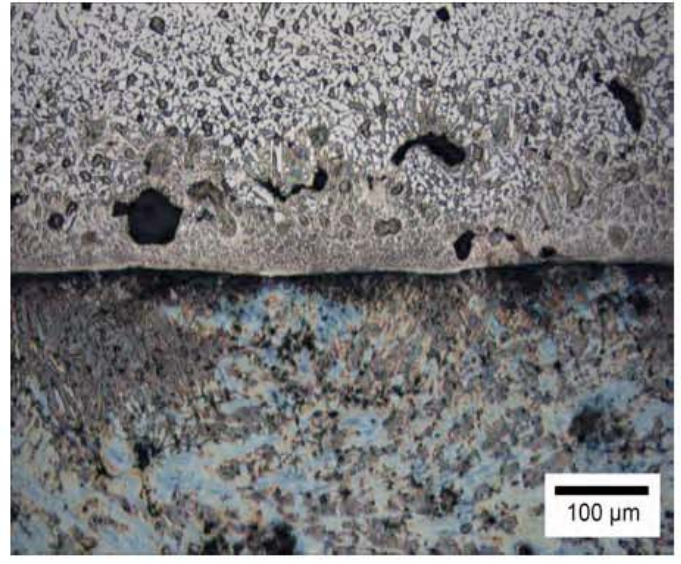

Microstructure of substrate and coating interface $100 \mathrm{X}$

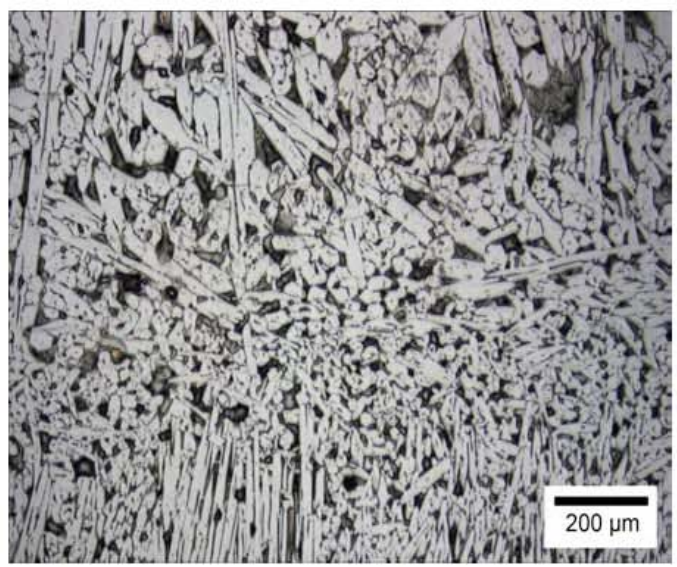

Microstructure of coating at $2 \mathrm{~mm}(50 \mathrm{X})$

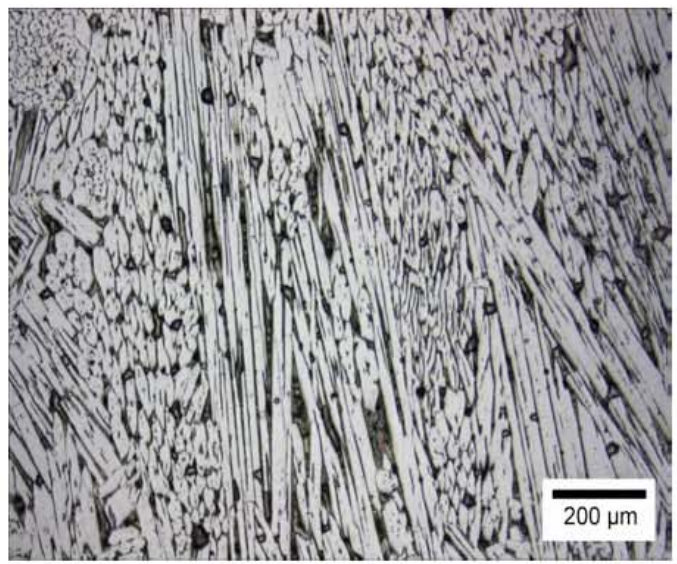

Microstructure of coating at $4 \mathrm{~mm}(50 \mathrm{X})$

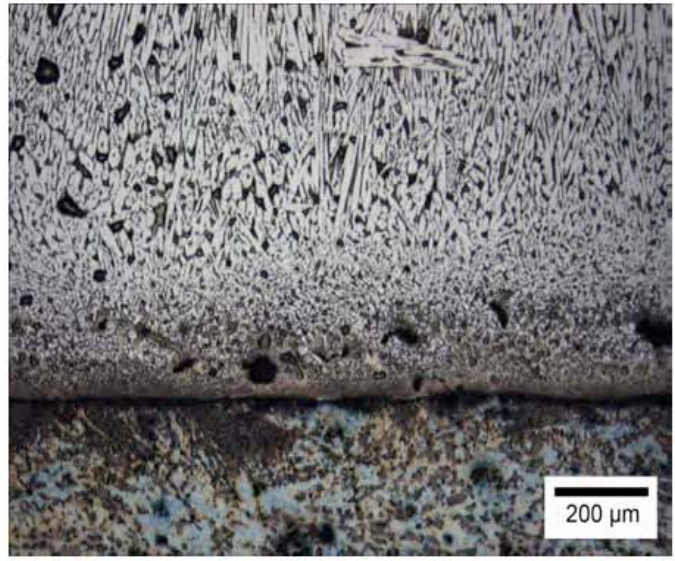

Microstructure of coating at $1 \mathrm{~mm}(50 \mathrm{X})$

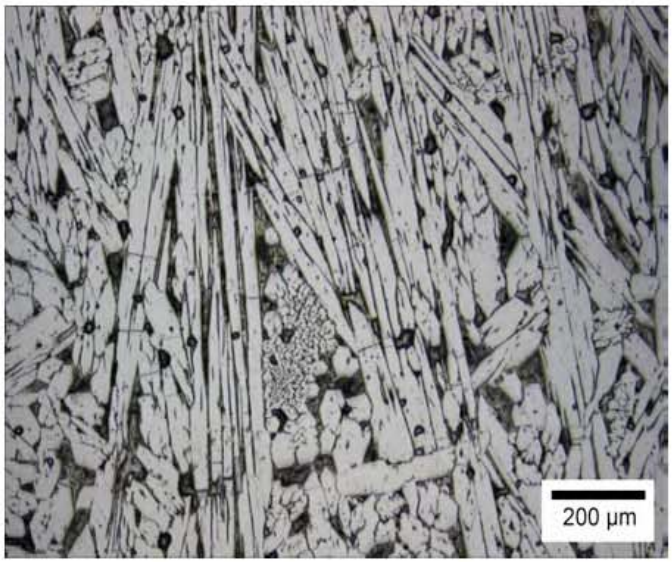

Microstructure of coating at $3 \mathrm{~mm}(50 \mathrm{X})$

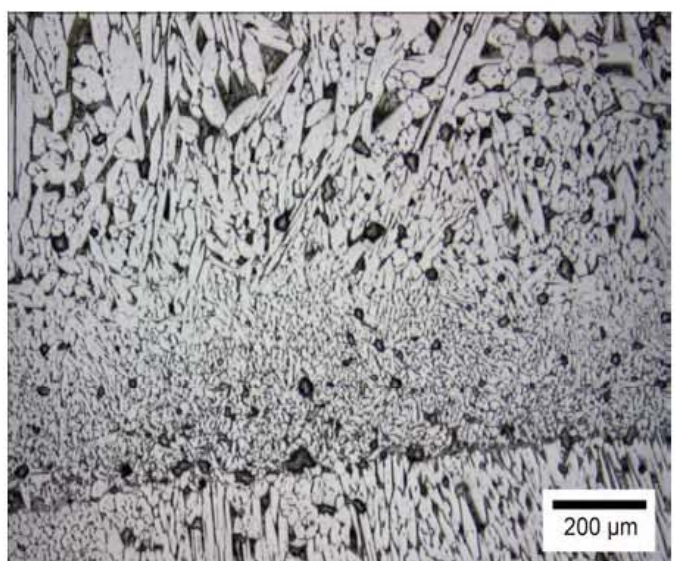

Microstructure at $1^{\text {st }}$ and $2^{\text {nd }}$ pass interace $(50 \mathrm{X})$

Figure 55. Microstructures of PTA coatings of a commercial wear resistant alloy with air cooling. 


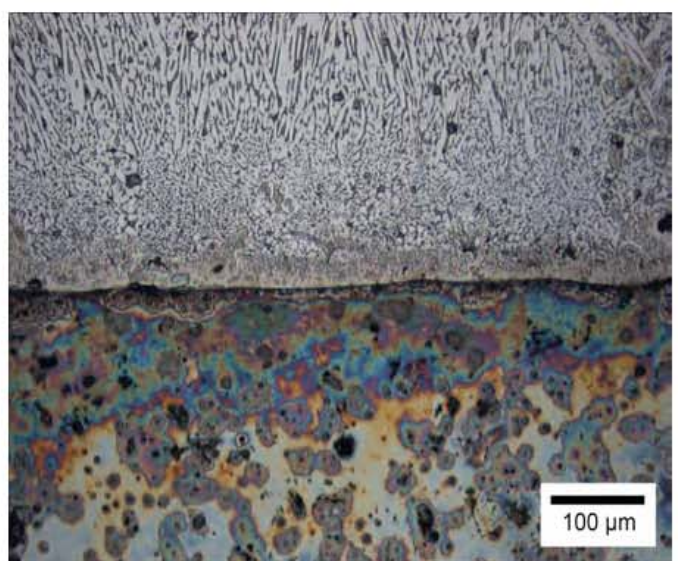

Microstructure of substrate and coating interface $100 \mathrm{X}$

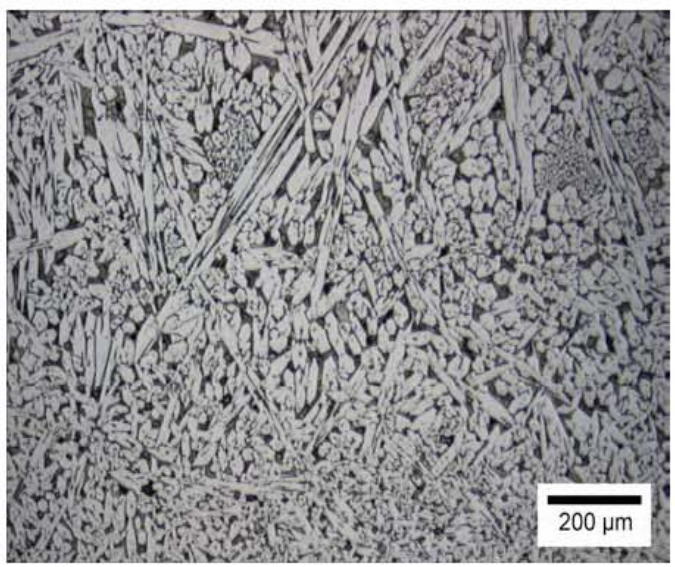

Microstructure of coating at $2 \mathrm{~mm}(50 \mathrm{X})$

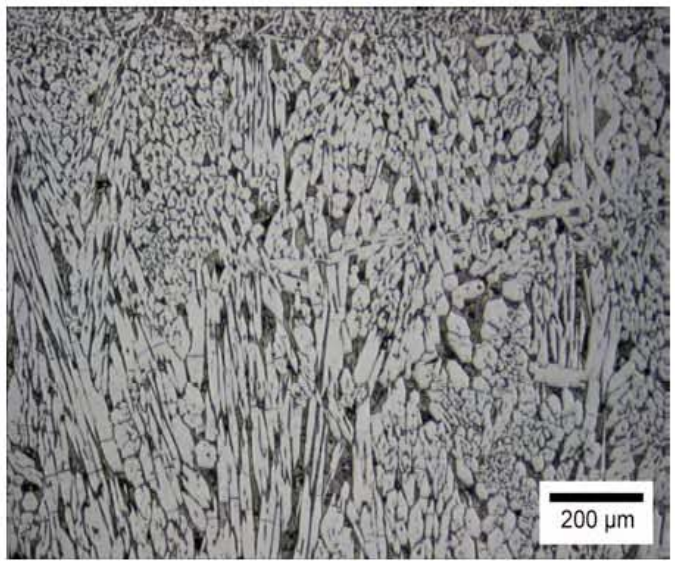

Microstructure of coating at $4 \mathrm{~mm}(50 \mathrm{X})$

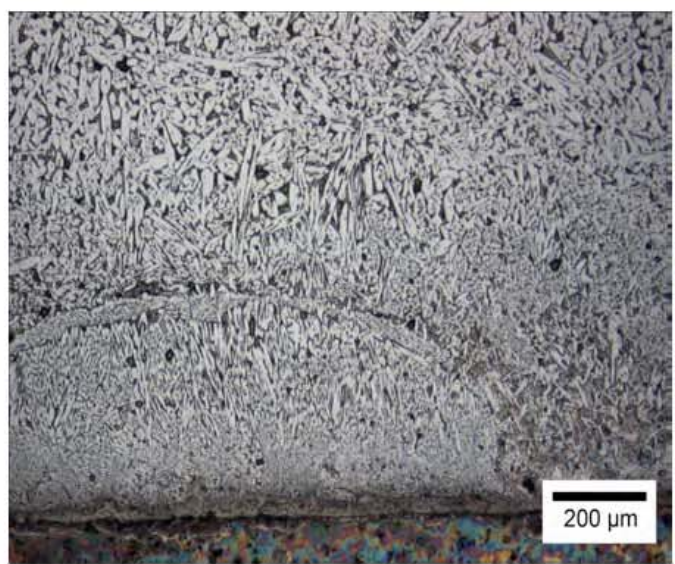

Microstructure of coating at $1 \mathrm{~mm}(50 \mathrm{X})$

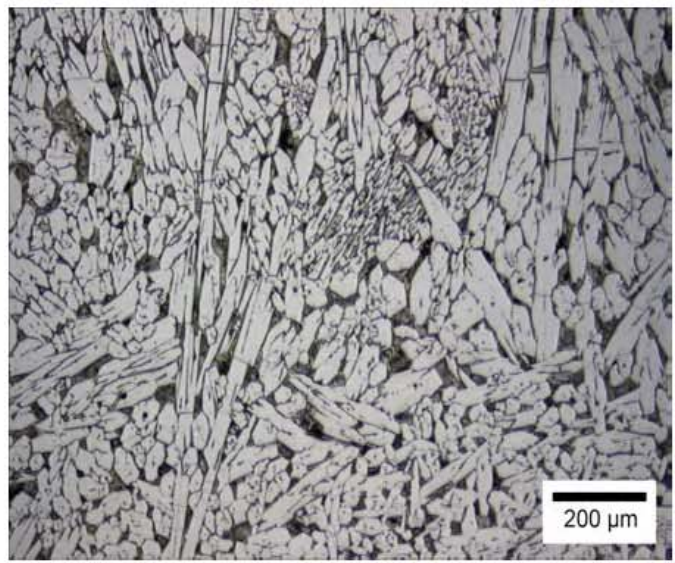

Microstructure of coating at $3 \mathrm{~mm}(50 \mathrm{X})$

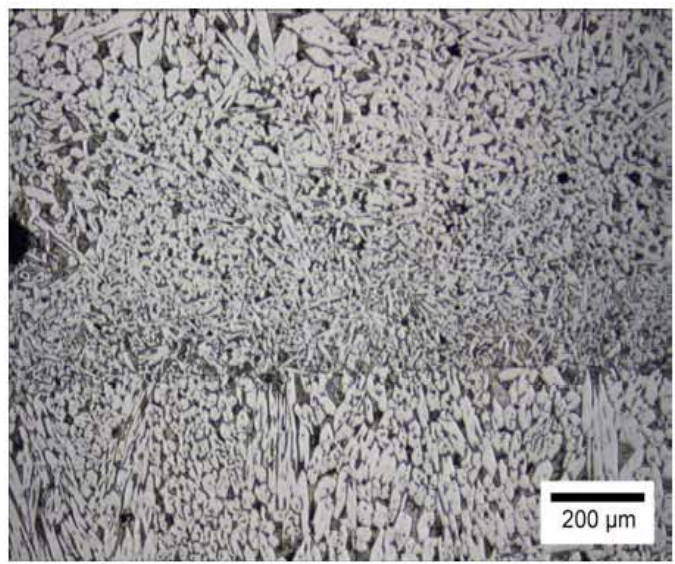

Microstructure at $1^{\text {st }}$ and $2^{\text {nd }}$ pass interface

Figure 56. Microstructures of PTA coatings of a commercial wear resistant alloy with oil cooling. 


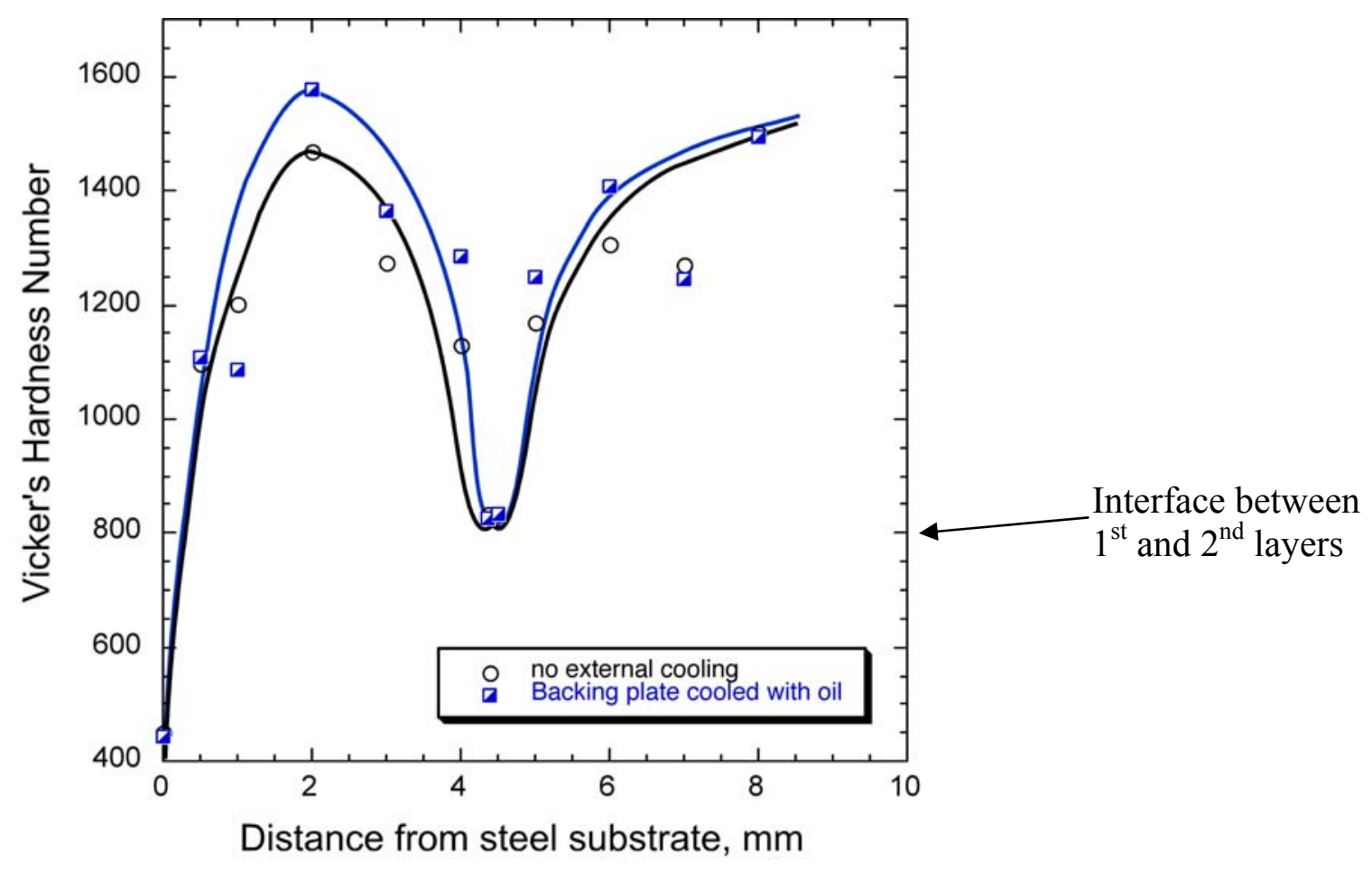

Figure 57. Hardness profiles through the PTA coatings. The drop in hardness shown at approximately 4.4 $\mathrm{mm}$ corresponds to a transition zone between the first and second PTA layers. This zone has a fine equiaxed microstructure. 


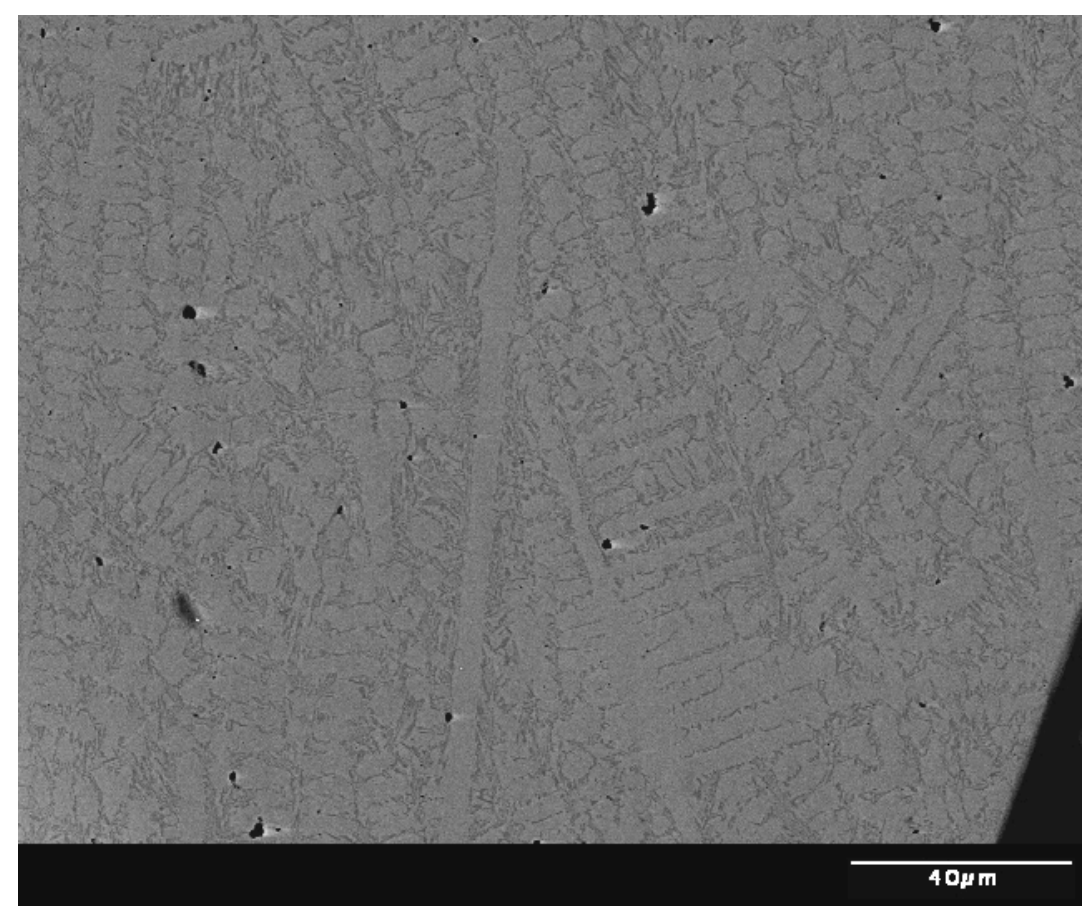

(a)

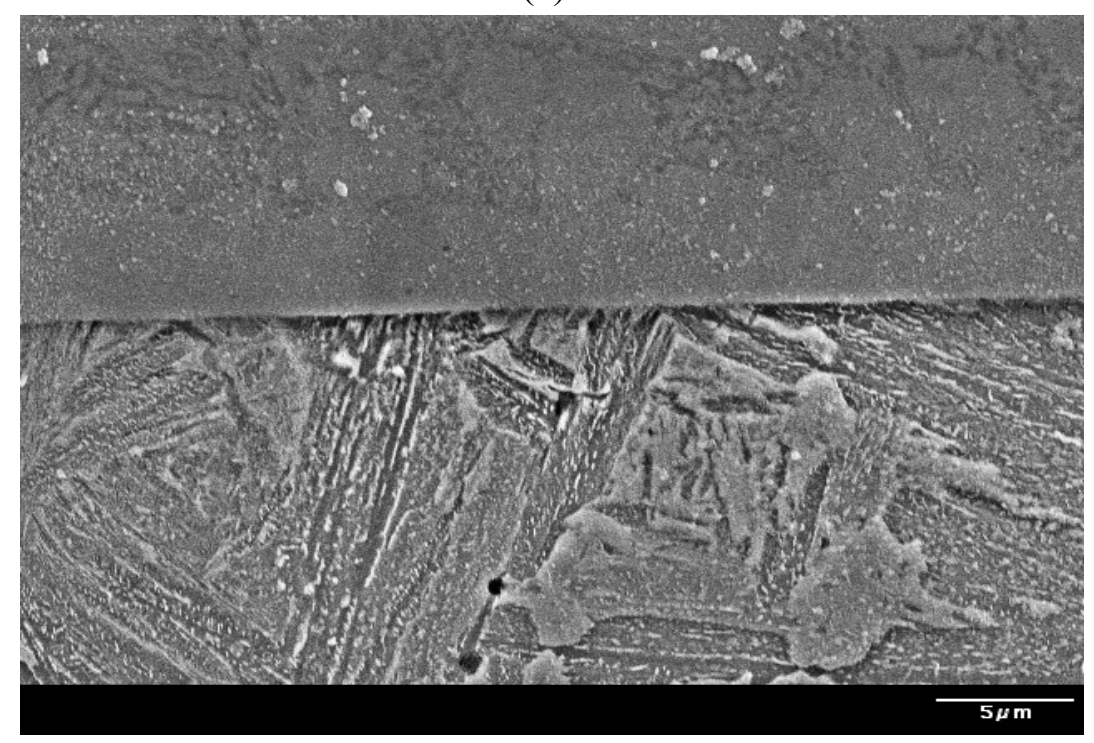

(b)

Figure 58. (a) Backscattered electron image of the Deloro PTA coating showing a dendritic microstructure. (b) Secondary electron image of PTA coating and base metal interface. Heat affected zone next to the PTA coating has a bainitic microstructure. 


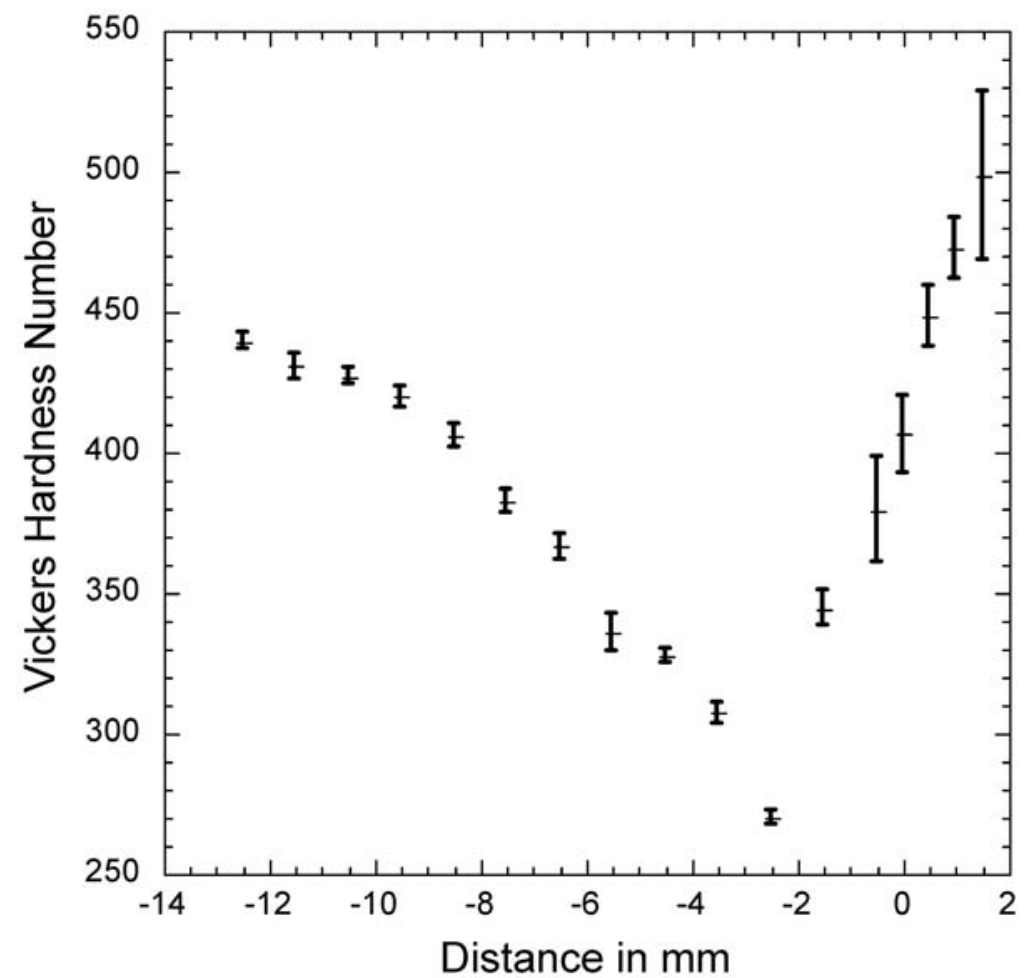

Figure 59. Microhardness profile of the heat affected zone (HAZ) and Deloro 60 coating material. The PTA coating interface is positioned at zero and the negative direction is into the steel base metal.

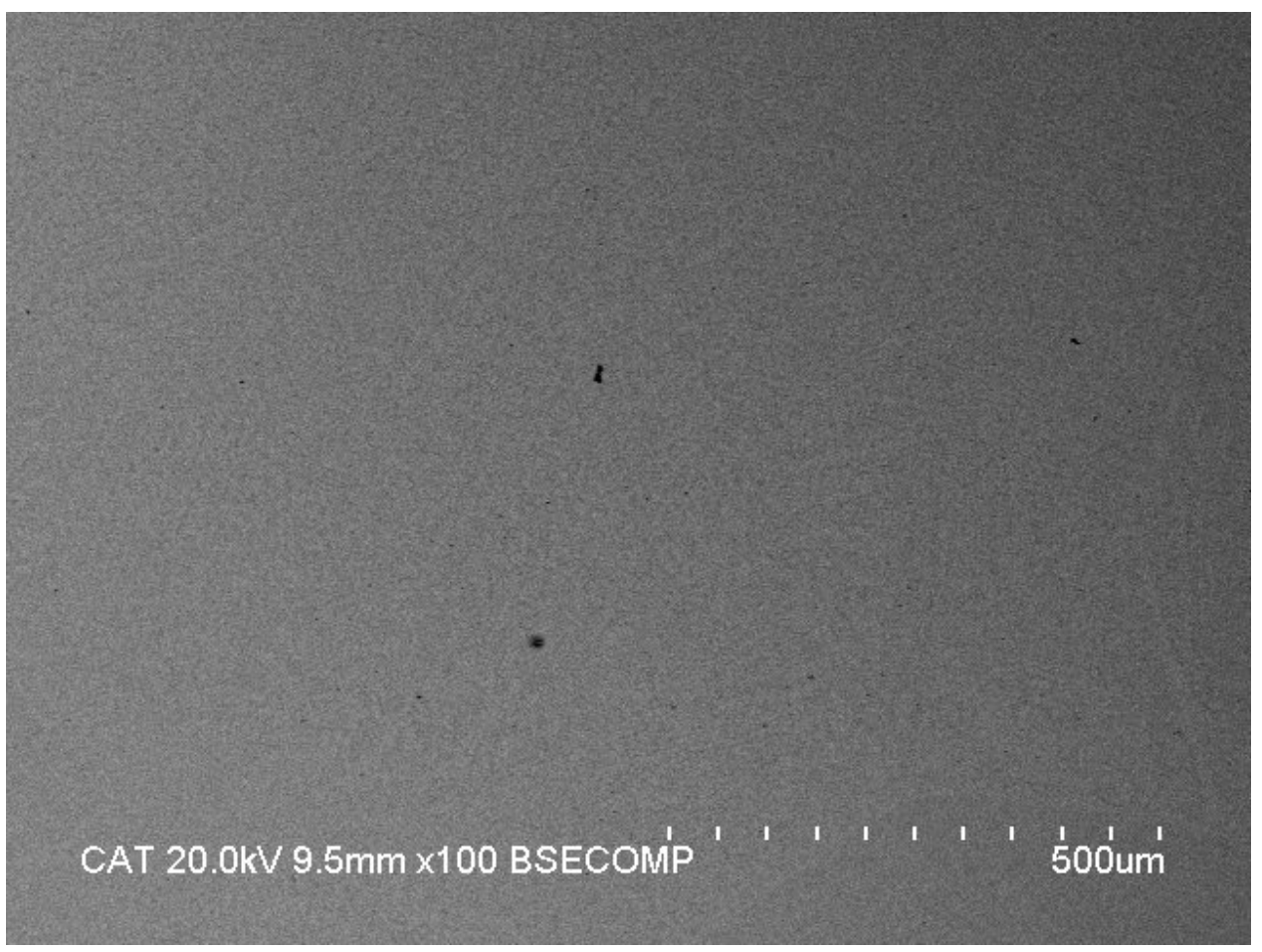

Figure 60. Microstructure of a commercially available wear resistant alloy (Deloro 60) on a top mounted wear plate. 

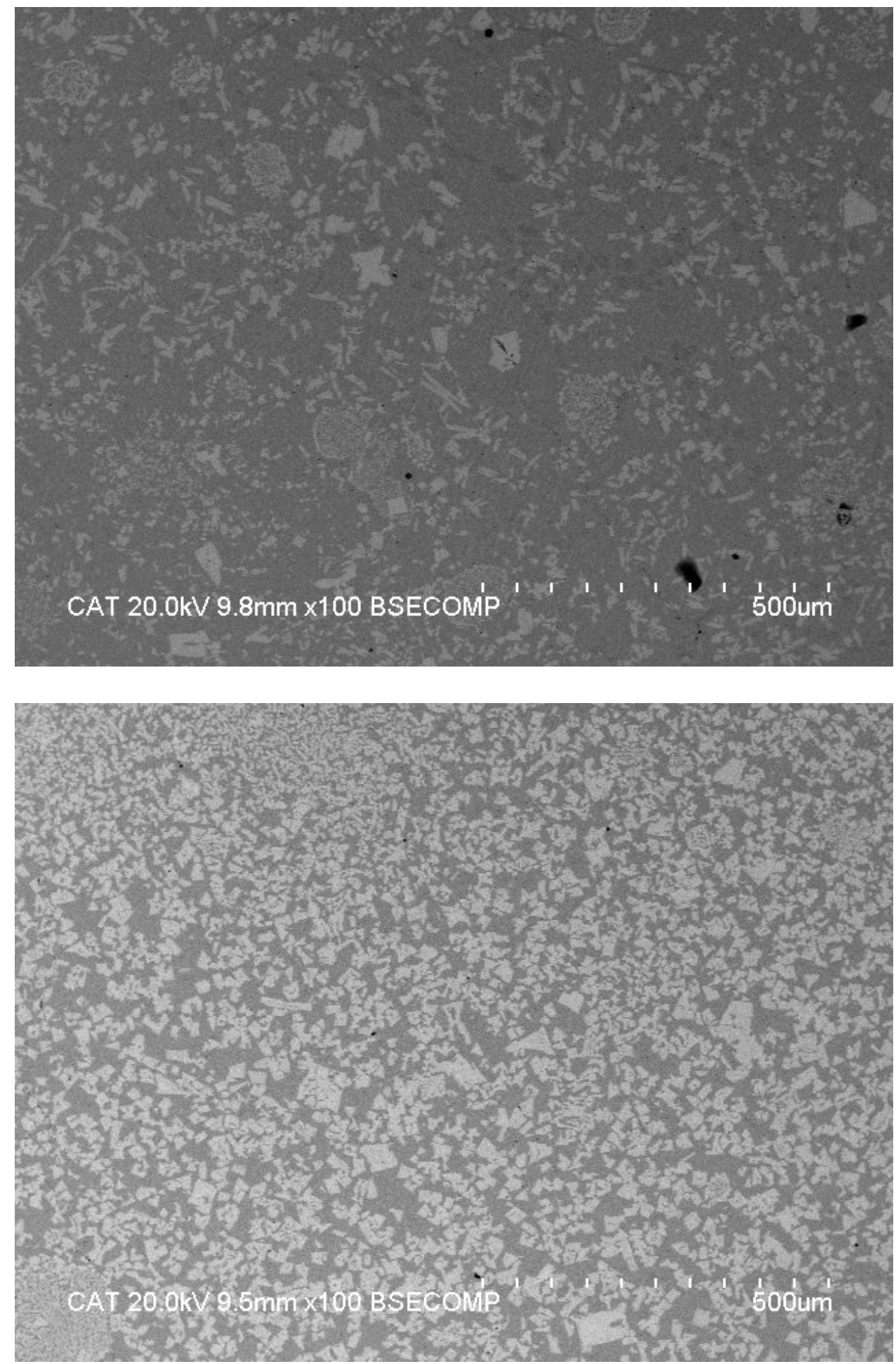

Figure 61. Microstructures of SA7 (top) and SAQ4 (bottom) coatings on top mounted wear plates. 


\subsubsection{Wear testing}

One of the key properties of the new alloys developed under this project is wear resistance. In addition to ranking the wear resistance of the alloys relative to each other, it is essential to compare the wear resistance of the new alloys with commercially available wear resistant alloys. The commercially available alloys used as baseline materials are listed in Table 7 with the corresponding designations shown in Figure 62 and Figure 63.

Table 7. Commercial alloys used as baselines for wear testing.

\begin{tabular}{|l|l|}
\hline Alloy designation & Commercial name \\
\hline C1 & WOKA 7439 \\
\hline C2 & Deloro 60 \\
\hline C3 & D2 tool steel \\
\hline C4 & AISI 52100 \\
\hline
\end{tabular}

The alloys under development in this project are intended for use on ground-engaging tools (GET) or undercarriage components that operate in a wide variety of environments. It is critical to determine the range of environments these alloys may be used in, based on lab screening tests before putting test samples in the field. For example, a coating that is appropriate for a rock quarry (e.g., high impact) may not be appropriate for a coal pile (e.g., high corrosion). The first step in evaluating the alloys is the selection of appropriate wear tests. If possible, a wear test should be selected based on the worn surface of a component from the field. In the case of GET the wide range of environments and wear surfaces does not narrow down the number of potential wear tests. Field sites can be classified in terms of abrasion and impact. Consequently, for screening purposes three wear tests were chosen: dry sand rubber wheel (DSRW), pin-on-drum (POD), and impact impeller testing. The DSRW and POD tests are representative of low and high load sliding wear (i.e., abrasion). The impact impeller test examines the resistance of the material to high load cyclic contact.

All of the wear tests used in this project directly measure mass loss. For a more physically meaningful comparison of wear rates, the mass loss must be converted to volume loss by dividing by the density of the wear material. The densities of two SICWC alloys, SA1 and SA4, were determined to be 6.0 and $7.1 \mathrm{~g} / \mathrm{cc}$. These densities are similar to the density of typical steels (about $7.8 \mathrm{~g} / \mathrm{cc}$ ). Unfortunately, the densities of the other SICWC alloy samples used for wear testing were not measured. To allow for a comparison of the widest number of alloys, the comparison of wear will be based on mass loss rather than volume loss.

The results of the DSRW testing are shown in Figure 62. In general the SICWC alloys perform as good or better than the commercial alloys. While wear resistance in this test is encouraging, it is important to note that the DSRW test historically does not correlate well with wear resistance in GET field applications. The results of the POD tests are shown in Figure 63. In the assprayed condition, the SICWC alloys generally have higher wear rates than commercially available alloys; however, arc lamp fusion causes significant wear rate reductions in four of the 
five alloys tested. In fact, after arc lamp fusion the wear rates of the SICWC alloys are generally lower than the commercial alloys.

The results of both the DSRW and POD tests are shown in Figure 64. There is no clear correlation between the two sets of test results either for the SICWC or commercial alloys. This lack of correlation is typical for these two tests. Figure 65 shows the correlation between wear rates in the POD test with hardness. In this test there appears to be a weak correlation between hardness and wear resistance. A correlation between hardness and wear rate is typical for the POD test.

Each of the wear tests produces distinctive wear scars. Examples of these wear scars are shown in Figure 66 and Figure 67. The DSRW test (Figure 66) produces relatively shallow wear scars parallel to the direction of rotation of the rubber wheel. The POD test (Figure 67) produces deeper wear scars in various directions.

In a GET application, a coating must be able to withstand impact loading without debonding from the substrate. For this reason the impact impeller testing of these coatings is of distinct interest. Samples for the impact impeller test must be machined to fit properly in the sample holder and it was common to observe some chipping of the coating prior to testing. Figure 68 shows one of the more severe examples of chipping before and after impact testing. While the sample started with less coating, the effect of the wear test can still be measured through mass loss. Figure 69 shows typical as-sprayed and arc lamp coated samples after impeller testing. Qualitatively it is clear that the arc lamp process significantly improves wear resistance. Mass loss values for these samples are shown in Figure 70. In every sample except SAQ4 the mass loss is lower after arc lamp processing. Photographs of as-sprayed and arc lamp processed samples with the lowest mass loss are shown in Figure 71.

Mass loss is the standard for quantifying many wear tests where material loss takes place through abrasion; however, this may not be appropriate for the impact impeller test where bulk pieces of material may be removed. Mass loss in and of itself does not differentiate factors such as coating thickness (i.e., if a thick coating delaminates more mass will be removed than for a thin coating), coating density, and cohesive strength of the coating (i.e., a coating will tend to spall in large chunks if the cohesive strength is similar to or higher than the adhesive strength of the interface). An alternative to mass loss is the use of areal measurements such as the recession of the coating from the edge (i.e., the "coating removal point" shown in Figure 72) or the remaining coating area. Figure 73 shows the correlation between mass loss and area remaining. For the SA series alloys mass loss and area loss are proportional. For the SAQ series alloys, the remaining area at a given mass loss is lower than for the SA series alloys. This indicates that the SAQ series alloys tend to delaminate in large chunks compared to the SA series alloys. The bulk delamination vs. wear in the SAQ vs. SA series alloys can also be seen in the photographs in Figure 69. This indicates that the arc lamp processing for the SAQ series resulted in a lower interfacial adhesion strength than the SA series alloys. Another measure of the performance of a material in the impeller test is the difference between the mass loss during the first and second hours of the test. Among the as-sprayed samples alloys, SA1 and SA11 were the best while for the arc lamp processed samples alloys, SA6 and SA9 performed best. 
The POD and impeller test results are summarized in Figure 75. In general, arc lamp processing improves wear resistance for samples in both tests. Correlations between the POD and impeller tests for all of the samples tested are shown in Figure 76. There appears to be little or no correlation between POD and impeller wear rates. Figure 77 shows this data for arc lamp processed samples only (a subset of the data in Figure 76). For arc lamp samples there does not appear to be a correlation between POD and impeller wear rates. This is not surprising due to the difference in physical mechanisms affecting wear rate in those tests (i.e., abrasion vs. delamination). Similarly, Figure 78 shows that there is little or no correlation between hardness and impeller test wear rate. 


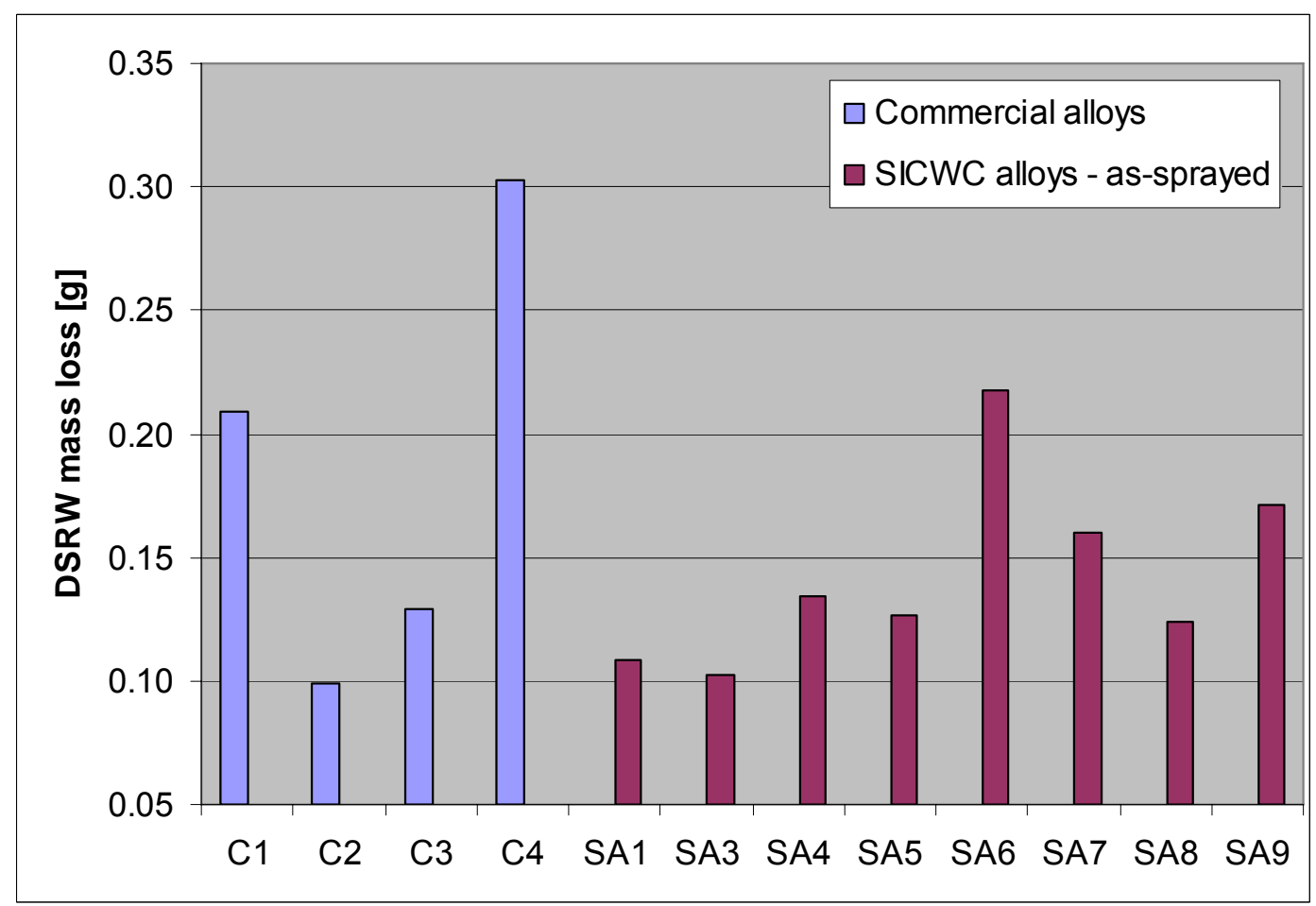

Figure 62. DSRW test results from SICWC and commercially available alloys.

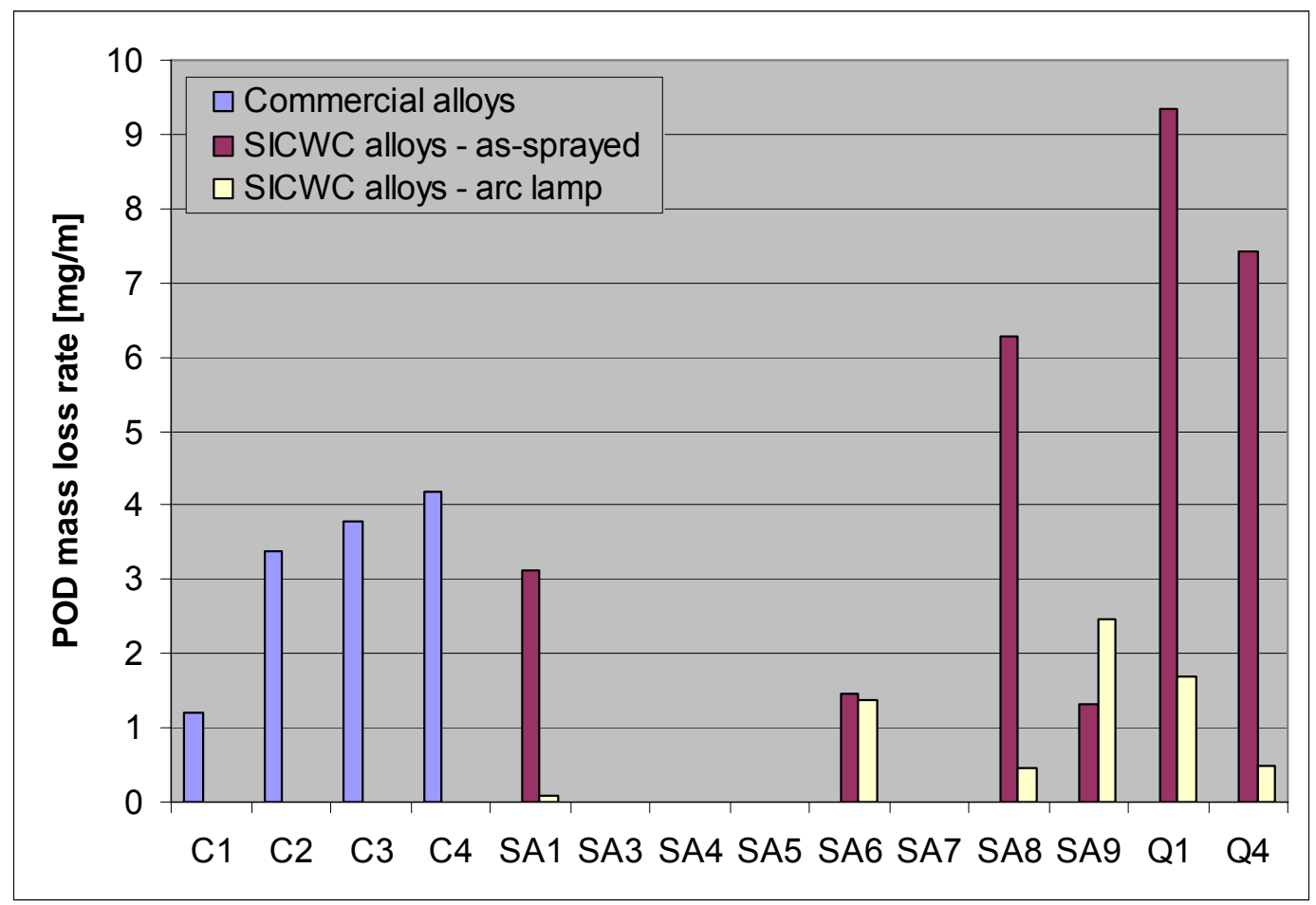

Figure 63. POD test results from SICWC and commercially available alloys. 


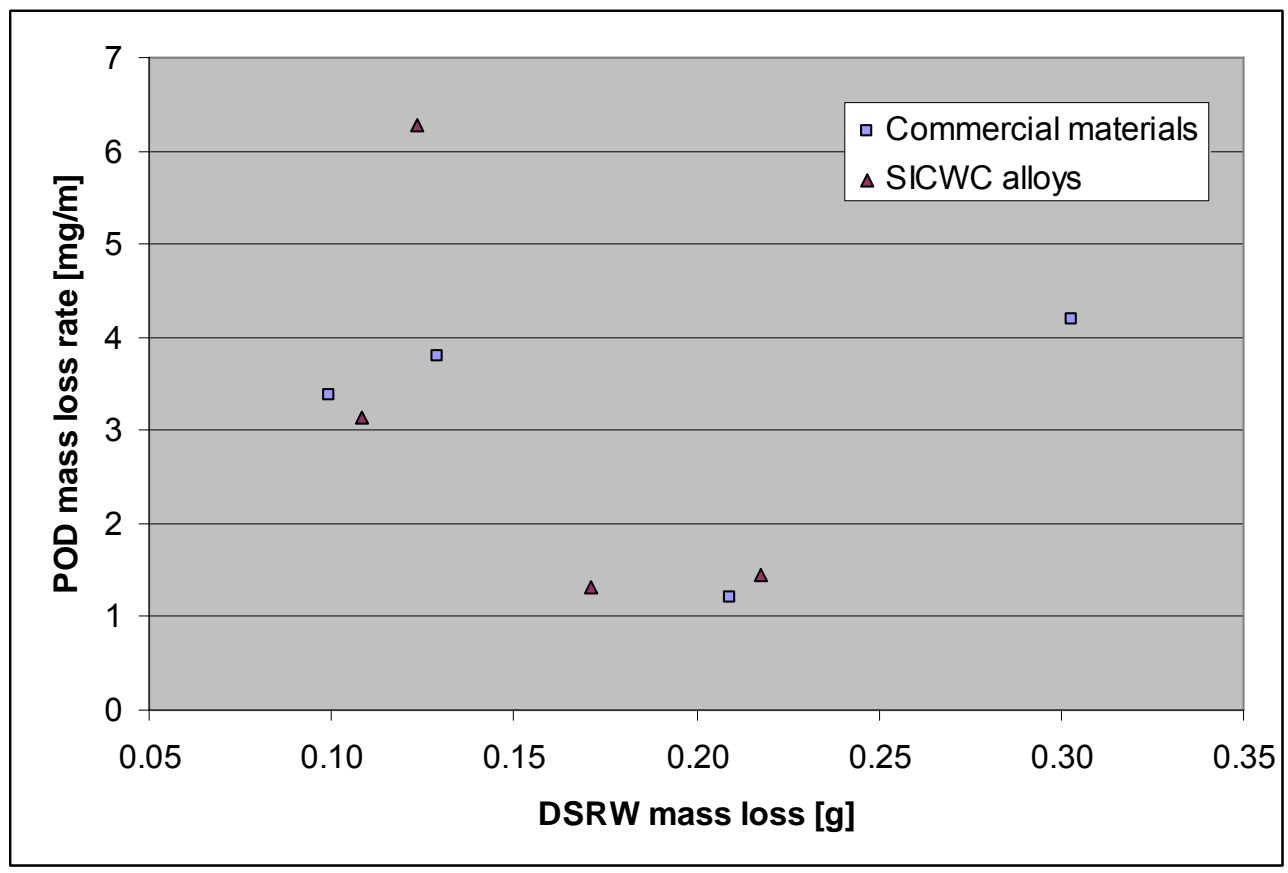

Figure 64. Relationship between POD and DSRW wear rates for SICWC and commercially available alloys.

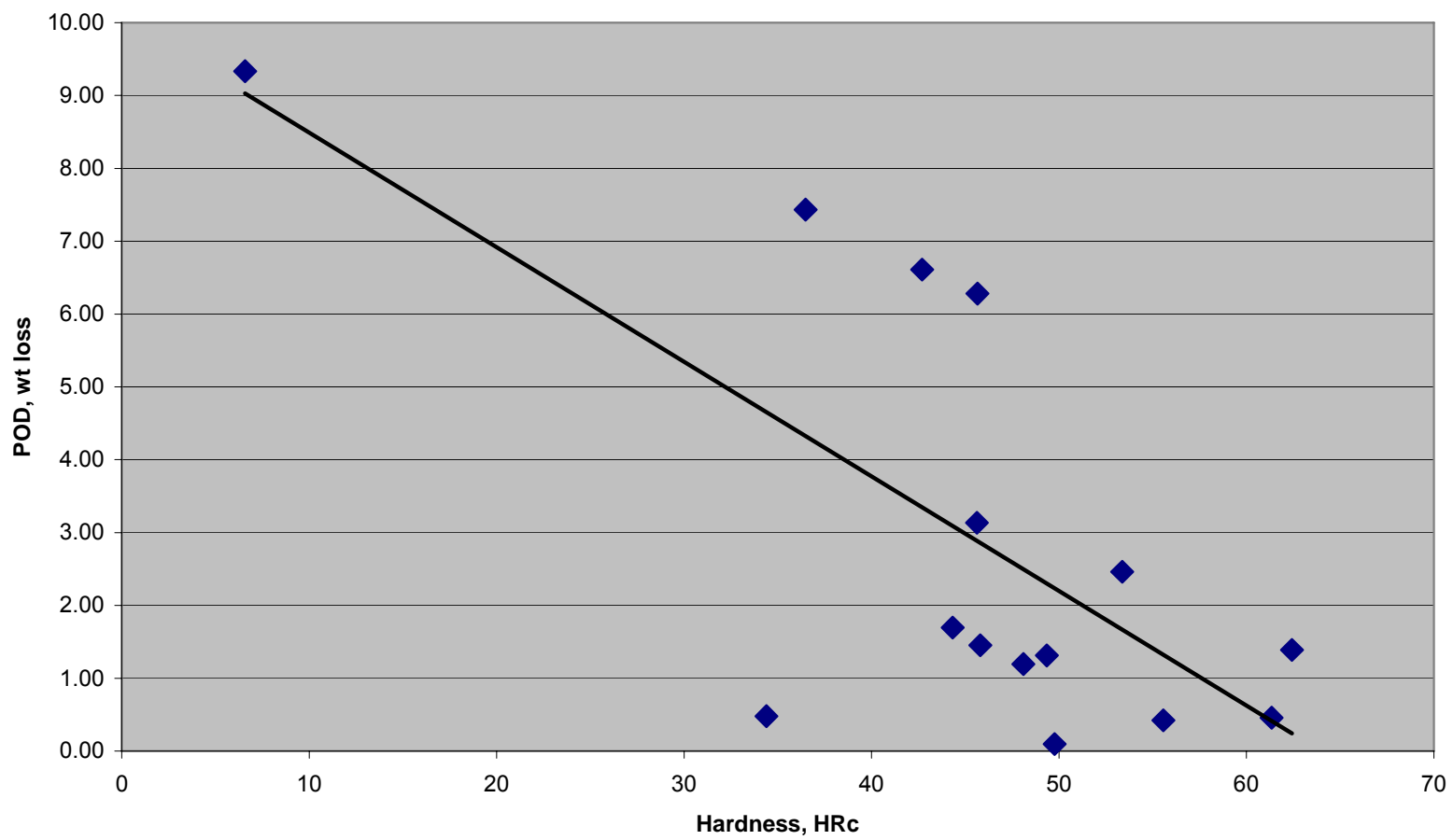

Figure 65. POD wear rate as a function of hardness for selected SICWC alloys. 


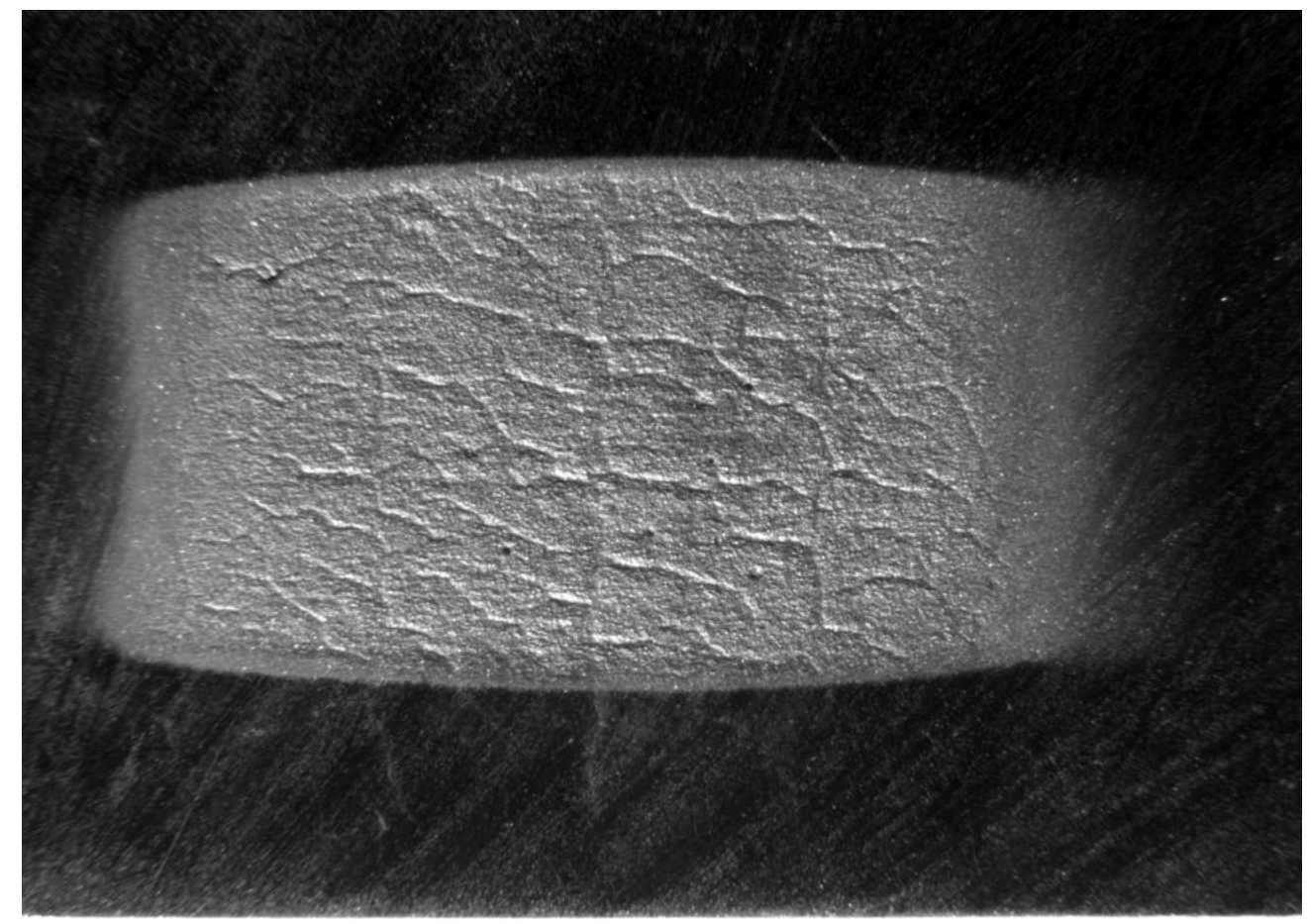

$4 \mathrm{~mm}$

Figure 66. Typical wear surface of a SICWC alloy after the DSRW test.
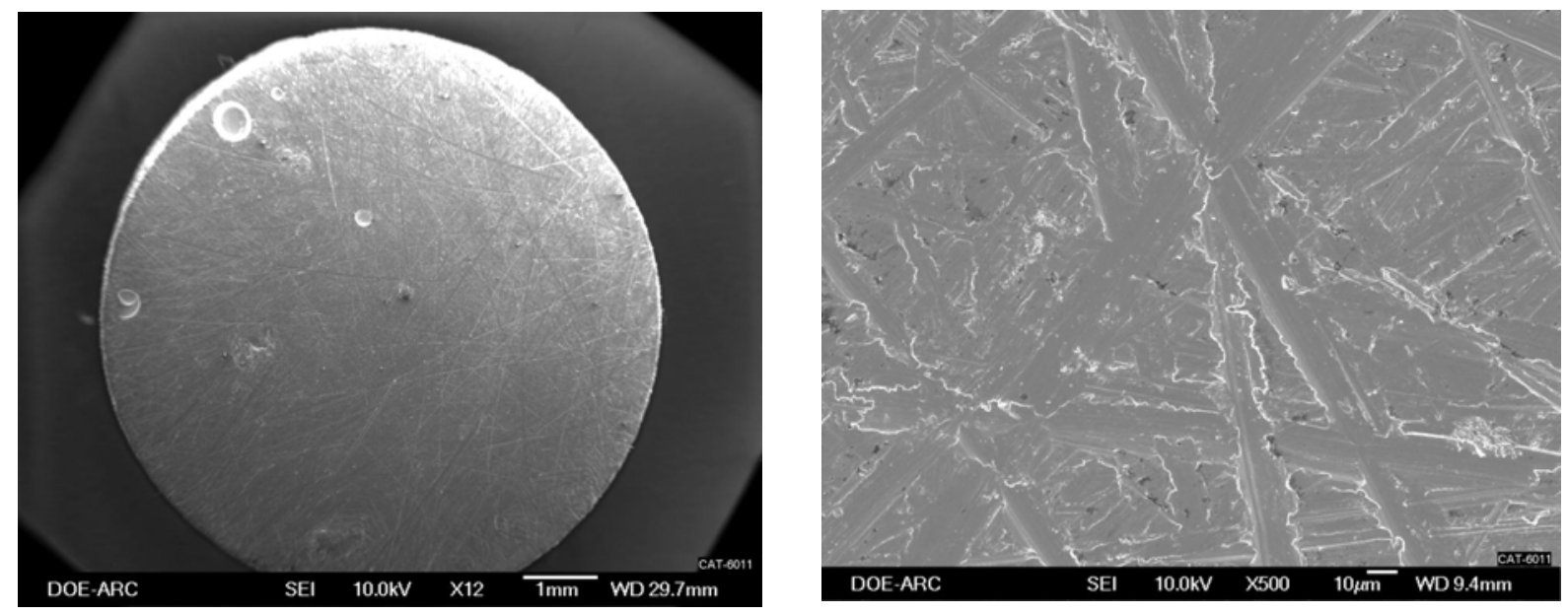

Figure 67. Typical wear surface of a SICWC alloy after the POD test. 


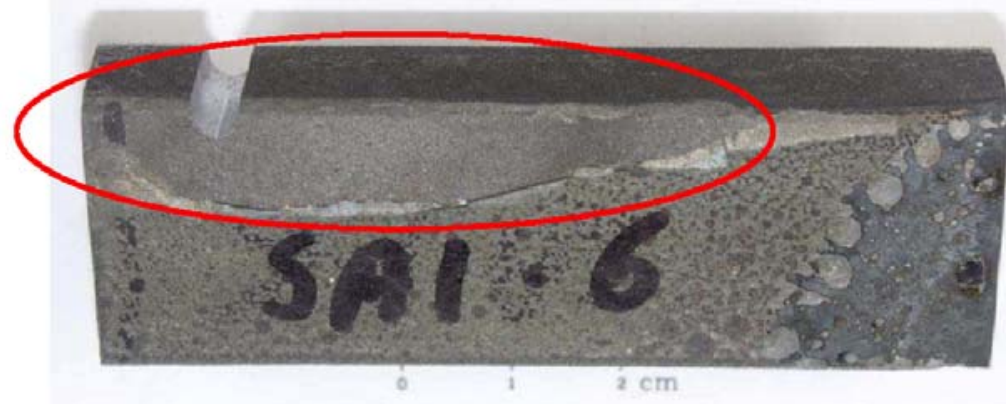

\section{Before Testing}

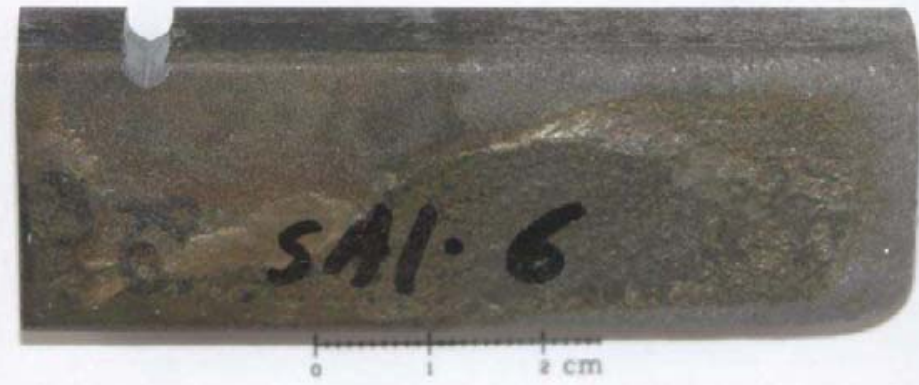

After Testing

Sample SA1-6

Figure 68. Photograph showing a chipped coating after sample preparation for the impact impeller test.

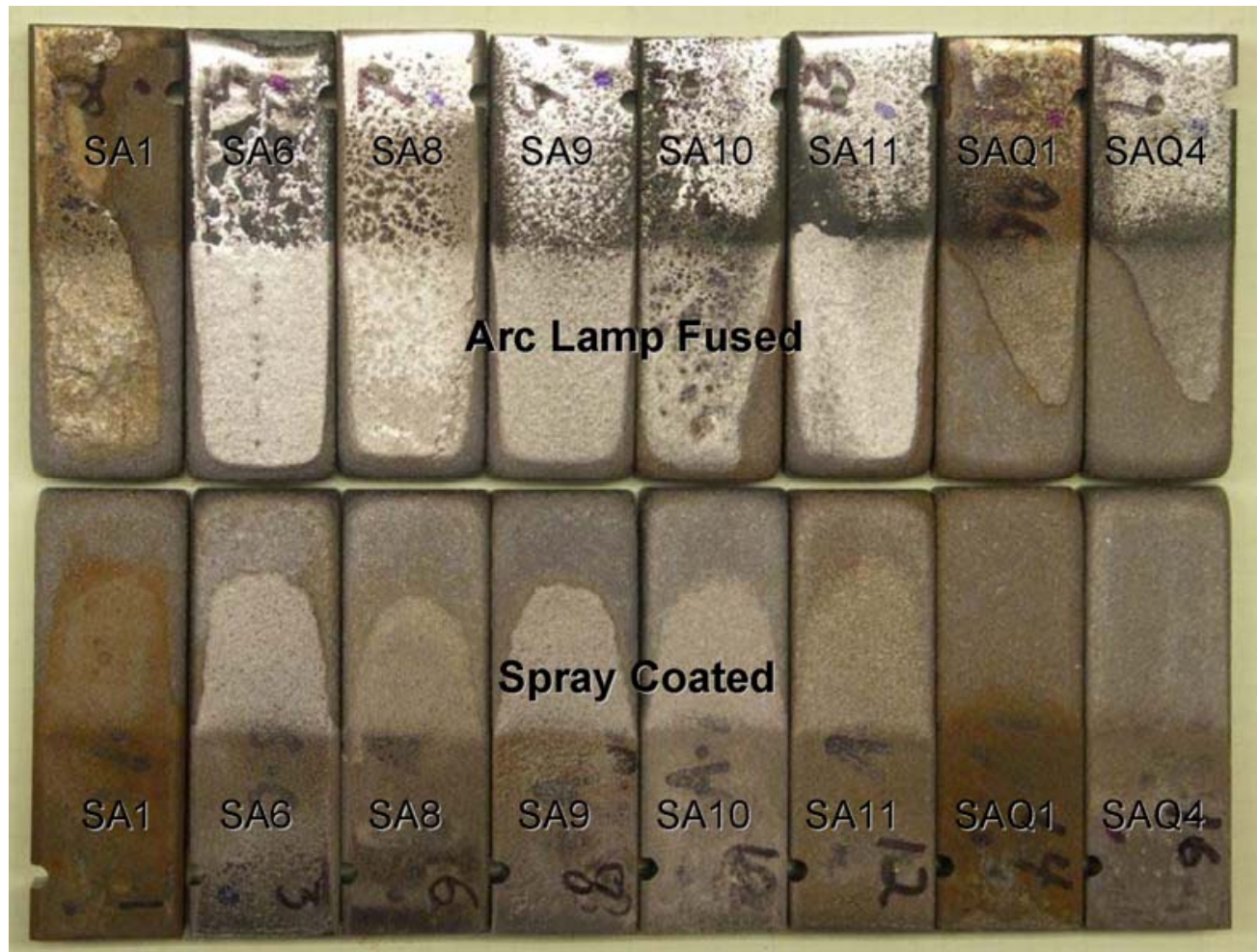

Figure 69. As-sprayed and arc lamp processed SICWC alloy samples after impeller testing. 


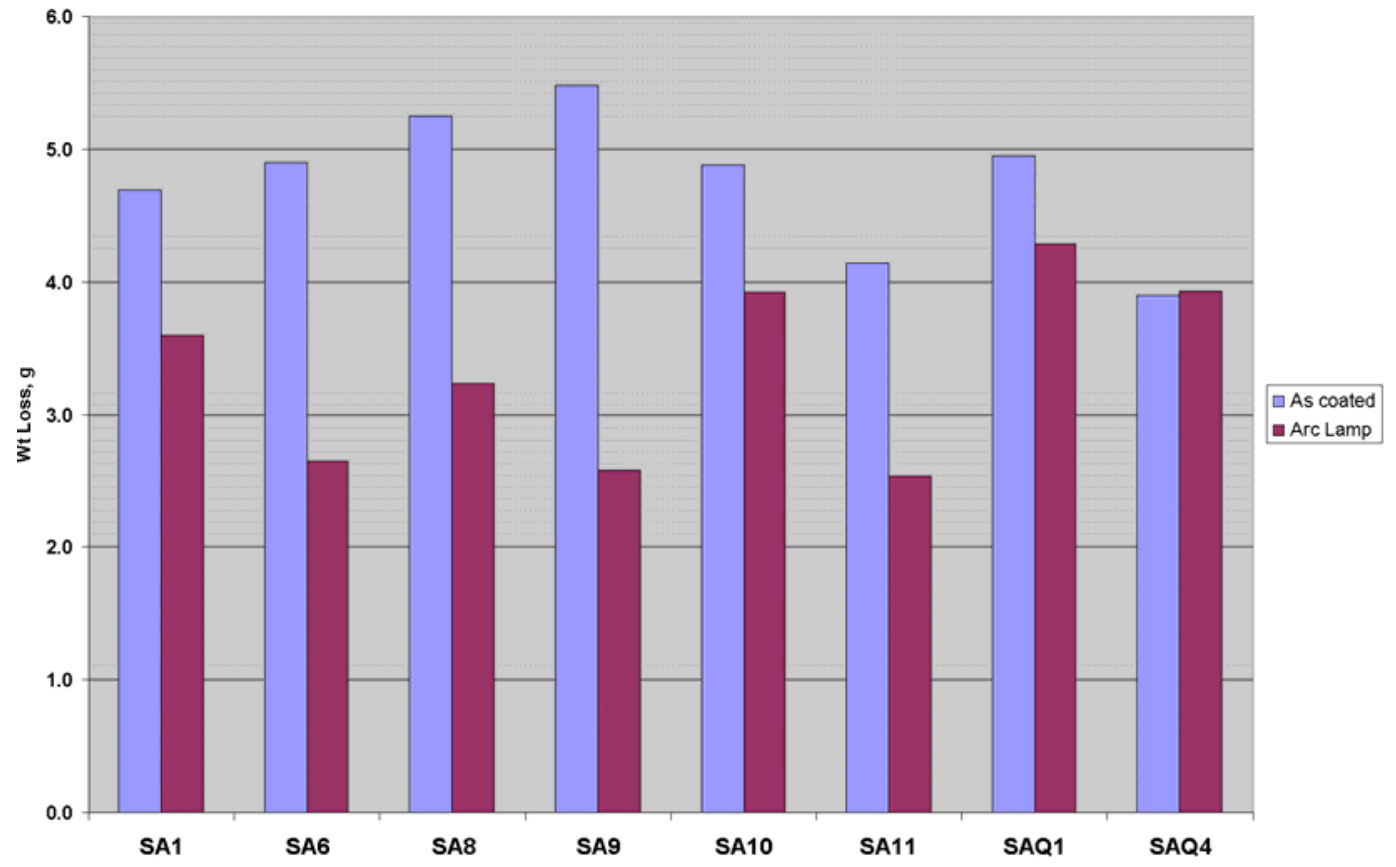

Figure 70. Wear rate of as-sprayed and arc lamp processed SICWC alloys after impeller impact wear testing.

-Spray Coating

- SA1-0

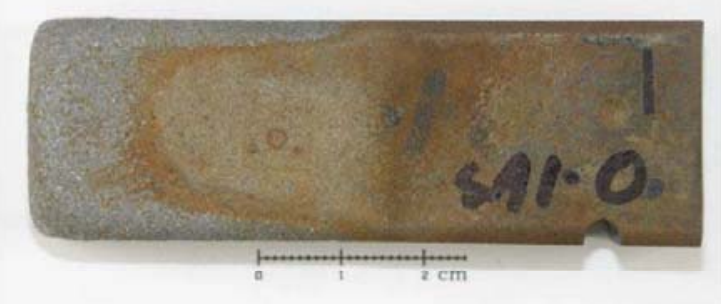

- SA11-0

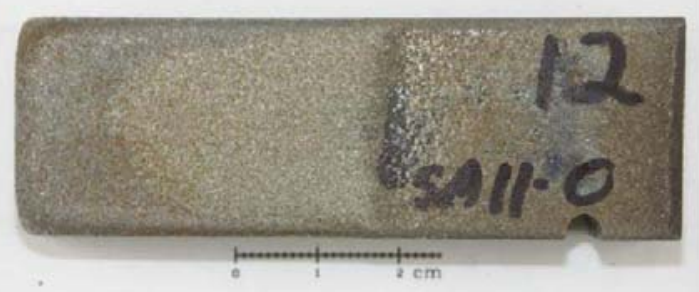

\section{-Arc Lamp \\ - SA6-6}

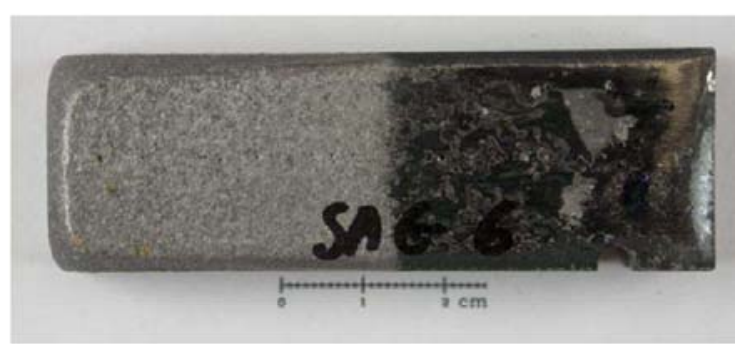

$$
\text { - SA9-6 }
$$

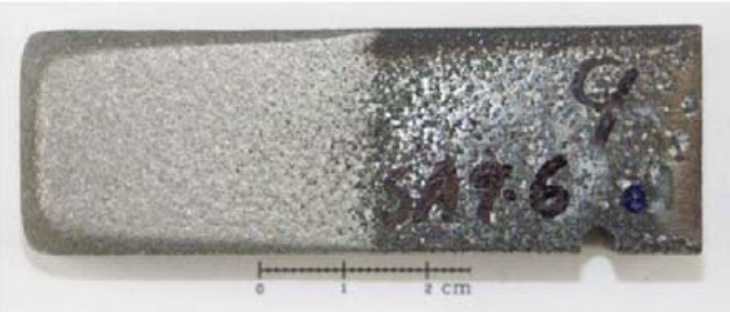

Figure 71. Photographs of the best performing samples from the impact impeller wear test. 


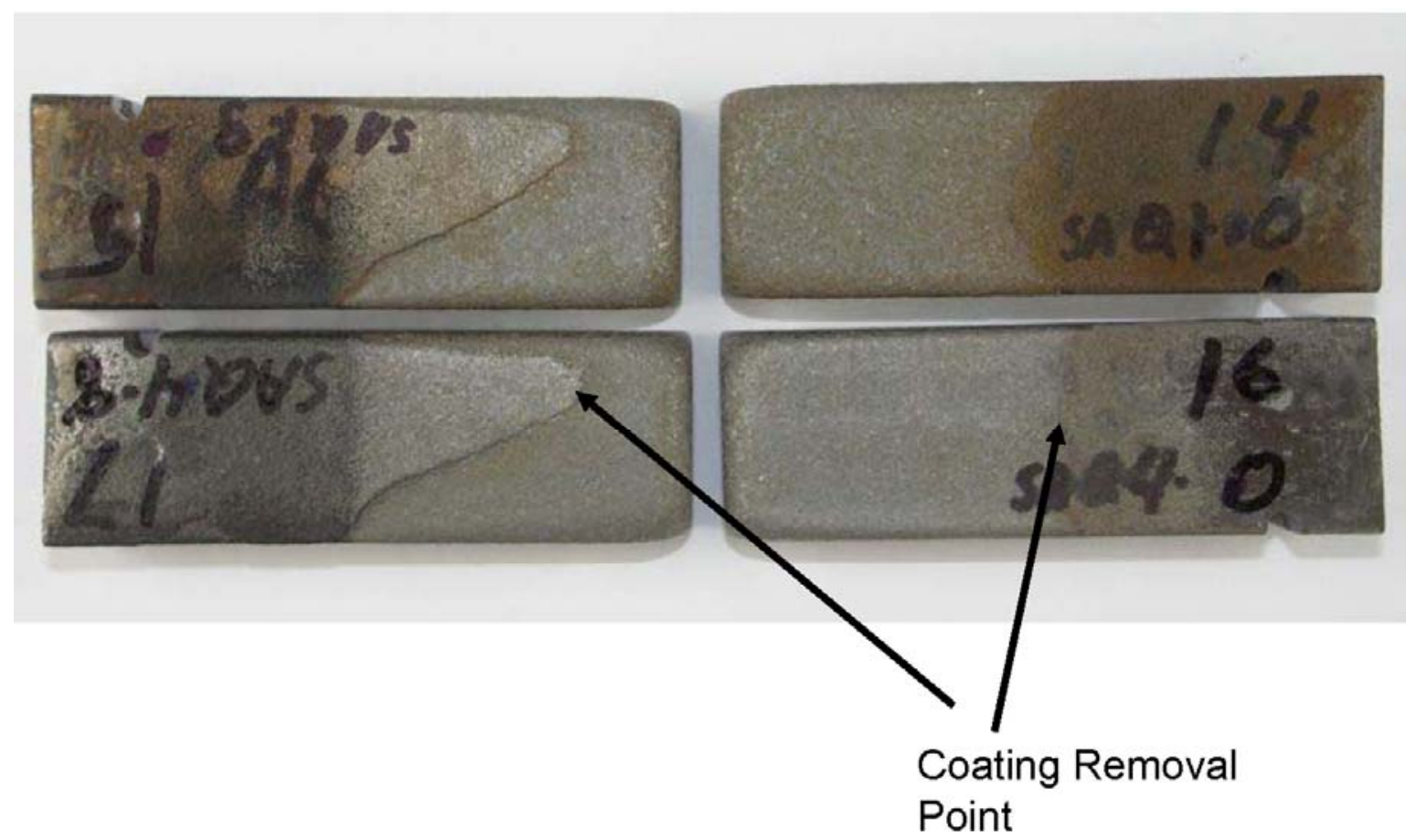

Figure 7'2. Photograph of coating removal points after impeller wear testing.

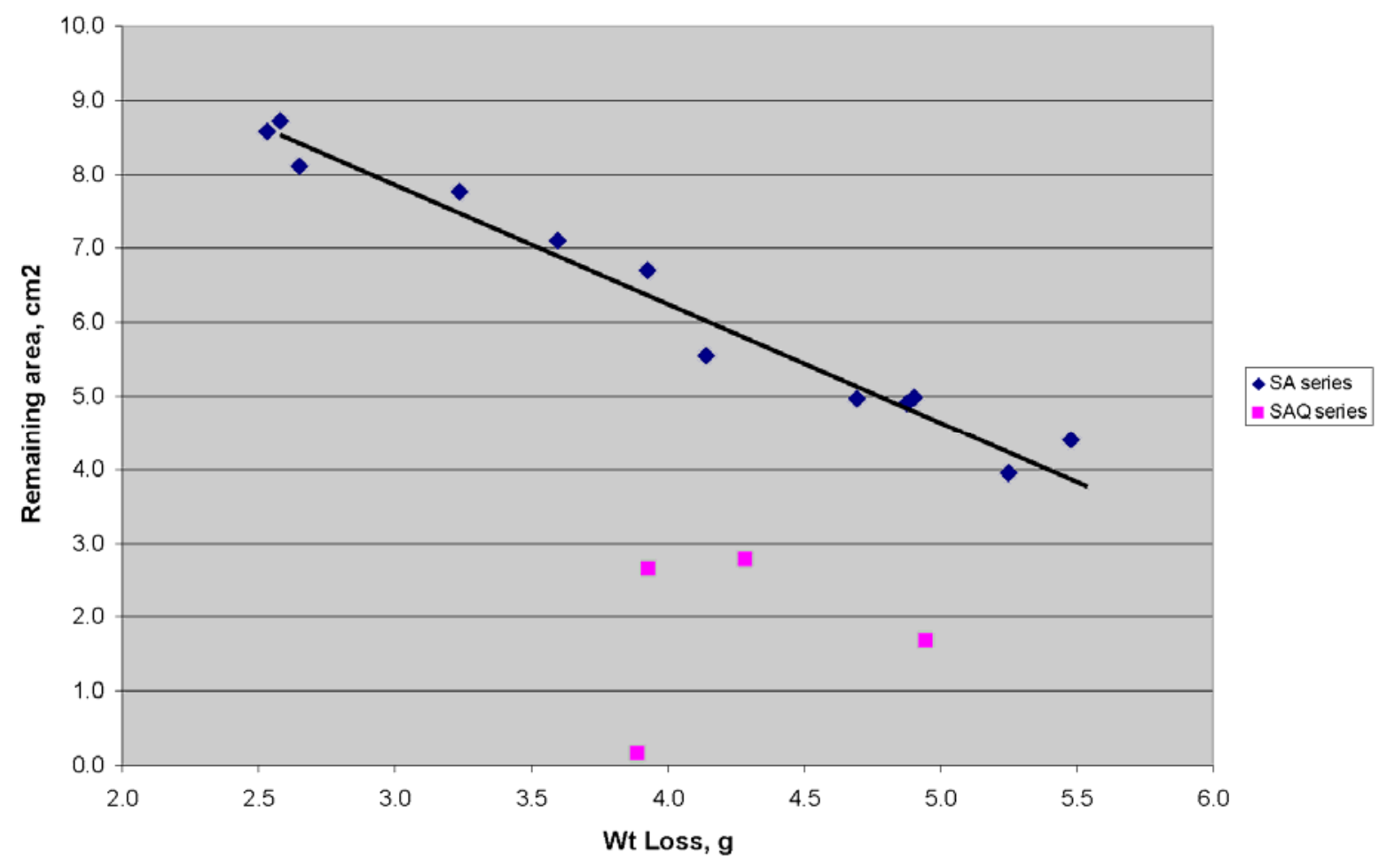

Figure 73. Correlation between mass loss and coating area remaining after impeller wear testing. 


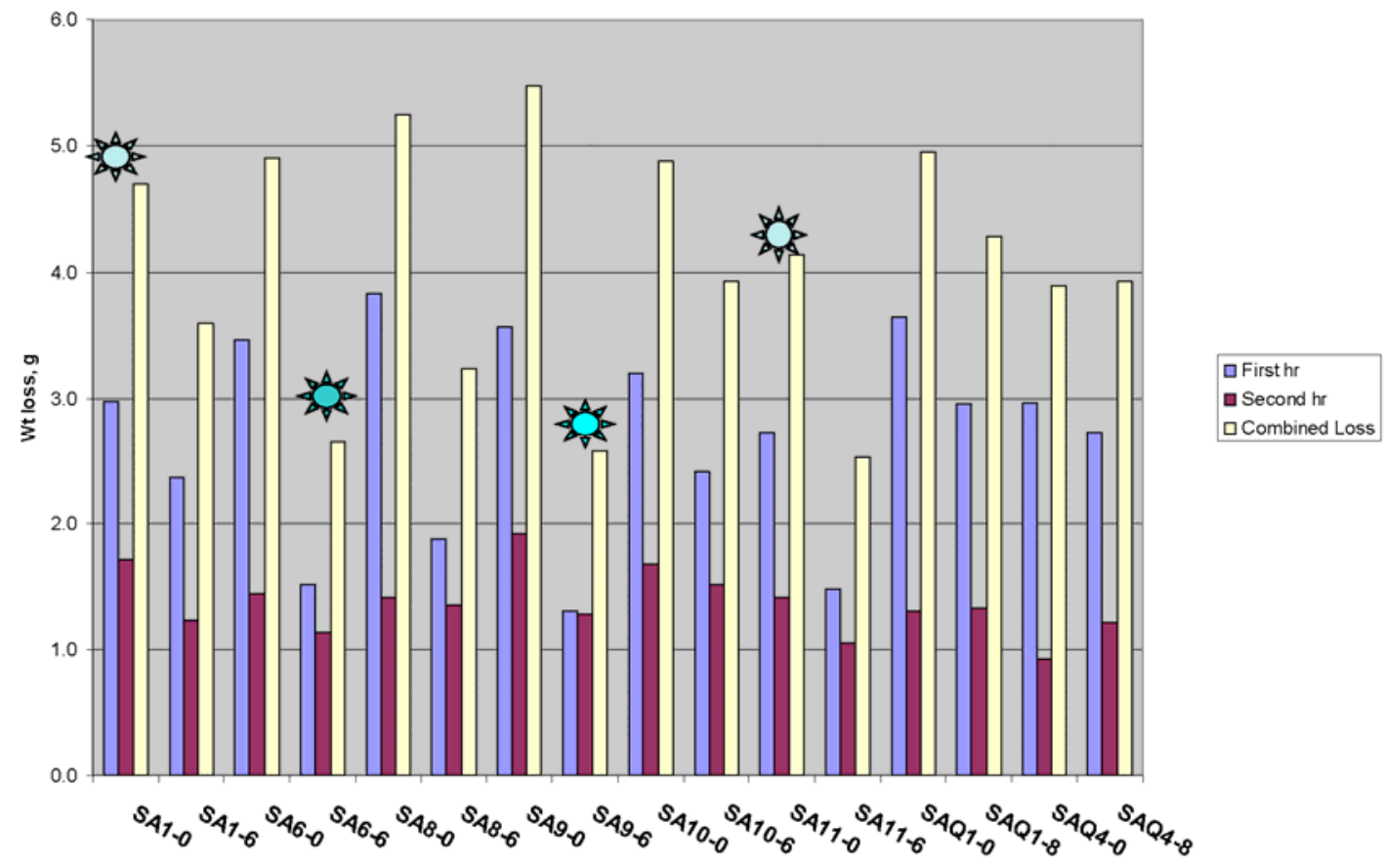

Figure 74. Mass loss for the first and second hours of impeller wear testing. The samples with the lowest wear rate for the as-sprayed (light green) and arc lamp fused (dark green) are indicated with markers.

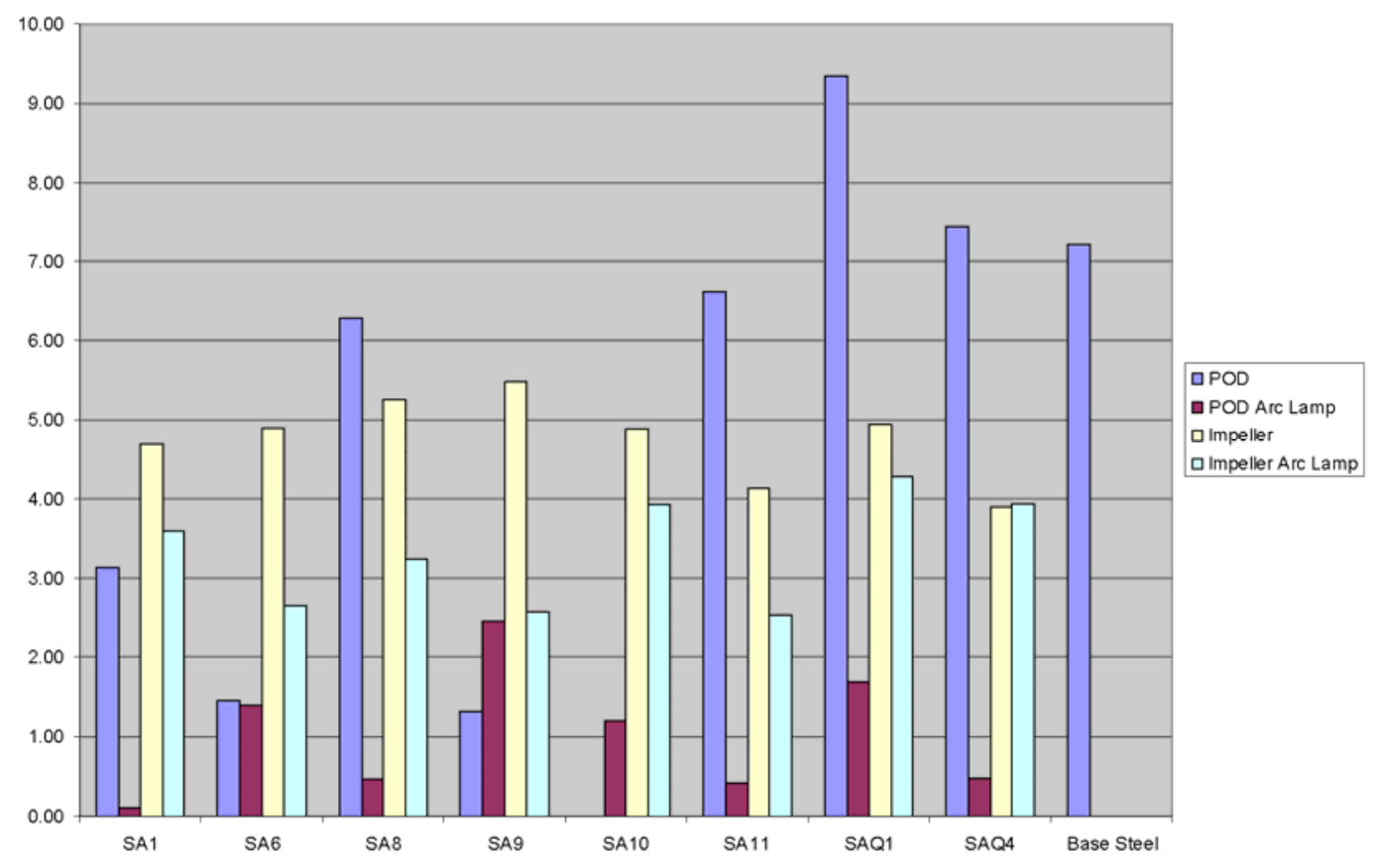

Figure 75. Overview of POD and impeller wear test results. 


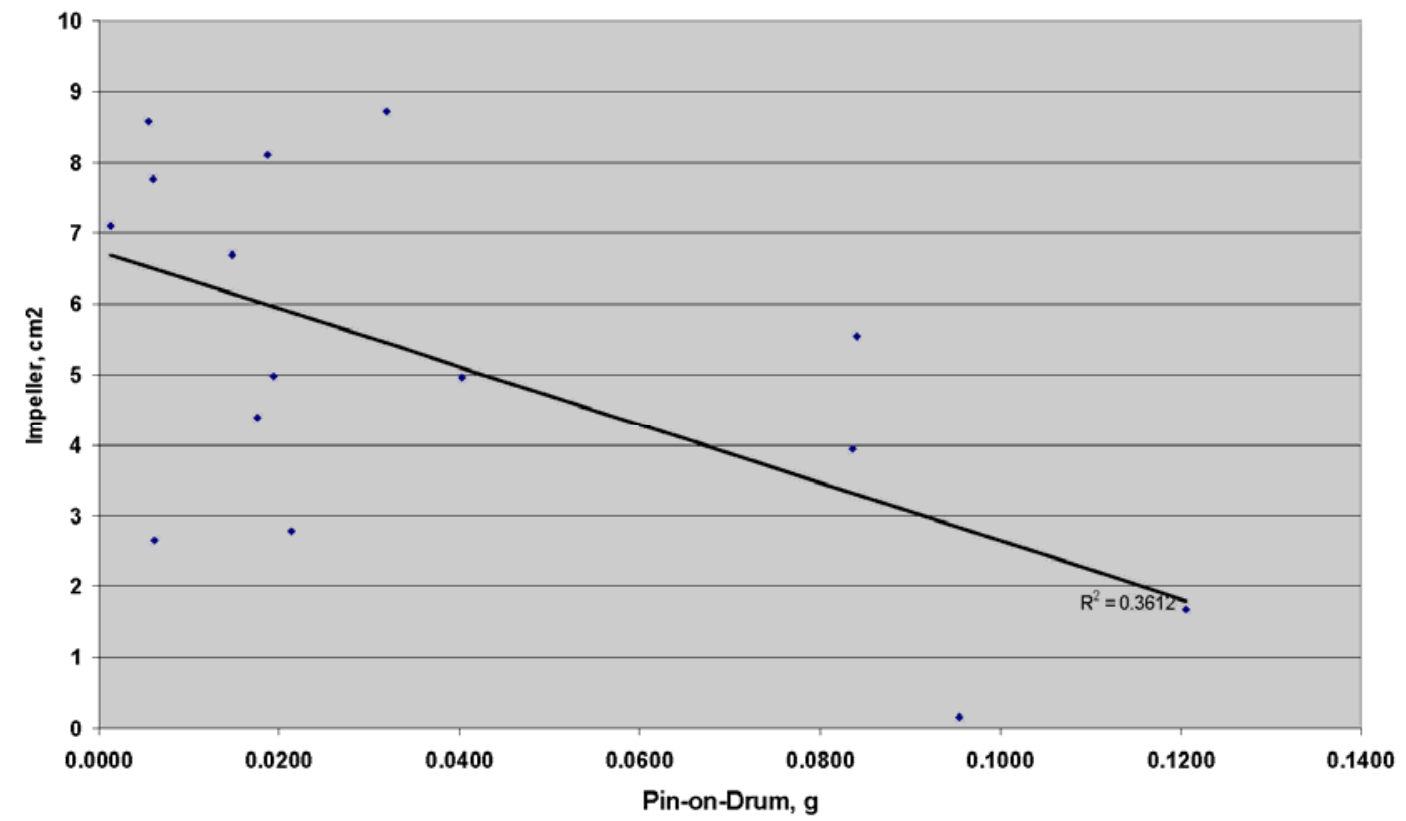

Figure 76. Relationship between POD and impeller wear test results.

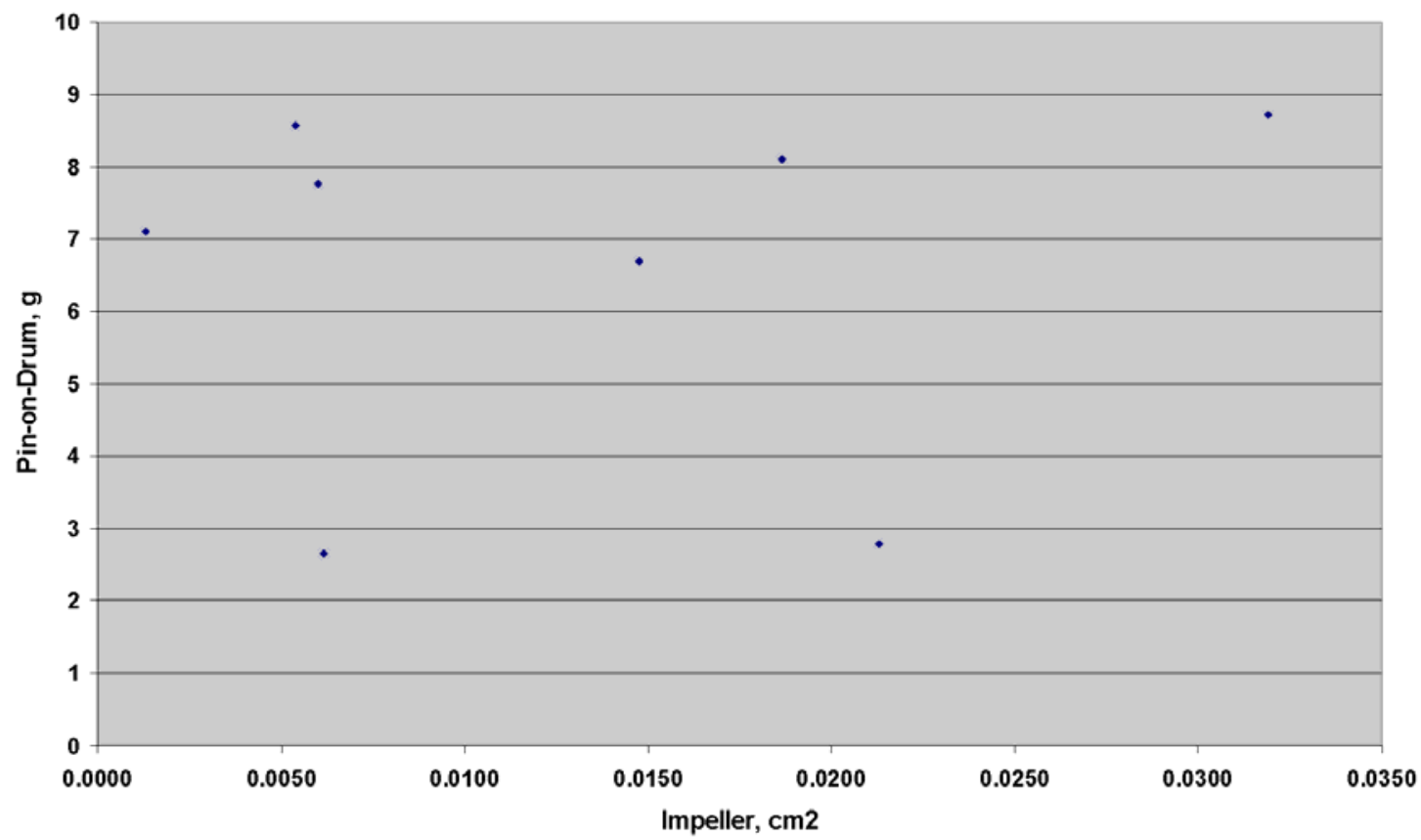

Figure 77. Relationship between POD and impeller wear test results for arc lamp processed alloys. 


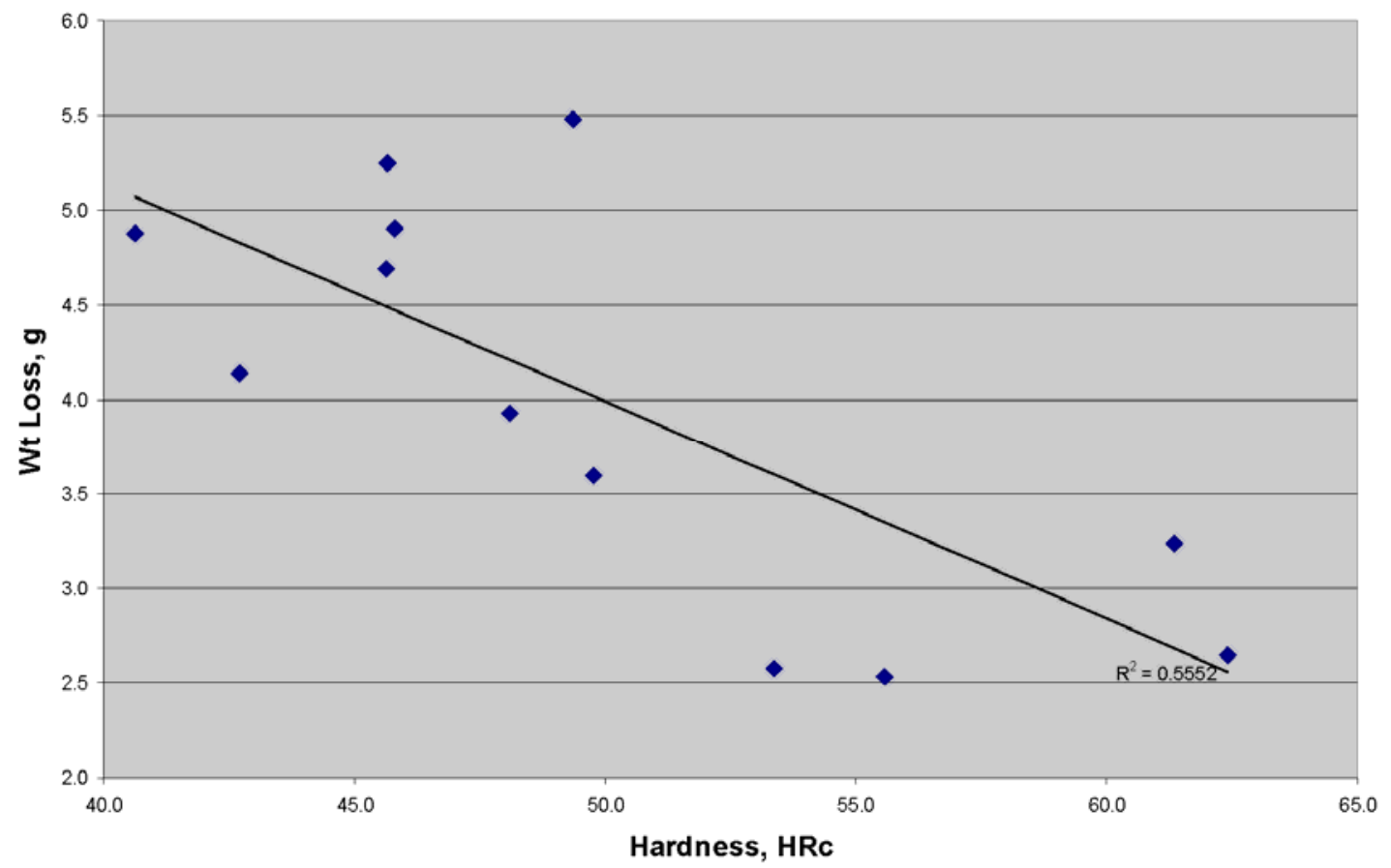

Figure 78. Mass loss in the impeller wear test as function of hardness. 


\subsubsection{Corrosion testing}

Examination of the corrosion behavior of as-sprayed and arc lamp processed SICWC alloys 6, 8, and 9 has been performed. Arc lamp processing parameters are shown in Table 8. The results are shown in Figure 79. The samples were salt fog corrosion tested (ASTM B117) for a total of 10 days. The corrosion results for the plasma-sprayed coatings and those modified by the arclamp treatment showed that the latter had a dramatic increase in corrosion resistance. Even after 240 hours in the corrosion test, all of the arc lamp processed coatings showed only small amounts of corrosion (in the form of red-rust formed on the surface of the coatings). By contrast, the unmodified coatings showed appreciable corrosion after 72 hours in the salt-spray environment. This may be due to a homogenization of the chemistry or due to the elimination of cracks or through-coating connected porosity present in the as-sprayed coatings.

Table 8. Arc lamp processing parameters for various processing designations.

\begin{tabular}{|l|l|l|}
\hline $\begin{array}{l}\text { Processing } \\
\text { designation }\end{array}$ & $\begin{array}{l}\text { Preheat parameters } \\
\text { [current/time] }\end{array}$ & $\begin{array}{l}\text { Pulse parameters } \\
\text { [current/time] }\end{array}$ \\
\hline-0 & $\mathrm{~N} / \mathrm{A}$ & $\mathrm{N} / \mathrm{A}$ \\
\hline-4 & $150 \mathrm{~A} / 120 \mathrm{~s}$ & $800 \mathrm{~A} / 2 \mathrm{~s}$ \\
\hline-5 & $150 \mathrm{~A} / 120 \mathrm{~s}$ & $1000 \mathrm{~A} / 1 \mathrm{~s}$ \\
\hline-6 & $150 \mathrm{~A} / 120 \mathrm{~s}$ & $1000 \mathrm{~A} / 2 \mathrm{~s}$ \\
\hline
\end{tabular}




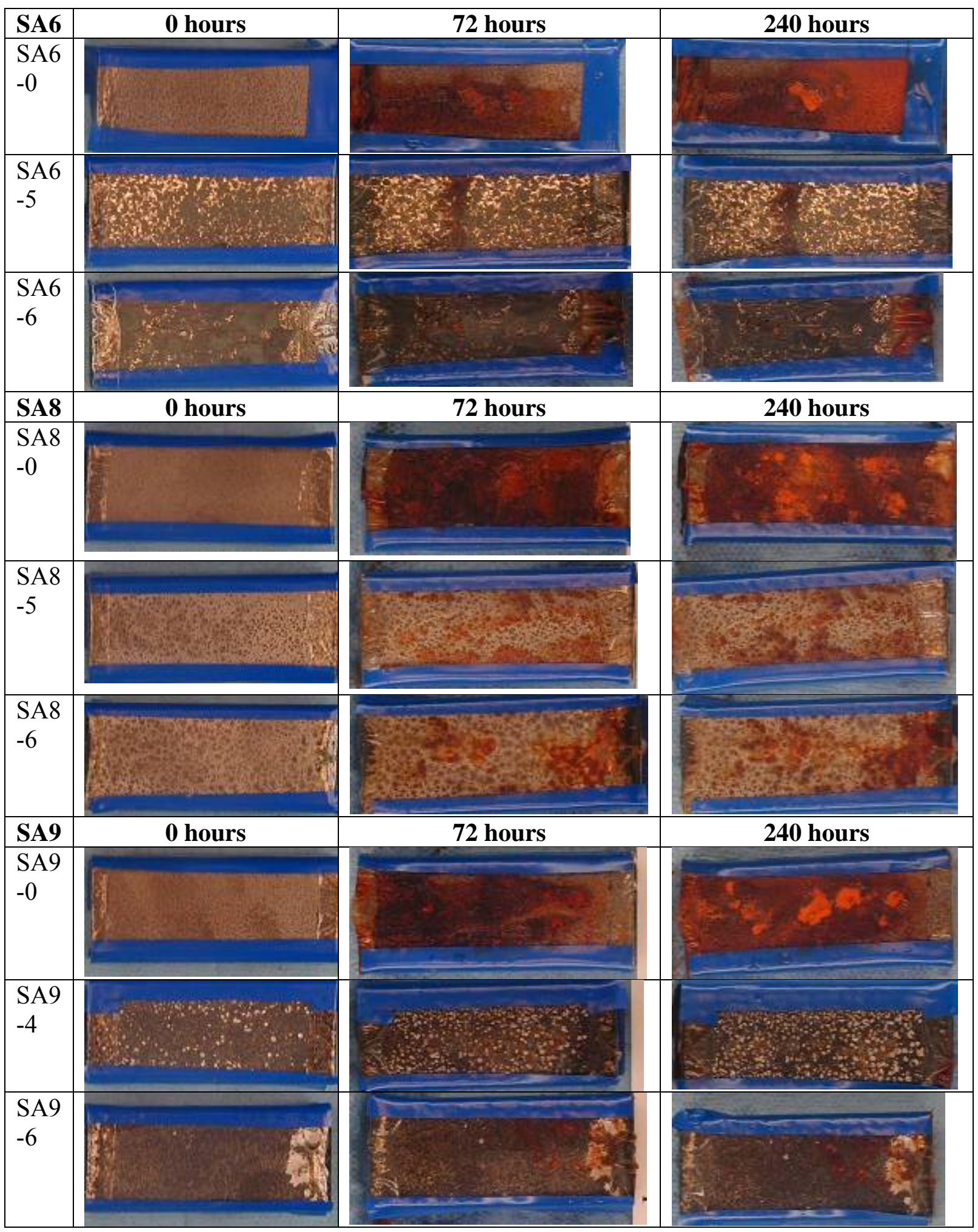

Figure 79. Photographs of corrosion tested samples of SICWC alloys SA6, SA8, and SA9. 


\subsubsection{Mechanical testing}

One of the factors limiting the applicability of coatings on GET parts is the adherence of the coating to the substrate. The coating must not be easily removed by spallation during impact loading. This means that the interfacial strength between the coating and substrate must be large. Measurement of the interfacial strength of well-bonded coatings has been a continual challenge. The interfacial strength of the coating must be measured through mechanical testing; however, the test specimen geometry and the analysis of the results are not always straightforward. Initial work on a new mechanical test specimen design was performed by Dr. Darrel Socie at UI. In 2006, this work was continued by Dr. David Van Aken at the Missouri University of Science and Technology (formerly University of Missouri - Rolla, UMR).

UMR designed a new test sample geometry to test the adhesive properties of the coatings in this study. The sample can be tested under either static or dynamic loading conditions. Crack growth can be measured using an optical system. The first coating to be tested using this new technique was Deloro 60 applied using the PTA process. This material was one of the commercially available baselines in the wear plate field test of the SICWC alloys. This alloy was chosen because it showed the least amount of cracking among the alloys in field test. Four bend specimens were EDM cut from the water-jet cut blocks. Two test coupons were EDM cut normal and two were cut parallel to the PTA weld path. Coating thickness was reduced to approximately 0.06 " in thickness and EDM wire cutting was used to produce a starting crack at the coating/substrate interface. The Deloro 60 coatings had a dendritic microstructure with minimal porosity and a very sharp microstructural interface between the coating and the substrate. A photograph of the Deloro 60 test coupon and the test rig are shown in Figure 80.

The theory behind the crack growth analysis used in this work is detailed as follows:

Fatigue Crack Growth Studies Advanced structures\bucket weight calculations

$$
\frac{d a}{d N}=C(\Delta K)^{m}
$$

where $\frac{d a}{d N}$ is the crack growth per load cycle and $\Delta K$ is the stress intensity range usually given as $K_{\max }-K_{\min }$. $\quad \mathrm{C}$ and $\mathrm{m}$ are empirical constants related to microstructure and the conditions of the test, e.g. test frequency, mean stress, environment and temperature. The stress intensity is usually written as

$$
K=Y \sigma \sqrt{\pi a}
$$

where $Y$ is a calibration constant that is dependent upon test configuration, crack length, $a$, and the applied stress, $\sigma$. 
The first step in the analysis of the interfacial strength of the coating was the measurement of the monotonic tensile properties of the Deloro 60 coating. A dog-bone shaped tensile specimen was machined from the PTA Deloro 60 coating (Figure 81). The gage thickness was $1.41 \mathrm{~mm}$ and the average gage area was $5.063 \mathrm{~mm}^{2}$. Tensile loading was conducted in displacement control and the strain was measured using a laser extensometer. The stress-strain response is shown in Figure 82 and the tensile properties of the coating are summarized in Table 9.

Table 9. Monotonic properties of PTA Deloro 60 coating

\begin{tabular}{|l|c|c|}
\hline Property & & \\
\hline Young's Modulus & $120 \mathrm{GPa}$ & $17 \times 10^{6} \mathrm{psi}$ \\
\hline $0.2 \%$ Yield Strength & $690 \mathrm{MPa}$ & $100 \mathrm{ksi}$ \\
\hline Ultimate Tensile Strength & $860 \mathrm{MPa}$ & $125 \mathrm{ksi}$ \\
\hline Elongation to Failure & $1.90 \%$ & $1.90 \%$ \\
\hline
\end{tabular}

A key component of the specimen geometry development was the use of finite element analysis (FEA). The modeling results presented here assume linear elastic conditions. The ABAQUS model of the test specimen with a $10.2 \mathrm{~mm}(0.4 \mathrm{inch})$ symmetric crack is shown in Figure 83. Cracks were measured from the point of loading, i.e. middle of specimen. The objectives of these initial models were to determine an appropriate loading where linear elasticity was appropriate, calculate the stress intensity range, and to determine the load required to induce fatigue crack growth (i.e. determine a load range where $\Delta K>10 M P a \sqrt{m}$ ).

The finite element model, which uses a hexahedral element mesh at the crack tip, predicts that the coating will yield at an applied load of 2,580 N (580 lbf). Material properties used for the finite element model are given in Table 10. Poisson's ratio for the coating was calculated by assuming isotropic elasticity and values of shear modulus and Young's modulus that were measured by an ultrasonic technique. Stress intensity calculations were conducted for a load of $2,200 \mathrm{~N}$ ( $500 \mathrm{lbf}$ ), a load ratio of $\mathrm{R}=0.1$, and for seven different crack lengths ranging between $8.2 \mathrm{~mm}(0.32$ inches) and $18.7 \mathrm{~mm}$ (0.73 inches). Stress intensity factors for each crack length were calculated using the J-integral technique and the stress intensity range increased from 13.2 $\mathrm{MPa} \mathrm{m}^{1 / 2}$ to $31.8 \mathrm{MPa} \mathrm{m}^{1 / 2}$ with increasing crack length as shown in Figure 84.

Table 10. Elastic properties used in finite element model

\begin{tabular}{|l|c|c|}
\hline Material & Young's modulus & Poison's ratio \\
\hline Coating & $120 \mathrm{GPa}$ & 0.31 \\
\hline & $17 \times 10^{6} \mathrm{psi}$ & \\
\hline Steel substrate & $207 \mathrm{GPa}$ & 0.33 \\
\hline & $30 \times 10^{6} \mathrm{psi}$ & \\
\hline
\end{tabular}

Initial mechanical test results are shown in Figure 85. Sample 1 was loaded at $2200 \mathrm{~N}$ with $\mathrm{R}=0.1$ for 3000 cycles. Sample 2 contained a pre-existing through-coating crack that only became apparent after the sample was machined. This sample was loaded in a cantilever 
arrangement at $700 \mathrm{~N}$ with $\mathrm{R}=0.1$ for 300 cycles for testing purposes. Both samples showed through-coating cracks rather than interfacial cracks.

There are several reasons for the through-coating crack rather than the interfacial crack in these samples. The samples themselves did not have the notch machined at the interface. The notch was machined entirely inside the coating (Figure 86). This is due to the wavy interface that was produced as a result of the PTA process. It should be noted that if the crack started to propagate at the interface it should have followed the interface even if the interface was non-planar. Another factor that may contribute to the through-coating cracks is the dendritic microstructure of the coating (Figure 87). The dendrites are perpendicular to the interface due to the fact that heat is removed from the molten coating by the substrate. The interdendritic spaces have a lower mechanical strength than the dendrites themselves.

Further analysis of the FEA modeling can also give some insight into the failure mechanism for these samples. Figure 84 shows the stress intensity factor as a function of crack length. Theoretically, for a single crack propagation mode, this curve should not have any inflection points and be concave up. It is clear that this curve does have inflection points. These inflection points are the result of forcing the crack to follow the interface in the FEA model when the preferred crack path is through the coating. After the experiments were performed, the FEA model was analyzed to determine if the coating thickness could change the crack path. The results are shown in Figure 88 . For a $1.5 \mathrm{~mm}$ thick coating the stress intensity factor is highest through the coating. For a $4.5 \mathrm{~mm}$ thick coating, the stress intensity factor is highest along the interface. The stress intensity values are plotted in Figure 89. As another consistency check for the model, Figure 89 also shows that the stress intensity does not change as the mesh size changes.

The only alloy and process combination to be tested in this manner was Deloro 60 applied using the PTA process. This alloy was chosen because it showed the least amount of cracking among the alloys in field test. All of the other alloys used showed significant cracking. For a wear application such as the top mounted wear plate, a cracked coating is not detrimental as long as the coating is well-bonded to the substrate. Unfortunately, due to the cracking issues a comparison of alloys and processing methods could not be performed. 


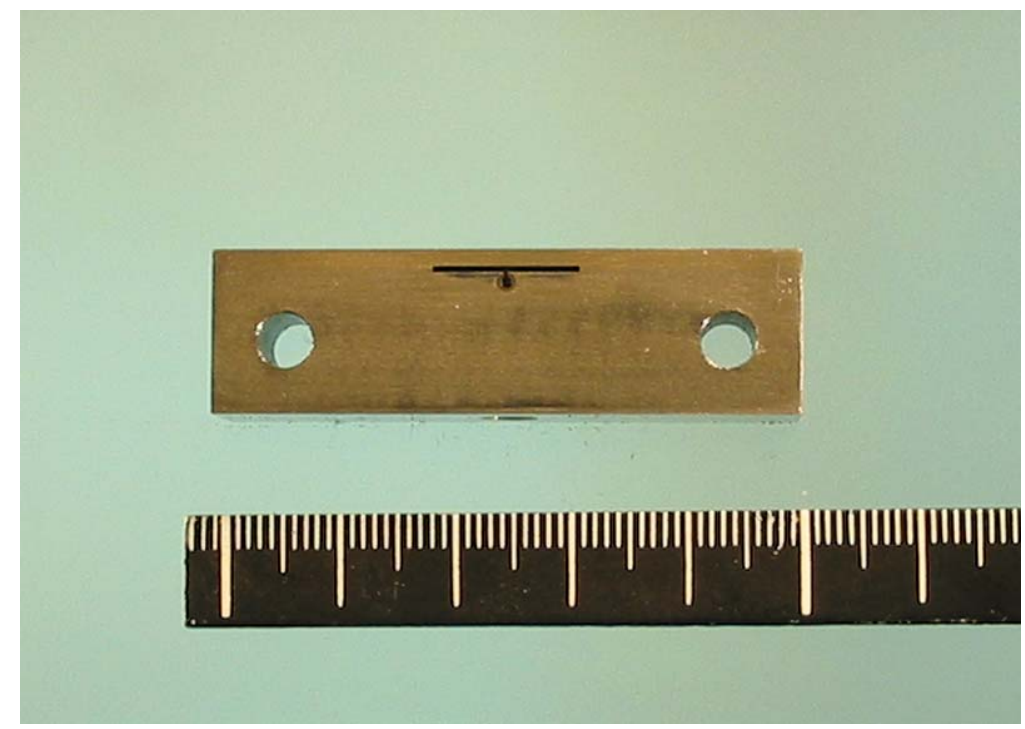

(a)

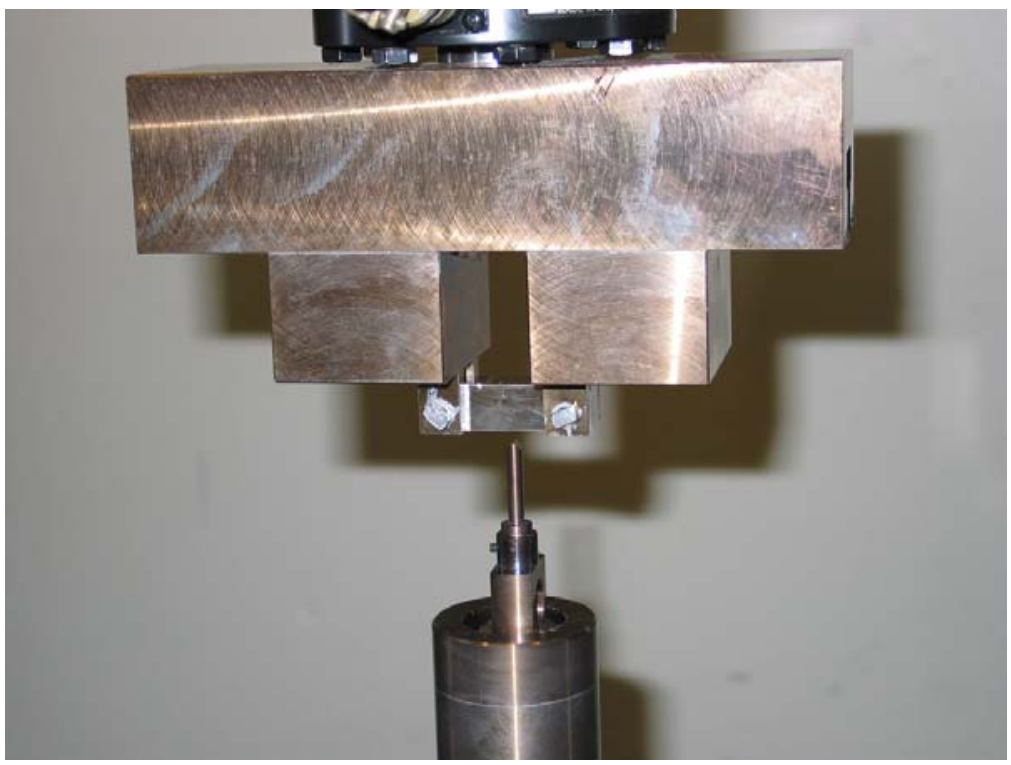

(b)

Figure 80. Photographs of (a) the Deloro test coupon and (b) the bend test fixture for PTA coating tests. 


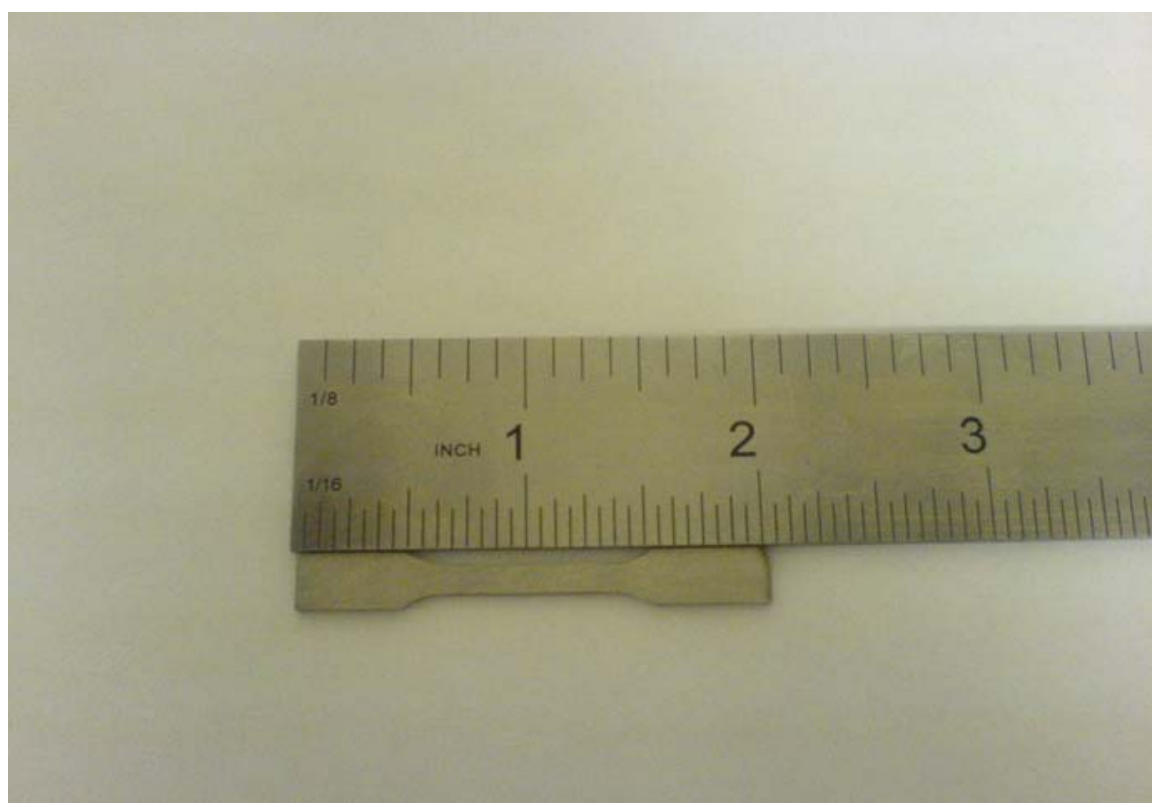

Figure 81. Photograph of dog-bone shaped tensile specimen used to measure monotonic tensile properties of PTA Deloro 60 coating.

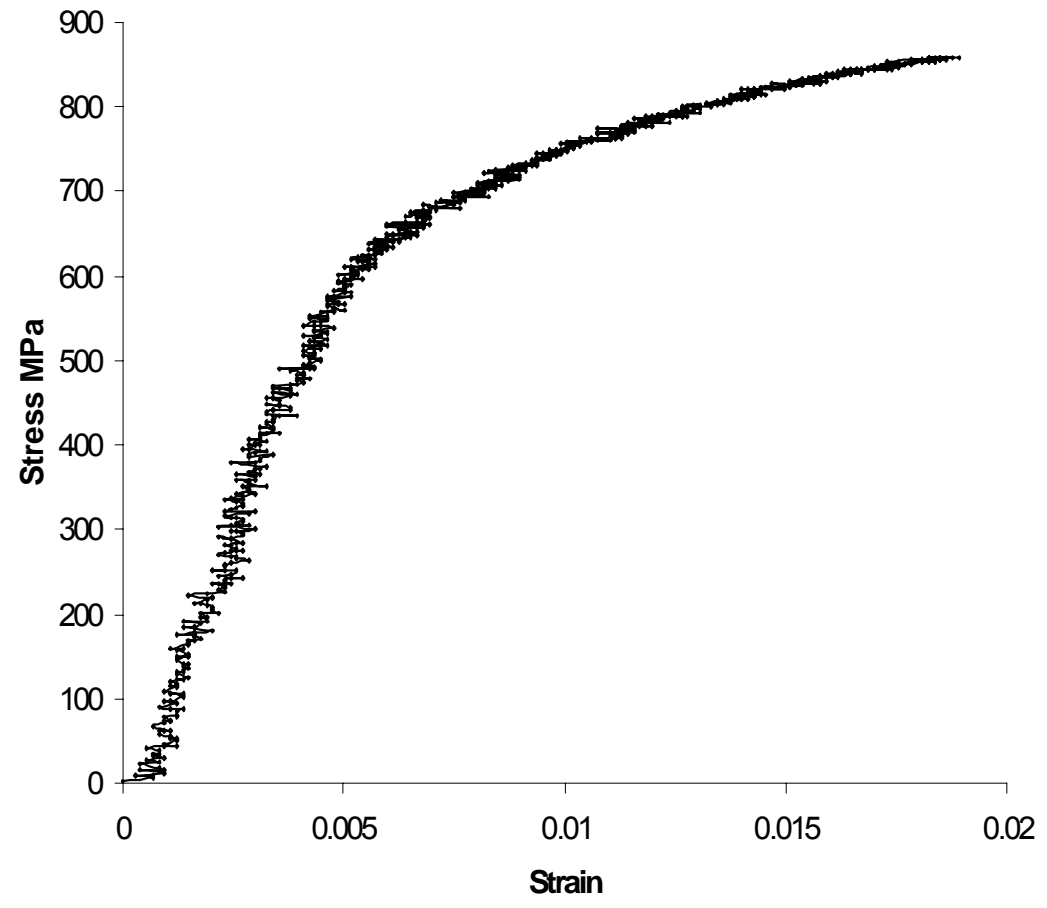

Figure 82. Measured stress and strain response of the Deloro tensile specimen. Strain was measured with an MTS laser extensometer. 


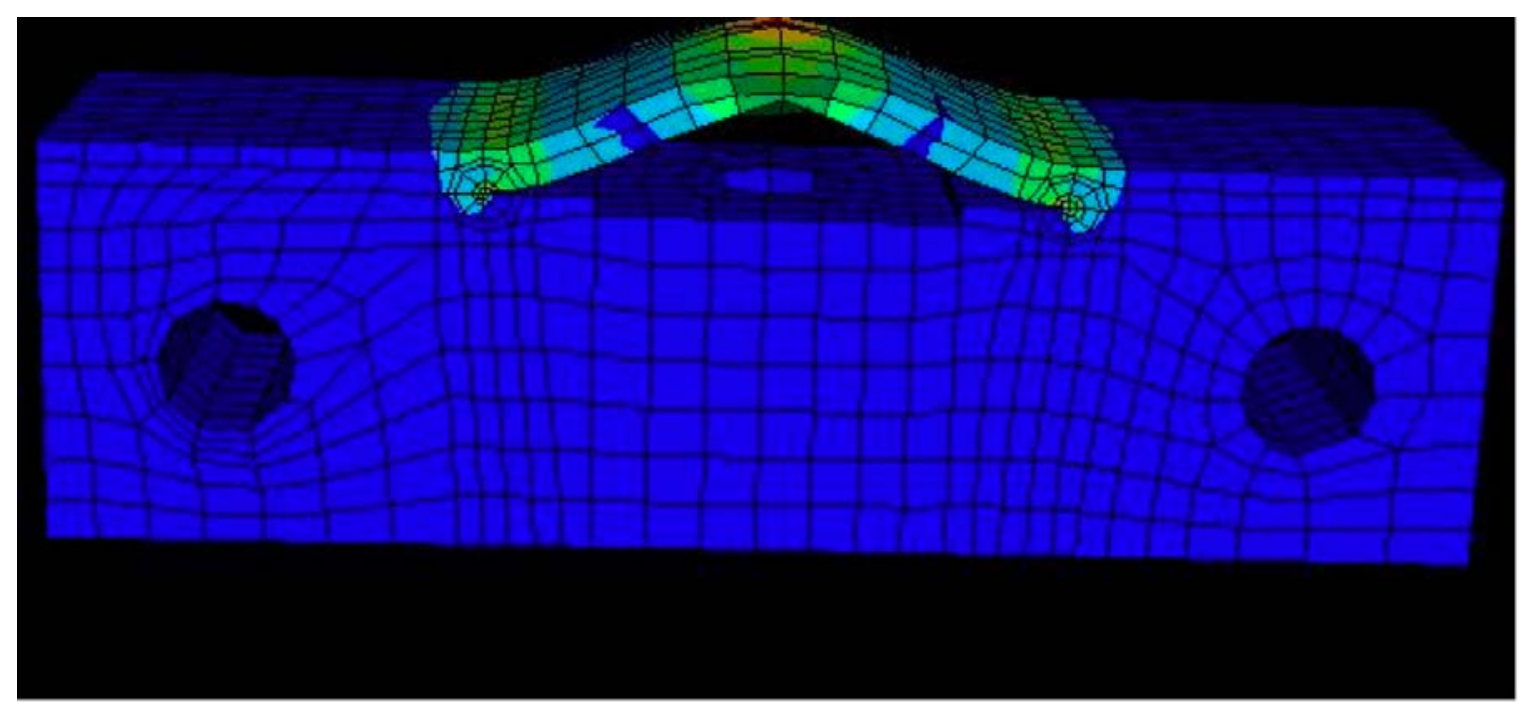

Figure 83. Finite element model of MS\&T test specimen geometry.

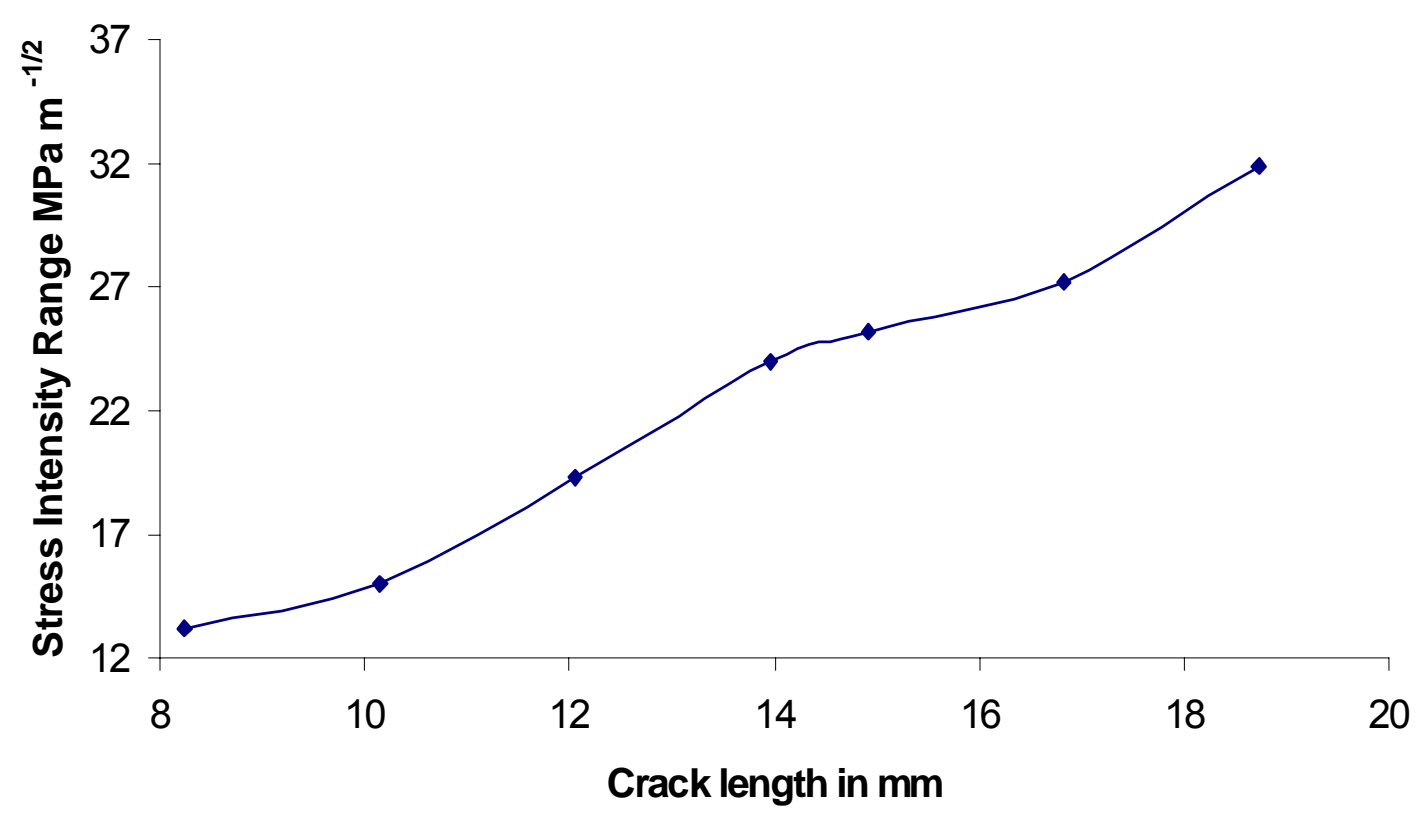

Figure 84. Calculated stress intensity range for a load of $2,200 \mathrm{~N}(500 \mathrm{lbf})$ and a load ratio of $\mathrm{R}=0.1$. 


\section{Sample 1}

\section{Sample 2}

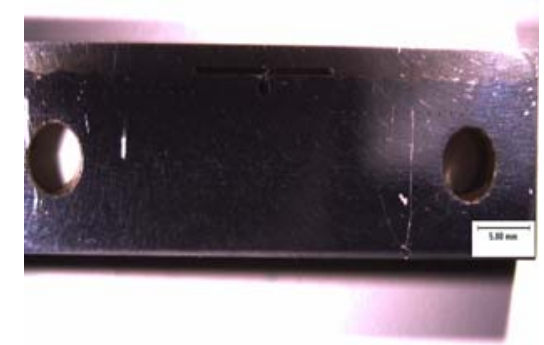

\section{Crack}

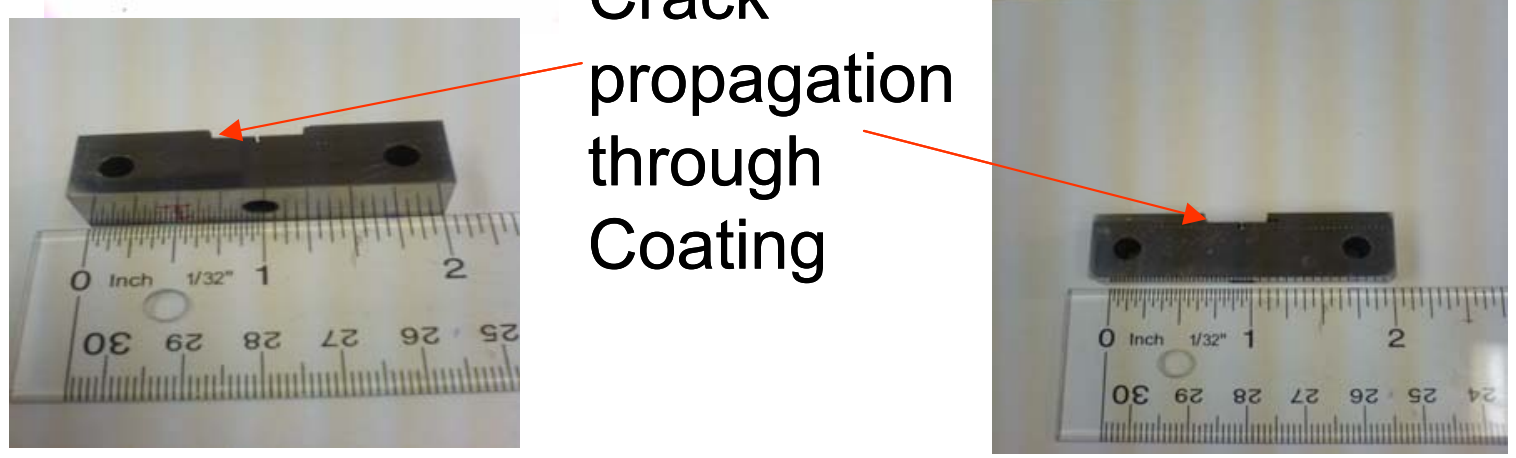

Figure 85. Initial mechanical test samples showing through-coating cracks.

- Notch is above the interface

- Wavy Interface

Fatigue crack nucleation would have occurred at interface if notch was below the interface

Principal PTA weld path is left to right

Figure 86. Mechanical test sample 1 showing the notch is entirely within the coating. 


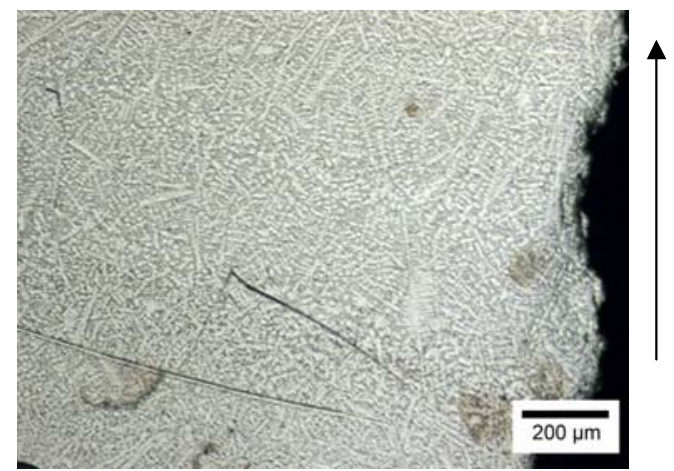

\section{Crack} Propagation Direction
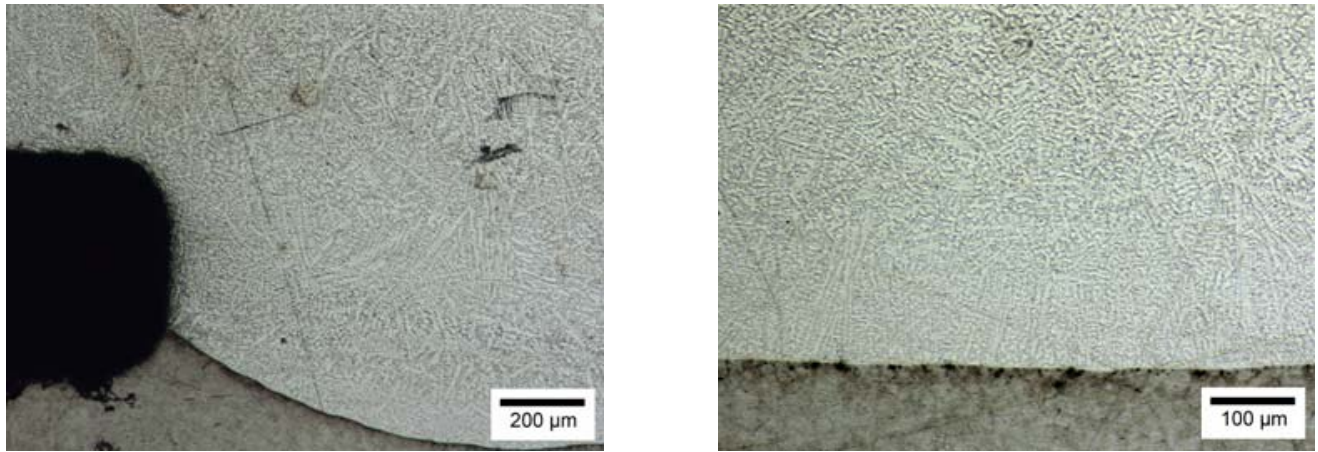

Figure 87. Coating microstructure showing dendrites oriented in the direction of crack propagation.
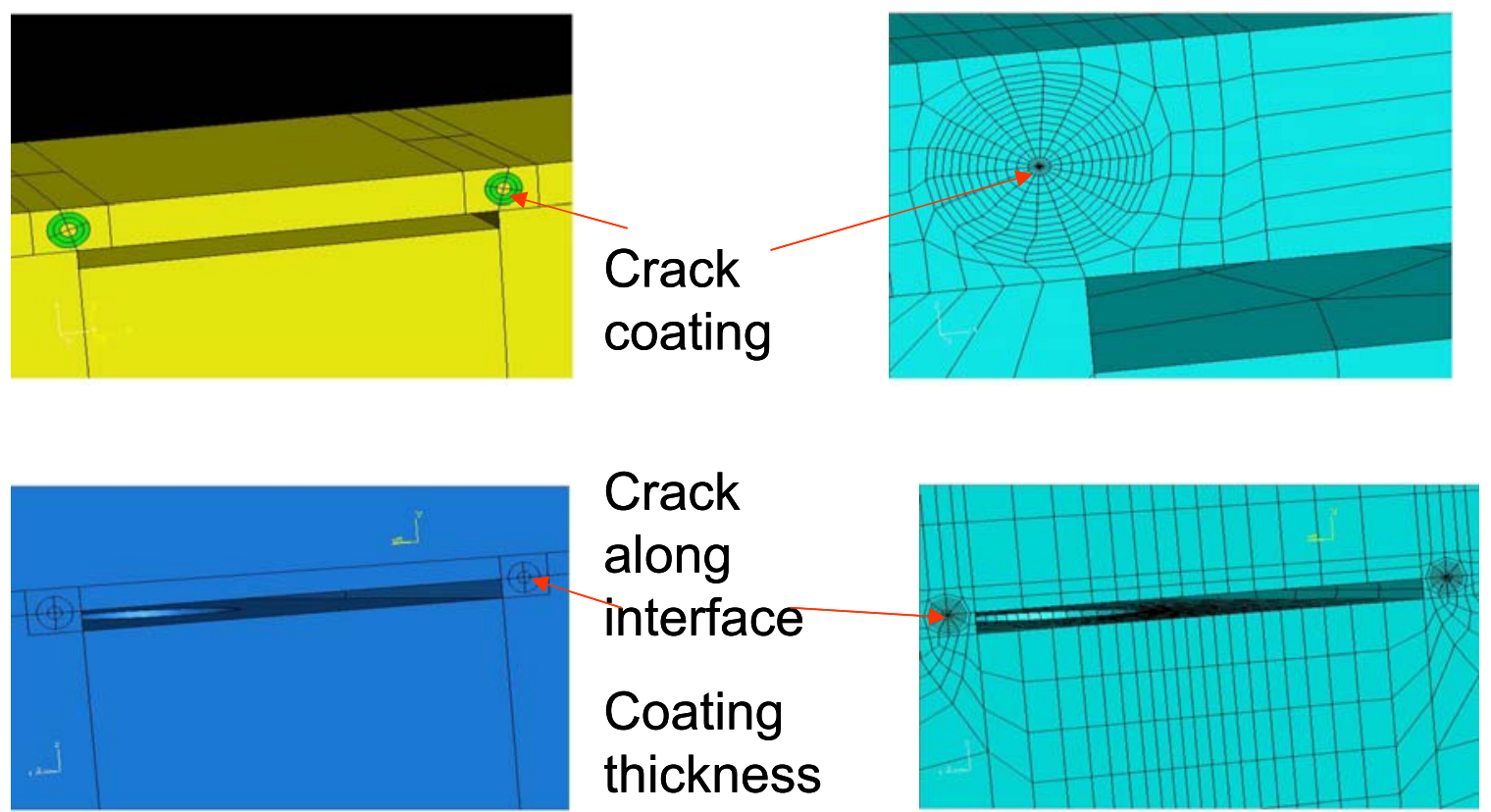
tripled

Figure 88. Stress intensity factor for thin ( $1.5 \mathrm{~mm}$, top images) and thick (4.5 $\mathrm{mm}$, bottom images) coatings. 


\section{Convergence of Contours for 7.1mmcrack}

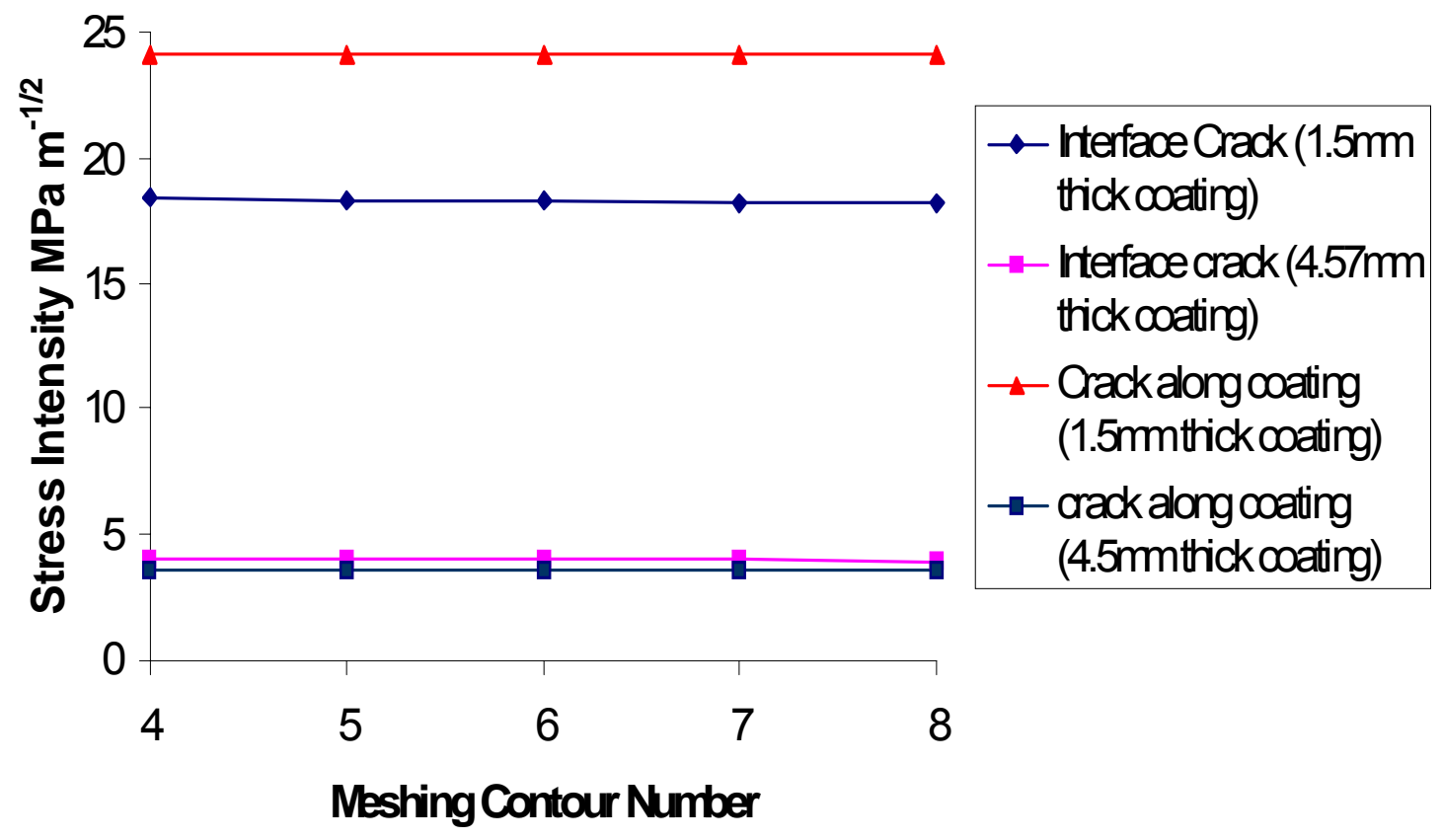

Figure 89. Effect of coating thickness on stress intensity factor along the interface and through the coating. 


\subsubsection{Thermophysical property measurement}

At the beginning of this project, Caterpillar provided ORNL with several different coating compositions (coatings were thermally sprayed onto steel substrates) for which we determined the thermophysical properties for the substrate (as a baseline) and each coating-substrate pair. One objective of this effort was to determine the thermophysical conductivity of the baseline/substrate steel and the coatings selected. An Anter Flashline 5000 laser flash system was used to determine the thermal diffusivity of the substrate and the coatings. A two layer method was used to calculate the thermal diffusivity of the coatings. The thermophysical properties results are summarized below in Figure 90. The thermal conductivities were calculated from the thermal diffusivity, specific heat, and density of the coatings. Using the specific heat $(\mathrm{Cp})$, density $(\rho)$ and thermal diffusivity $(\alpha)$, thermal conductivity was calculated using the following relationship:

$$
\mathrm{k}=\alpha \rho \mathrm{Cp} \text {. }
$$

Figure 90(c) shows the thermal conductivity vs. temperature plots of the 5 samples and the substrate (labeled BASE) material. The samples names, alloys, and processing parameters are shown in

Table 11. Samples used for thermophysical property determination.

\begin{tabular}{|l|l|l|}
\hline Sample ID & Alloy & Arc lamp current $[\mathrm{A}] /$ time $[\mathrm{s}]$ \\
\hline $9 \mathrm{~A}-1$ & SA9 & $600 \mathrm{~A} / 1 \mathrm{~s}$ \\
\hline $9 \mathrm{~A}-2$ & SA9 & $600 \mathrm{~A} / 2 \mathrm{~s}$ \\
\hline $6 \mathrm{~A}-1$ & SA6 & $600 \mathrm{~A} / 1 \mathrm{~s}$ \\
\hline $6 \mathrm{~A}-2$ & SA6 & $600 \mathrm{~A} / 2 \mathrm{~s}$ \\
\hline $11 \mathrm{~B}$ & SA11 & No $\operatorname{arc}$ lamp processing \\
\hline
\end{tabular}

The large increase for the substrate is attributed to the large $\mathrm{Cp}$ value available from the existing database. In reality the "hump" actually would be a straight line connecting the two nearest neighboring points. As can be seen in Figure 90(c), the thermal diffusivity of the substrate material drops to $\sim 50 \%$ approximately at the eutectic transition temperature $(\sim 740 \mathrm{C})$, followed by an increase as it passes through the Curie transition.

In an effort to gain a more fundamental understanding of the heat flow/transfer across the coating -substrate interface, and eliminate uncertainties, Caterpillar attempted to produce and provide free standing coatings. This latter effort was intended to provide independent thermophysical property data for the substrate and the coatings, so that the thermophysical properties of the coating and substrate could be decoupled to more accurately model the heat flow across the coating-substrate interface providing more accurate thermal processing modeling simulations yielding more accurate predictions for the HDI processing parameters. These capabilities in conjunction with determining the presence of any convective stirring would significantly extend 
the technology base and facilitate the transitioning of the PAL processing to industrial practice. Therefore, Caterpillar made several attempts at thermally spraying free-standing coating samples and provided several samples with the coating compositions of interest. Several attempts were made using both EDM (to cut out the rough dimensions) and special handling grinding equipment to carefully grind these analytic sample blanks to, or at least close to, the final dimensions required. Unfortunately, all of the samples provided were so badly distorted (dished like potato chips) during the arc lamp process that when these samples were finally flat and parallel enough to be suitable for obtaining the analytic data from them, these samples were much too thin to obtain accurate analytic measurements. An example of a sample with a nonuniform thickness profile is shown in Figure 91. Only a few of these samples proved useful for "coating only" analytic properties to be determined from them, and the specific heats for two of these coating samples are shown in Figure 92. The two alloys are SA1 (8286 in the figure) and SA2 (8292 in the figure). Two heating and cooling cycles are shown for each alloy, denoted by HT for the heating cycles and CL for the cooling cycles.

Prior to determining analytical data on an experimental alloy composition, it is common practice to verify these alloy melting temperatures to facilitate the experiments on and the use of the actual analytic equipment. The platinum sample holder/tray was selected based on the melting temperatures anticipated for these coatings as well as the purported coating chemistries. In fact, Caterpillar provided an estimate of the melting temperatures of these coating compositions as predicted by ThermoCalc. While the coatings were being tested and evaluated at ORNL, one of these coatings suddenly reacted with the Pt tray and melted onto the DSC heat sensor below damaging it, and making this analytic equipment unavailable for further testing.

It has been postulated that this unanticipated melting event could have resulted from the introduction of Si into the coatings by one of two plausible events. First, a day earlier (unknown to ORNL), during some analytic SEM material evaluations on their coatings, Caterpillar inadvertently had discovered that silicon (Si) was present. Knowing that silicon was not part of their intended coating chemistry, they deduced that it must be present because it was a constituent in the binder that was used to thermal spray these coatings. Being unaware that Si may be able to be present in these coatings, the Pt pan was used to hold the free-standing coatings. Consequently, if $\mathrm{Si}$ were present, it could have chemically reacted with the Pt pan resulting in the formation of the low melting eutectic that is know to form when Pt combines with $\mathrm{Si}$. An alternate scenario is that the equipment operator had used silicon based grit papers to smooth the surface of these coatings just prior to his thermophysical data collection. It therefore is also possible that some of this $\mathrm{Si}$ could have become embedded into the porous coating resulting in a low temperature eutectic during heating in the Pt pan. However, to conserve funding, we did not determine the definitive source of the $\mathrm{Si}$, but we postulate that it came from the grinding papers, since the Si present in the water-based binder is less than $1 \%$. However, regardless of what caused the Si melting reaction observed to occur, the unexpected low melting phase that formed dripped onto the sapphire crystal in the thermophysical testing instrument, rendering it out-of-service. Consequently, the heat capacity data were determined for only two (2) free standing coatings. The remainder of these free-standing coating samples could not be measured due to the equipment damage, and the lack of budget available to repair this equipment within the timeframe of this project. 
a)

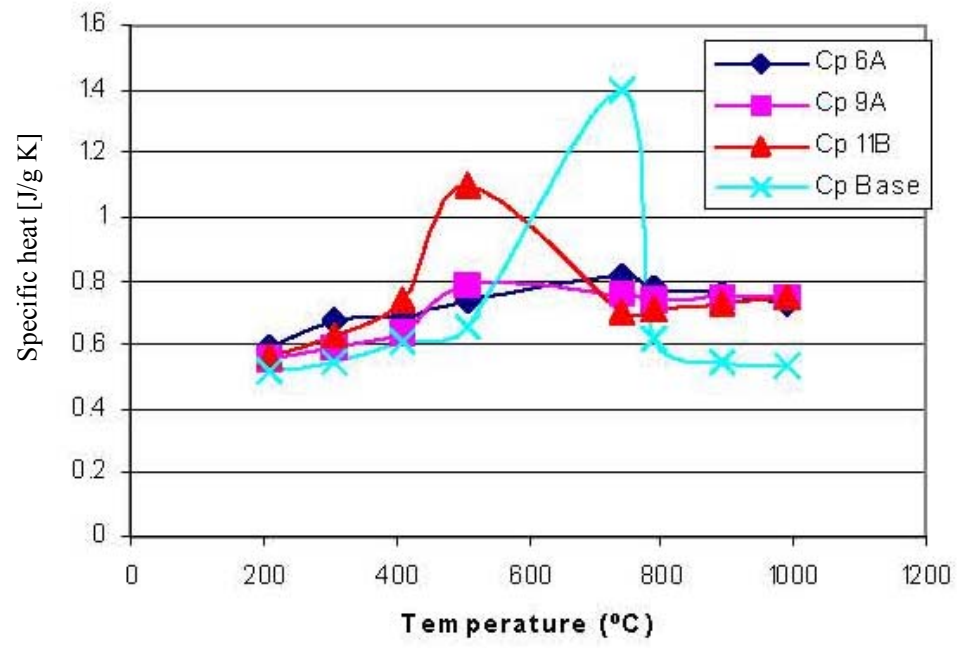

b)

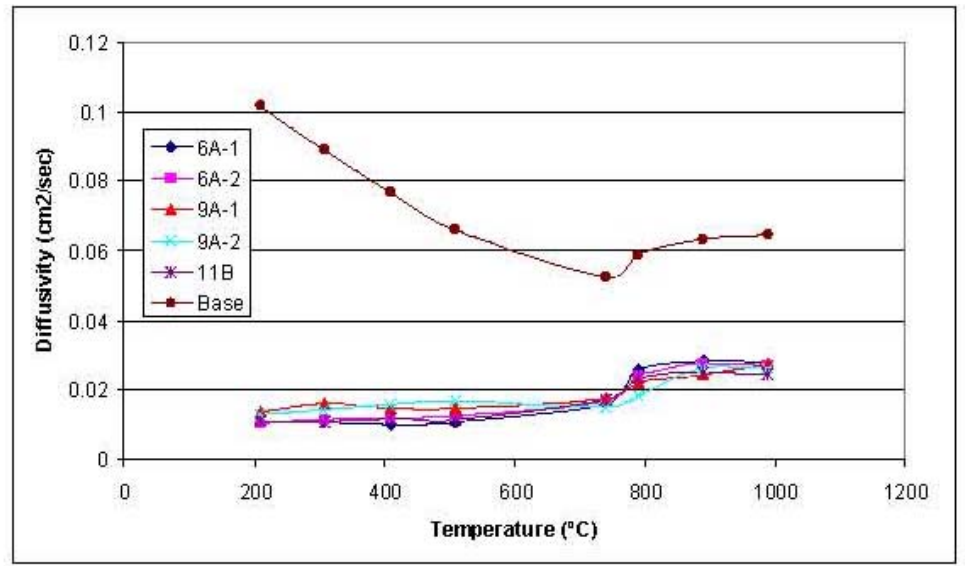

c)

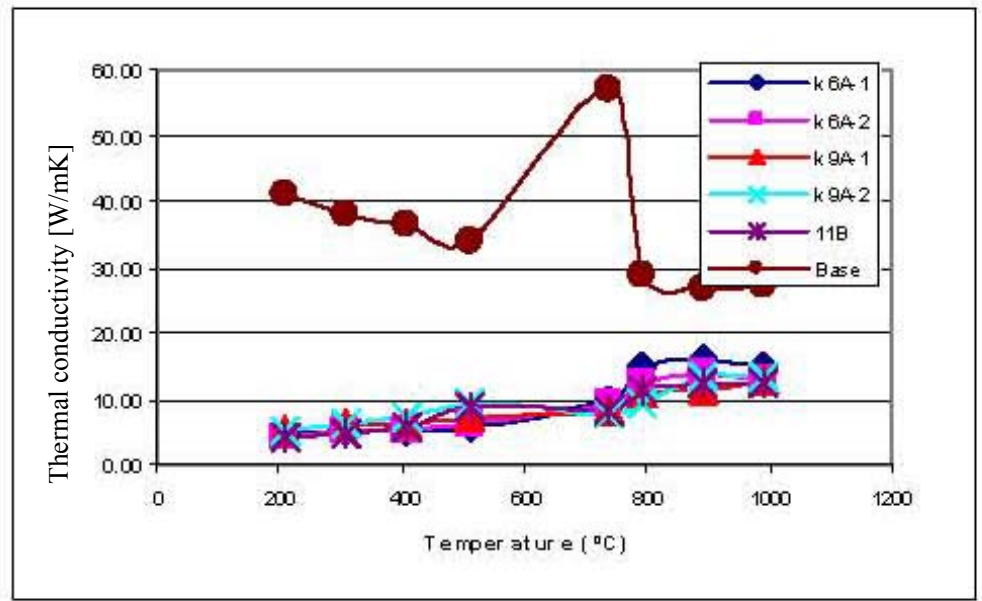

Figure 90. Thermophysical properties determined for the substrate (labeled "BASE" in this figure), and for the composite coatings as thermally sprayed onto the substrate - a) Specific heat, (b) thermal diffusivity, and c.) thermal conductivity. 


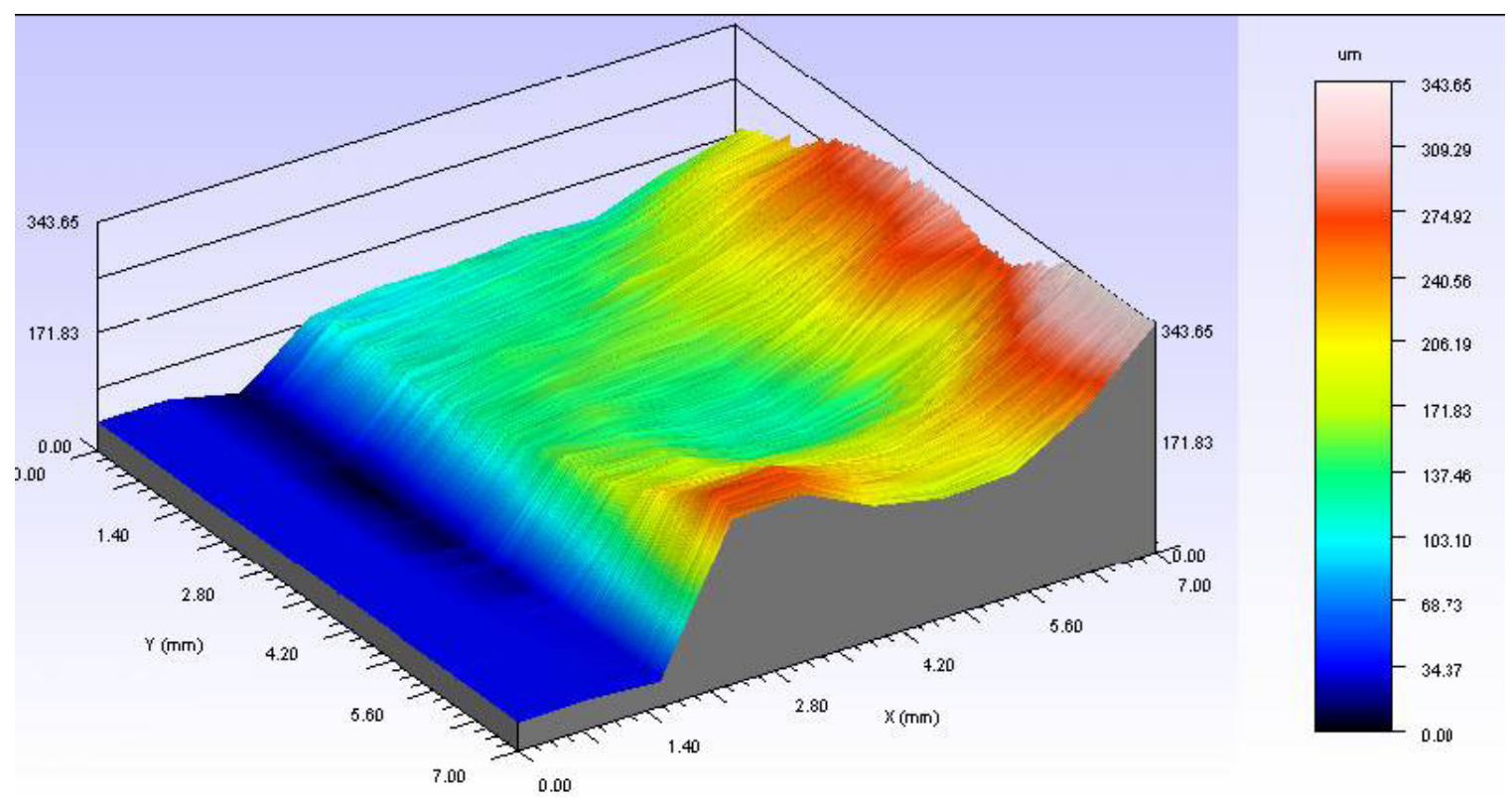

Figure 91. Example of 3D laser profilometry scan determined for splat samples demonstrating non-uniform thicknesses.

COATING SAMPLES

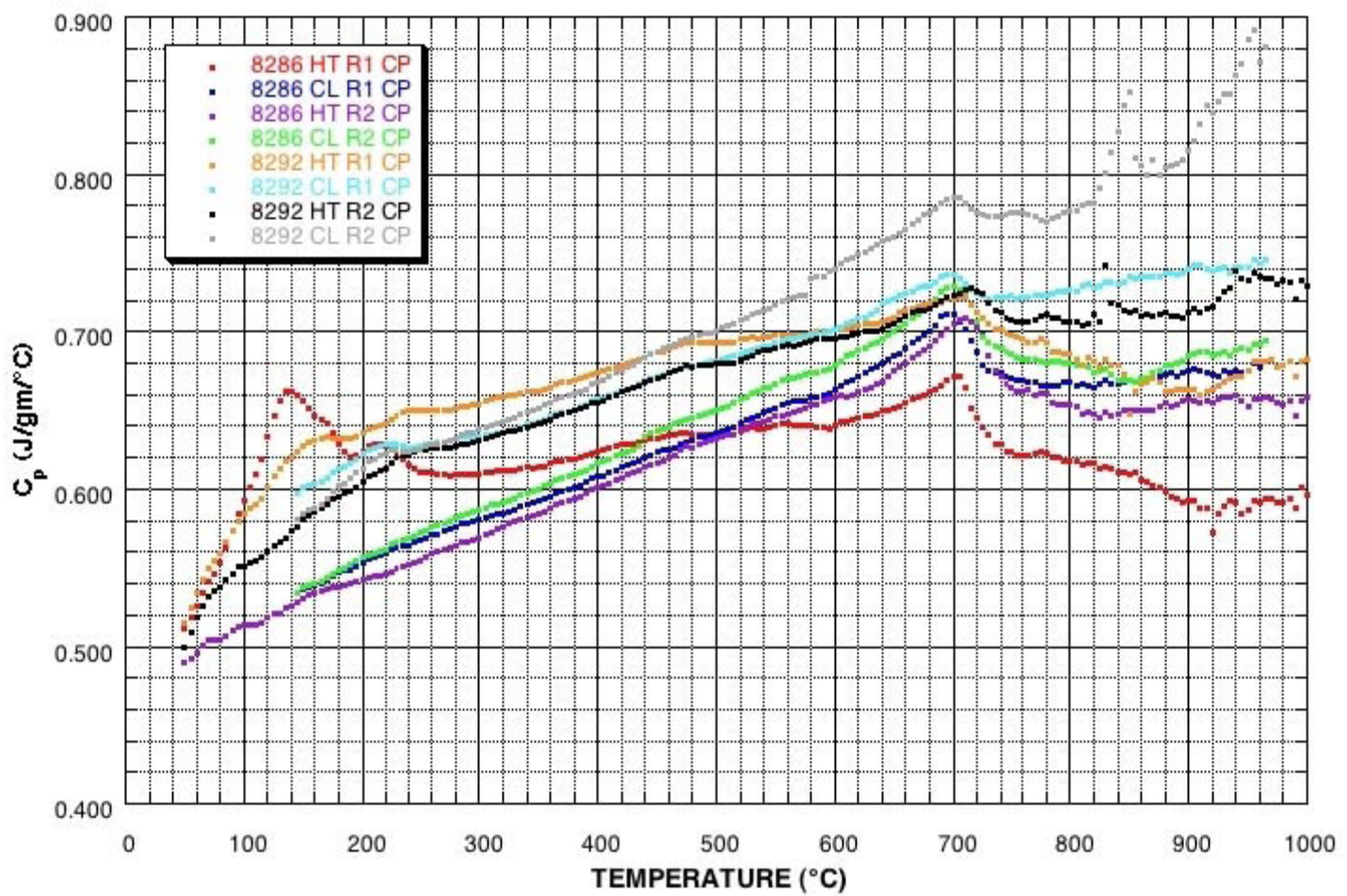

Figure 92. Specific Heat data plots determined for comparing stand-alone coating materials for two (2) of the coating compositions of interest.

Caterpillar Inc. - DE-FC36-04GO14037 


\subsubsection{Residual stress measurement}

The PTA process was used to apply hardface coatings to substrates similar to those used in Caterpillar undercarriage components. The coatings were a commercial alloy (WOKA 7439) and a composite of WOKA7439 and a carbide material. X-ray residual stress measurements were performed on these specimens by ORNL. The residual stress profiles are shown in Figure 93 and Figure 94. These profiles indicate that the residual stresses in the substrate become tensile and larger in magnitude near the coating. The stress profiles in the coating were not calculated due to the lack of a strain-free reference.

ORNL also performed work to develop a new technique to measure the residual stress in boron containing coatings. The HFIR cycle 407 started Dec 21 st and ended January 13, 2006. Two flat plate samples were examined on January 9-11. One PTA weld overlay coating contained boron (alloy SA1) the other did not (WOKA 7439). Both coatings were applied to a 1018 steel substrate. In the latter, strains were measured as a function of depth by both the conventional neutron and $\sin ^{2} y$ methods. The conventional method involved measuring the strain relative to a strain free reference in three orthogonal directions. In the $\sin ^{2} y$ method, the d-spacing is measured as a series of tilts, $y$, starting from zero and increasing up to a maximum tilt. The change in d-spacing as a function of tilt was observed, and from the change in d-spacing with $\sin ^{2} y$ one can obtain the in-plane stress assuming that the normal stress is zero. In the boroncontaining weld overlay coating we measured the stress as a function of depth by the $\sin ^{2} y$ method. The analyses of the WOKA 7439 data by both the conventional and $\sin ^{2} y$ methods were completed and the two analyses are in rough agreement. Further analysis showed that the $\sin ^{2} y$ method was not applicable to boron-containing coatings. 


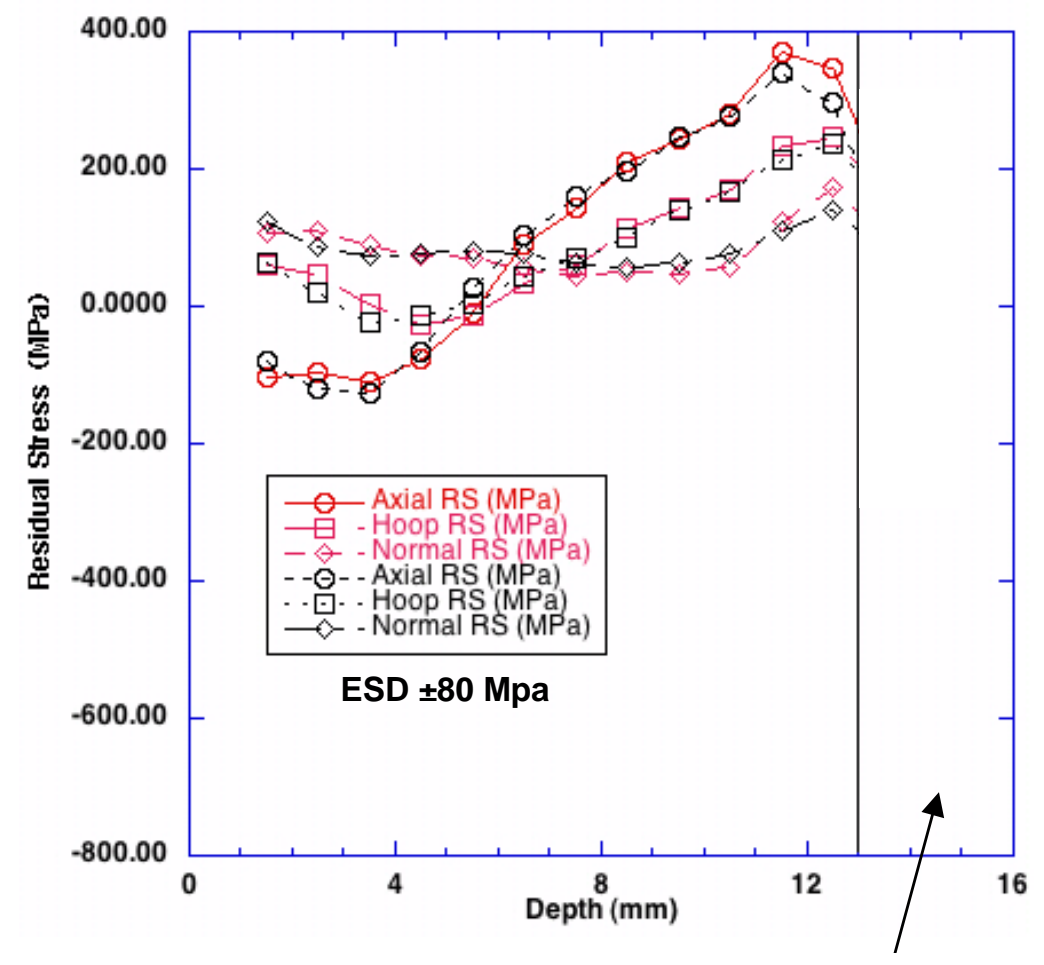

Figure 93. Residual stress profile in the substrate of a commercial material. The arrow indicates the coating location.

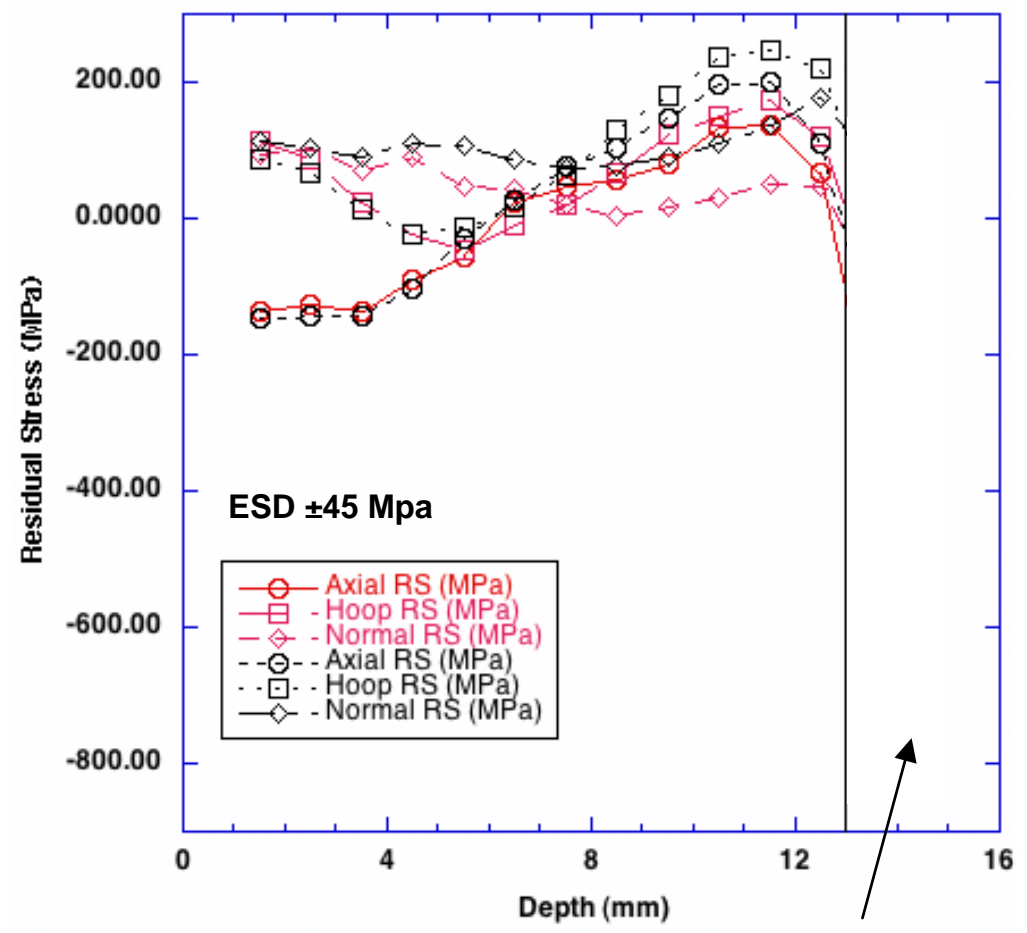

Figure 94. Residual stress profile in the substrate of a composite material. The arrow indicates the coating location. 


\subsubsection{Field test}

Field testing is a critical performance test of any new product or process change. While lab tests are useful for screening materials, any design change (such as adding a coating to an existing component) must be validated with a field test. The purpose of these field tests was to evaluate the wear behavior of selected coatings on carefully selected components in carefully selected sites. The reasons for choosing a given alloy, application process, and field test component will be discussed for each test.

The key field test component in this project was the top mounted wear plate. The component is a wear plate that is bolted onto the inside of a wheel loader bucket. A photograph of a coated top mounted wear plate installed on a customer wheel loader is shown in Figure 95. This component was selected through discussions with the GET field test team at Caterpillar because it is relatively flat (to ease coating processing) and it has a large surface area (to accommodate testing several alloy coatings on a single component). All of the coatings on the plates were applied using the PTA process. The PTA process was chosen because it is similar to processes currently in production on GET. The wear plates were coated with SICWC alloys SA7 and SAQ4 as well as 4 other commercially available wear resistant alloys. These alloys were chosen because lab testing indicated that these alloys should have good wear resistance. There were a total of six field test sites with a variety of abrasive environments. A more detailed summary of the field test sites and the number of hours on the machines at the end of the field tests are in Table 12. The wear for each material was quantified by measuring the coating thicknesses in several locations via ultrasonic probe before and after the test. The target performance improvement was 4 to 8 times greater wear resistance than heat-treated steels.

Table 12. Top mounted wear plate field test sites.

\begin{tabular}{|c|l|l|l|l|r|}
\hline Site & lustomer & Location & Material & Machine & total hours \\
\hline 1 & Florida Rock, Sandy Point & Charles City, VA & Sand & $980 \mathrm{H}$ & 1595 \\
\hline 2 & Gila River Sand \& Gravel & Sacaton, AZ & River Rock & $980 \mathrm{G}$ & 2113 \\
\hline 3 & Mesa Materials & Mesa, AZ & River Rock & $980 \mathrm{G}$ & 1139 \\
\hline 4 & North Vulcan Quarry & Winston Salem, NC & Granite & $980 \mathrm{G}$ & 1505 \\
\hline 5 & Vulcan Quarry, Stokesdale & Stokesdale, NC & Granite & $980 \mathrm{G}$ & 1624 \\
\hline 6 & Luck Stone, Fredericksburg & Fredericksburg, VA & Granite & $980 \mathrm{H}$ & 1658 \\
\hline
\end{tabular}

Pictures of the wear plates are shown in Figure 96 through Figure 100. There are several qualitative trends visible in these pictures. As expected, granite caused significantly more wear than river rock. Qualitatively, one commercially available material (Deloro 60) was clearly less wear resistant than the other alloys while the alloys with the best wear resistance were SAQ4 and one commercial alloy (SHS 9290). Quantitative measurements of the wear rate have been performed using ultrasonic thickness measurements. The procedure is outlined in Figure 101 and Figure 102 and the results are shown in Figure 103. In this figure, CAT2 is SA11, CAT3 is SA7, CAT4 is SAQ4). The SICWC alloys CAT3 and CAT4 had the lowest wear rates of the 
alloys on this plate, and the wear resistance was at least $4 \mathrm{X}$ greater than the base steel. The lowest wear rates could not be measured precisely due to uncertainty in the ultrasonic measurements as a result of the pixel size.

The PTA process was used to apply coatings of a commercially available alloy (WOKA 7439) to the sideshift wear strip of a $24 \mathrm{M}$ motor grader blade. This component was chosen because a field test machine was available and there was a request from the motor grader design group to increase the wear resistance of this component. . The alloy for the PTA motor grader wear strip test was chosen because it is commercially available. The PTA process was chosen because it is an established technology that could be implemented rapidly in existing production facilities. The current test plans for this coating include performing operator evaluations at the Peoria Proving Grounds to determine if the coating has any adverse effects on blade operation. Assuming no adverse effects the blade will be installed on a field follow machine and the wear performance will be monitored. Photographs of the PTA coating process and a close-up of the wear strip installed in the field are shown in Figure 104. If this field test is successful this application may be a candidate for field test of a SICWC alloy.

A third field test component was a track shoe bolt. This component was selected because a field test was already underway where these components could be incorporated easily. Track shoe bolt heads were plasma sprayed with SICWC alloys SA1 and SA2. These early coating alloys were selected because these components were coated at the beginning of the project and lab test results were not available to indicate the alloys with the best wear resistance. The resulting wear from these field tested coating would also aid in interpretation of the lab testing as to how well the lab test indicted field performance. The coating application process (plasma spray) was selected because the alternative coating processes such as slurry coating were not developed at that point in the project and the geometry of the bolt head would make PTA difficult. The track shoe bolt coatings were fused with Caterpillar's arc lamp under a variety of time and power levels. Arc lamp fusion was chosen for process efficiency, meaning that the entire bold head could be processed at one time. Example photographs of the installed track shoe bolts are shown in Figure 105. One issue that is clear is the chipping of the coating, especially near the corners of the bolt heads. There are two reasons for this effect. The first is related to the loading and material properties of these two alloys. The bolts are subjected to large impact-type loading during installation, and it has already been demonstrated that SICWC alloys SA1 and SA2 are brittle. The second reason is incomplete fusing at the corners and edges of the bolt head. This illustrates the sensitivity of the resulting materials properties to the distance between the lamp and the sample during arc lamp processing. The substrate and coating must be flat or the lamp must be moved to match the contours of the part. Therefore, in interpreting the field test results, only those areas know to be well fused were consider in the analysis. 


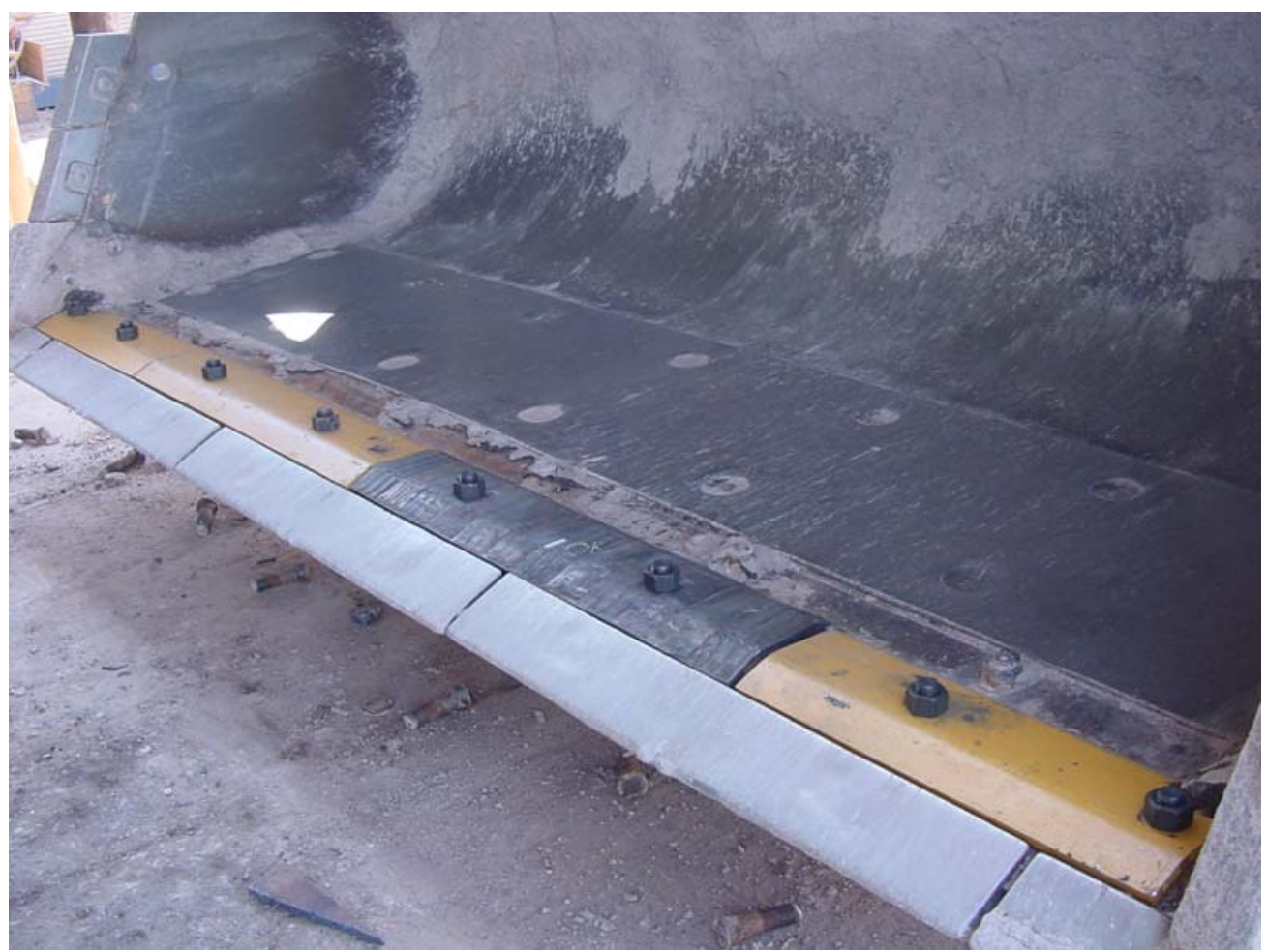

Figure 95. Top mounted wear plate coated with SICWC and commercial alloys installed on a 992G wheel loader at Mesa Materials in Mesa, AZ. 
Gila River Sand and Gravel, Sacaton AZ, river rock, 2113 hours, plate 6-18

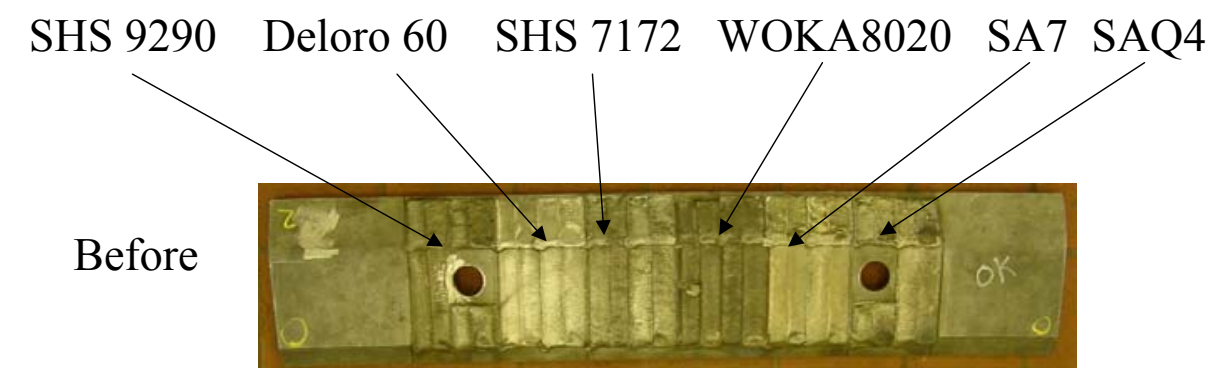

After
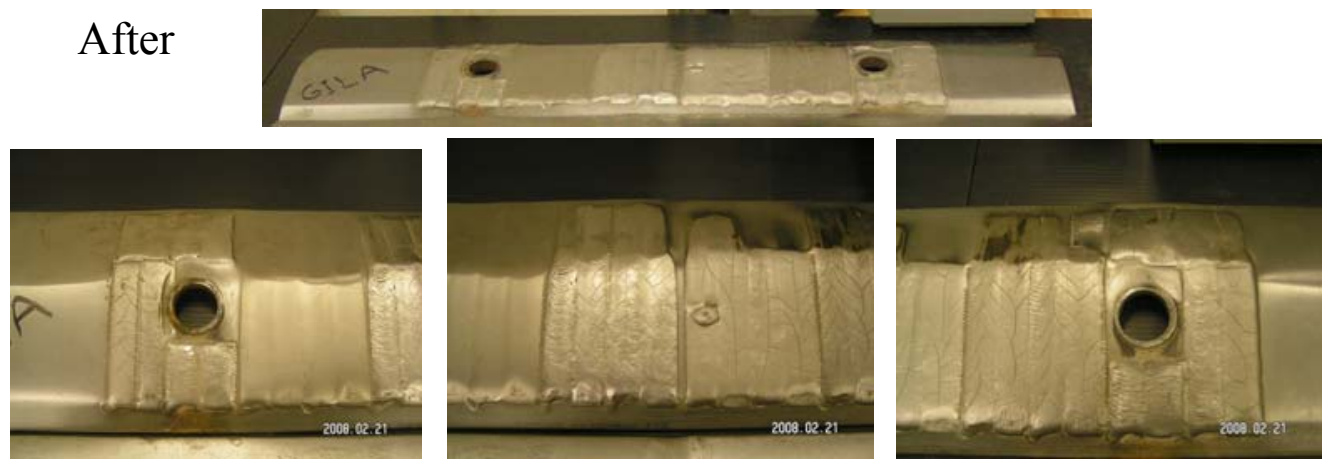

Figure 96. Wear plate from the field test at Gila River.

Mesa Materials, Mesa AZ, river rock, 1139 hours, plate 6-7-1
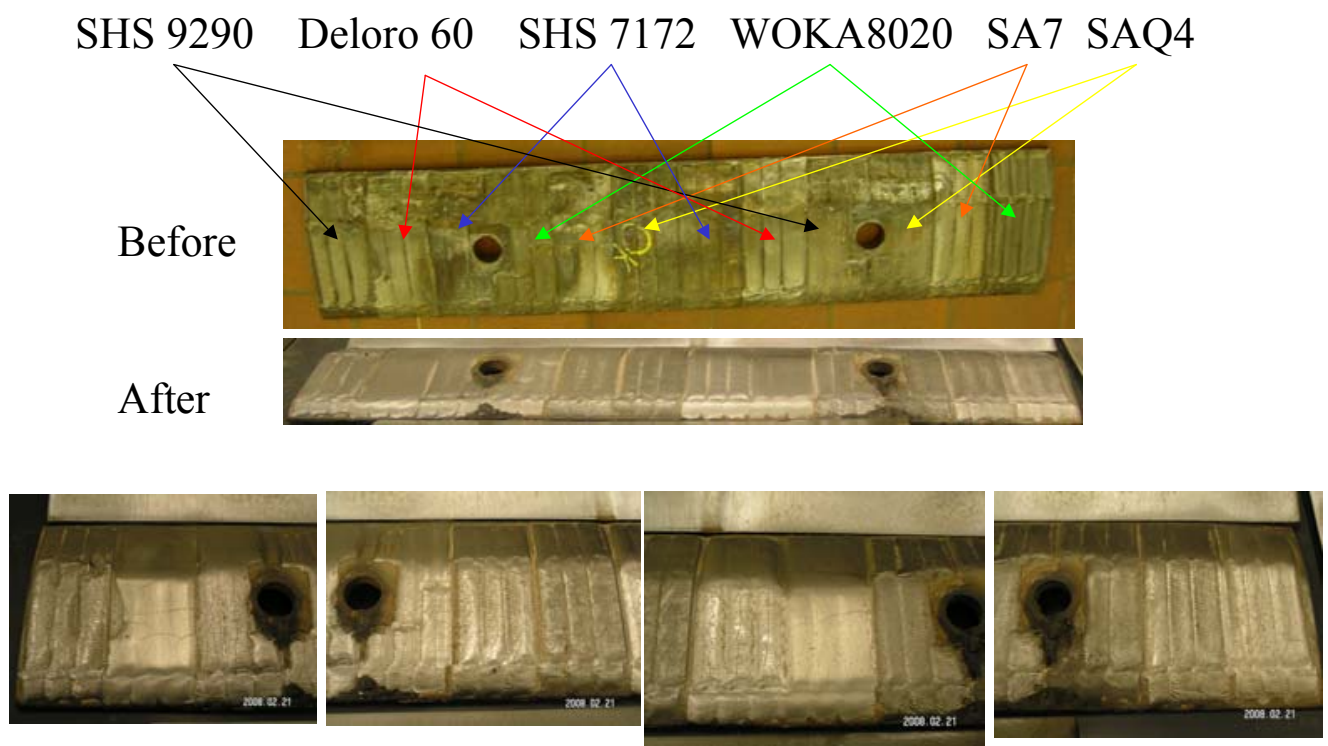

Figure 97. Wear plate from the field test at Mesa Materials. 
Vulcan Quarry, Stokesdale NC, granite, 1624 hours, plate 6-25

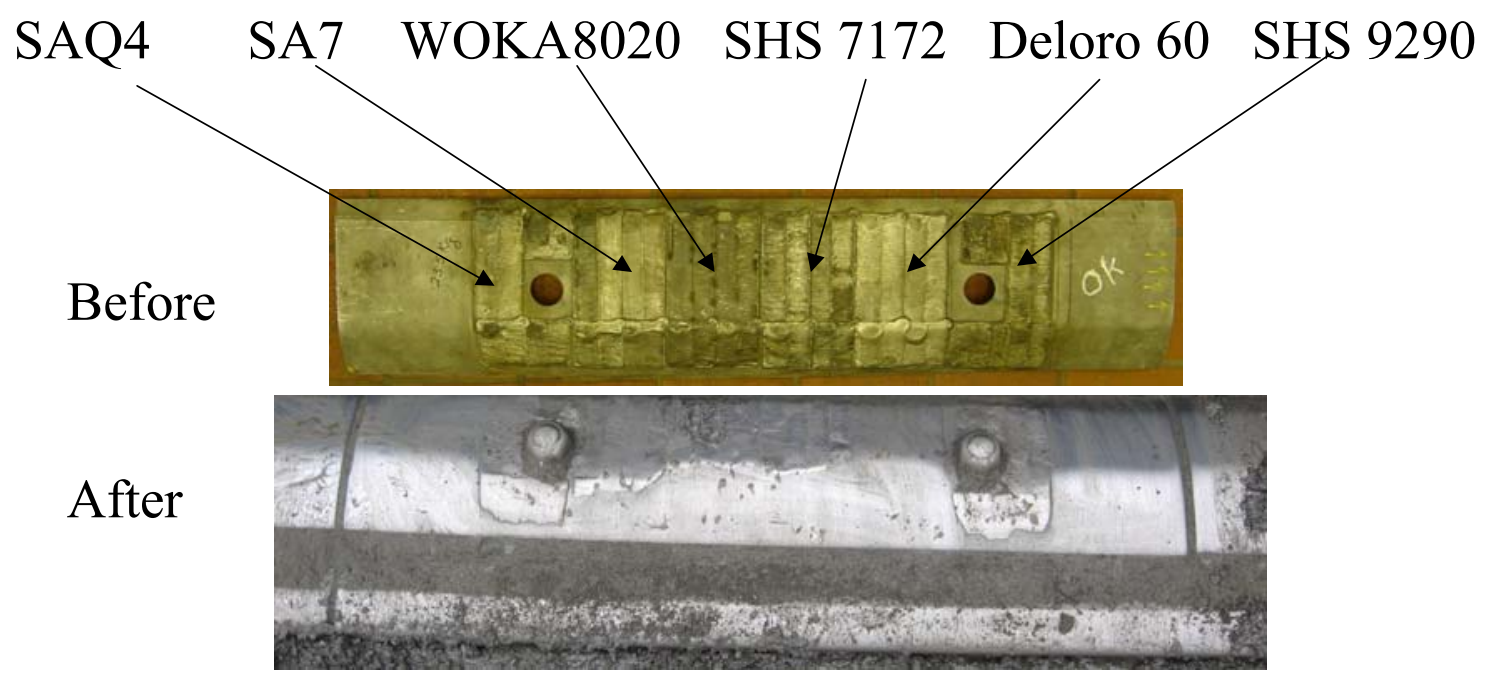

Figure 98. Wear plate from th e field test at Vulcan Quarry.

Vulcan Quarry North, Winston Salem NC, granite, 1505 hours, plate $6-26$

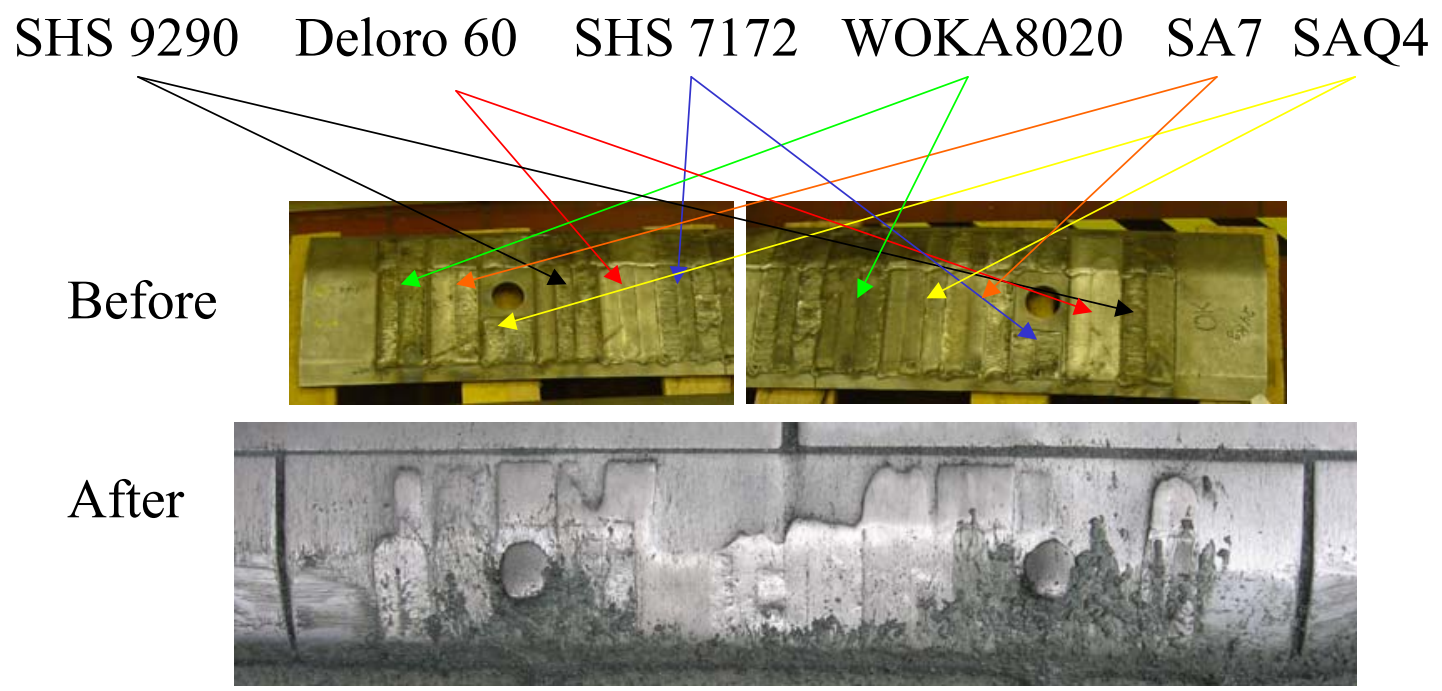

Figure 99. Wear plate from field test at North Vulcan Quarry. 
Luck Stone, Fredericksburg VA, granite, 1658 hours, plate 6-20

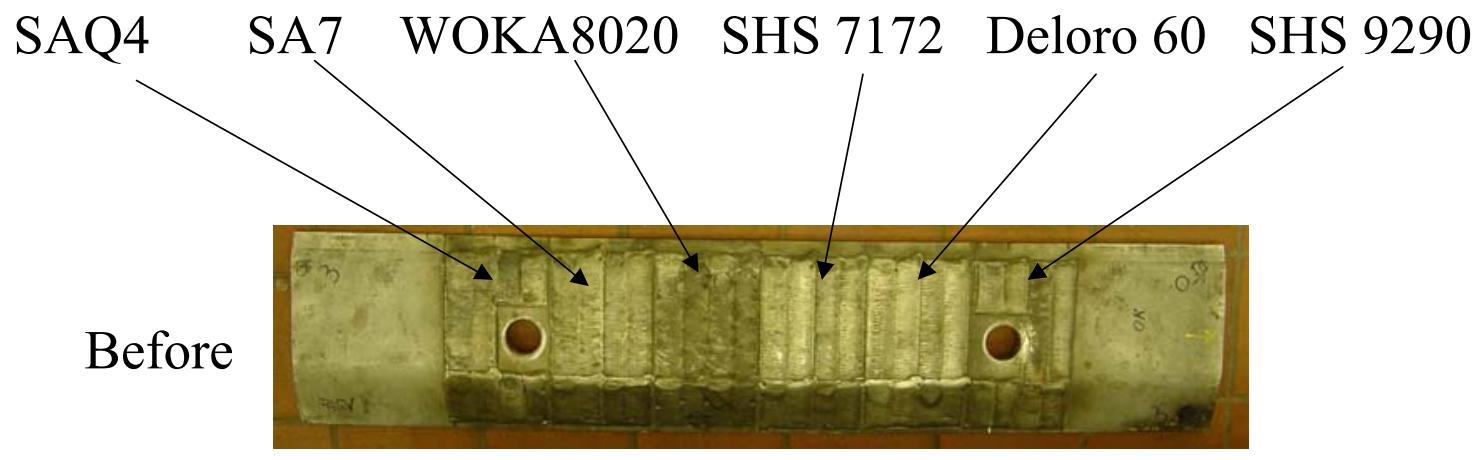

After

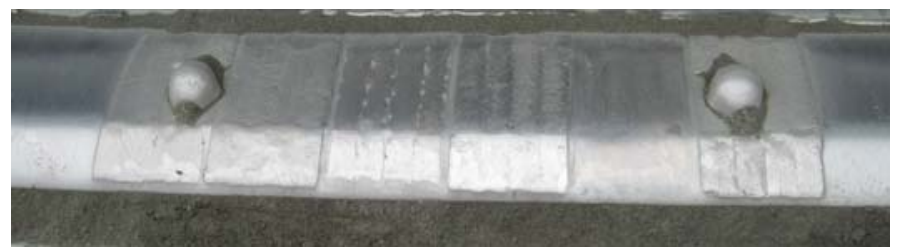

Figure 100. Wear plate from the field test at Luck Stone. 


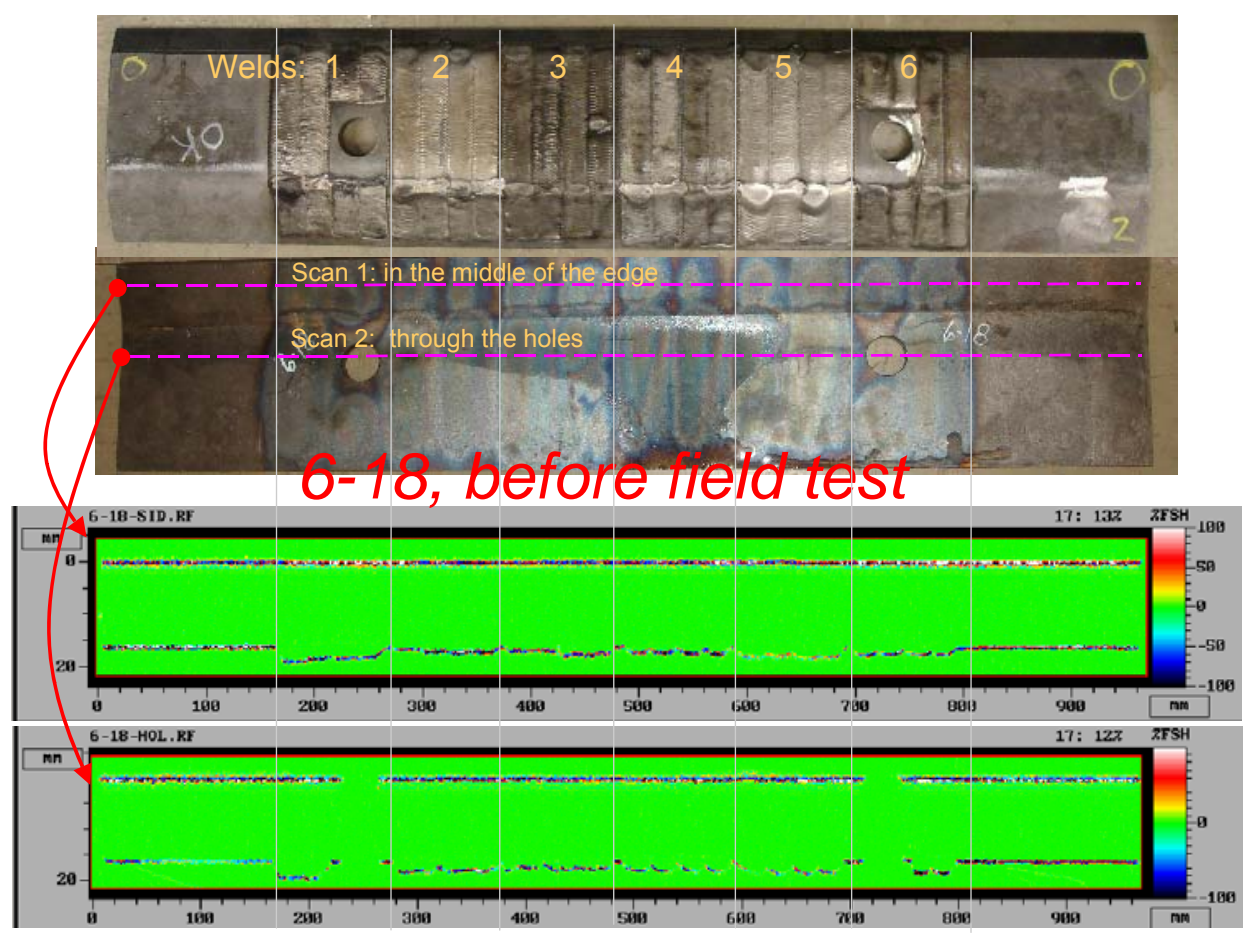

Figure 101. Ultrasonic thickness measurements of a wear plate before field test.

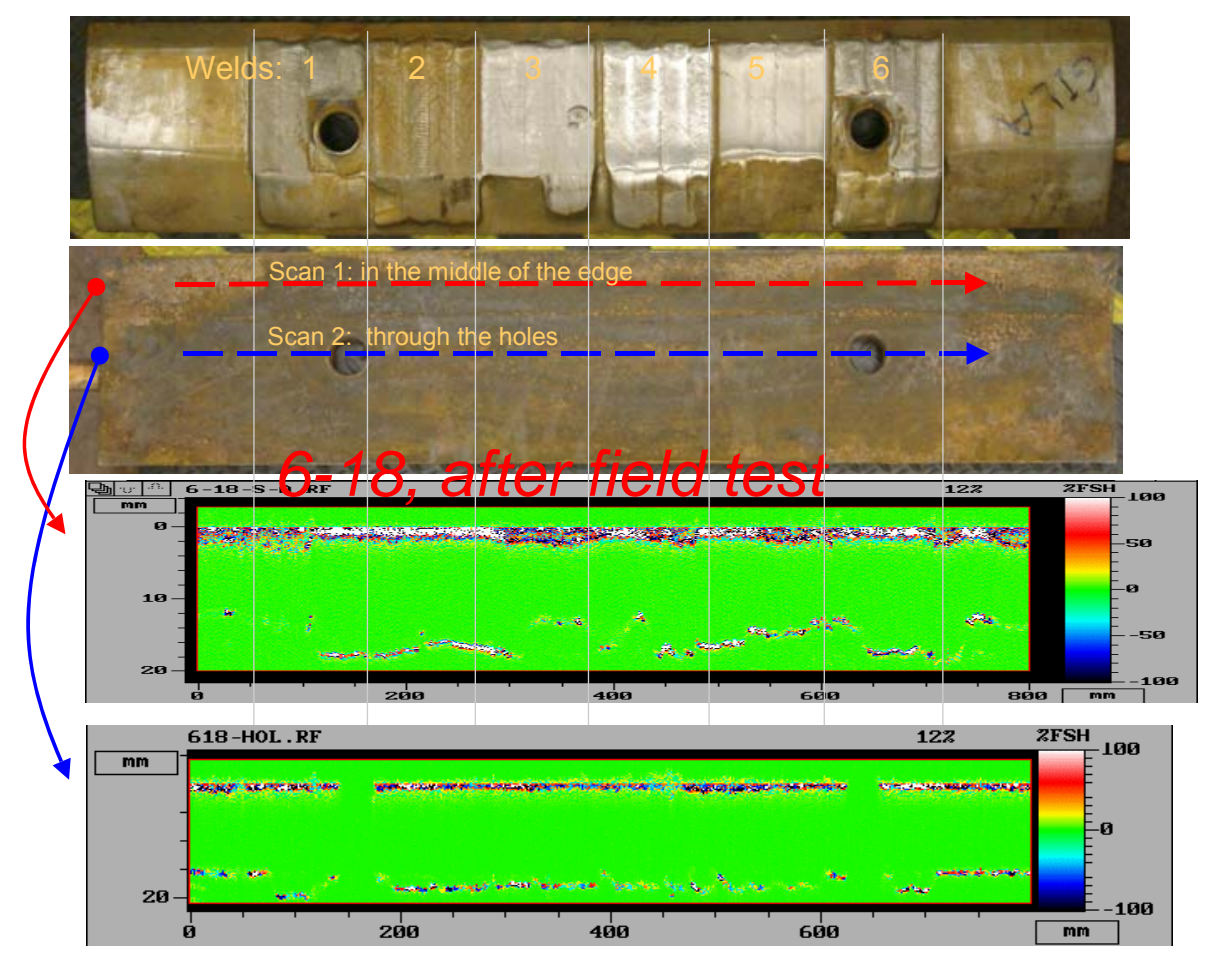

Figure 102. Ultrasonic thickness measurements of a wear plate after field test. 


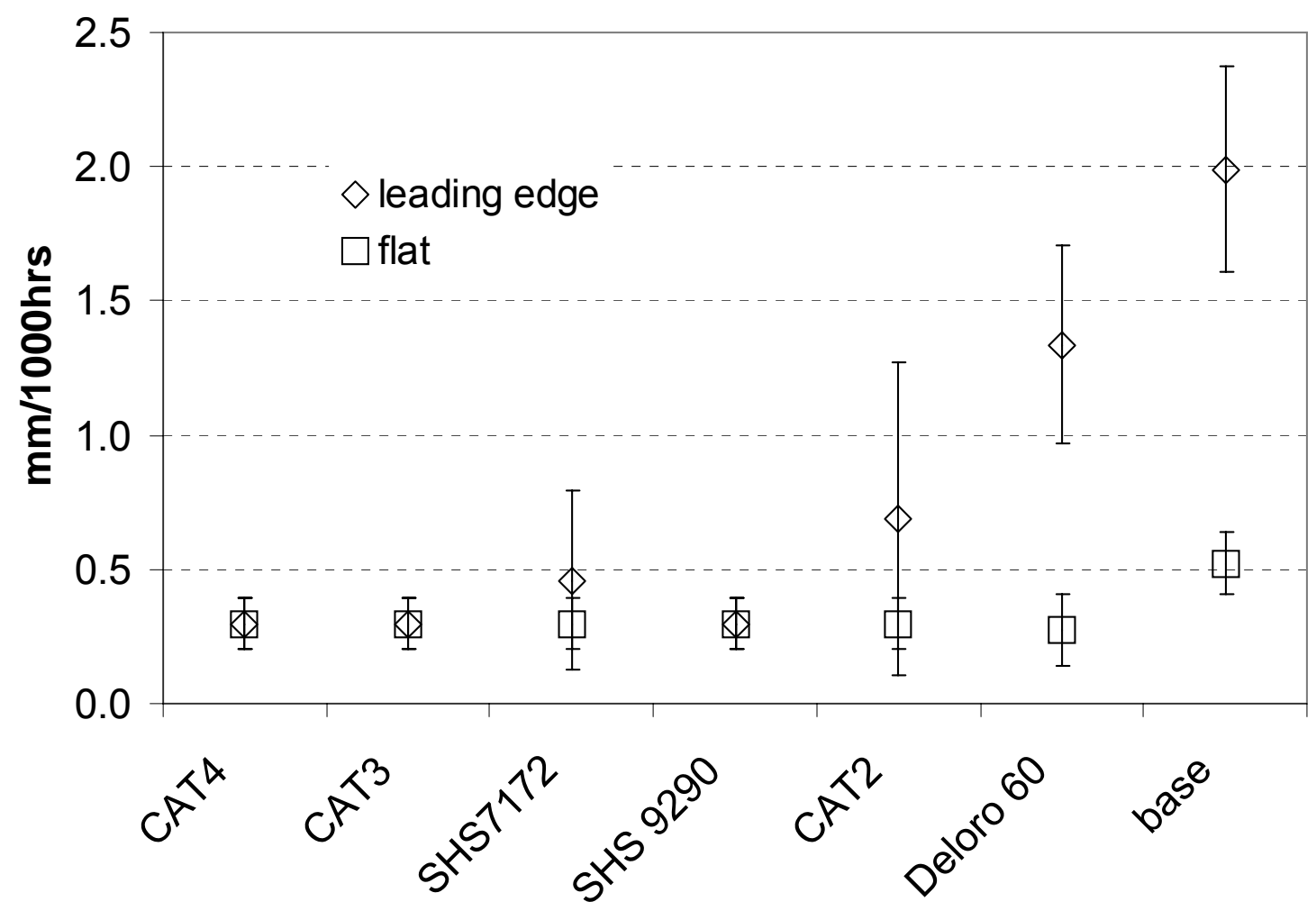

Figure 103. Wear rates of PTA coatings on top mounted wear plates from field test in Gila River Sand and Gravel. 

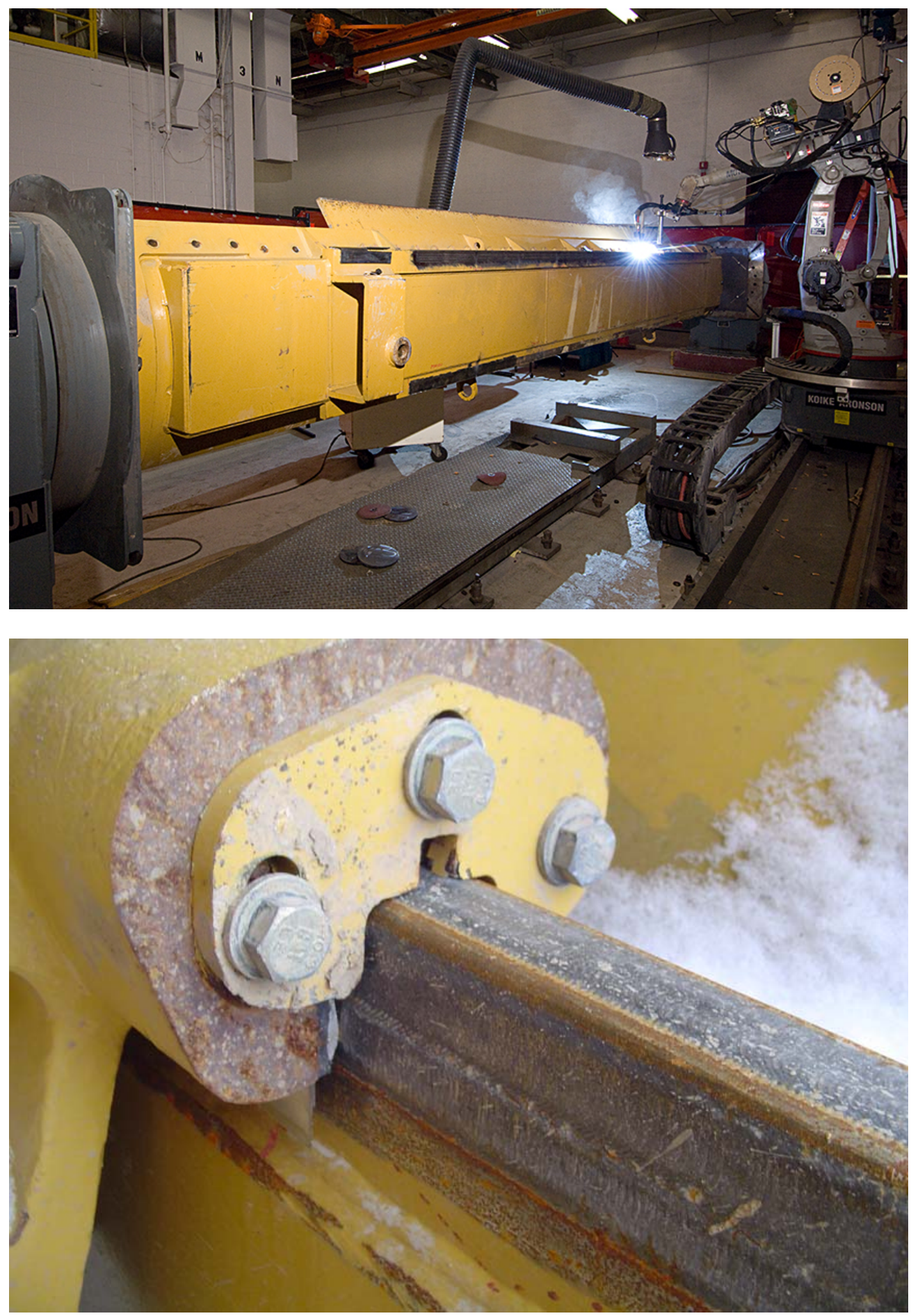

Figure 104. PTA coating process for a 24M motor grader blade wear strip (top) and the wear strip on the blade after installation (bottom). 


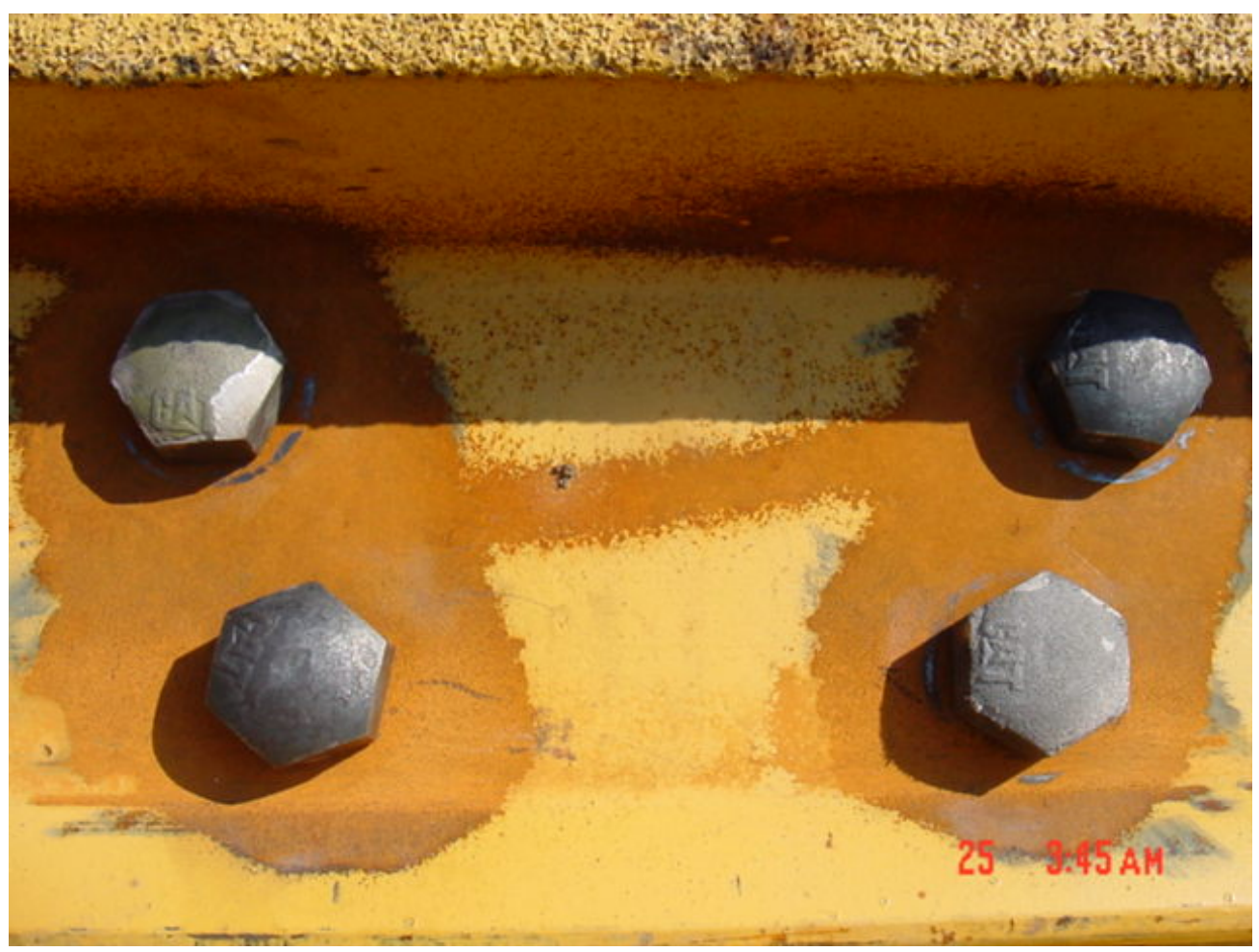

Figure 105. Track shoe bolts with arc lamp fused SICWC alloy coatings. 


\section{Discussion}

This section will discuss the results presented in the previous section in terms of processing methods, alloy compositions, wear resistance, corrosion resistance, and computational modeling.

\subsection{Processing methods}

In general the plasma arc lamp has proven to be a useful process for surface modification. For example, this process can produce both equilibrium and non-equilibrium microstructures (Figure 46). It is important to keep a few key processing hints in mind when working with the lamp. One key process step is the use of a preheat cycle followed by a pulse at high power. Another key process step is the reduction of the power level to prevent excessive heat input at the start/stop points on a round part (Figure 22) or a part large enough to require motion of the lamp or part.

It appears that a larger melting range is beneficial to both fusion of the coating to the substrate and changing the structure of the coating itself. This is illustrated by examination of alloy SA8 after arc lamp processing (i.e., micrograph for SA8-5 in Figure 42). In terms of physical properties, thermodynamic calculations indicate alloy SA8 had the highest solidus temperature $\left(\sim 150{ }^{\circ} \mathrm{C}\right.$ higher than the nearest alloy) and the lowest liquidus $\left(\sim 200{ }^{\circ} \mathrm{C}\right.$ lower than the nearest alloy) compared to alloys SA6, SA9, SAQ1, and SAQ4. In terms of processing, alloy SA8 had the second highest fraction of borides in the feedstock powder of all the SICWC alloys. Alloy SA8 also retained much of its as-sprayed structure after arc lamp processing such as the layered structure, fine scale (i.e., $\sim 5 \mu \mathrm{m}$ ) mixture of phases, and non-spherical porosity. The high solidus and large fraction of high melting point boride phases resulted in very little liquid formation during arc lamp processing at certain parameters. The equilibrium phases were not able to form due to a lack of liquid diffusive mixing. In addition, the porosity was not spherodized due to a lack of liquid fluid flow. Consequently, the borides from the as-sprayed coating and much of the as-sprayed coating structure were retained after arc lamp processing. The narrow melting range also results in a narrow processing window of arc lamp parameters that will result in a fused coating.

The experiments show that a significant fraction of the fusion zone is a result of melting of the substrate. Figure 45 shows several micrographs of alloys with fusion zones. In several locations the interface is curved behind particles of alumina grit that were embedded during the grit blast process. These embedded grit particles are markers of the location of the coating/substrate interface prior to treatment with the arc lamp. The fusion zone surrounds many of the grit particles indicating that the substrate (in addition to the coating matrix) was molten. The alumina grit particles have a much lower thermal conductivity than the surrounding metal and act as thermal barriers reducing the heating rate of the substrate underneath them. These particles also act as a chemical barrier to fusion zone formation due to the poor wetting characteristics of ferrous alloys on alumina. A surface preparation method that may reduce these effects is blasting with steel shot rather than oxide grit. Steel shot blasting produces a surface with a lower roughness than oxide grit blasting; however, if there is a metallurgical bond between the coating 
and substrate after arc lamp processing the surface roughness (needed for a mechanical bond between the coating and substrate) is much less important, or possibly irrelevant, for adhesion. These micrographs also illustrate that for fusion-bonded coatings it is critical to include the substrate properties as well as the coating properties in the design of the coating system. A change in the substrate solidus temperature may change the fusion zone width or fusion bond strength.

The PTA process is a more established commercially available technology. It is used to apply thick $(>1 \mathrm{~mm})$ coatings and requires high heat input into the substrate and coating. The coatings are applied in a linear pattern covering approximately $100 \mathrm{~mm}^{2} / \mathrm{second}$. For comparison, the arc lamp covers $500 \mathrm{~cm}^{2}$ at one time.

\subsection{Coating alloy compositions}

The equilibrium microstructures of SICWC alloys SA1 through SA9 are shown in Figure 29. Several microstructural trends can be observed from this figure. In alloys without chromium or nickel (i.e., SA1, SA2, SA3) no fcc or bcc phase is formed. This observation agrees with thermodynamic predictions. At a constant iron:molybdenum:boron ratio, adding chromium (alone or in combination with nickel) increases the aspect ratio of the boride precipitates (e.g., compare SA1 with SA7). Chromium and nickel additions also appear to cause a distribution of fine scale phases within the ternary boride phase. These fine scale phases give the ternary boride phase a "feathered" appearance in the micrographs for alloys SA7, SA8, and SA9 compared to alloys SA1, SA2, and SA3.

\subsection{Wear resistance of coated samples}

In general the SICWC alloys perform as well as commercially available alloys in the dry sand rubber wheel (DSRW) wear tests (Figure 62). While these results are encouraging, it is important to remember that DSRW test results do not correlate well with wear trends in field test data. Due to this poor correlation, the pin-on-drum (POD) test results will be the standard by which the alloys are compared.

The wear results for POD abrasion testing of plasma sprayed coatings and arc lamp modified coatings illustrate some of the microstructure characteristics that result in wear resistance. The arc lamp processed alloys (with the exception of alloy SA9) show increased wear resistance. The root cause of this improvement is not clear from the available data, but there are several possible explanations. This improvement may be due to the formation of equilibrium ternary borides that are more wear resistant than the phases present in the as-sprayed coatings. Another possibility is that arc lamp processing results in microstructural changes (e.g., the elimination of splat boundaries or small pores in the coating) that could improve the cohesion of the coating and reduce material loss during the wear test. The free surfaces of the arc lamp processed coatings also were generally smoother than the as-sprayed surfaces. The poor performance of the assprayed coatings could be due to easy removal of the peaks of the coating during the test. 
The mass loss in the pin-on-drum test is somewhat correlated with hardness (Figure 65). It can be seen in Figure 40 through Figure 42 that hardness is qualitatively correlated with the amount of boride phase in the coating. Consequently, coatings containing higher fractions of borides tend to have higher wear resistance. After arc lamp processing, alloy SA6 and SA9 coatings were very similar in both structure and percentage of borides present and they performed similarly in wear testing. Arc lamp processed alloy SA8 coatings showed the highest wear resistance and the highest hardness; however, this coating was more brittle than the other SICWC alloy coatings. The brittle nature of the coating was observed during the sample preparation process where the coating often chipped or cracked as a result of machining. This behavior is due to the fact that this alloy does not have an equilibrium fcc or bcc phase. The lack of an fcc or bcc phase was predicted by thermodynamic calculation and confirmed experimentally.

Performance in the impeller test is more difficult to evaluate quantitatively because this test is sensitive not only to coating microstructure but also interface properties. The entire SA series of alloys was given a preheat cycle as part of arc lamp processing while the SAQ series was not given a preheat. This was because the SAQ series of alloys visually appeared to be well fused without the preheat cycle. While these results indicate the importance of the preheat cycle, they do not give insight into the mechanism for the improvement.

The field test results were encouraging. The SICWC alloys performed well in terms of wear resistance and did not show large scale spallation despite the presence of cracks in the coating. The wear on the leading edge of the plate (i.e., the edge to first contact the material going into the bucket) showed more wear than the trailing edge. This is expected due to the higher forces during bucket loading. The results of the field test agree with the lab test results showing that the SICWC alloys are at least $4 \mathrm{X}$ more wear resistant than a typical heat treated steel.

\subsection{Corrosion resistance of coated samples}

As shown in Figure 79, arc lamp processing results in significant improvements in corrosion resistance. From a comparison of the as-sprayed and arc lamp processed microstructures (e.g., Figure 35) it is clear that many of the microstructural changes will impact the corrosion behavior. The as-sprayed microstructure shows a layered structure typical of thermal spray coatings with fine scale phase and composition variations. One change produced by arc lamp processing is the morphology of the porosity in the coating. Arc lamp processing creates spherical porosity that appears to be discontinuous (i.e., there is no direct connected path through the porosity from the coating surface to the coating-substrate interface). Another microstructural change is the homogenization of the coating composition. Arc lamp processing also increases the microstructural scale and reduces the roughness of the coating surface.

In these alloy compositions all of the changes produced by the arc lamp process are beneficial for corrosion protection. Disconnected porosity prevents a physical path for corrosive media to reach the substrate. Reducing the surface roughness of the coating eliminates nucleation sites for pitting corrosion. Homogenization of the phases and alloying elements distributes the $\mathrm{Mo}, \mathrm{Cr}$, and $\mathrm{Ni}$ throughout the microstructure to prevent uniform and pitting corrosion. Given the 
available data, it is not clear how much each of these factors contributes to the improvement in corrosion resistance.

\subsection{Usefulness of computational modeling}

When discussing the computational modeling it is important to keep in mind the three types of models used in this project: thermodynamic models, empirical process models, and physicsbased process models. The thermodynamic models were critical to the success of the project. These models allowed the accelerated development of alloy compositions that would have the desired phases as well as estimates of the physical properties (e.g., solidus and liquidus temperatures) of those compositions.

Physics-based process modeling was helpful but not to the degree of the thermodynamic modeling. The process models such as varying the power of the arc lamp during a run to maintain a target temperature (Figure 21) and rotating a cylinder at relatively high RPM under the arc lamp (Figure 22). While these results were useful, the quantitative predictive capabilities of the process models are limited by the accuracy of the material property inputs for the model. The sample manufacture and preparation for the measurement of these properties caused significant delays. Unfortunately, one issue that was not explored was the sensitivity of the process models to variation in the material and process parameter inputs. Another issue with the physics-based modeling is that the models require complex computer codes and long computation times.

As an alternative to the physics-based process models, empirical process models were developed. Similar to the physics-based models, the empirical models were useful for an initial evaluation and relative comparison of new processing techniques such as pre-heating (Figure 24 and Figure 25). In contrast to the physics-based models, the empirical models do not require thermophysical property measurement. Empirical models require the measurement of a process output (e.g., sample temperature) as a function of process parameters. Compared to measuring sample thermophysical properties, measuring the output of a process such as sample temperature generally requires no specialized equipment. Using these process output measurements, fitting parameters can be calculated that are incorporated into the finite element analysis. The fitted model can then be applied to other process parameters. The simplicity of an empirical model reduces the computation time. While empirical models may not explicitly take into account all of the physical phenomena occurring in a material, they provide a practical balance of speed and accuracy. 


\subsection{Process economics}

In the analysis of the material properties and test results in this project, it is critical to balance performance with cost. The total cost of the coating process includes both the raw material for the coating, the cost of processing the raw material to produce a feedstock for the coating process (i.e., powder or wire), the cost of applying the coating (i.e., PTA, plasma spray, or slurry coat), and the cost of any post-processing of the coating (i.e, arc lamp).

For the purposes of this economic analysis, three processes will be examined: PTA, plasma spray/arc lamp, and slurry coat/arc lamp. The PTA process is included as a baseline because it is an established production process for the application of hard, wear-resistant coatings. While different feedstock materials can be used for these processes, the feedstock materials will be assumed to be powder for all of these processes in this analysis. The economic factors examined in this analysis are electricity, material, labor, and capital equipment. The part used for this economic analysis is a track shoe grouser. The grouser is the part of the track shoe that penetrates the ground to provide better traction. This area of the track shoe experiences high impact and wear in many applications. It is also currently offered with optional wear resistant coatings. The retail price of a track shoe without the optional wear resistant coatings is about $\$ 150$.

Raw material costs have been calculated for the initial SICWC alloys (i.e., SA1 through SA9) as well as the optimized alloy compositions calculated by QuesTek (i.e., alloys Q1, Q4, and Q7) and are shown in Table 13 below. Currently, the prices of molybdenum, ferromolybdenum, and nickel are relatively high compared to other materials. This means that alloys with high molybdenum and nickel contents (e.g., alloys 3, 6, 9, Q1, Q4, and Q7) would require a larger improvement in wear life to justify the additional expense.

Table 13. SICWC alloy feedstock costs.

\begin{tabular}{|c|r|}
\hline Alloy & $\begin{array}{l}\text { Cost } \\
(\$ / 1 b)\end{array}$ \\
\hline SA1 & 12.25 \\
\hline SA2 & 8.17 \\
\hline SA3 & 19.19 \\
\hline SA4 & 11.55 \\
\hline SA5 & 8.28 \\
\hline SA6 & 17.10 \\
\hline SA7 & 11.88 \\
\hline SA8 & 8.61 \\
\hline SA9 & 17.43 \\
\hline SAQ1 & 23.17 \\
\hline SAQ4 & 18.65 \\
\hline SAQ7 & 19.44 \\
\hline
\end{tabular}


The estimated electrical costs of the three processes are shown in Table 14. These calculations assume an electricity cost of $\$ 0.05 / \mathrm{kWh}$. Initially it may seem that electrical costs would be significant to all of these processes; however, the short processing times and low cost of electricity result in very small contributions to the overall process cost. The plasma spray/arc lamp fuse process has the highest electrical cost because both the coating application process and arc lamp fusion require electricity.

Table 14. Comparison of estimated electricity usage of the three coating processing methods.

\begin{tabular}{|l|l|l|l|}
\cline { 2 - 4 } \multicolumn{1}{l|}{} & \multicolumn{1}{|c|}{ PTA } & $\begin{array}{l}\text { Plasma spray/arc lamp } \\
\text { fuse }\end{array}$ & $\begin{array}{l}\text { Slurry coat/arc } \\
\text { lamp fuse }\end{array}$ \\
\hline $\begin{array}{l}\text { Coating application } \\
\text { energy [kWh] }\end{array}$ & $\begin{array}{l}200 \mathrm{~A} * 25 \mathrm{~V} * 1 / 5 \mathrm{~h} \\
(12 \mathrm{~min})=1 \mathrm{kWh}\end{array}$ & $\begin{array}{l}525 \mathrm{~A} * 60 \mathrm{~V} * 1 / 30 \mathrm{~h} \\
(2 \mathrm{~min})=1 \mathrm{kWh}\end{array}$ & 0 \\
\hline $\begin{array}{l}\text { Arc lamp fusion } \\
\text { energy [kWh] }\end{array}$ & 0 & $\begin{array}{l}400 \mathrm{~kW} * 1 / 120 \mathrm{~h}(30 \\
\text { seconds })=3 \mathrm{kWh}\end{array}$ & $\begin{array}{l}400 \mathrm{~kW} * 1 / 120 \\
\mathrm{~h}(30 \mathrm{keconds})= \\
3 \mathrm{kWh}\end{array}$ \\
\hline Electricity cost [\$] & $\$ 0.05$ & $\$ 0.20$ & $\$ 0.15$ \\
\hline
\end{tabular}

The estimated material costs of the three processes are shown in Table 15. These calculations assume that the cost of the coating powder is $\$ 40 / \mathrm{lb}$ including raw material and powder production costs. Similar to the electricity usage, the plasma spray/arc lamp fuse process is the most expensive in terms of material usage. This is a direct result of the low deposition efficiency of the plasma spray process. Both the PTA and slurry coating processes have very high deposition efficiency. This is critical when using expensive powders such as those under consideration in this project.

Table 15. Comparison of estimated material costs of the three coating processing methods.

\begin{tabular}{|c|c|c|c|}
\hline & PTA & $\begin{array}{c}\text { Plasma spray/arc lamp } \\
\text { fuse }\end{array}$ & $\begin{array}{l}\text { Slurry coat/arc } \\
\text { lamp fuse }\end{array}$ \\
\hline Material type & Powder $(-150+53 \mu \mathrm{m})$ & Powder $(-106+53 \mu \mathrm{m})$ & Powder $(-53 \mu \mathrm{m})$ \\
\hline $\begin{array}{l}\text { Deposition } \\
\text { efficiency }\end{array}$ & $98 \%$ & $<50 \%$ & $98 \%$ \\
\hline Powder usage [lbs] & 0.13 & 0.23 & 0.13 \\
\hline Powder cost $[\$ / \mathrm{lb}]$ & 40 & 40 & 40 \\
\hline Material cost [\$] & 5.20 & 9.20 & 5.20 \\
\hline
\end{tabular}

The estimated labor costs of the three processes are shown in Table 16. These calculations assume that the cost of labor is $\$ 25 / \mathrm{hr}$. These calculations also assume a labor ratio of 1.3 to take into account factors that reduce the time a worker spends actively performing their job (e.g., breaks, sick days, holidays). Similar to the material costs, the plasma spray/arc lamp fuse process is the most expensive in terms of labor. This is a result of using two processes where the setup is labor intensive. In all three cases, the process time is less than the handling and setup time. 
Table 16. Comparison of estimated labor costs of the three coating processing methods.

\begin{tabular}{|l|r|r|r|}
\cline { 2 - 4 } \multicolumn{1}{c|}{} & \multicolumn{1}{c|}{ PTA } & \multicolumn{1}{c|}{$\begin{array}{c}\text { Plasma spray/arc lamp } \\
\text { fuse }\end{array}$} & \multicolumn{2}{c|}{$\begin{array}{c}\text { Slurry coat/arc } \\
\text { lamp fuse }\end{array}$} \\
\hline Process time [min] & 12 & 2 & 5 \\
\hline $\begin{array}{l}\text { Handling/setup time } \\
{[\text { min] }}\end{array}$ & 20 & 40 & 20 \\
\hline $\begin{array}{l}\text { Total labor time } \\
{[\text { hrs] }}\end{array}$ & 0.53 & 0.70 & 0.42 \\
\hline Labor rate [\$/hr] & 25 & 25 & 25 \\
\hline Labor ratio & 1.3 & 1.3 & 1.3 \\
\hline Labor cost [\$] & 17.20 & 22.75 & 13.65 \\
\hline
\end{tabular}

The estimated capital costs of the three processes are shown in Table 17. Some capital items that are common to all three processes are a robot, a dust collector, and a dedicated room or rooms for the process. The arc lamp is a large capital investment requiring a dedicated room, part fixturing and positioning, and water chillers for process cooling. The increase in piece part price is based on a demand of 2000 parts/year and a depreciation time of 7 years.

Table 17. Comparison of estimated capital costs of the three coating processing methods.

\begin{tabular}{|l|l|l|l|}
\cline { 2 - 4 } \multicolumn{1}{c|}{} & \multicolumn{1}{c|}{ PTA } & \multicolumn{1}{c|}{$\begin{array}{c}\text { Plasma spray/arc lamp } \\
\text { fuse }\end{array}$} & $\begin{array}{l}\text { Slurry coat/arc } \\
\text { lamp fuse }\end{array}$ \\
\cline { 2 - 5 } Equipment required & $\begin{array}{l}\text { PTA system } \\
\text { Robot } \\
\text { Dust collector } \\
\text { Dedicated room }\end{array}$ & $\begin{array}{l}\text { Arc lamp } \\
\text { Plasma spray system } \\
\text { Robot } \\
\text { Dust collector } \\
\text { Dedicated room }\end{array}$ & $\begin{array}{l}\text { Arc lamp } \\
\text { Fixturing } \\
\text { Mixing } \\
\text { equipment }\end{array}$ \\
\hline Capital cost [\$] & $0.2 \mathrm{M}$ & $1.2 \mathrm{M}$ & $1.0 \mathrm{M}$ \\
\hline $\begin{array}{l}\text { Increase in piece } \\
\text { part price due to } \\
\text { capital [\$] }\end{array}$ & 14.29 & 85.71 & 71.43 \\
\hline
\end{tabular}

A summary of the economic analyses of all three processes is shown in Table 18. It is clear that labor costs are the source of the majority of the process cost. Labor costs drive the selection of processes requiring short setup and handling times. The material costs suggest processes with the highest powder utilization. Electrical costs are not a significant factor in the process economics. 
Table 18. Economic analysis summary.

\begin{tabular}{|c|c|c|c|}
\hline & PTA & $\begin{array}{c}\text { Plasma spray/arc lamp } \\
\text { fuse } \\
\end{array}$ & $\begin{array}{c}\text { Slurry coat/arc lamp } \\
\text { fuse }\end{array}$ \\
\hline Material cost [\$] & 5.20 & 9.20 & 5.20 \\
\hline Labor cost $[\$]$ & 17.20 & 22.75 & 13.65 \\
\hline Electricity cost $[\$]$ & 0.05 & 0.20 & 0.15 \\
\hline $\begin{array}{l}\text { Subtotal before } \\
\text { capital costs }[\$]\end{array}$ & 22.45 & 32.15 & 19.00 \\
\hline Capital cost $[\$]$ & 14.29 & 85.71 & 71.43 \\
\hline $\begin{array}{l}\text { Total process cost } \\
{[\$]}\end{array}$ & 22.45 & 117.86 & 90.43 \\
\hline
\end{tabular}

The PTA process is clearly the least expensive, primarily due to the capital cost requirements; however, the performance of the coatings must be considered when choosing a coating process. 


\section{Accomplishments}

This section will discuss the accomplishments of the project in terms of the stated objectives of the project, presentations at conferences, patents, and student development.

\subsection{Project accomplishments}

The proposal for this project set several computational and experimental goals. This project accomplished many of those goals, including the development of metallurgically bonded coatings with wear and corrosion improvements compared to commercially available heat treated steels designed for wear resistance. Field tests support the lab test results regarding the wear resistance of these alloys. Integral to the selection of alloy compositions was the development and validation of thermodynamic models of the alloy system. These thermodynamic models enabled the prediction of alloy compositions with targeted equilibrium phase compositions and phase fractions. Arc lamp processing techniques were developed and used to produce both equilibrium and non-equilibrium microstructures. These technologies were demonstrated in field tests of a wear component (top mounted wear plates).

\subsection{Presentations}

"PTA Hardfacing Material for Earthmoving Equipment Applications", Xiangyang Jiang, presented at International Thermal Spray Conference, Seattle, WA, May 15-18, 2006.

"Erosion Resistant Coatings and Development of New Application Techniques", J. Sebright; B. Beardsley; A. McGilvray presented at 31st International Conference on Advanced Ceramics and Composites, meeting of the American Ceramics Society; Daytona Beach, FL, January 23, 2007.

"Wear and Corrosion Properties of Iron Based High Hardness Weld Materials", O. Racek, M. B. Beardsley, presented at Materials Science \& Technology 2007 Conference and Exhibition, September 16-20, COBO Center, Detroit, Michigan.

"Wear resistant plasma-transferred-arc coatings for lightweight structures", O. Racek, J. Sebright, B. Beardsley, presented at ITSC 2008, Maastricht, The Netherlands, June 2-4, 2008.

\subsection{Patents}

The following Invention Notification Forms (INF) were filed under this project:

INF 05-611 "Ferrous Alloys and Composites for Wear Resistance", Sebright, J.L.

INF 06-389 “Drop Tube to Drop Wear Resistant Particles”, Fischer, K.D., Henderson, S.L., 
INF 07-107 "Abrasive Resistant Material on a Track Shoe Grouser", Afdahl, C.D., Diekevers, M.S., Fischer, K.D., Steiner, K.L.

INF 08-563 “Abrasive Resistant Material With Extended Particle Size Range”, Barnes, C.A., Fischer, K.D.

\subsection{Student Development}

Several students worked as part of this project. Rebecca Ahrens, a concurrent BS/MS student at Iowa State University (ISU), worked on the SICWC project during 2007. She worked during the school year at ISU on the analyis of Caterpillar-provided samples. She was hired as a summer intern during May-August 2007 to work at the Caterpillar Technical Center on arc lamp processing of slurry coatings. She graduated in December 07 with an MS in Materials Science. Ryan Haase, another concurrent BS/MS student at ISU, was an intern from January - August 2007. Part of his work included slurry coated arc lamp samples with Rebecca. Ryan graduated in December 07 with a concurrent BS/MS in Materials Science. Bingtao Li, a post-doc at ISU, also contributed extensively to the equilibrium microstructure evaluation. All three ISU workers were members of Prof. Brian Gleeson's research group. At MS\&T, Ravi Mokirala worked with Prof. Van Aken in FEA analysis and sample testing. Ravi graduated in August 08 with an MS in Materials Science. 


\section{Conclusions}

- Thermodynamic models were developed to predict compositions with desired phase mixtures for the alloy system of interest (Fe-Mo-B-Cr-Ni)

- The thermodynamic model was used to calculate three new alloy compositions that were specifically designed for arc lamp processing.

- Microstructural examinations validated the thermodynamic models

- Arc lamp processing produced equilibrium and non-equilibrium microstructures

- Arc lamp processing improved the corrosion resistance of the alloys studied in this project

- Arc lamp processing improved the wear resistance of the alloys in this project in three lab wear tests (DSRW, POD, Impeller)

- Field testing of two alloys in this study applied to top mounted wear plates using the PTA process showed a $4 \mathrm{X}$ improvement in wear resistance compared to the base steel

- The PTA coating process is the least expensive process examined due to the low labor, material, and capital cost 


\section{Recommendations}

The commercialization path for these alloys and processes is still under evaluation. The market for these alloys would be limited due to the high price of the alloys (due to the molybdenum and nickel content) relative to the performance increase.

Additional R\&D work should address the following:

- Cost reduction will be required for the commercialization of these alloys and processes. Alternate lower cost alloys should be investigated using similar material design approaches to reduced molybdenum and/or nickel content. (Currently under way in follow-on work funded by Caterpillar.)

- The thermophysical properties of the alloy systems should be measured to provide accurate input for the thermodynamic and process models. (Currently under way in follow-on work funded by Caterpillar.)

- A sensitivity analysis should be performed on all of the process models. (To be done once thermophysical properties are available.)

- The test specimen for measurement of the interface mechanical properties should be redesigned to insure crack propagation along the interface. (Underway at Missouri University of Science and Technology, funded by Caterpillar.)

Additional work related to these recommendations to be funded by Caterpillar Inc. is planned for the remainder of FY2008 and FY2009. 


\section{References}

\footnotetext{
${ }^{1}$ R.R. Rich: Atmosphere-related Carbon Monoxide Emissions from Heat-Treating Furnaces and a New Technology for Recovery and Recycling, Heat Treatment of Metals, pp. 12-19, 1997.

${ }^{2}$ T. Kenichi, T. Watanabe, T. Ando, Y. Kondo. "EFFECT OF MOLYBDENUM AND CARBON ON THE PROPERTIES OF IRON MOLYBDENUM BORIDE HARD ALLOYS”, International Journal of Powder Metallurgy (Princeton, New Jersey), v 22, n 2, Apr, 1986, p 91-92, 94-96
}

${ }^{3}$ V. Jankauskas, .R. Kreivaitis, D. Milcius, A. Baltusnikas, “Analysis of abrasive wear performance of arc welded hard layers", Wear, v 265, n 11-12, Nov 26, 2008, p 1626-1632

${ }^{4}$ J. Kazior, A. Molinari, C. Janczur, T. Pieczonka, "Microstructural characterization and properties of thermochemically treated iron-based alloys", and Coatings Technology, v 125, n 1, Mar, 2000, p 1-8

${ }^{5}$ US Patent 4778522, "Wear resistant iron-base sintered alloy"

${ }^{6}$ US Patent 4832912, "Thermal and wear resistant tough alloy"

${ }^{7}$ US Patent 4235630, "Wear-resistant molybdenum-iron boride alloy and method of making same"

${ }^{8}$ S. Sen, O. Ibrahim, U. Sen, C. Bindal, "Mechanical Behavior of Borides Formed on Borided Cold Work Tool Steel." Surface and Coatings Technology 135 (2001): 173-177.

${ }^{9}$ O. Ozdemir, U. Metin, C. Bindal, A.H. Ucisik, "Hard Iron Boride (Fe 2 B) on 99.97 Wt\% Pure Iron”, Vacuum, 80 (2006): 1391-1395

${ }^{10}$ Gonzalez, R., M. Cadenas, R. Fernandez, J. L. Cortizo, and E. Rodriguez. "Wear Behaviour of Flame Sprayed NiCrBSi Coating Remelted by Flame or by Laser." Wear 262 (2007): 301-307.

${ }^{11}$ Mateos, J., J. M. Cuetos, E. Fernandez, and R. Vijande. "Tribological Behavior of Plasma-Sprayed WC Coatings with and Without Laser Remelting." Wear 239 (2000): 274-281.

${ }^{12}$ Mateos, J., J. M. Cuetos, R. Vijande, and E. Fernandez. "Tribological Properties of Plasma Sprayed and Laser Remelted 75/25 Cr3C2/NiCr Coatings." Tribology International 34 (2001): 345-351.

${ }^{13}$ Liang, G. Y., T. T. Wong, J. M. K. Macalpine, and J. Y. Su. "A Study of Wear Resistance of Plasma-Sprayed and Laser-Remelted Coatings on Aluminium Alloy." Surface and Coatings Technology 127 (2000): 233-238.

${ }^{14}$ Suutala, Jyrki, Jari Tuominen, and Petri Vuoristo. "Laser-Assisted and Laser Treatment of Thermally Sprayed Coatings." Surface and Coatings Technology 201 (2006): 1981-1987.

${ }^{15}$ Hamatani, Hideki, and Yasunobu Miyazaki. "Optimization of an Electron Beam Remelting of HVOF Sprayed Alloys and Carbides." Surface and Coatings Technology 154 (2002): 176-181.

${ }^{16}$ Utu, D., W. Brandl, G. Marginean, I. Cartis, and V. A. Serban. "Morphology and Phase Modification of HVOFSprayed MCrAlY-Coatings Remelted by Electron Beam Irradiation." Vacuum 77 (2005): 451-455.

${ }^{17}$ Blue, Craig A. "High-intensity lamp opening new surface treating vistas.” Industrial Heating Vol. 69. (Mar 2002): 79-82 
${ }^{18}$ Rivard, J.D.K., C.A. Blue, R.D. Ott, A. Sabau, M. Santella, T.Y. Pan and a. Joaquin. “Advanced Manufacturing Technologies Utilising High Density Infrared Radiant Heating.” Surface Engineering. (2004): 220-228.

${ }^{19}$ Craig A. Blue, Vinod K. Sikka, Evan K. Ohriner, P. Gregory Engleman, and David C. Harper: JOM-e. (JOM Electronic Supplement), 2000, 52 (1).

${ }^{20}$ Tao, D., C. Blue, N.B. Dehotre, R. Honaker, B.K. Parekh, P.G. Engleman, C. Zhao, and H. Han. "High-densityinfrared (HDI) treatment of mineral processing equipment for enhanced wear resistance." Minerals Engineering. (2006): 190-196. 